Konstantin M. Wacker

\title{
Empirical Aspects of Foreign Direct Investment and Economic Development
}



Empirical Aspects of Foreign Direct Investment and Economic Development

This work is licensed under the

Creative Commons License 3.0 "by-nd", allowing you to download, distribute and print the document in a few copies for private or educational use, given that the document stays unchanged and the creator is mentioned.

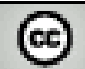

SORERIGHIS RESERVED 
erschienen im Universitätsverlag Göttingen 2013 
Konstantin M. Wacker

Empirical Aspects of Foreign

Direct Investment and

Economic Development

With Contributions by

Y. Hashimoto, K.C. Vadlamannati,

A. Cooray and I. Gaddis

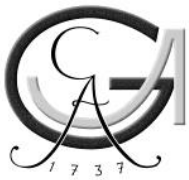

Universitätsverlag Göttingen 2013 


\section{Bibliographische Information der Deutschen Nationalbibliothek}

Die Deutsche Nationalbibliothek verzeichnet diese Publikation in der Deutschen Nationalbibliographie; detaillierte bibliographische Daten sind im Internet über $<$ http://dnb.ddb.de $>$ abrufbar.

Address of the author

Konstantin M. Wacker

e-mail: konstantin.m.wacker@gmail.com

This work is protected by German Intellectual Property Right Law.

It will be available after some delay as an open access version through the publisher's homepage and the online catalogue of the State and University Library of Göttingen (http://www.sub.uni-goettingen.de). Users of the free online version are invited to read, download and distribute it. Users may also print a small number for educational or private use.

Set and layout: Konstantin Wacker

Cover design: Franziska Lorenz

(C) 2013 Universitätsverlag Göttingen http:/ / univerlag.uni-goettingen.de ISBN: 978-3-86395-113-9 


\section{献给中国人民}

and to all other people striving for order, progress, and development 



\section{Contents}

1 Introduction and Overview 15

2 Measuring MNCs $\quad 27$

2.1 Measuring Activities of Multinational Corporations . . . . . . . . . . . 28

2.1 .1 FDI Data . . . . . . . . . . . . . . . . . 28

2.1.2 Other Operational Data . . . . . . . . . . . . . . 32

2.2 An Accounting Example . . . . . . . . . . . . . . . . . . 35

2.3 The Relationship Between FDI Stocks, Flows and Other Operational

Data . . . . . . . . . . . . . . . . . 38

2.3.1 Stocks and Flows in the Steady State . . . . . . . . . . . . 38

2.3.2 The Production Process and its Reflection in the Data . . . . . 39

2.4 A Glance at the Data . . . . . . . . . . . . . . . . . . . . 43

2.5 Estimating the Determinants of MNCs' Activities . . . . . . . . . . . 46

2.5.1 A Real-Data Example . . . . . . . . . . . . . . . 53

2.5.2 The Real Valuation Problem ... . . . . . . . . . . 59

2.6 Discussion and Conclusion . . . . . . . . . . . . . . . . . 60

3 Information \& FDI (with Y. Hashimoto) 65

3.1 Introduction . . . . . . . . . . . . . . . 65

3.2 Investment: Model, Previous Evidence and Data . . . . . . . . . . . 67

3.2.1 Portfolio and Foreign Direct Investment . . . . . . . . . . . . . 68

3.2 .2 Econometric Model . . . . . . . . . . . . . . . . . . . 69

3.2.3 Determinants of International Investment Flows . . . . . . . . 69

3.2 .4 Risk . . . . . . . . . . . . . . . . . 72

3.2.5 Information . . . . . . . . . . . . . . . . . 74

3.2.6 Spatial Interdependencies . . . . . . . . . . . . . . . . . 79

3.3 Main Empirical Results . . . . . . . . . . . . . . . . . . . . . . 83

3.4 Robustness and Further Results . . . . . . . . . . . . . . . . . . . . . . 88

3.4.1 Identifying Assumptions . . . . . . . . . . . . . . . . . . . . . 88

3.4.2 Parameter Robustness . . . . . . . . . . . . . . . . . . 91

3.4.3 Dynamics . . . . . . . . . . . . . . . . . 92

3.4.4 Spatial Correlation Patterns . . . . . . . . . . . . . . . 94

3.5 Discussion and Conclusion . . . . . . . . . . . . . . . . . . 95

3.5.1 Main findings . . . . . . . . . . . . . . . . 95

3.5.2 Relation to Other Findings in the Literature . . . . . . . . . . 96

3.5.3 Further Results . . . . . . . . . . . . . . . . . . . . . . 98

3.5.4 Perspectives on Further Research and Policy Issues . . . . . . . 98

4 FDI \& Terms of Trade $\quad 99$

4.1 Introduction . . . . . . . . . . . . . . . . . . . . . . . . . . . . 99

4.2 Multinationals and Terms of Trade - A Theoretically Unclear Link . . 100

4.2.1 Prebisch and Singer on Multinationals and Terms of Trade . . 100

4.2.2 Expanding the Macro Transfer Problem . . . . . . . . . . . . . 101

4.2.3 Impacts on the Micro-Level . . . . . . . . . . . . . . . . . . 101 
4.2.4 Terms of Trade in the Long Period . . . . . . . . . . . . . . . . 102

4.3 Data and Methodology . . . . . . . . . . . . . . 103

4.3.1 Terms of Trade Data . . . . . . . . . . . . . . . 103

4.3.2 Data on MNC's Activity (FDI) . . . . . . . . . . . . 104

4.3.3 Other Controls . . . . . . . . . . . . . . . 105

4.3.4 Model Specification . . . . . . . . . . . . . 107

4.4 Empirical Results . . . . . . . . . . . . . . . . . . . 107

4.4.1 Robustness Checks ... . . . . . . . . . . . . 113

4.4 .2 Economic Relevance . . . . . . . . . . . . . . . . . . 117

4.5 Discussion and Conclusion . . . . . . . . . . . . . . 117

$5 \quad$ FDI \& Labor Standards (with K.C. Vadlamannati) 121

5.1 Literature Review . . . . . . . . . . . . . . . . . . . . 121

5.2 A Simple Model of FDI and Labor Conditions . . . . . . . . . . . . . 123

5.3 Data and Methodology . . . . . . . . . . . . . . . . 128

5.3 .1 FDI Data . . . . . . . . . . . . . . . . . . . . . . . . . . . . . . . . . . . . . . . 128

5.3 .2 Labor Rights . . . . . . . . . . . . . . . . . . . . . . . . . . . . . . . . . . . . . .

5.3.3 Other Control Variables . . . . . . . . . . . . . . . 132

5.3.4 Econometric Model . . . . . . . . . . . . . . . . 133

5.4 Empirical Results . . . . . . . . . . . . . . . . . . . 134

5.4.1 Static Estimation . . . . . . . . . . . . . . . 134

5.4 Dynamic Estimation . . . . . . . . . . . . . . 136

5.4 .3 Other Controls . . . . . . . . . . . . . . . 136

5.4 Identifying the Economic Channel . . . . . . . . . . . . 138

5.4.5 Economic Relevance . . . . . . . . . . . . . . . 138

5.5 Conclusion . . . . . . . . . . . . . . . . . 139

6 FDI \& Female Labor Force (with A. Cooray and I. Gaddis) 141

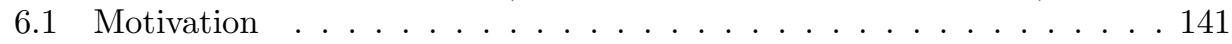

6.2 Data . . . . . . . . . . . . . . . . . . . . . . . . . . . . . . . . . . . . . .

6.2.1 Descriptive Analysis . . . . . . . . . . . . . . . 144

6.3 Econometric Model . . . . . . . . . . . . . . . . . . . 146

6.3.1 Error Structure of the Model . . . . . . . . . . . . . . . 147

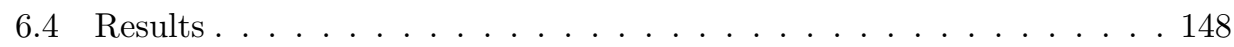

6.5 Discussion and Conclusion . . . . . . . . . . . . 156

$\begin{array}{lr}\text { A Appendix - Chapter 2 } & 159\end{array}$

B Appendix - Chapter 3 161

B.1 Information on SDDS . . . . . . . . . . . . . . 161

B.2 Sample, Variables and Descriptive Statistics . . . . . . . . . 163

$\begin{array}{ll}\text { C Appendix - Chapter } 4 & 164\end{array}$

D Appendix - Chapter 5 165

$\begin{array}{lll}\text { E Appendix - Chapter } 6 & 170\end{array}$ 


\section{Constitutive publications}

1. Hashimoto, Yuko and Konstantin M. Wacker (2012): "The Role of Risk and Information for International Capital Flows: New Evidence from the SDDS," IMF Working Papers 12/242, International Monetary Fund.

2. Hashimoto, Yuko and Konstantin M. Wacker (2012): "The Role of Risk and Information for International Capital Flows: New Evidence from the SDDS," Courant Research Centre: Poverty, Equity and Growth - Discussion Papers 124, Courant Research Centre PEG.

3. Wacker, Konstantin M. (2011): "The Impact of Foreign Direct Investment on Developing Countries Terms of Trade," UNU-WIDER Working Paper 2011/06, World Institute for Development Economic Research

4. Wacker, Konstantin M. (2011): "Do multinationals beat down developing countries' export prices? The impact of FDI on net barter terms of trade," IAI Discussion Paper 211, Ibero-America Institute for Economic Research.

5. Wacker, Konstantin M. and Krishna Chaitanya Vadlamannati (2011): "Do Multinationals Influence Labor Standards? A Close Look at US Outward FDI," Courant Research Centre: Poverty, Equity and Growth - Discussion Papers 98, Courant Research Centre PEG.

6. Cooray, Arusha, Isis Gaddis, and Konstantin M. Wacker (2012): "Globalization and Female Labor Force Participation in Developing Countries: An Empirical (Re-)Assessment," Courant Research Centre: Poverty, Equity and Growth Discussion Papers 129, Courant Research Centre PEG. 


\section{Abbreviations and Notation}

Abbreviations

\begin{tabular}{|c|c|}
\hline AFTA & ASEAN Free Trade Area \\
\hline AIC & information criterion A ('Akaike Information Criterion') \\
\hline AR & autoregressive / autoregression \\
\hline ASEAN & Association of Southeast Asian Nations \\
\hline $\mathrm{BE}$ & between effects (estimator) \\
\hline $\mathrm{BIC}$ & information criterion B ('Bayes-Schwarz Information Criterion') \\
\hline BMA & Bayesian Model Averaging \\
\hline $\mathrm{BOP}$ & Balance of Payments \\
\hline BOPM & Balance of Payments Manual \\
\hline CAFTA & Central American Free Trade Agreement \\
\hline $\mathrm{CEO}$ & Chief Executive Officer \\
\hline CRTS & constant returns to scale \\
\hline DGP & data generating process \\
\hline EAPEP & Estimates and Projections of the Economically Active Population \\
\hline ECB & European Central Bank \\
\hline ESS & explained sum of squares \\
\hline FDI & foreign direct investment \\
\hline FE & fixed effects (estimator) \\
\hline FGLS & feasible GLS \\
\hline $\mathrm{FLFP}(\mathrm{R})$ & female labor force participation (rate) \\
\hline FPOP & female population \\
\hline GDP & gross domestic product \\
\hline GLS & generalized least squares \\
\hline GMM & generalized methods of moments \\
\hline HAC & heteroskedasticity and autocorrelation (robust) \\
\hline IAI & Ibero America Institute for Economic Research \\
\hline IFRS & International Financial Reporting Standards \\
\hline IFS & International Financial Statistics (of the IMF) \\
\hline i.i.d. & independent and identically distributed \\
\hline IIP & International Investment Position \\
\hline ILO & International Labour Organization \\
\hline IMF & International Monetary Fund \\
\hline IPA & investment promotion agency \\
\hline ISIC & $\begin{array}{l}\text { International Standard Industrial Classification } \\
\text { (of All Economic Activities) }\end{array}$ \\
\hline IV & instrumental variable \\
\hline LASSO & Least Absolute Shrinkage and Selection Operator \\
\hline LDV & lagged dependent variable \\
\hline LHS & left hand side \\
\hline LIBOR & London Interbank Offered Rate \\
\hline LR & labor rights / likelihood ratio \\
\hline LSDV & least squares dummy variable (estimator) \\
\hline
\end{tabular}




\begin{tabular}{|c|c|}
\hline $\mathrm{M} \& \mathrm{~A}$ & merger and acquisition \\
\hline $\mathrm{MC}$ & Monte Carlo \\
\hline MNC & multinational corporation \\
\hline MU & Monetary Unit \\
\hline MVU & minimum variance unbiased (estimator) \\
\hline NAICS & North American Industry Classification System \\
\hline NBER & National Bureau of Economic Research \\
\hline NBTT & net barter terms of trade \\
\hline OECD & Organisation for Economic Co-operation and Development \\
\hline OLS & ordinary least squares \\
\hline p.c. & per capita \\
\hline p.a. & per anno \\
\hline PIM & Perpetual Inventory Method \\
\hline PIR & physical integrity rights \\
\hline POLS & pooled OLS \\
\hline PPE & Plant, Proterty and Equity \\
\hline PPP & Purchasing Power Parity / Parities \\
\hline $\mathrm{R} \& \mathrm{D}$ & research and development \\
\hline $\mathrm{RE}$ & random effects (estimator) \\
\hline RHS & right hand side \\
\hline RSS & residual/unexplained sum of squares \\
\hline RTA & Regional Trade Agreement \\
\hline SAR & spatial autoregression \\
\hline SDDS & Special Data Dissemination Standard \\
\hline SDR & Special Drawing Right (IMF MU) \\
\hline $\mathrm{SE}$ & standard error \\
\hline $\mathrm{SIC}$ & Standard Industrial Classification \\
\hline SIMSDI & $\begin{array}{l}\text { Survey of Implementation of Methodological Standards } \\
\text { for Direct Investment }\end{array}$ \\
\hline SNA & System of National Accounts \\
\hline SSCI & Social Science Citation Index \\
\hline TSS & total sum of squares \\
\hline UK & United Kingdom \\
\hline UNCTAD & United Nations Conference on Trade and Development \\
\hline UNU-WIDER & United Nations University - \\
\hline & World Institute for Development Economics Research \\
\hline US & United States \\
\hline UVI & Unit Value Index \\
\hline $\mathrm{VCV}$ & variance-covariance (matrix) \\
\hline WDI & World Development Indicators \\
\hline WEO & World Economic Outlook (of the IMF) \\
\hline
\end{tabular}




\section{Notation}

Generally, and unless noted otherwise, I rely on the $5 \%$ level of statistical significance and refer to the $10 \%$ level as "weak significance," and the $1 \%$ level as "strong significance." Concerning notation, small Greek letters like $\alpha, \beta, \phi$ etc. characterize (population) parameters, $\hat{\alpha}, \hat{\beta}, \hat{\phi}$ etc. denote the respective estimates of these parameters from a sample. $\bar{\rho}$ denotes the (estimated) average of $\rho$, for example. Small Roman letters like $c, x, y$ etc. denote variables, a response variable is usually denoted as $y$ while 'explanatory' variables ('covariables') are denoted $x$. Large Roman letters like $X$ usually denote a matrix, in this specific case a matrix that collects a certain sum of observations over $k$ (co-)variables. $I$ is the identity matrix. Observations are usually subindexed with $i=1, \ldots, N$ for cross-sections, mostly countries, and $t=1, \ldots, T$ time periods. Unless stated otherwise, $\varepsilon$ and $\nu$ denote i.i.d. error terms with $\mathbb{E}(\varepsilon)=\mathbb{E}(\nu)=0$. " $\Rightarrow$ " denotes 'it follows' or, equivalently, "if'; " $\sim$ " reads 'is distributed as', " $\sim$ " denotes 'is asymptotically distributed as'; " $\Delta$ " is the first difference of a variable, " $\rightarrow$ " denotes the limit of a function $f(\cdot)$ or of a sequence. $f(x \mid y)$ is a function of $x$ conditional on $y$, " $=$ " defines a restriction, ":=", or $\equiv$ defines an identity. " $\mathbb{1}$ " is the indicator function. I refer to the model of the DGP as the "operating model' following the terminology of Zucchini (2000); in the terminology of Leeb and Pötscher (2005) this is the 'true model.' It is assumed that this model has an explicit functional form, though it may be very complex. Accordingly, I label an inappropriate functional form as a 'functional misspecification.' This has to be distinguished from problems such as omitted variables (although omitted interactions and powers of variables can be interpreted as omitted variables) and contains, for example, the specification of an additive model when a multiplicative model is the operating model.

Results are generally calculated using STATA versions 10 to 12 . The estimators for the spatial correlation patterns in section 3.4.4 are implemented using the RPROJECT. 


\section{Acknowledgements.}

Ein edler Mensch kann einem engen Kreise

Nicht seine Bildung danken. Vaterland

Und Welt muss auf ihn wirken. Ruhm und Tadel

Muss er ertragen lernen. Sich und andre

Wird er gezwungen recht zu kennen. Ihn

Wiegt nicht die Einsamkeit mehr schmeichelnd ein.

Es will der Feind - es d a r $f$ der Freund nicht schonen. ${ }^{1}$

\section{J.W. Goethe - Torquato Tasso}

Development, as Amartya Sen (1999, p. 35) pointed out, is not a fierce process where wisdom demands toughness, but a rather friendly action. For my personal and intellectual development throughout the last three years, this is indeed the case. I am especially grateful for the friendly and intellectually open environment that I have experienced in Göttingen in general and at the chair of Development Economics in particular. This also highlights that development is never exclusively desarollo desde dentro or desarollo hacia afuera, but is always a combination of both. Representative of all the others, I want to thank Andreas Fuchs, Friederike Greb, Jan Höffler, Kristina Meier, Stefan Meyer, Chris Muris, and Malte Reimers as well as my housemates and Laura Altenkirch for giving me such a good time throughout the last years.

Stephan Klasen provided extensive comments and feedback on my work and ideas, and kindly supported all my ambitious efforts for which I am very grateful. Needless to say that without him, the excellent and intellectually enriching research environment in Göttingen would have been impossible.

Throughout my time here, I have learned a great deal from my teachers Ron Davies, Walter Zucchini and Uli Schneider and would also like to thank the former for supporting my applications and for his comments on my work and the latter for sharing many perspectives on academics from the viewpoint of a junior professor. I am grateful to Inmaculada Martínez-Zarzoso for her extensive feedback on various of my papers and presentations and to Amelia Santos-Paulino for her support and for the enriching time working with her at UNU-WIDER which was very important in encouraging me to carry on with my research in times where I had the same doubt that probably most $\mathrm{PhD}$ candidates share. In this context, I am also very thankful for many interesting discussions, comments and critiques at seminars and conferences in Aarhus/Kolding, Beijing, Göttingen, Graz, Hamburg, Hannover, Helsinki, Linz, Madrid, Vienna and at the IMF since they gave me the impression of general interest in my work. I furthermore want to thank the IMF and UNU-WIDER and my colleagues at these institutions for my mind-enriching time there and for providing financial and research support. I have highly benefited from discussions and working cooperations with my co-authors Krishna Chaitanya Vadlamannati, Arusha Cooray, Isis Gaddis, and Yuko Hashimoto, with my MA students Philipp Grosskurth and Katharina Trapp, as well as from feedback from Yvonne Wolfmayr on the paper in chapter 5 and from comments

\footnotetext{
1 'In a contracted sphere, a noble man // Cannot develop all his mental powers. // On him his country and the world must work. // He must endure both censure and applause, // Must be compell'd to estimate aright // Himself and others. Solitude no more // Lulls him delusively with flattering dreams. // Opponents will not, friendship d a $r$ e not, spare.'
} 
of Wolfgang Schweiger on scientific aspects of chapter 2.

In financial respect, I am grateful for the support from the German Academic Exchange Foundation (DAAD) and the China Scholarship Council (CSC). The fact that I was not able to acquire the same support from sources in Austria, where GDP p.c. in PPP is $10 \%$ higher than in Germany and more than 4 times as large as in China, ${ }^{2}$ highlights that the connections between income and capacity are not that tight and that departures are often much more important than the limited concurrences of the two variables (cf. Sen 1999, p. 20).

I would also like to thank my undergraduate teachers Joachim Becker, Jesús CrespoCuaresma, and Neil Foster for ongoing support.

'Changing the country more often than the shoes' and focusing on my work would have been impossible without the private backing of such exceptional friends as Judith Hörlsberger, Gerd Jung, Paul Kielmansegg, Georg Krizmanics, Saskja Schindler and Daniel Schuster thanks guys, you are the best! Similarly, I want to thank my family; especially for their patience with my academic career which I really appreciate since we all grew up in an environment were education was merely a means, not an end.

Special thanks apply to Sandra Stern who opened a door to an intellectual palace, and to Anna Orthofer for reminding me what is essential for two of the most important economic actors, firms and individuals.

Beijing/Göttingen, 2012

\footnotetext{
${ }^{2}$ Based on IMF WEO data for 2012 .
} 


\section{Introduction and Overview}

Die fortwährende Umwälzung der Produktion, die ununterbrochene Erschütterung aller gesellschaftlichen Zustände, die ewige Unsicherheit und Bewegung zeichnet die Bourgeoisepoche vor allen anderen aus. ${ }^{3}$

\section{K. Marx \& F. Engels - Manifest der Kommunistischen Partei}

The last decades have seen an increasing interest in a process usually referred to as 'globalization,' and a growing controversy about its characteristics and effects. This dissertation deals with a feature and a driver of this process that potentially distinguishes the recent wave of globalization from any previous one: ${ }^{4}$ the continuously increasing relevance of multinational corporations $(\mathrm{MNCs})^{5}$ in organizing production and other social relations. The following chapters empirically contribute to existent discussions in the academic literature and in the general public and add to previously rather neglected aspects.

The reflection of the increased relevance of MNCs in the Financial Account ${ }^{6}$ is an increase in foreign direct investment (FDI) - capital flows with the aim of establishing control or a significant degree of influence in another enterprise, as discussed in more

\footnotetext{
3 'Constant revolutionising of production, uninterrupted disturbance of all social conditions, everlasting uncertainty and agitation distinguish the bourgeois epoch from all earlier ones.'

${ }^{4}$ Cf., inter alia, Baldwin and Martin (1999, ch. 4.2). The authors classify the periods 1820/1870 - 1914 and 1960 to the present as two waves of globalization. Robertson (2003), for example, labels the post-1500 era as a third wave.

${ }^{5}$ In the literature of the 1970s and early 1980s, the term 'transnational' has often been used to characterize these corporations. Especially sociologist analysts of 'globalization' continue using this term and want to highlight that capital structures from one type of countries ('the Center') penetrate the capital structures of other countries ('the Periphery'). But UNCTAD also follows this terminology in most cases. As will be apparent from the first chapters of this dissertation, the data does not provide strong evidence that this is the prevailing form of foreign direct investment. Rather, a complex international merger of capital structures takes place that results in a production process that is, as Blonigen et al. (2007, p. 1304) put it, more and more "multilateral in nature." Baldwin and Martin (1999) in fact point out that the current intra-industry pattern of North-North FDI is one of the differences between the current and the first wave of globalization. In accordance with the current mainstream economics literature, I hence use the term 'multinational.' Furthermore, I prefer using the term 'corporation' over 'firm' in most cases, to highlight the complex interdependencies in this type of enterprise that usually arise from the separation of ownership from management and to emphasize that most multinational enterprises chose this legal form to limit liability, to ease the transfer of ownership and thus enhance the ability to raise finance. See Ross et al. (2007, p. 10ff) for a basic introduction.

${ }^{6}$ Some contributions refer to the Financial Account of the Balance of Payments (BOP) as 'capital account.' From a BOP perspective this is misleading since the Capital Account is part of the Current Account and captures primarily transfer payments. However, the System of National Accounts refers to the BOP Financial Account as 'capital account.' I follow the BOP convention in this work.
} 
detail chapter 2. Figure 1 depicts to what extent FDI has globally increased over the last decades. ${ }^{7}$ As can be seen, FDI surged to about the tenfold of its 1980 level in the last thirty years, while merchandise and services trade increased by a factor of 3.2 and 3.8, respectively, still outperforming GDP which roughly doubled throughout the period (factor 2.3). Despite FDI being considered a relatively stable form of international capital flow, the data also show a large degree of volatility in FDI flows, so that the increase of FDI would be larger if other period ends than 2010 were chosen. However, I decided not to smooth the series to highlight this cyclical pattern. ${ }^{8}$ Peak levels of global FDI flows (with a factor above 17) were reached in 2000 and 2007, another peak (though at a far lower level) in 1989 and 1990. These were the years directly predating the three last US recessions (as classified by NBER), suggesting that home-country effects in the world's most important investing economies considerably influence global FDI patterns.

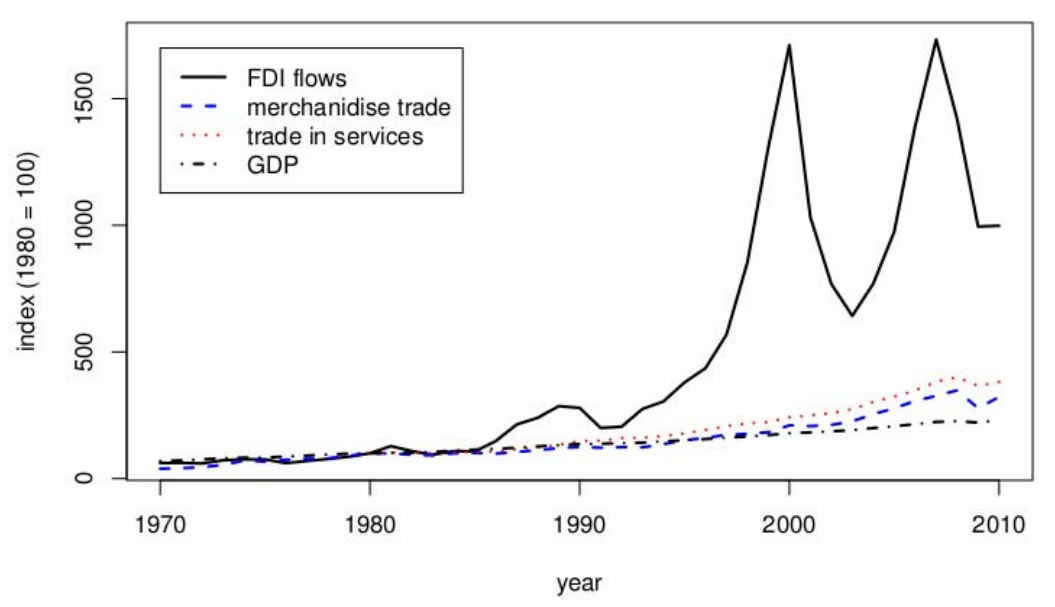

Figure 1: Development of Selected Global Macro Variables

Figure 1 does not simply compare series that are independent from each other in order to put the surge of FDI into perspective. The qualitative implication of these numbers is a production process (which generates world GDP) that is structured more and more globally (cf. Gereffi 2005, p. 161; Bair 2005), with an increasing number of internationally traded goods, parts and components (including services) incorporated in the world's output and consumption. Furthermore, this production

\footnotetext{
${ }^{7}$ The figure uses UNCTAD data for FDI flows, trade in merchandises, trade in services, and gross domestic product (GDP) for the world in total, using the GDP deflator to compute constant prices. FDI flows are inflows, trade data are (imports + exports)/2. FDI flows are taken rather than stocks because the other series are flow variables as well. The series are indexed with $1980=100$.

${ }^{8}$ See Kinoshita (2012) for a recent survey on FDI volatility.
} 
process (including trade) is increasingly dominated and controlled by agents conducting FDI, most notably MNCs. This can hardly leave local producers unaffected, even more so in developing countries, where the 'globalization' trend was even more pronounced than figure 1 suggests: Calculations based on data from World Bank (2010b) WDI show that for high-income countries the share of exports (goods and services) over GDP has risen from an average of 19.3 (16.7) \% in the 1980s (1970s) to $25.4 \%$ in the 2000 s while it increased relatively faster for low and middle income countries, from 15.9 (11.9) \% to $29.6 \%$. For FDI, calculations based on data from UNCTAD show that developing and industrialized countries were both affected by an internationalization of their capital structure to a similar extent: FDI inflows made up for 3.1 (2.8) \% of gross fixed capital formation in developing countries in the 1980s (1970s) but for $12.6 \%$ in the 2000s. For industrialized countries, the increase was from $2.8(1.8) \%$ to $11.6 \%$.

To draw another picture of the relevance of MNCs in the global economy: According to UNCTAD (2010, Annex table 26), the world's largest non-financial MNC in 2008, 'General Electric,' commanded assets of almost 800 billion US- $\$ 9$ - more than half of which were located outside of the United States, the corporation's home economy. Also, more than half of the total sales worth 183 billion US-\$ (equivalent to $44 \%$ of Austria's GDP) occurred outside the US and more than half of the 323,000 employees (9.5\% of employment in Austria) work abroad - internationalization ratios that are relatively modest, compared to other large non-financial MNCs. The asset-values become even more drastic when looking at financial MNCs: According to UNCTAD (2010, Annex table 28), 'BNP Paribas' held assets worth 2.9 trillion of US-\$, spread over 755 affiliates, thereof 596 in 61 host countries outside its home country, France.

Fortunately, the increased relevance of FDI and MNCs is reflected in a growing discussion, both in the academic literature and among a wider public audience. Table 1 highlights by how much academic interest in FDI and MNCs has increased over the last decades: While only 15 articles in journals captured by the 'Social Science Citation Index' under the listing of 'Economics' and 'Business' had one of the terms 'Multinational Corporation,' 'Multinational Firm,' 'MNC,' 'Foreign Direct Investment,' or 'FDI' in their title in the $1960 \mathrm{~s}$, this number increased to 1,138 in the 2000s. Of course, such trend statistics should take into account that the total number of journals, hence of journal articles, has increased. To correct for this issue, I 'price-deflated' the series, i.e. I compared it to the development of the keyword 'price' in titles of corresponding articles which serves as a proxy of total articles published because 'price' is assumed to be a central category of market economies and its investigation therefore should not follow too dramatic cycles and fashions over the decades. ${ }^{10}$ As can be seen in the last column of table 1 , the number of articles

\footnotetext{
${ }^{9}$ For comparison: the Irish Central Statistics Office (2011) estimates that the Irish net capital stock of fixed assets amounted to 423.9 billion Euros in 2008, about 590 billion US-\$ or $74 \%$ of General Electric's assets. The OECD structural analysis (STAN) database estimates Austria's gross capital stock by 2007 as 1.3 trillion Euros or 1.8 trillion US-\$.

${ }^{10}$ The recent boom in commodity and housing prices might have had an impact on this
} 
covering MNC/FDI related topics increased much faster than the overall number of articles published. This was not so much driven by MNC-related articles. As can be seen from the last line of the table, its 'real' number remained fairly stable. ${ }^{11}$ 'Upside risks' rather came from FDI-related articles: By any meaningful definition of 'price stability,' the development of FDI-related articles was clearly inflationary. Even more, the real increase in FDI-related articles by far outnumbers the increase of real FDI in the three decades 1980 - 2010.

Table 1: Mentioning of Keywords in Social Science Citation Index (in Title)

\begin{tabular}{|c|c|c|c|c|c|c|c|}
\hline period & $\begin{array}{r}\text { "Multi- } \\
\text { national } \\
\text { Cor- } \\
\text { poration" }\end{array}$ & $\begin{array}{l}\text { "Multi- } \\
\text { national } \\
\text { Firm" }\end{array}$ & $\begin{array}{r}\text { "Foreign } \\
\text { Direct } \\
\text { Invest- } \\
\text { ment" }\end{array}$ & "FDI" & "MNC" & "Price" & $\begin{array}{r}(1)-(5) \\
/(6)\end{array}$ \\
\hline $1951-1960$ & 0 & 0 & 0 & 0 & 0 & 437 & \\
\hline $1961-1970$ & 9 & 1 & 5 & 0 & 0 & 1,080 & $1.4 \%$ \\
\hline $1971-1975$ & 31 & 24 & 12 & 0 & 3 & 901 & $7.8 \%$ \\
\hline $1976-1980$ & 34 & 10 & 23 & 2 & 8 & 1,357 & $5.7 \%$ \\
\hline 1981-1985 & 28 & 7 & 28 & 1 & 8 & 1,525 & $4.7 \%$ \\
\hline $1986-1990$ & 9 & 3 & 50 & 4 & 4 & 1,667 & $4.2 \%$ \\
\hline 1991-1995 & 10 & 6 & 84 & 11 & 1 & 1,708 & $6.6 \%$ \\
\hline $1996-2000$ & 12 & 3 & 164 & 30 & 7 & 1,704 & $12.7 \%$ \\
\hline $2001-2005$ & 12 & 10 & 247 & 95 & 26 & 1,856 & $21.0 \%$ \\
\hline 2006-2010 & 29 & 21 & 370 & 280 & 48 & 2,707 & $27.6 \%$ \\
\hline 2011 & 8 & 3 & 86 & 76 & 15 & 574 & $32.8 \%$ \\
\hline \multicolumn{8}{|l|}{ growth } \\
\hline p.a. & $-2.79 \%$ & $0.17 \%$ & $7.21 \%$ & $15.22 \%$ & $3.74 \%$ & & \\
\hline
\end{tabular}

Statistics are limited to business \& economics journals, SSCI accessed February, 2012. Growth p.a. is the 'real' growth rate (deflated by the 'price' series) p.a. over the 30 years $1976-80$ to $2006-10$

\section{An Outline}

This inflationary increase in academic and public interest also led to something Keynes (1936, p. 161/162) might have labeled 'animal spirit' - an often more spontaneous than well-founded 'urge to action' concerning the issue, driven by a 'spontaneous optimism' towards the data used for empirical analysis and without spending too much efforts reasoning whether they appropriately represent the underlying fundamentals. In chapter 2, I therefore introduce the different concepts of measuring

measure, however, it is remarkable that the share of MNC/FDI-related articles increased despite the peak of price related articles between 2006 and 2010. It could not be identified from SSCI, which specific goods were the overall 'price' drivers in this period.

${ }^{11}$ A substitution from 'Multinational Corporation' to 'MNC' took place; summing up both of them, the real development was $-0.28 \%$ p.a. 
multinational corporations' relevance with the aim of drawing a consistent picture of how to measure activities of MNCs and how to estimate their determinants and hence provide some guidelines for applied research as the one in the chapters thereafter. Of course, technical definitions of these concepts were available before. However, I discuss in more detail which relations exist between these measures under which economic assumptions and statistical compiling techniques and show that there is in fact a tight correlation between these measures, at least for the widely used data provided by the US Bureau of Economic Analysis. To the best of my knowledge, Lipsey (2007) provided the only notable contribution raising similar concern about the data we use for analysis. Yet, chapter 2 goes more into detail and provides a more optimistic picture concerning the appropriateness of FDI data for measuring the activities of MNCs by taking a comprehensive and intertemporal approach towards the production process. The second part of this chapter then argues that estimating what determines MNCs' activities by using usual static models (FE, RE and other GLS approaches) can pose some econometric problems and, more importantly, can lead to wrong conclusions about the quantitative design of policies and about our understanding of multinational firms. In this context, the chapter provides some guidelines how data on MNCs could and should be used for empirical investigation from both an economic and a more statistical perspective.

Following up on the methodological results from chapter 2, the 3nd chapter contributes to the literature on the determinants of FDI by investigating whether better information about the macroeconomic environment of an economy has a positive impact on its capital inflows, namely foreign portfolio and direct investment. Such capital flows from capital-abundant to capital-scarce countries are expected to increase growth and/or output of the global economy because resources would be allocated to its most productive deployment. This view, however, implicitly presumes that investors are aware of these productive investment opportunities - a condition that may not be fulfilled, especially since many frictions can arise in financial markets. The chapter is based on a joint research project with Yuko Hashimoto for the International Monetary Fund and has been circulated as Courant Research Centre Discussion Paper 124. The purpose of the study is to explicitly quantify information asymmetries by compliance with the IMF's Special Data Dissemination Standard (SDDS). The empirical investigation shows that FDI is indeed highly responsive to the dissemination of macroeconomic information about potential host economies: SDDS subscription initially increased inflows by about 60 percent. While we do not find such an effect for aggregate portfolio flows, this does not mean that the composition of these flows does not change due to the decrease of informational frictions. In line with the literature, we also find evidence for political and macroeconomic risk aversion of foreign investment. Another contribution of the chapter is the application of a non-parametric test for spatial correlation in the residuals of capital flows which is different from other, mainly autoregressive, attempts to study spatial patterns in capital flows and has the advantage of relying on less stringent assumptions.

I consider chapter 4, which also has been circulated as UNU-WIDER Working Paper 11-06 and as IAI Discussion Paper 211, as one of the most significant academic 
contributions of this dissertation. It empirically explores the economic relationship between FDI to developing countries and the export prices of the latter, measured by net barter terms of trade. I first show that economic theory suggests such a relationship for various reasons but is inconclusive about the direction, not to speak of the size, of the effect. To address this open issue empirically, I analyze data on more than 50 developing countries throughout the period 1980 - 2008 using dynamic panel data methods. The results show that FDI had an economically relevant and statistically significant positive impact on developing countries' export prices. A higher level of education in the developing country fosters this effect, highlighting the role of absorptive capacity. There is also some evidence that the effect is stronger for manufacturing (as opposed to commodity) exporters and for more closed economies, however, the latter differences are not statistically significant. The contribution of the chapter should be seen in the context of a discussion that emerged in the 1950s and intensified in policy-related debates in Latin America in the 1970s and the mainstream academic literature of the 1980s: the hypothesis of Singer (1950) and Prebisch (1950) that terms of trade of developing countries suffered from a structural tendency to decline and the explicit or implicit-view that multinational corporations and their FDI would be responsible for this trend. In fact, my contribution is the first one to empirically address this issue and shows, they are not.

The two chapters thereafter deal with the relationship between FDI and labor markets. Chapter 5, which is the outcome of a joint study with Krishna Chaitanya Vadlamannati that has been circulated as Courant Research Centre Discussion Paper 98, looks at the impact of multinational firms' labor demand on labor rights - an issue that is continuously discussed quite controversially in the public, but also among academic scholars. A key contribution of the chapter is to argue why horizontally motivated FDI should be different from vertically motivated, especially skill-seeking FDI $^{12}$ and to disentangle US FDI data for 34 advanced host countries throughout the period 1997 - 2002 into these two types of investment motivation to finally investigate the effects of multinational corporations on de facto and de jure labor standards. We show that horizontal FDI has a significant and considerable negative impact on labor standards that operates via practices (as opposed to law) while the impact of vertical FDI is more ambiguous. This suggests that the mentioned disaggregation is important to obtain robust results. We also conclude that our results do not necessarily imply that the negative effect of horizontal FDI leads to a decrease in welfare in the host economy but that in the welfare optimization process employment, income and job-quality serve as substitutes with an (absolute) elasticity positively depending on the equilibrium unemployment rate. Our focus on US FDI going to industrialized countries is motivated by data availability and especially by homogeneity considerations: We expect that labor markets in industrialized countries generally work in a similar manner, while the same cannot be assumed for developing countries and that

\footnotetext{
${ }^{12} \mathrm{~A}$ vertical multinational organizes the value chain globally within one firm: goods produced in one (upstream) country serve as input in another (downstream). In contrast, horizontal investment is undertaken to gain advantage in supplying local markets, e.g. by overcoming trade costs.
} 
different impacts may occur between different investor home countries. Nevertheless, I see our investigation as a contribution to the impact of FDI on development in a freedom-centered sense similar to Sen (1999, esp. p. 24), who also emphasizes the generic similarity of such a perspective on development to the common concern with 'quality of life' in industrialized countries.

Finally, chapter 6 investigates the impact of FDI and trade, as two broad measures of globalization, on female labor force participation (FLFP) in a panel of 80 developing countries over the time period 1980 - 2005. The results suggest that FDI and trade have a negative impact on the FLFP rate though the impact is mostly of negligible economic size (and shows a large degree of regional heterogeneity). The chapter is based on a joint research project with Arusha Cooray and Isis Gaddis. Our finding is possibly driven by the fact that FDI and trade lead to a sectoral upgrading in developing countries, thereby accelerating industrial "modernization." This process may first prefer employing men in the newly developing industrial sectors due to the fact that their physical labor is more productive in traditional manufacturing sectors. Since there may be a large pool of under- or unemployed men which will keep wage levels low, the newly developing sectors could first go for these "low-hanging fruits." With the development of the openness-oriented sectors, a sectoral diversification may take place that generates new jobs attractive to women. Our findings suggest that once the industrial sector is developed, FDI (interacted with the share of the industrial value added) no longer has a negative effect on the FLFP rate. FDI has a positive effect on the FLFP rate when economies have reached a particular threshold level of industrial value added of $16-28 \%$ of GDP, depending on the functional form of the estimated model. Another contribution of the chapter is to disaggregate the determinants of FLFP rate by age cohorts, showing that younger women experience stronger effects.

\section{Globalization and Development - An Interpretation}

This dissertation hence builds a bridge from the measurement and definition of FDI to its determinants and effects, with the latter focusing on development aspects, especially in labor markets. The empirical investigation shows that FDI can lead to more favorable export prices for developing countries, though not in all cases, that it can negatively affect labor standards and that it generally has a negative, though small, impact on female labor force participation in developing countries. This raises the question how development outcomes of globalization could be interpreted in such different spheres. By looking into this issue, I follow the arguments of Sen (1999, e.g. p. 7), that the absence of markets can be one obstacle to development, and Rodríguez-Clare (1996), who provides an economic rationale for a low-development equilibrium with a shallow division of labor because of a too narrow extent of the market. For this purpose, I apply a concept of 'markets' that is rather wide and abstract and roughly means a sphere creating 'opportunities of transaction' (cf. Sen 1999, p. 25). The argument is hence also related to Stiglitz (1989), who sees failures of markets (in a narrow sense) as a development challenge, and to the matchingliterature (Mortensen 1982; Diamond 1982). 
Assuming that people have certain 'capacities' to perform some meaningful tasks (such as education), 'markets' provide a mechanism to translate these capacities into 'outcomes,' i.e. things that people value and have reason to value (income, a long and healthy life, being literate, having decent employment etc.). Globalization may increase the 'extent of the market', i.e. it may increase the number of relations ('matches') possible between capacity and outcomes, e.g. through FDI. This concerns the fact that MNCs link domestic producers to international markets but also reflects that corporations themselves can be a sphere of transaction-opportunity and of allocation of capacities and production (cf. Stiglitz 1989, p. 202). ${ }^{13}$ While a shallow division of labor under autarky may provide few working opportunities, the matching-opportunities can thus increase considerably with globalization since "the ease in finding a trading partner depends on the number of potential partners available" (Diamond 1982, p. 893). Globalization could hence bring into motion a virtuous cycle, where the economy converges to an equilibrium with a deeper division of labor, a process that has considerable effects on the internal market structure ${ }^{14}$ and generally entails a more efficient allocation of human capital, talent, and intellectual resources.

In the context of chapter 4, this might entail positive upgrading effects to (and within) sectors with more favorable terms-of-trade development. Since the manufacturing sector generally provides more space for diversification and hence to perform tasks that match with individual capacities, one would expect more benefits from extending its market than from a larger market of primary goods. Also, well-educated people will find much more opportunities and benefits from an increased extent of the market (and from other possibilities provided by MNCs) than less-educated ones because the former possess a larger portfolio of performing tasks. Finally, to the extent trade and (horizontal) FDI act as substitutes, the supplementary benefits of FDI in extending the market will be smaller in an economy which is already very open to trade than in a relatively closed one. These are exactly the above-mentioned results of chapter 4 one can see in table 15 on page 115 and which are in line with the finding of Borensztein et al. (1998) that FDI flows have a positive impact on developing countries' productivity only when the absorptive capacity of the latter has reached a minimum level of human capital. Furthermore, the results from chapter 5 are explained through a channel which is essentially an 'extension of the market:' The higher productivity of multinationals enables a larger proportion of the labor force to find employment and allows them a trade of wages against labor standards. In the notion of Sen $(1999$, p. 75$)$, this extends the capability set from not working by the possibility of working under deteriorated conditions. To what extent people have real opportunities crucially depends on their outside options, in this case especially on the social security system. Similarly, despite the finding of a negative impact of

\footnotetext{
${ }^{13}$ In fact, the value of transactions in US firms is approximately equal to that in US markets (Lafontaine and Slade 2007).

${ }^{14}$ Cf., for example, the argument in Reardon and Timmer (2007, p. 2827) that globalization, especially FDI, had an important impact on domestic food markets.
} 
globalization on FLFP, it may still increase the real options of women by giving them the freedom to seek employment (Sen 1999, p. 115) and/or by increased household incomes. ${ }^{15}$

These arguments concern the increased coordination/matching space due to extended markets in the course of globalization. However, since economic markets also perform an incentive function (cf. Roemer 2011, p. 12), the enlarged extent of the market increases the incentive for people to invest in their capacities, resulting in an indirect effect that globalization may exercise on development. An example is the response of women to stay out of the labor force and invest in more education due to globalization, as argued in chapter 6 , although this channel demands further affirmation in future micro studies.

This leads to the bottom line of my argument concerning the evaluation of development impacts of globalization: Any comprehensive metric trying to assess the impacts of globalization on human development must take into account the differential effects that globalization has on outcomes, capacities, and the extent on the market relating these two, both directly and indirectly and must thereby address the efficiency and equity aspect simultaneously (Sen 1999, pp. 119/120). Despite the recent advancements of experimental economics, the generally non-experimental nature of economic events like globalization makes such a metric virtually impossible. However, instead of jumping to a conclusion when empirically investigating the welfare impacts of globalization, it is important to have these effects in mind. For example, it would be premature to interpret the results from chapter 6 as an impediment to the empowerment of women. On the contrary, the decision to stay out of the labor market and invest in education, besides from the intrinsic value of education itself, may enlarge occupational choices over the lifetime. Similarly, an individual may prefer to work under deteriorated labor rights over not having employment at all (cf. chapter 5). However, in all these cases the external effects of someone's individual choices on the social outcome have to be considered. ${ }^{16}$

Finally, despite a potentially increased coordination/matching space due to globalization, potential conflicts can arise with the long-run incentive structure of globalization under certain circumstances. The development of FDI flows depicted in figure 1 as well as the 'Great Trade Collapse' in the course of the 'Great Depression' highlight that globalization can make economies and their individuals more prone to volatilities and hence more vulnerable. If capital flows are mainly driven by home country effects (Calvo et al. 1993; Fernandez-Arias 1996; di Giovanni 2005), agents

\footnotetext{
${ }^{15}$ It is worth highlighting that globalization does not only impact the extent of the market but can also directly impact capacities and outcomes. On the outcome side, multinationals may create employment or pay higher wages (Lipsey 2002). As far as capacities are concerned, Görg and Strobl (2005) show that MNCs can provide additional education to their employees (which can be accounted for on the outcome side as well).

${ }^{16}$ Therefore, the above statement does not mean that labor standards should necessarily be softened to create employment. As argued in section 5.5, lowering the equilibrium unemployment rate(s) would be a policy option that increases people's real opportunities.
} 
in the host countries face considerable uncertainties concerning their future and bear the costs that can arise from foreign investment due to their external effects (see Bianchi 2011, for a recent, though very specific model). As pointed out by Rajan (2010), it is therefore questionable to what extent Adam Smith' claim, that actions of self-interested agents within competitive markets benefit social welfare, still holds in our globalized economy, especially under the aegis of financial markets. To the extent globalization creates conflicting ends between profit-maximization and social welfare, i.e. to the extent it allows profit-maximization to become an end in itself without providing means to development, political regulation is required to provide a framework that ensures a socially beneficial outcome to the best extent possible.

\section{Policy Implications}

While the above considerations highlight the complexity of channels relating globalization to development, a few general policy conclusions can still be drawn from the presented analysis. ${ }^{17}$ The concept of 'linkages' is essential in this context. While the 'enclave' type of foreign investment has not proven to be especially effective in promoting sustainable development in the past, the results from chapter 4 and the cited work of Borensztein et al. (1998) as well as a number of other contributions (e.g. World Bank 2010a) highlight that the absorptive capacity of the host economy and its potential to form linkages with foreign producers matters.

Hence, a certain level of education is necessary to attract modern production technologies and to allow for spillover effects. ${ }^{18}$ However, it also requires a functioning market structure in sectors related to multinational production networks. Both, theoretical arguments and empirical evidence suggest that especially suppliers of MNCs can benefit from 'backward' spillovers (Javorcik 2004; Blalock and Gertler 2008). This implies that attracting FDI should be targeted towards certain industries ${ }^{19}$ and these policies should be conceptually in line with the factor endowment and hence the level of human capital development of the host economy. However, it also requires a dynamic view of comparative advantages and hence a corresponding forward-looking industrial and development policy (cf. Lin 2011).

Similar considerations apply to the financial sector, where linkages necessarily occur in the course of FDI. Policymakers should ensure that FDI does not crowd out domestic investment due to shallow financial markets, a situation described in subsection 2.2 of this dissertation. Underdeveloped financial markets may not only hinder domestic agents from creating linkages, expanding activity and upgrading, they may even create considerable vulnerabilities due to 'fault lines' that emerge when financial systems of different development levels interact (see Rajan 2010, especially in

\footnotetext{
${ }^{17}$ More specific policy implications are given towards the ends of the individual chapters.

${ }^{18}$ See Havranek and Irsova (2011) for a recent meta-analysis of studies on FDI spillovers. They conclude that greater spillovers are generated by foreign direct investors who have only a slight technological edge over local firms.

${ }^{19}$ See Harding and Javorcik (2011) for the effectiveness and implementation of investment promotion.
} 
application to the Asian Crisis). Policy options include financial sector reform and macro-prudential policies. ${ }^{20}$ On the fiscal side, public budget constraints imply that funds have to be optimally allocated between targeted FDI attraction and leveraging domestic financial markets. ${ }^{21}$

In any case, to create incentives for foreign and domestic agents to conduct investments that allow for sustainable linkages and hence provide people with the opportunity of performing meaningful tasks, policy measures should take into account ownership considerations and hence ensure well-defined property rights.

Stimulated by surges in capital flows and the corresponding macroeconomic vulnerabilities, and promoted especially by the IMF, a growing literature focuses on the macroeconomic management of capital flows, including the design of capital controls (IMF 2011b; Ostry et al. 2011; Jeanne 2012; Ostry et al. 2012; Kim and Zhang 2012; Bianchi 2011). Since investment cycles can, inter alia, arise as the result of a 'trial and error' strategy of underinformed foreign investors that lead to an amplification mechanism, providing public information to financial markets, as discussed in section 3, can be a reasonable strategy in a corresponding policy-mix since this may attract longer-horizon foreign investment which tends to internalize adverse effects to a larger extent.

Information is not only essential for investors but also for people's decisions making in the development context (cf. Sen 1999, ch. 3). This is especially true in the context of globalization because of the above-mentioned volatilities, the 'everlasting uncertainty and agitation.' Women must know, for example, whether it pays off in the long run to temporarily stay out of the labor force and invest in education, i.e. whether MNCs will continue to maintain their production facilities in the country or move on to other countries eventually. Policy measures should hence aim at increasing the information available to people when making a decision. This includes a comprehensive education system that is not exclusively tailored to narrow technical skills exploitable by foreign and exporting firms but provides a broad (and hence flexible) basic education that educates people in performing technical skills as well as to comprehend the system of social interactions, including the market mechanism. It also requires a transparent policy process and institutional context and increased monitoring of economic risk. Since in an open developing economy the latter is largely multinational in nature, recent efforts by the IMF (2011a) are welcome in this regard. Furthermore, where funds and monetary space are available, fiscal and

\footnotetext{
${ }^{20}$ Brazil has also recently made a case for well-targeted capital controls toward different types of capital inflows.

${ }^{21}$ In contrast, Havranek and Irsova (2011) find that the financial development of the host country has a negative effect on FDI spillovers. While this supports the view that direct investment enterprises can help domestic suppliers and affiliates to ease credit constraints in the short run, it seems worrisome and barely sustainable to transfer ownership over a country's industrial development strategy to foreign investors and hence to profit maximization considerations that are largely influenced by developments in other countries and can thus exert adverse externalities on the host country.
} 
monetary policy should aim at absorbing temporal external shocks that can arise due to increased openness (e.g. through capital flows or terms of trade). On the fiscal side this involves the design of appropriate automatic stabilizers (cf. Blanchard et al. 2010, pp. 212f). While Blanchard et al. (2010) prefer "rules that allow some transfers or taxes to vary based on prespecified triggers tied to the state of the economic cycle," the advantage of "truly automatic stabilizers" for individuals' decisions in my view lies in the predictability of transfer schemes that would be viewed as a legal claim by people and hence involve them into the policy process to a larger extent, while general rules can imply a certain level of arbitrariness, especially in the context of weak institutional environments where expectations are not well-anchored. Concerning monetary policy and structural reform, external reserves and labor market mobility have generally shown to help buffer the impact of large negative external shocks (Berg et al. 2011).

\section{Further Questions}

The results presented in this dissertation also give rise to a number of research questions currently under investigation or potentially worth exploring in the future. In relation to the econometric modeling of FDI, this especially concerns the persistence and exact dynamics of FDI stocks, comprising such issues as unit-root testing under cross-sectional dependence and modeling the dynamics with respect to financial development. Concerning the relationship between information and international capital markets, an open issue of interest concerns the volatility in capital flows associated with information asymmetries. In relation to this, it could also be investigated how public data dissemination changes the external capital structure, especially the relationship between large and small portfolio investors (with potentially differing investment time horizons). Another channel worth exploring in future work is the role of information in the capital flow - growth nexus: If information is incomplete, capital might not flow into the most productive assets and 'sudden stops' that occur after realizing a lower-than-expected productivity may have adverse effects on growth, resulting in ample impacts in the relationship between open financial accounts and growth and thereby explain why the empirical relationship between the latter does not turn out to be robust (cf. Jeanne et al. 2012, ch. 3 and 4). The results from chapter 4 call for an investigation how FDI influences product upgrading in the export sector and to what extent this might show up as a terms-of-trade increase. Another line of research might explore the relationship between globalization and terms-of-trade volatility, motivated by a model of Razin et al. (2003). The investigation of chapter 5 could be extended to the question whether the potential to outsource or conduct outward FDI lowers domestic labor rights and whether the increased demand for high-skilled laborers in the presence of foreign (vertical) direct investors leads to an increase of labor standards. Finally, more information is needed on the response of women in developing countries to increased globalization with respect to their choices of investing in education and joining the labor force. Micro-level investigations and studies that put more emphasis on the exact dynamics of the process would be helpful. 


\section{Measurement and Determinants of Activities of Multinational Corpo- rations and Foreign Direct Investment}

THOMAsinA: If there is an equation for a curve like a bell, there must be an equation for one like a bluebell, and if a bluebell, why not a rose? Do we believe nature is written in numbers?

Septimus: We do.

Thomasina: Then why do your shapes describe only the shapes of manufacture?

Septimus: I do not know.

Thomasina: Armed thus, God could only make a cabinet.

SEPTimus: He has mastery of equations which lead into infinities where we cannot follow.

THOMASINA: What a faint-heart! We must work outward from the middle of the maze. We will start with something simple.

Tom Stoppard - Arcadia

As outlined in the introduction to this dissertation, scholarly interest in determinants and impacts of multinational corporations (MNCs) has risen considerably over the last decades. In combination with the advancement of empirical methods and econometrics, this has resulted in an increasing ad hoc practice to quantify MNCs' operations. There are several methods in the literature to measure the relevance of multinational firms, first and foremost data on FDI stocks and on sales of multinationals' foreign affiliates, but also data on FDI flows and various operational data of multinationals' foreign affiliates, such as employment data. Few studies explicitly explain why they use a specific measure, but rather assume implicitly that the different data are to some extent tantamount to each other. ${ }^{22}$ Neither do most of them motivate the precise functional form of their estimable model ${ }^{23}$ when trying to estimate determinants of MNCs' activities.

The aim of this chapter is to go 'back to the basics' of how to measure MNCs' activities. $^{24}$ Therefore, the measures outlined above are discussed before I demonstrate what advantages and drawbacks these measures might have in view of an underlying

\footnotetext{
${ }^{22}$ Among the exceptions worth noticing is Davies (2008, p. 263f) who discusses different findings between a FDI stock and a sales data sample by asking what economic mechanisms and data recording techniques may cause this sensitivity. However, his discussion is mainly focused on the specific application.

${ }^{23}$ Cf. Spanos (1993, p. 21) who refers to an estimable model as a "particular form of the theoretical model which is potentially estimable in view of the actual DGP and the observed data chosen" and explicitly distinguishes it from the theoretical model, the statistical model, and the empirical econometric model.

${ }^{24}$ I therefore follow a country-approach, i.e. the question is to measure from a countryperspective, how relevant MNCs are in its economy. This will be largely but not perfectly identical with an aggregated firm approach to measure how relevant certain host country activities are from the firm's perspective. I do not discuss any disaggregated direct measures of MNCs at the micro level such as firm-level datasets.
} 
Cobb-Douglas production function with or without different forms of technological progress and potential differences in factor prices, and under the assumption that MNCs produce technologically and allocatively efficient. I then provide empirical evidence that most measures of MNCs' activities are in fact highly correlated to each other. Finally, I investigate in how far these different measures and different functional forms of the estimable model lead to diverging parameter estimates in a very parsimonious model of MNCs' determinants before concluding the chapter with a summary what empirical researchers but also policy makers and economists working on the nature of the multinational firm can potentially take away from this exercise.

\subsection{Measuring Activities of Multinational Corporations}

\subsubsection{FDI Data}

FDI data is an ad hoc candidate and widely used to quantify the relevance of multinational firms. ${ }^{25}$ They either come as flow or as stock data and are recorded in a country's Financial Account of the Balance of Payments (BOP) or International Investment Position (IIP), respectively, which are statistical statements that systematically summarize the economic transactions (or assets and liabilities, respectively) of that country with the rest of the world. The primary publications for international FDI statistics are the IMF's 'Balance of Payments Statistics Yearbook, ${ }^{26}$ OECD's 'International Direct Investment Statistics Yearbook, ${ }^{27}$ UNCTAD's 'World Investment Report, ${ }^{, 28}$ and Eurostat's 'European Union Foreign Direct Investment Yearbook. ${ }^{29,30}$

A main reference manual on measuring FDI data is IMF's "Balance of Payments and International Investment Position Manual" (BOPM), ${ }^{31}$ currently in the 6th edition (2009), with earlier editions published in 1993, 1977, 1961, 1950, and 1948. IMF

\footnotetext{
${ }^{25}$ Examples of important studies using FDI data are Baltagi et al. 2007, 2008 and a sample of Blonigen et al. 2003 for stocks and Borensztein et al. 1998; Davies and Voy 2009 and Harding and Javorcik 2011 for flows.

${ }^{26}$ The IMF provides BOP and IIP data in its International Financial Statistics (starting in the early 1990s) for each member country as they report them to the Fund. Furthermore, IMF's World Economic Outlook data provide data that date back longer in time. The WEO data are compiled by IMF staff based on the information gathered by the IMF country desk officers in the context of their missions to IMF member countries and through their ongoing analysis of the evolving situation in each country. Historical WEO data are updated on a continual basis, as more information becomes available, and structural breaks in data are often adjusted to produce smooth series with the use of splicing and other techniques.

${ }^{27}$ As a main advantage, OECD data generally provide a geographical and industry breakdown.

${ }^{28}$ UNCTAD provides stock and flow data as early as 1970, in current and constant values and as a percentage of GDP or of gross fixed capital formation.

${ }^{29}$ As a main advantage, Eurostat data generally provide a geographical and industry breakdown.

${ }^{30}$ Note that data across these sources need not be identical (cf. IMF 2004, p. 9f).

${ }^{31}$ Another central source is the OECD's Benchmark Definition.
} 
(2009a, cf. paragraphs 6.8 - 6.24) BOPM6 defines FDI as a "category of cross-border investment with a resident in one economy having control or a significant degree of influence on the management of an enterprise that is resident in another economy" (emphasis added).

More precisely, FDI requires that a long-term relationship is established between a foreign direct investor (either a natural person or a corporate body in the 'source' or 'home' country) and a direct investment enterprise in the 'host' country, where the former has a lasting interest and a significant degree of influence in the latter. ${ }^{32}$ Since it is too complex to evaluate this criterion on a case-by-case basis, the relevant criterion for an investment to be classified as FDI (as opposed to portfolio investment) is that the direct investor directly or indirectly ${ }^{33}$ owns "equity that entitles it to 10 percent or more of the voting power [i.e. of ordinary or voting shares] in the direct investment enterprise." Once this direct investment relationship has been established, all subsequent capital transactions between direct investor and direct investment enterprise are considered to be direct investment. These transactions are recorded on a net basis within an existing direct investment relationship, ${ }^{34}$ more precisely as assets for the economy of the direct investor and as liability for the economy of the direct investment enterprise (cf. IMF 2004, pp. 5 and 19f).

Note that the $10 \%$ criterion means that FDI does not necessarily imply full control of the direct investor over the direct investment enterprise. ${ }^{35}$ In practice, however, a large proportion of FDI involves majority-owned subsidiaries and branches. For example, Graham and Krugman (1989, p. 10) showed that raising the classification

\footnotetext{
${ }^{32}$ In accordance with the BOPM and current accounting practices, "foreign" refers to residence, not nationality or citizenship.

${ }^{33}$ In practice, this measurement of indirect ownership poses serious problems, see IMF (2004, box 5.1 on p. 21 and paragraphs $6.15-7.17$ ).

${ }^{34}$ This shall not be confused with net capital flows between countries, where the net flow from country A to country B is calculated as the flow from A to B minus the flow from B to $\mathrm{A}$ and which is relevant for movements in a freely floating exchange rate, for example. What is meant here is that flows within a direct investment relationship are netted. For example, the direct investor may invest 100 monetary units (MUs) of equity in the direct investment enterprise but takes a loan of 20 units from this enterprise (called a 'reverse investment'), resulting in a net flow of 80 units. Hence, this concept of net recording of flows and stocks does not mean that FDI inflows in B from A equal (negative) inflows in A from B (but that FDI inflows in B from A equal outflows from A to B). A special case emerges when the equity participations are at least 10 percent in both directions, i.e. the equity participation by the direct investment enterprise in its direct investor entity reaches or exceeds $10 \%$ of the latter's total equity. Then, the BOPM recommends that two direct investment relationships be established. The praxis of netting also explains why one sometimes finds negative FDI flows (or even negative stocks).

${ }^{35}$ The BOPM defines control if the investor owns more than $50 \%$ of the direct investment enterprise and significant influence if it owns between 10 and $50 \%$. The BOPM further distinguishes this immediate direct investment from indirect direct investment, where the control or influence is exercised through a chain of direct investment relationships, cf. footnote 33 .
} 
criterion to 20 or even 50 percent would only have a minor impact on the measurement of US firms classified as being under foreign control. IMF (2004, p. 19) highlights that majority-owned subsidiaries and branches accounted for $93 \%$ of Canada's inward and $94 \%$ of its outward FDI stock in 2001 and that similar ratios of 94-96 $\%$ for inward and 83-97 \% for outward FDI prevail in most industrialized countries, while equity holdings of $10-25 \%$ only account for 1 or $2 \%$ of FDI stocks (cf. IMF 1992). Finally, note that the criterion requires that only one investor (or a related group) holds the share of $10 \%$ or more, not a group of unrelated investors.

Based on this definition, three different forms of FDI can be distinguished, where only the first one can constitute a foreign direct investment relationship while the others are characterized as FDI (and recorded as such in the BOP or the IIP) once a FDI relationship has been established:

1. equity capital, which makes up for the main part of FDI (cf. IMF 2004, paragraph 3.4 or Lehmann et al. 2004, table 1 on p. 5); ${ }^{36}$

2. reinvested earnings are the direct investor's share of earnings not distributed as dividends by subsidiaries and associated enterprises and earnings of branches not remitted to the direct investor during the reporting period, ${ }^{37,38}$ and

3. other capital, mainly intercompany debt. ${ }^{39,40}$

\footnotetext{
${ }^{36}$ This does not imply, that equity capital of foreign direct investors is the main source of finance for direct investment enterprises. The issue is addressed below. Also note that throughout this work, I do not refer to 'capital' in a colloquial way, i.e. I do refer to capital as a liability, not an asset. Even the term 'fixed capital' should make clear that it is the part of capital (liabilities) that - as a mirror image in the books - is fixed in assets (such as buildings, machines etc.). The issue should be more clear after consulting section 2.2.

${ }^{37}$ The concept of reinvested earnings does not apply to the BOP category of portfolio investment equities because - contrary to the FDI case - the investor has not consciously chosen to forgo a distribution of income and elected to increase its investment (IMF 2004, p. 20).

${ }^{38}$ Reinvested earnings, together with dividends and distributed branch profits and interests on intercompany-debt FDI constitute FDI investment income flows, which are part of the Income Account of the BOP's Current Account, not of the Financial Account of the BOP (besides from reinvested earnings which is also part of the Financial Account). This makes sense once one understands that they are the income of an exported service. For the same reason, direct investors' incomes through management and other fees and charges levied on the direct investment enterprises which are recorded under 'business services transactions' are part of the Current Account, not the Financial Account.

${ }^{39}$ Intercompany transactions in financial derivatives are not considered FDI-although it may be hard to identify them so that they can end up in the 'other capital' category of FDI. Borrowings by direct investment enterprises from unrelated parties abroad that are guaranteed by direct investors ("contingent liabilities") are not FDI. Intercompany debt between affiliated banks or affiliated financial intermediaries is limited to permanent debt and fixed assets (cf. IMF 2004, pp. 3 and 20-21).

${ }^{40}$ Note, that this is a broad definition of 'capital' (for a primer about capital in the context of bank capital cf. Elliott 2010, pp. 2ff) and that debt on its own cannot constitute a FDI relationship.
} 
Stocks vs. Flows

Simply speaking, FDI stocks are the (revalued) cumulation of past flows, while flows are the current transaction taking place in a certain period $t$, most importantly within a year. The definition of what is characterized as FDI applies to both of them, though for stocks - which are recorded in the IIP — equity capital and reinvested earnings are combined into a single category because at the end of the period they both form equity capital holdings.

While the sum of transactions taking place throughout the period can be taken for flow data, stock data is more problematic because one is confronted with the question how to value assets of a multinational firm that were acquired in the past. Table 2 exemplifies the relation between FDI stocks and flows: Throughout the year, the assets held by the direct investor in the host economy have to be revalued: This includes a valuation to market values (price change), changes in the assets' value due to exchange rate changes (values are finally mostly reported in US-\$) and other changes such as write-downs and reclassifications. In the example in table 2, this leads to changes in the IIP of 5 Monetary Units before any flow has taken place. This highlights, that FDI flows are generally not equal to the first difference of FDI stocks. ${ }^{41}$ Nevertheless, when stock data is missing, summing capital flow data can be used as approximations to fill the data gaps, although this does not take into account nontransaction changes arising from, for example, exchange rate and price changes (cf. IMF 2004, p. 13). An example for such an application is given in the robustness check of chapter 4 .

\section{Table 2: FDI Stock Changes and the Relation to FDI Flows (fictive example)}

\begin{tabular}{lr}
\hline IIP assets at the beginning of the period ("stock") & 120 \\
\hline BOP transactions ("flows") & 15 \\
\hline price changes plus & 2 \\
exchange rate changes plus & 8 \\
other adjustments plus & 1 \\
\hline IIP assets at the end of the perios ("stock") & 130 \\
\hline
\end{tabular}

\section{FDI-specific Problems}

In one of the rather scarce attempts in the literature to address the appropriateness of FDI data to measure MNCs' output, Lipsey (2007) raises serious concerns about the use of FDI data because of the valuation problem, the intangible nature of most production generated by MNCs and the fact that even for production of tangible products, important parts of the assets that enter production are intangible,

\footnotetext{
${ }^{41}$ An exception is the special case when there are no revaluations or, which is the same, the investment position is recorded at historical values.
} 
especially financial assets. ${ }^{42}$ Since firms can almost arbitrarily attribute these intangible assets among countries, this would lead firms to "internationally shift assets and sales nominally [i.e. without any counterpart in movements of production] to low-tax countries to minimize taxes" (p. 14). With regards to country-level data, however, his concerns seem somewhat excessive in light of his results which are discussed in section 2.4 below and lead him to the conclusion that "the country distribution of the [US] outward FDI stock is a fairly good representation of the distribution of employment" in both 1994 and 1999 (p. 11) while the industry distribution is not (p. $12)$.

Another potential problem with FDI data, which I consider more interesting from the economic perspective and hence exemplify in section 2.2 below, is the question which other sources of finance besides from FDI a direct investment enterprise acquires, i.e. the question of its capital structure. Markusen (2002, p. xii) already noted that "the sourcing of finances for direct investments are often geographically disjoint from the actual parent country." Note that this issue is not resolved by the above-made argument that majority-owned subsidiaries are the main part of MNCs' affiliates because having knowledge about the foreign direct investor's holdings in the direct investment enterprise's (common or voting) shares does not tell us anything about the distribution between the shareholders and (long-term) creditors in the capital structure. In an interesting study on the determinants of these sources of finance, Lehmann et al. (2004) find that "for US affiliates in all countries, finance that can be attributed to US parents (that is, FDI stocks) represents no more than a third of total balance sheets" (p. 5). Almost another third is financed through host country residents' (current and long-term) liabilities, $14.3 \%$ through third-country liabilities. Probably even more important, the share of affiliates' host-country finance is larger in industrialized than in developing countries, suggesting that FDI structurally underestimates the share of foreign-controlled assets in the former countries compared to the latter ones. Moreover, while the total leverage (total debt to asset) ratios have remained fairly stable since the early 1990s (after some movements in the decade before), the importance of host country debt instruments has experienced a decline in both types of countries since then (p. 6).

\subsubsection{Other Operational Data}

The Bureau of Economic Analysis (BEA) of the US Department of Commerce does not only offer BOP and IIP data but also financial and operating data of US MNCs and on the US operations of foreign MNCs, such as total assets, employment, employee compensation, sales, and net income. ${ }^{43}$ These data are generally available

\footnotetext{
${ }^{42}$ His other main concern is the fact that the location of production associated with about a third of the total US outward stock is unknown. A similar issue applies to trade data, where global exports also do not balance global imports.

${ }^{43}$ OECD (2007) also provides data on similar variables on the ISIC Rev. 3 level, but only for a very limited time period (1999/2000 - 2003/2004). At stats.oecd.org, some operational data range for longer time periods, sometimes even outnumbering the BEA observations. I limit my discussion here to the BEA data since they are the most-widely used operational
} 
from 1997 for almost all countries and to some extent allow an industry-level breakdown. However, much data are subject to disclosure and missing values pose another problem, as does the sectoral classification change in 1999 and the change from only including nonbank foreign affiliates up to 2008 to including all foreign affiliates thereafter.

Since these data are only available for US-related multinationals and since outward investment motives are not necessarily limited to conditions in the host country (pull factors), but also in the home country (push factors; see Calvo et al. 1993; FernandezArias 1996; Chuhan et al. 1998; Albuquerque et al. 2005; di Giovanni 2005 and others) such as the Federal Reserve's policy of cheap money throughout most periods of the last decades, econometric studies using these data should give special emphasis to modeling all relevant push factors (a rather heroic claim) or, which comes down to the same, to include time dummies (a more pragmatic approach). ${ }^{44}$

To avoid the discussed problems of the direct investment enterprise's capital structure, using data on total assets, i.e. all owned physical objects or intangible rights with economic value to the firm, would be an option. While FDI is recorded as one component of the liabilities' side of the balance sheet of the host (direct investment) enterprise, total assets - by accounting identity (assets = liabilities) — are the mirror image of FDI and all other liabilities and typically include items such as cash, inventories, receivables, and property, plant, and equipment (PPE). It also includes equity investments in unconsolidated domestic and foreign businesses. However, the use of this data in the literature is not common, potentially because the gains are rather modest compared to using FDI data which provides a much larger availability. Also note that the data does not resolve the issue of intangible assets raised by Lipsey (2007) because they are one part of these assets as well.

One of the most commonly used measures for the activity of MNCs is sales data of MNCs' affiliates which is the value of goods and services sold and, for financial firms, also includes investment income. ${ }^{45}$ The data is net of returns, allowances, and discounts and excludes sale or consumption taxes levied directly on the consumer and excise taxes levied on manufacturers, wholesalers, and retailers. Accordingly, it includes intermediate inputs from other producers. To measure the extent of MNCs' output from its own production and to represent its contribution to GDP in the host country, it would hence be preferable to use value added data which would give a closer impression how much resources multinational firms directly command in an economy. Furthermore, the above-mentioned quote of Lipsey (2007, p. 14) makes clear that the problem of arbitrary international shifts of resources within a MNC also applies to sales data. This has to be the case because the corporation wants

\footnotetext{
data in the literature.

${ }^{44}$ While the same argument applies to the aggregate of all source countries, it is possible that such source-country effects cancel out at the aggregate level. In this case, however, I would still recommend the use of time dummies or to model 'global variables' such as the oil price and LIBOR when $T \rightarrow \infty$ and hence time dummies cannot be used.

${ }^{45} \mathrm{Cf}$. footnote 38 on page 30 .
} 
to realize the nominal profit where profit taxes are lowest. Therefore, the affiliates located in tax havens have to sell something in their books, most likely services (or intangibles). Furthermore, problems with the data might arise if the capital structure of the host producing the sales will change, depending on what is the purpose of measurement and the question under investigation. Therefore, note that sales data might remain unaffected (at least in the short run) while the share of FDI in the affiliate's equity might increase, giving the foreign direct investor other incentives to transfer technology or other intangibles, for example. Despite these and other potential problems, many of the most important studies in the literature on MNCs, such as Brainard (1997); Carr et al. (2001); Helpman et al. (2004); Blonigen et al. (2007); Ekholm et al. (2007); Davies (2008), use US affiliates' sales data for their empirical investigations. A potential reason is the fact that the literature on MNCs emerged widely from trade theory and is hence mainly concerned with the movement of goods across borders and potential substitutes, which is in fact best measured by sales data (but does not necessarily provide us a good picture of the multinational firm, especially when it comes to such important issues as corporate finance and corporate management).

Another common (descriptive) measure for MNCs' relevance is employment data of their affiliates, which is the number of full-time and part-time employees on the payroll at year-end in the BEA's accounts. The advantage of this data is the fact that it is a real variable, i.e. not expressed in monetary terms. However, this also is the data's main weakness because it bears few information about the economic value of these employees since both, a high-skilled and a low-skilled worker are recorded with the same real value though the former's productivity is expected to be much higher. Hence, the number of employees in MNCs' affiliates relative to total employment over the long run within a given economy might be a rough descriptive measure for the development of the MNCs' relevance in that economy, however, as discussed in section 2.3 below, this will only be appropriate under rather strict assumptions, such as no factor bias in technological progress across industries/firms. Probably more accurate is the comparison of the MNCs' employees as a share of total employees across sectors at a given point in time to describe the degree of multinationality across sectors in a given country since then the assumption of economic homogeneity of workers (between domestic and foreign firms within a given sector) is more reliable. Another problem in practice is the fact that employment data is often missing or only given in (rather large) intervals which can pose a serious problem in FE estimation because due to the interval-censored variable, there will not remain enough variation across time.

To resolve the problem of economic value of workers in the firm, data on compensation of employees could be used. It includes cash payments, payments-in-kind, and employer expenditures for employee benefit plans including those mandated by government statute, such as employer contributions for government social insurance. While this should also account for labor-saving technological progress in theory, because the increased marginal product due to the latter should be reflected in the worker's remuneration, this is very unlikely given the potentially strong bargaining 
power of MNCs. ${ }^{46}$

Finally, the BEA also provides net income data, that is the profit an affiliate earnings in a given time period. It equals total sales or gross operating revenues and other income less total expenses. It is net of, i.e. after deduction of, income taxes and includes income from equity investments. While probably not an appropriate measure for the overall relevance of MNCs, it might be used in industrial analysis to address the issue if MNCs' affiliates produce more profitable, conditional on the factor inputs, for example, although multinational tax incentives will again pose a serious problem in this context.

\subsection{An Accounting Example}

To get an intuition to what extent two of the most central concepts to measure the activities of MNCs, FDI stocks and affiliates' sales, could constitute different concepts, consider table 3 which depicts a fictive balance sheet of an (direct investment) enterprise A in country 1 . In the narrowest sense, the capital stock of the enterprise is the sum of common stocks held by the investors that amounts to 490 Monetary Units (MUs). Furthermore, the firm has issued preferred stocks of 90 MUs to investor $\mathrm{E}$ as a dept instrument that can be classified as capital in the narrow sense because investor $\mathrm{E}$ has no legal claim to ever get back this investment (see below). Note that capital is found on the liability side of the balance sheet. The firm can use this capital to buy things as machines or land that will be summarized under "property and equity" (in the case of machines and land, this will be 'fixed capital'), it holds some money, "cash," to carry out its daily business, and has some goods on storage. Since some of these assets have a relatively stable market value, the enterprise can take loans against these assets because even in times of a crisis (e.g. when the value of property and equipment decreases significantly), the capital owners do not have a strict legal claim on these assets because capital is by definition the portion of assets which have no associated contractual commitment for repayment (Elliott 2010, p. 1). In this case, the enterprise has taken total loans of 420 MUs. Since capital and loans sum up to 1,000 MUs and since assets and liabilities have to balance per definition, ${ }^{47}$ the (direct investment) enterprise (or, its management, or, its common shareholders) commands an equivalent of 1,000 MUs. Suppose that this stock of assets produces goods that are sold during the year at a total of 700 MUs.

In this example, the only foreign direct investor is investor $\mathrm{C}$ from country 2 because

\footnotetext{
${ }^{46}$ For a discussion of the bargaining power of foreign portfolio and direct investors in the context of developing countries, see Trapp (2012).

${ }^{47}$ Of course, not the assets will balance the liabilities but it is rather the capital part of the liabilities that will take care that liabilities equal assets, i.e. capital is the residual category that ensures this identity. However, a part of the capital structure may be reflected on the asset side as part of intangible assets. In fact, this should be a mechanism that allows the book values of capital to approach market values of traded capital, i.e. to relate the future with the present. Therefore note that market values of stocks are a present value (hence, a representation of a future value), while tangible assets should be current values.
} 
Table 3: Fictive Balance Sheet of (Affiliate) Enterprise A in Country 1

Balance Sheet of Enterprise A (country 1)

\begin{tabular}{lr|lr}
\hline \hline \multicolumn{1}{c|}{ Assets } & & \multicolumn{2}{c}{ Liabilities } \\
\hline Cash & 50 & Common Stock of Investor B in Country 1 & 400 \\
Property and Equipment & 600 & Common Stock of Investor C in Country 2 & 70 \\
Intangible Assets & 300 & Common Stock of Investor D in Country 2 & 20 \\
Storaged Goods & 50 & Preferred Stock of Investor E in Country 2 & 90 \\
& & Long-term Loan from Bank in Country 1 & 250 \\
& & Long-term Loan from Bank in Country 2 & 70 \\
& & Short-term Loan from Bank in Country 2 & 100 \\
\hline Total & 1,000 & Total & 1,000 \\
\hline
\end{tabular}

it is both foreign and its capital stock amounts to $70 / 490=1 / 7$ of the total voting shares which is clearly larger than the $10 \%$-cut-off point in the BOPM. The capital stock of investor D amounts to $20 / 490<10 \%$ of the relevant capital structure and is hence classified as portfolio investment in the IIP and the stock of investor B is domestic, not foreign. Preferred stock (under usual circumstances) carries no voting rights, investor $\mathrm{E}$ hence does neither have control nor a significant degree of influence on the management of company A. There are at least three important lessons depicted in the balance sheet in table 3 :

1. The amount classified as FDI can by far underestimate the assets commanded by MNCs. In the present case, it may be questionable how much ownership and control investor $\mathrm{C}$ can really exercise, but assume that it would buy stocks from investor B worth 180 MUs. It will then hold 250/490 >50\% of the firm and exercise full control over assets worth 1,000 MUs with an investment worth 250 MUs. Since long-term debt and preferred stock can be classified as capital in the wider sense, it will command capital worth 900 MUs with an FDI equal to 250 MUs.

2. This illustrates that conclusions from using FDI data can vary significantly from those using sales data. In our case, the first amounts to $70 \mathrm{MUs}$ (250 MUs after the purchase from investor B), the second one to 700 MUs. Which one is more appropriate depends on the question being analyzed. Suppose we want to estimate the impact of multinationals on labor relations in a cross-country sample or a fixed-effect panel setting. Then, sales data will probably not be the preferred option because it implicitly assumes that the "multinational" part of the enterprise is $100 \%$. More realistically, labor and industrial relations in our company A will be shaped by (domestic) investor B and its preferred management style might vary considerably from the one of investor C. Also, in the above case, where investor $\mathrm{C}$ buys the majority share and may hence change the dominant management practice, FDI data will notice the increased influence of investor $\mathrm{C}$ whereas sales data remains unaffected.

As a counter-example, suppose we want to estimate some industrial organi- 
zation effects of increased competition by multinationals in a given market. Then, the sales data of 700 MUs may be appropriate since the overall structure of the firm may be very different from a domestic one: The foreign investor, although inessential in the capital structure, may still bring in certain technologies or managerial skills or, for example, the opportunity to leverage via banks in the parent country 2 that might be especially beneficial when there is a credit crunch in host country 1 . These factors are not only beneficial to $1 / 7$ or $50 \%$ of the production process but to the whole production process and hence sales data may provide the better statistics to address the question at hand. However, note that the foreign direct investor may have more incentive to transfer knowledge to the direct investment enterprise (affiliate), if it owns a larger share of equity in this enterprise.

3. Finally, the balance sheet in table 3 makes clear that it is somehow problematic to consider FDI as a simple capital flow. One well-known question is to what extent multinational firms replace domestic firms. However, even if they supplement domestic firms in the real production process, they may still detract capital from the domestic market to a considerable extent, hence crowd out domestic firms via a financial channel. Suppose, enterprise A produces exclusively inputs for investor $\mathrm{C}$ in country 2. Looking at the accounting figures of the IIP, we would assume that there was an accumulated financial stock of $70+20+90+70+100=350$ MUs from country 2 to country 1 . Economically, however, capital worth $650 \mathrm{MUs}$ is detracted from country 1 to country $2{ }^{48}$ In some sense, hence, the "capital inflow" makes capital more scarce in the host country 1, although, of course, in equilibrium this should result in a more productive resource allocation in the host country and the increased income can be spent on import of goods and services. Nevertheless, Vora (2001) and Harrison and McMillan (2003) provide evidence that foreign-owned affiliates' host country leverage aggravates credit constraints of domestic firms in Morocco and Ivory Coast, respectively.

Under certain conditions, a FDI-type capital 'inflow' can indeed be an outflow of capital from the host market. Suppose, the fictive US-based software corporation 'Macrohard' decides to establish an affiliate in Ireland, due to tax purposes. It sets up a $100 \%$ owned greenfield letterbox company named 'Pear' and injects capital of 110 million US-\$. This shows up as an equivalent FDI inflow for Ireland in the BOP. Assume, the affiliate is basically virtual, i.e. it consists of a small office and one employee. Now, suppose the affiliate takes up a long-term loan equivalent to 90 million US-\$ at the Irish capital market. With the 200 million of capital (in the wider sense), the affiliate acquires the intellectual property rights of Macrohard's flagship software product 'Doors.' Consequently, for any future sales of 'Doors' worldwide, the parent firm 'Macrohard' would have to pay fees to the affiliate 'Pear' so that the multinational firm's profit occurs in low-tax Ireland. This is an example of the above-mentioned arbitrary international shift of nominal assets and sales. In this

\footnotetext{
${ }^{48}$ Strictly speaking, the bank loans are not capital in the firm's balance sheet but should be considered capital on the international level.
} 
case neither FDI nor (service) sales data give an accurate picture of the economic relevance of the MNC in the host country and, moreover, the capital 'inflow' of 110 million $\$$ effectively detracts 90 million $\$$ from the Irish capital market. The only real capital that flows into the Irish economy are the subsequent interest payments (from the 90 million $\$$ loan). Of course, this is an extreme (and fictive) case but for some countries quite accurate. For example, Lipsey (2007, table 14) shows that the worldwide average of 'profit-type return' of nonbank majority-owned US affiliates relative to compensation of employees in 2004 was 0.79 . However, this ratio was 4.85 for Ireland and even above 13 for the region of 'Other Western Hemisphere,' mainly Caribbean type coconut islands, with Barbados taking the cake with a ratio of 72.67. As Lipsey (2007, p. 20) argues with convincing evidence, this type of "allocation of assets to tax havens is not simply a consequence of the composition of concentration of investment in the finance sector [which would be expected to have a higher capital/labor ratio per se], but takes place within that sector as well." 49

These issues emphasize potential pitfalls of measures quantifying MNCs. From this example, I now turn to a more systematic way of comparing the different measures by looking at conditions under which these measures should be tantamount to each other and which economic changes could lead to a divergence between the measures. Afterwards, I will present some figures that demonstrate that the empirical correlation between most of these measures is relatively strong.

\subsection{The Relationship Between FDI Stocks, Flows and Other Operational Data}

\subsubsection{Stocks and Flows in the Steady State}

Assuming that host and home economy and the MNC are in equilibrium and none of the variables underlying the FDI decision changes, the FDI stock should be in a steady state:

$$
\text { FDIstock }{ }_{i t} \stackrel{!}{=} \text { FDIstock } k_{i, t-1} \text {. }
$$

This means that the multinational firm has no incentive to adjust its FDI stock. Does equation (3) imply that there is no FDI flow in the BOP? To assess this question, it is important to note that the capital stock in time $t$ necessarily consists of the stock inherited from $t-1$, minus depreciations of this stock and plus (minus) changes due to flows:

$$
F D I \text { stock }_{i t}:=\text { FDIstock } k_{i, t-1}-\delta F D I \text { stock }_{i, t-1}+\text { FDIflowit },
$$

which will be discussed in more detail below. If $\delta>0$, i.e. a certain fraction of the capital stock depreciates and $\delta$ is fixed, i.e. does not change over time and countries, substituting the steady-state condition (1) into condition (2) implies

$$
\delta F D I \text { stock }_{i, t}=F D I \text { flow }_{i t} \quad \forall i, t .
$$

\footnotetext{
${ }^{49}$ On the issue, see also the recent contribution of Karkinsky and Riedel (2012).
} 
This is equivalent to the well-known steady-state condition in the neoclassical exogenous growth model and intuitively means that the multinational has to make up for the depreciated stock by a FDI flow from the parent to the host of equal size as the depreciation. $^{50}$ One could add $\eta t$ to the right hand side of equation (1) and hence the left hand side of equation (3) that might capture an underlying process such as the steady-state growth rate of total output (hence market size) or other trends such as political globalization that leads to a deterministic trend in FDI stocks, however, to emphasize the argument made here, I assume $\eta=0$.

This trivial conclusion has a very practical implication: To estimate any equilibrium model for the multinational firm, it theoretically does not matter wheter one uses FDI stocks or FDI flows because the latter is a (homogeneous) function of the former. I will show in section 2.4 below, that the correlation in the data can indeed be very high and will discuss the implications for applied research in the concluding section. ${ }^{51}$

\subsubsection{The Production Process and its Reflection in the Data}

The concerns about FDI data that Lipsey (2007) raises, address such questions as if we "wish to say that the location of output has changed because, for example, firms have chosen to place their holding of their affiliates' stock in their Irish subsidiaries? Do we wish to say that the location of output has changed because firms have chosen to place ownership of their patents or corporate logos, which they use all around the world, in Ireland or in some Caribbean Island?" (p. 20). These accounting issues are of course important questions and can result in misleading data as exemplified above. However, while Lipsey provides some suggestions how primary data compiling techniques could help resolve the problem, most applied researchers are limited to the use of the above-mentioned secondary data. Also, it seems questionable that arbitrary shifts in books constitute the most important problem in measuring MNCs' activities in general, although there can be no doubt that they are substantial for specific countries. I think the middle of the maze and hence the overall problem starts before that problem and we must work our way outward from there: the production process.

\footnotetext{
${ }^{50}$ Note that reinvested profits should be part of the FDI flows as they are recorded in the home country's Financial Account as a debit entry under 'FDI abroad' with an offsetting credit entry in 'reinvested earnings' under 'FDI investment income' in the Current Account in order to ensure the BOP identity. Cf. footnote 38 on page 30.

${ }^{51}$ An important technical caveat to the condition derived in equation (3) should be highlighted: Throughout the last decade, more and more countries adopted the 'Current Operating Performance Concept' instead of the 'All-Inclusive Concept' to measure FDI earnings, as suggested by the BOPM (see IMF 2004, p. 29). Under this practice, depreciations are subtracted from the investors' earnings, hence while the earnings of the affiliate still make up for the depreciation, this transaction is not recorded in the BOP. However, until the early 2000s, not even one third of national compilers fully applied the 'Current Operating Performance Concept' (cf. IMF 2004, p. 29)
} 
Therefore, consider the simple Cobb-Douglas production function

$$
Y_{t}=A_{t} K_{t}^{a} L_{t}^{b}
$$

where $Y$ is the real output / sales, $K$ is the stock of fixed capital/assets and current physical assets (especially intermediate inputs), which is probably proxied best by the category 'plant, property and equity' (PPE), $L$ is labor input and $A$ is a technology parameter. $t$ can be thought of indexing observations over time and/or over cross-sections, most importantly countries. Apparently, it is reasonable to assume $a, b>0$ and for simplicity assume $a+b=1$, which leads to constant returns to scale (CRTS). I will assume that production is both technologically and allocatively efficient.

For now, let us consider that factor prices are constant and technology is fixed and homogeneous across firms. This entails, that the $K / L$ ratio will remain constant in the optimum and any increase in $Y$ can only be achieved by an increase in $K$ and $L$, both of the same proportion (under CRTS) and hence it does not matter under these circumstances, if data on sales $(Y), P P E(K)$ or employment $(L)$ is used.

But how does FDI relate to this? Therefore note that $K$ has to be paid for in advance while $L$ can principally be paid from current cash flows (or using short-term debt or financial instruments such as repos in case the period between production and sales lasts longer than from the beginning to the end of the payment period). Hence, capital in a wider sense is a manifest proxy for $K$ and to the extent that FDI is part of capital, it will be a proxy for $K .^{52}$

But this leads to a potential problem: It is quite realistic that the cost of capital is lower for multinational firms ${ }^{53}$ due to reasons like easier access to different capital markets and because parents may provide contingent liabilities. This will lower the relative price of $K$ vis-a-vis $L$ and hence lead to a higher $K / L$ ratio for MNCs when producing the same output as a domestic firm on the same isoquant. It hence follows that employment data is likely to be a downward biased measure of MNCs' relevance in a host economy, while data proxying for $K$ is likely to be an upward biased measure for MNCs' relevance in the host economy. ${ }^{54}$

This statement concerns the coordination function in a market economy. However, any market will also perform some degree of incentive function (cf. Roemer 2011, pp.

\footnotetext{
${ }^{52}$ In fact, most of long-term financing of corporations comes from internal financing, i.e. retained profits (cf. e.g. Ross et al. 2007, p. 396). Note that this is also capital and, more importantly, reflected in FDI data as discussed above.

${ }^{53}$ I deliberately use the term 'firm' here to emphasize the fact of multinationality, not the fact that being a corporation might lower capital costs.

${ }^{54}$ The example of General Electric on page 17 of this dissertation may depict this issue: Its ratio of assets to Austria's capital stock is way higher than its ratio of employment to Austrian employment; its sales to Austrian GDP ratio is in between the two. While this example is plagued by many problems (estimation of capital stock, sales/GDP instead of value added/GDP etc.), this is the outcome one would expect from the above discussion.
} 
$12 f f$ and the introductory chapter of this dissertation). This leads to the question of technological progress and the potential problems that arise under a dynamic ${ }^{55}$ view of the production process.

Therefore, first make clear that a technological change of general nature which is Hicks-neutral will pose no problem as long as sales will be normalized by the respective measure for the total economy or domestic producers. ${ }^{56}$ But since MNCs potentially face a permanently lower price for capital (as well as technology and learning-by-doing spillovers between affiliates or parent and affiliates) they might have a higher incentive to conduct more $\mathrm{R} \& \mathrm{D}$ and hence experience a faster rate of technological change, especially one that is labor-saving. Let us consider the substitution and the productivity effect of this technological progress separately.

As far as there is only a factor bias but no productivity change, we will obtain a similar result as above: To the extent that the bias is labor-saving, employment data is likely to be an understating (downward biased) measure and data proxying for $K$ is likely to be an exaggerating (upward biased) measure for the change of the MNCs' relevance in the host economy. Since the latter (and hence output or sales) will remain unaffected (only substitution, no productivity effect takes place), this means: $K$ will rise and $L$ will fall (over time), leading to a negative correlation between the two. ${ }^{57}$

Things get more complicated when a MNC-specific productivity increase occurs. First of all, measures for $L$ and direct measures for $K$ are unlikely to capture this change in MNCs' relevance accurately because $L$ and $K$ may remain unchanged while the output, hence the market share, and hence the relevance of the MNC increases in the long run. Depending on the market form, however, the short-run response of the firm to the productivity change will differ from the long-run equilibrium and hence a discrepancy between the two as well as the prevailing price elasticity of demand might pose additional problems. The long-run impact should be quite clear: The MNC will gain market shares and pricing power and the increased relevance will be reflected in the real sales data in the new equilibrium, while both $K$ and

\footnotetext{
${ }^{55}$ Since time is not conceptually different from space, 'dynamic' could not only be interpreted over time but also as indexing $t$ across countries with different production technologies.

${ }^{56}$ This normalization is necessary because an absolute increase in real sales will occur without a change of the relative relevance of MNCs' activities. Note that $K$ and $L$ should remain unaffected as long as the technological progress is of general nature and hence no substitution between sectors takes place. If the latter would be the case and the sector with a productivity increase (which is assumed to be MNCs-intensive) would expand production, the increase in MNCs' real sales would correctly reflect its increased relevance in the overall economy but this might be achieved with $K$ and $L$ unaffected.

${ }^{57}$ Of course, one would not expect a negative correlation between $K$ and $L$ in the data, this statement is the outcome of a restrictive thought-experiment. However, it might explain why the empirical correlation between employment and assets is lower than one may expect (cf. table 5 on page 45).
} 
$L$ are seemingly inaccurate measures. The way to get there, however, may include engagements in price wars or quantity competitions. Say, the MNC uses a predatory pricing strategy to drive competitors out of the market and that the price elasticity of demand is smaller than 1 (in absolute terms) - favorable long-run conditions for the MNC. In the short run, however, the price decrease will not be compensated by the increase in demand, meaning that the value of sales will decrease although the competitive position of the MNC and hence its relevance has increased. ${ }^{58}$

In a perfect world, we could compare the equilibrium before the technology change with the long-run equilibrium after the change, however, if we consider equilibrium not as a (comparative) static concept but as a gravitational center of the economy, we should prefer a real-time measure that captures the potential long-run changes ahead of time. Basically, this would just be the price of the firm, because any asset's current value should equal the present value of its future (net) cash flow. The economic agent who performs the task of valuing a (listed) firm is - the stock market. And the value of a firm's common stock to the investor is equal to the present value of the expected future dividends, i.e. distributed profits. Since changes in firms' market values (that should represent changes in the underlying fundamentals) should be reflected in the FDI stock data, I suggest that FDI stock is the most appropriate measure to value the relevance of $M N C s$ at any point in time.

Of course, some limitations to this view apply. First, one may argue that the value of the affiliate may be different for the direct investor than for the rest of the market because of intra-firm spillovers and other external effects. But if the goal is to proxy for the relevance in the host market, the pricing of the market is probably a preferable indicator over the pricing by the parent firm. The other problem is that this view requires at least some version of an Efficient Market Hypothesis (cf. e.g. Ross et al. 2007, p. 376) and correct compilation by national statistical authorities, that is, no market and no government failures - a pill that most economies might find hard to swallow. Admittedly, the Great Recession questions the proposition that stock markets get the pricing right and, as Krugman (2011, p. 308) points out, the real housing prices after 2002 were "the clearest market mispricing" in the last decades although houses differ from modern MNCs in the sense that they "have been with us for 7,000 years or so, and we should have a reasonable idea of what they're worth." Despite these concerns about the market's ability to get prices right, few economists would find it a theoretically appealing argument that stock markets get firm values systematically wrong and hence one could argue, that on average the market price will be a consistent statistic for the firm's economic value. Since it is a statistic and no parameter, this allows for a certain variability around the true value but the advantage over other measures might be that it is finally consistent while other measures like PPE (for $K$ ) and employment (for $L$ ), as argued above, can be systematically biased and the response of sales data to changes might be severely

\footnotetext{
${ }^{58}$ It is assumed that the share of the MNC's products in the overall economy is small enough to not (considerably) influence the consumer price index that is used to deflate the sales series.
} 
delayed. As far as the recording practices of the data are concerned, this potential error does not necessarily have to add up with any error from market pricing - in fact, it might well be the case that they cancel out under certain circumstances. IMF's SIMSDI 2001 showed that $41 \%$ of the surveyed countries used market values, with no obvious difference between OECD and non-OECD countries, but the tendency since the 1997 SIMSDI was rapidly increasing and some countries used a combination of book and market values (cf. IMF 2004, §6.24). In the latter case, the combination of the two may even lead to a more appropriate estimate than the market value if markets are systemically over-optimistic about the future performance of companies. A problem, however, is the fact that FDI can also come in the form of private equity, for example, where companies are not listed on stock markets. While a joint ECB/Eurostat task force proposed how to treat such cases (cf. IMF 2004, §6.26), it is probable that there still remains a systematic difference between the valuation of listed and non-listed firms. To the extent that the fraction of the latter will be higher in developing countries, this may lead to a systematic difference in FDI data for developing and industrialized countries.

\subsection{A Glance at the Data}

After this rather extensive discussion of technical concepts to measure MNCs and of potential relations and discrepancies between them, I provide a descriptive picture how much the common measures for MNCs diverge from each other. I will start with the relationship between FDI stocks and FDI flows and therefore use UNCTAD annual FDI data in current US-\$ and at current exchange rates in millions from 1980 to 2010 for the liabilities' side ('inward') of the US and the world as a whole (hence, the sample size is 31 in each case). ${ }^{59}$

Figure 2 and table 4 depict the relationship between FDI stocks and flows and show that it is indeed a tight one as we would expect from identity (3). ${ }^{60}$ The right panel shows the US data, the left panel shows the data for the whole world. A strong positive relationship between the two series is visible, with a correlation coefficient $\hat{\rho}_{U S}=0.83$ for the US data. For the global data, the relationship is even stronger: $\hat{\rho}_{\text {world }}=0.90$. OLS regression of flows on stocks for the US and global data leads to a (highly significant) parameter estimate $\hat{\beta}$ of 0.064 and 0.087 , respectively. ${ }^{61}$ If we

\footnotetext{
${ }^{59}$ I picked the US as the single-country example because it is the world's largest economy and we would not expect cross-country heterogeneity in compiling inward FDI data from one host country.

${ }^{60}$ Note that there is no sense in empirically testing an identity or a theorem. The reason of this exercise is to investigate if the steady-state equilibrium assumption is an empirically valid generalization, so that flow and stock data can indeed be treated as substitutes, or not.

${ }^{61}$ One could argue that the identity (3) is homogeneous of degree 1 while the regression line in figure 2 does not go exactly through the origin and the underlying regression includes a constant (not listed in table 4). However, the parameter estimate of the constant $(\hat{\alpha})$ is not statistically different from 0 (t-statistic of 0.776 for the global data, 0.618 for the US data). Nevertheless, the model is not estimated under the constraint $\alpha \stackrel{!}{=} 0$ because
} 

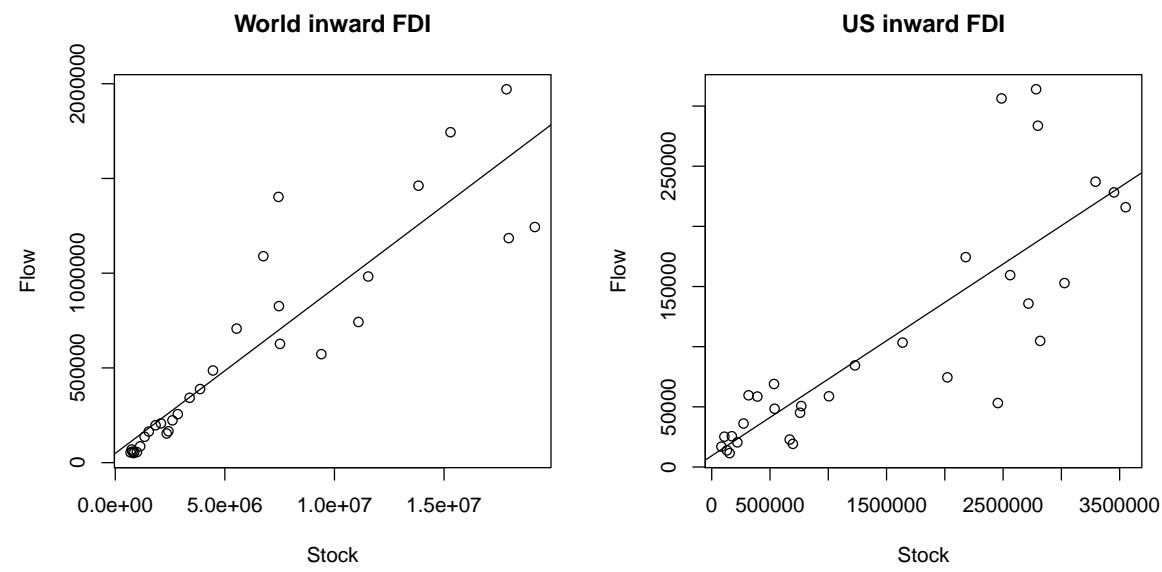

Figure 2: Relationship Between FDI Stock and Flow Data

assume no time trend in FDI stocks, $\eta t \stackrel{!}{=} 0$, this parameter can be interpreted as the depreciation rate, i.e. for every unit of FDI stock there has to be a corresponding flow of 0.06 or 0.09 units to replace the depreciated stock. More realistically, this figure should be interpreted as the depreciation plus a deterministic growth rate (which operates through flow data). This size makes sense from an economic perspective. The explanatory power of this simple regression is considerable: the variation in stocks explains $69 \%$ of the variation of flows for the US and even $82 \%$ for the world in total. The overall F-statistic for the US model is 64.56 , for the global model it is 130.3. Since applied researchers consider instrumental variables to have reasonable predictive power with an F-statistic of 10 and above as a rule of thumb (cf. Staiger and Stock 1997), it is hard to argue why one should not use FDI flow data instead of stock data in case one has specific reasons to do so.

Table 4: Regression of UNCTAD FDI Flow on Stock

\begin{tabular}{lrr}
\hline & World & US \\
\hline$\hat{\beta}$ & 0.087 & 0.064 \\
t-stat of $\hat{\beta}$ & 11.414 & 8.035 \\
R-squared & 0.818 & 0.690 \\
\hline Correlation Coefficient & 0.904 & 0.831 \\
\hline
\end{tabular}

in such a homogeneous model the decomposition of the TSS $:=\sum_{t=1}^{T} y_{t}^{2}$ into the ESS $:=\sum_{t=1}^{T}\left(y_{t}-\hat{y}_{t}\right)^{2}$ and the RSS $:=\sum_{t=1}^{T} \hat{\varepsilon}_{t}^{2}$ is not possible and hence no (meaningful) R-squared (=ESS/TSS) can be computed. 
Table 5 shows the (estimated) correlation coefficient for different measures of US MNCs' outward activities, taken from BEA and compared over time and across host countries (hence incorporating both types of variation). The operational data are described in subsection 2.1.2 above. 'Stocks' are the US direct investment position abroad on a historical-cost basis (book values), 'flows' are financial outflows without current-cost adjustment, i.e. they consist of reinvested earnings without current-cost adjustment and equity and intercompany debt transactions. BEA provides current data, so all data (besides from employment) are deflated using the GDP deflator from IMF's WEO database. The main picture of the correlations is that that most measures, besides from flows and income, show a reasonably well correlation with all other measures. The highest single correlations are between sales and wages $(\hat{\rho}=0.95)$ and between stocks and assets $(\hat{\rho}=0.93)$. On average, stocks show the highest correlation with all other measures $(\overline{\hat{\rho}}=0.82=4.89 / 6)$, followed by sales $(\overline{\hat{\rho}}=0.79)$ and assets $(\overline{\hat{\rho}}=0.77)$. Although this is no indication that these measures are appropriate, it provides some evidence that one can hardly be wronger using them instead of the others and that one can generally treat them tantamount to each other (especially since the pairwise correlations are above 0.8 in each case).

\section{Table 5: Correlation Coefficients between Different BEA Measures}

\begin{tabular}{lrrrrrrr}
\hline & stock & flows & assets & empl. & wages & sales & income \\
\hline stock & 1.00 & & & & & & \\
flows & 0.77 & 1.00 & & & & & \\
assets & 0.93 & 0.67 & 1.00 & & & & \\
employment & 0.71 & 0.51 & 0.69 & 1.00 & & & \\
wages & 0.80 & 0.54 & 0.83 & 0.89 & 1.00 & & \\
sales & 0.87 & 0.62 & 0.84 & 0.88 & 0.95 & 1.00 & \\
income & 0.80 & 0.68 & 0.67 & 0.38 & 0.45 & 0.61 & 1.00 \\
\hline$\Sigma$ & 5.89 & 4.80 & 5.63 & 5.08 & 5.47 & 5.76 & 4.60 \\
\hline \multicolumn{7}{l}{ sample containing 913 observations over time (1997-2008) and host countries } \\
$\Sigma$ is the sum over all correlation coefficients of the measure, & \\
not just the ones displayed.
\end{tabular}

Also note that the correlations provide some evidence for the theoretical considerations outlined above: I argued, that to the extent that FDI is equity capital, it should be a good proxy for $K$, the latter being also captured well by 'assets.' Indeed, FDI 'stocks' show the highest correlation with 'assets' $(\hat{\rho}=0.93)$ and 'assets' show the highest correlation with 'stocks.' On the other hand, I argued, an increase in 'stocks' does not necessarily have to be accompanied by an increase in $L$ if the increase in 'stock' (or $K$ ) is due to labor-saving technological progress. In fact, 'stocks' show the lowest correlation with 'employment' $(\hat{\rho}=0.71)$. Since workers in that case might somewhat gain from the increase in their marginal product despite being at a relatively weak bargaining power vis-a-vis the MNC, the correlation is stronger between 'stocks' and 'wages' ( $\hat{\rho}=0.8)$. And as expected, the correlation between 'stocks' and 
'sales' is in between these correlations $(\hat{\rho}=0.87)$.

Tables 25 to 28 in appendix A provide the same correlation coefficients limited to cross-country correlations in 1997 and 2008 and to correlations over time for Canada (as the main location of US outward FDI) and the aggregate of all countries. The main conclusions are that the average correlations of all measures across countries were higher in 1997 than in 2008. This is consistent with the finding of Lipsey (2007, p. 7) that the cross-country relationship of investment positions to factor inputs in US outward FDI were all weaker in 1999 than in 1994 and might be an indication that arbitrary financial shifts in the books increase over time (hence reducing the correlation of BOP data with operational data) and that technological progress has experienced an increasing factor bias (hence, for example, reducing the correlation between $K$ and $L$ ). Overall, FDI stock seems to perform quite well, though better in the cross-country case (where no other measure has a higher average correlation) than in the case of correlation over time. Flows perform very poorly for correlations over time in case of US FDI in Canada. The reason may be that the relationship between stocks and flows in condition (3) is a steady-state, i.e. an equilibrium condition. In reality, however, FDI flows are very volatile, as shown in figure 1 on page 16, and to the extent that this volatility (across countries) is considered to be the stochastic component of an i.i.d. random variable with finite first moment, the mean over host countries of these flows will converge towards the true parameter (the 'equilibrium'), according to the Chebyshev Inequality and the Law of Large Numbers. Intuitively, this means that volatility noise will cancel out across different countries.

\subsection{Estimating the Determinants of Multinational Corporations' Activities}

A main application of the data discussed above is the estimation of location decisions of MNCs. The goal of such studies is to estimate what variables influence MNCs' decision of supplying certain markets in the form of local affiliates as opposed to exports or why firms chose to produce downstream inputs in affiliates instead of outsourcing via arms length relations. Most empirical studies either use sales or FDI stock data. To illustrate my point of concern with these studies, I will discuss the firm's location decision based on stock data $(y)$ and market size $(x)$. The goal of this exercise it not to come up with a precise point estimate for market size but to make a general statement concerning the functional form of estimation that is exemplified with only one explanatory variable in order to make things easier (and because of a relatively small sample size). I will then argue that the problem I raise also prevails to sales data because sales can be seen as a function of stock, as discussed above. Econometrically, the issues I raise can be resolved, however, these solutions come at a cost as well. I will hence argue that flows can provide an alternative response variable that may be preferable under some circumstances.

For this example, assume that the activity of a MNC in a host market $i$ at time $t$, denoted $y_{i t}$ and measured by FDI stocks, is a function of the demand for products 
in that market, $x_{i t}:^{62}$

$$
\mathbb{E}\left(y_{i t}\right)=f_{i}\left(x_{i t}\right)
$$

For simplicity, I will first assume that this market size is perfectly flexible. Of course, there will be many relevant factors influencing MNCs' activities, such as the relative price of MNCs' production or the relative preference for foreign goods which are omitted here, but this is irrelevant to the point I want to highlight. The latter concerns the fact that when making its allocation decision based on $x$ at time $t$, the firm has inherited $y_{t-1}$ from the previous period, which has depreciated at a rate $\delta$ with $0 \leq \delta \leq 1$. In order to reach the new equilibrium stock $y_{t}$, the firm's additional FDI will hence be larger than the incremental change $\Delta y:=y_{t}-y_{t-1}$ because it will also include the reproduction of depreciated stock, $\delta y_{t-1}$. Leaving besides exchange rate fluctuations, this is exactly why the first difference of stocks is not equal to flows (compare table 2). The relevant quantity of decision for the MNC is hence

$$
\begin{aligned}
y_{t}^{*} & =y_{t}-\left(y_{t-1}-\delta y_{t-1}\right) \\
& =\Delta y_{t}+\delta y_{t-1} \\
& =y_{t}-(1-\delta) y_{t-1} \\
& \equiv y_{t}-\phi y_{t-1} .
\end{aligned}
$$

In accordance with the literature (e.g. Phillips and Sul 2007), I will refer to expression (9) as the 'quasi-difference' of $y$. Note that one cannot observe this quasi-difference from FDI stock data in the IIP. The reason why the firm can only decide on the quantity $\left|y_{t-1}^{*}\right| \leq\left|y_{t}\right|$ is the fact that $y_{t-1}$ and hence $\delta y_{t-1}$ in $y_{t}$ is predetermined in period $t$.

Economists attributing higher prior beliefs to the proper functioning of markets may object here by emphasizing that firms will be able to sell the assets $\phi y_{t-1}$ in period $t$. To some extent, this is a legitimate objection. However, as I will argue in the next pages, there are good economic reasons why the extent of these asset sales will be very limited in practice, especially for MNCs. The first reason is the wider argument of transaction costs. It may not only cause costs to 'go to the market' (a point emphasized especially by Diamond 1982, and well-known to economics PhDs on the job market), but there are also highly asymmetric information and associated frictions in the market for used assets, the standard example provided by Akerlof (1970) concerning used cars. This causes potentially high screening costs and leads to arguments related to risk aversion in general. More specifically, firms may not only be uncertain if they can repurchase an asset of the same quality at the same price in the next period but if there is a market for these (used) assets in the next period at all. Under risk aversion, the firm might hence rethink twice if it is willing to sell the asset in response to a contraction in market size that may turn out to be

\footnotetext{
${ }^{62}$ For clearer visibility, I skip the subscript $i$ in the remainder of the text if the interpretation is unambiguous.
} 
temporary.

However, even abstracting from this problem, there are two important arguments that prevent firms from commanding totally flexible over $\phi y_{t-1}$, one relating to the nature of the firm (more precisely, the corporation) and its corporate management, the other one to the nature of the multinational firm and its production process.

First, Coase (1937) emphasized in his classical work on the nature of the firm, that firms would save certain transaction costs over market transactions. However, this has to be balanced against certain principal-agent problems. In a corporation, rational owners might have an incentive to maximize profits and hence the firm's value. Rational managers might in principle share that objective, however, also live from their income and extract utility from their prestige (Jensen and Meckling 1976). ${ }^{63}$ Hence, they may resist selling assets over which they command and which help increase their utility, resulting in a persistence of assets (due to persistence of management caused by search costs in the labor market). ${ }^{64}$

Second, and in relation to this argument, it should be emphasized that the modern production process is very complex, especially for MNCs, and it is not easily possible to break off certain fractions or factors from this process. The disaster of the Space Shuttle 'Challenger' highlighted that in modern production even such a tiny element as an O-ring might have severe consequences for the final product. Therefore, MNCs could be seen as organic systems - systems that have grown (and are growing) over time. And while there is flexibility in this growth process that could be interpreted as some degree of randomness, these 'random' events have a memory - a process related to the concept of 'Kontingenzkausalität' (Luhmann 1975, p. 156f.) and known to economists as 'path-dependence' (cf. Goldin 1995; David 1985). Living organisms might serve as an analogy: Cells grow, divide, differentiate and die based on their specific role in the tissue they belong to. Similarly, the purchase of an asset entails that a certain fraction of the firm's labor force will work with this asset, together with using other assets, and a certain part of the management will have control over these complex processes, causing further interactions and production networks. For such production factors like for cells, a certain 'randomness' allows them to evolve from generation to generation, and reaction to external factors (all kinds of stresses) also plays a role, but their fate is basically predetermined by their biological/economic function in the organism. This is why the person that goes to bed at the end of the day is virtually identical to the person that wakes up in the same bed on the very next day. ${ }^{65}$ This is why a firm with asset structure $y_{t}$ will inherit the asset structure

\footnotetext{
${ }^{63}$ Spulber (2009, p. 63) even defines the firm as an "transaction institution whose objectives differ from those of its owners." It should be noted that strong conflicts of interest between owner and manager are rather specific to the US and the UK, see Porta et al. (1999).

${ }^{64}$ For a model where managers are discouraged from reversing prior resource allocations due to a friction, see e.g. Hart and Holmstrom (2010).

${ }^{65}$ Of course, not all cells reproduce over night. Skin cells, for example, divide all few days, germs every few minutes.
} 
$\phi y_{t}$ in the next period.

Rome was not built in a day, and its imperial status made it special from othersand exactly this uniqueness also explains why the market for a MNC's assets may be imperfect and hence creates additional forces that prevent the firm from selling down certain assets when their profitability decays (see e.g. Blonigen 1997 for the case of firm-specific assets and the returns it generates to the MNC).

In the attempt to cope with its daily business as efficient as possible, systems get more and more complex and develop some specifics (such as proprietary assets). However, since these specifics are special to time and space, such systems will find it difficult to adopt to a departure from 'business as usual' because every part and component in such an organic system requires the existence of every other part and component and takes it for granted. The bottom line is the argument that even if firms may be able and willing to sell down parts of $\phi y_{t-1}$, however, there will be a limit to this effort. Hence, although a MNC might influence the size of $\phi$, it is nevertheless reasonable to assume $\phi>0(\leftrightarrow \delta<1)$ and that $y_{t}^{*}$ is therefore (at least in the short run) bounded from below.

Accordingly, the behavioral relation in equation (5) should be rephrased as being conditional on $y_{i t-1}: y_{i t}=f_{i}\left(x_{i t} \mid y_{i t-1}\right)$, or:

$$
\mathbb{E}\left(y_{i t}^{*}\right)=f_{i}\left(x_{i t}\right)
$$

Assuming a linear relationship, this can be modeled as

$$
y_{i t}^{*}=\alpha_{i}+x_{i t} \beta+\varepsilon_{i t},
$$

where $y^{*}$ (nor $\left.\delta, \phi\right)$ cannot be observed from FDI stock data in the IIP. But one can instead rearrange equation (11) using expression (9) to obtain

$$
\begin{aligned}
y_{i t}^{*}=y_{i t}-\phi y_{i t-1} & =\alpha_{i}+x_{i t} \beta+\varepsilon_{i t} \\
\Rightarrow y_{i t} & =\phi y_{i t-1}+\alpha_{i}+x_{i t} \beta+\varepsilon_{i t},
\end{aligned}
$$

which is estimable since $y_{i t}$ and $y_{i t-1}$ can readily be observed from the IIP. ${ }^{6}$ Note that an estimator $\hat{\beta}$ for $\beta$ will in this case provide a short-run estimator while the long-run impact is obtained by $\hat{\beta} /(1-\hat{\phi}){ }^{67}$ Instead of the dynamic equation (12), most studies in the literature use a static model, hence estimate a model under the

\footnotetext{
${ }^{66}$ In practice, estimation of such dynamic models pose some econometric problems that I will shortly mention in the application below.

${ }^{67}$ To see this, note that $\beta$ will not only impact $y_{t}$ but via $\phi y_{t}$ also $y_{t+1}$ and via $\phi^{2} y_{t+1}$ also $y_{t+2}$ etc., so after $q$ periods the long-run impact $\beta_{L R}$ will be $\beta_{L R}=\beta+\phi \beta+\phi^{2} \beta+\ldots \phi^{q} \beta=$ $\beta\left(\phi^{0}+\phi^{1}+\phi^{2} \ldots+\phi^{q}\right)$. Multiplying $\phi$ on both sides and subtracting the latter from the former gives $\beta_{L R}(1-\phi)=\beta\left(1-\phi^{q+1}\right)$ and hence $\beta_{L R}=\beta\left(1-\phi^{q+1}\right) /(1-\phi)$ and in the limit $\lim _{q \rightarrow \infty} \beta\left(1-\phi^{q+1}\right) /(1-\phi)=\beta /(1-\phi)$. Apparently, this is simply the convergence of a geometric series.
} 
implicit assumption $\phi \stackrel{!}{=} 0$, that is a perfect (i.e. frictionless) adaption process. ${ }^{68}$

I will now discuss the consequences of such static estimation in the case of the fixed effects (FE) estimator because the fact that it only exploits the variation within cross sections over time of a panel makes it intuitively easy. Accordingly, it is also often referred to as the 'within estimator.' Furthermore, it is the main estimator used in the empirical investigations throughout this dissertation and should always provide a consistent estimates for $\beta$ if the functional form of the model is correctly specified (e.g. the DGP is static and a static FE estimator is used). I will then establish a relation to the (efficient but probably inconsistent) random effects (RE) and pooled OLS (POLS) estimator as well as to the between effects (BE) estimator.

A first consequence of estimating (12) under $\phi \stackrel{!}{=} 0$ is that the estimated model will be

$$
y_{i t}=\alpha_{i}+x_{i t} \beta+u_{i t}, \quad u_{i t} \equiv \varepsilon_{i t}+\phi y_{i t-1}
$$

and since in view of $(12), \operatorname{Cov}\left(y_{i t-1}, y_{i t-2}\right)>0 \Rightarrow \mathbb{E}\left(u_{i t}, u_{i t-1}\right) \neq 0$, which is a violation of the Gauss Markov assumptions. However, this autocorrelation causes a minor problem that is easy to solve even within a static framework by using a heteroscedasticity and autocorrelation consistent (HAC) estimator (e.g. Newey and West 1987) for the variance-covariance (VCV) matrix $\Omega$ to correct standard errors or by applying some GLS approach to obtain a "best" linear unbiased (MVU) estimator, i.e. one that approaches the Cramér-Rao bound. ${ }^{69,70}$

However, the point I want to emphasize is more of an economic nature. Note that (12) is a dynamic process in the sense that it allows $x_{i t}$ to influence not only $y_{i t}$ but also more future values $y_{i t+h}$ via the lagged dependent variables $\phi^{h} y_{i t}$. On the other hand, the static model in (13) generally only allows for an influence of $x_{i t}$ on $y_{i t}{ }^{71}$ Accordingly, FE estimation will only provide a short-run impact whereas a

\footnotetext{
${ }^{68}$ An exception worth noticing is Cheng and Kwan (2000), who motivate a similar dynamic model as above but against another background, i.e. agglomeration effects. In this context, $\phi$ is a positive parameter because past FDI attracts current FDI due to economic externalities.

${ }^{69}$ The difference between HAC and GLS is the fact that GLS estimation has an impact on the estimated parameters $\hat{\beta}$. To understand the idea, first note that the OLS estimator $\hat{\beta}_{L S}=\left(X^{\prime} X\right)^{-1} X^{\prime} y$ can trivially also be written as $\hat{\beta}_{L S}=\left(X^{\prime} I X\right)^{-1} X^{\prime} I y$. The inclusion of the identity matrix $I$ highlights, that equal weight is given to each observation. GLS, on the other hand, will weight the observations inversely to the conditional VCV structure of $\varepsilon, \Omega^{-1}: \hat{\beta}_{G L S}=\left(X^{\prime} \Omega^{-1} X\right)^{-1} X^{\prime} \Omega^{-1} y$. Intuitively, this gives more weight to observations that have less variance and that we are hence 'more certain' about. Note that $\Omega$ is usually not known but has to be estimated.

${ }^{70}$ Again, the issue of autocorrelated errors applies in the same way to correlation across cross-sections and similar methods can be used, see e.g. Conley (1999). Baltagi et al. (2008) and chapter 3 of this dissertation provide applications to FDI models.

${ }^{71}$ To see this, note that $\mathrm{FE}$ due to using the within-variation is closely related to estimating the first-differenced equation using POLS (Wooldridge 2002, pp. 284-286), where (13) becomes $\Delta y_{i t}=\Delta x_{i t} \beta+\Delta u_{i t}$. To make things clear, first assume that $\Delta x$ is not serially
} 
microeconomic analysis of the multinational firm is usually concerned about effects in equilibrium, that is the long run.

Besides from using a dynamic model like (12), what could one do? One approach would be modeling the lags explicitly:

$$
y_{i t}=\alpha_{i}+\beta_{1} x_{i t}+\beta_{2} x_{i t-1}+\beta_{3} x_{i t-2}+\beta_{4} x_{i t-3}+\beta_{5} x_{i t-4}+\ldots+\varepsilon_{i t} .
$$

Note that the restriction $\beta_{1+j} \stackrel{!}{=} \phi^{j} \beta_{1}$ leads to the dynamic model in (12). However, since the applied researcher is usually not interested in only one but more explanatory variables, this approach may quickly result in a shortage of degrees of freedom for estimation. ${ }^{72}$

A more pragmatic approach would be 'laissez-faire econometrics' and do nothing. To see why this might still lead to a reasonable long-run estimate in practice, assume that (14) is indeed the operating model but the researcher fits $y_{i t}=\alpha_{i}+$ $\beta_{1} x_{i t}+u_{i t} . \quad x_{t-l} \forall l \geq 1$ will then end up in the error term $u$, leading to an omitted variable problem. This will bias $\beta_{1}$ if $x_{i t}$ and $u_{i t}$ are correlated, for example when $x_{i t}$ is weakly dependent. For the OLS estimator (and hence LSDV and $\mathrm{FE}), \mathbb{E}(\hat{\beta})=\mathbb{E}\left[\left(X^{\prime} X\right)^{-1} X^{\prime} y\right]=\beta+\mathbb{E}\left[\left(X^{\prime} X\right)^{-1} X^{\prime} u\right]$. The important part concerns the term $\mathbb{E}\left(X^{\prime} u\right)$, in our case the covariance between $x_{i t}$ and $u_{i t}$. Remember that $u_{i t}=\beta_{2} x_{i t-1}+\beta_{3} x_{i t-2}+\ldots+\varepsilon_{i t}$ and now assume that the $x_{i t}$ are positively serially correlated (which is realistic for many time series, especially in macroeconomics), for example in the form $x_{i t}=\rho x_{i t-1}+e, 0<\rho<1$. This will bias the estimator for $\beta_{1}$ upwards and hence into the direction of the long-run impact of $X$ on $y$. Generally, the smaller the distance $\sum_{j=1}^{\infty}\left[\operatorname{Cov}\left(x_{i t}, x_{i t-j}\right)-\operatorname{Cov}\left(\beta_{1}, \beta_{1+j}\right)\right]$ is, the closer will $\beta_{1}$ be to the long-run estimate. A special case in this example of an $\operatorname{AR}(1)$ series with an operating model of the form described in (12) occurs when $\phi=\rho$ because then the bias of $\hat{\beta}_{1}$ is exactly large enough to mimic the long-run estimator. While this equality is certainly too restrictive in practice, the difference between the two may often not be all too large. ${ }^{73}$

correlated, either because $x$ is i.i.d. or follows a random walk (and leave besides problems described by Pesaran and Smith 1995 and Kao 1999). Then, $\hat{\beta}$ will only describe an impact that market size $x$ has on MNCs' activities $y$ in (and only in) period $t$.

${ }^{72} \mathrm{~A}$ potential solution to this problem would be using a shrinkage-type estimator like the LASSO (cf. Tibshirani 1996 and Knight and Fu 2000) that performs model selection to identify the relevant covariables even when the potential regressors outnumber the observations.

${ }^{73}$ Similarly, Baltagi and Griffin (1984) argue that the greater the correlation between the omitted lags and the current values of the covariables, the closer the static coefficients will be to the sum of the dynamic coefficients - i.e. the long-run effect. Monte Carlo studies by Egger and Pfaffermayr (2005) show that the static FE estimator is downward biased even compared to the short-run effects when the operating DGP is dynamic and explanatory variables are not serially correlated; but when the level of serial correlation is high, the FE estimator converges towards the long-run effects. 
If one does not feel confident with this approach, taking averages of the data over longer periods would be an option, e.g. 5-year or 10-year averages. In the latter case and formulated in first-difference terms, this means that one estimates the impact of a change in the average of $x$ over one decade on the change in the average of $y$ over one decade. This will allow the response to take a longer time period and should converge towards the long-run impact. However, the method also calls for a longer $T$ dimension of the panel.

A special case of this idea occurs, when one averages over all $T$ time periods. Then, of course one could not estimate a FE model (because there are no first differences to form or, equivalently, data de-meaning will make all data equal to 0) but one could take the remaining $N$ averaged observations and simply run an OLS regression. This is called the between effects estimator (BE) because its coefficient estimates only exploit variation between countries and not within countries, though they use the entire dataset to construct the estimates. This estimator makes no specific assumptions about the time process. Given homogeneity across panels and time and no correlation between the covariables and the error term, BE is a consistent estimator of the long-run relationship between the variables when the time series are stationary or stochastically trending and is super-consistent for cointegrating panels. BE should provide consistent estimates even in the presence of powers of unit root variables (cf. Baltagi and Griffin 1984; Pesaran and Smith 1995; Pirotte 1999 for these issues). In a specific Monte Carlo simulation of growth models, Hauk and Wacziarg (2009) show that $\mathrm{BE}$ is the best performer among potential panel data estimators when the orthogonality assumption is violated and measurement error is present. Stern (2010, p. 2175) even sees "a consensus that BE is the best estimator of long-run relations in panel data" but this should be evaluated against the background that his econometric discussion motivates his study of first using a BE estimator to explore the environmental Kuznet's curve.

The use of dynamic models or BE estimation, however, is not very common in the applied economic literature on FDI determinants. Most important studies (e.g. Brainard 1997; Carr et al. 2001; Ekholm et al. 2007; Davies 2008) rather use a POLS or a GLS estimator such as random effects (RE) to estimate the determinants of MNCs' activities. The reason why I chose to discuss FE and BE first instead of $\mathrm{RE}$, is the simple fact that $\mathrm{RE}$ is a (matrix-weighted) average of the former two estimators (Maddala 1971). To the extent that RE is an efficient version of POLS, a similar conclusion applies to the latter. The intuition of this result is the fact that RE and POLS both consider variation between and within cross-sections. I will now exemplify which different parameter estimates can be obtained from using a dynamic specification, static FE, static RE and BE, how the results relate to the (analytically) expected values for these estimators, and how the dynamic adjustment process of FDI from one equilibrium to another might look like. 


\subsubsection{A Real-Data Example}

The aim of this subsection is to describe the differences that can occur from fitting these different models and using the different estimators with an example of realworld data. As response variables, I use outward stock, flow and sales data from US MNCs provided by BEA in US- $\${ }^{74}$ and deflated using the US GDP deflator from WEO. Since the only purpose of the exercise is to highlight the different impacts that can occur from choosing different econometric models, I limit the set of explanatory variables to market size of the host country which is proxied by GDP in US-\$ and deflated using domestic GDP deflators, both taken from IMF WEO. First, stock is regressed on its lagged value and on GDP for all cross-sections where neither flows nor stocks nor sales data are missing at any year under consideration. The subsequent analysis is then restricted to the subsample of these 297 observations $(N=27, T=11) \cdot{ }^{75}$

I start by using a dynamic model with one lagged dependent variable, similar to (12). It is well-known that estimation of such models can induce a bias when using traditional estimation strategies such as POLS or FE (cf. Nickell 1981). Conventional approaches to address this problem include the GMM estimators developed by Arellano and Bond (1991); Arellano and Bover (1995), and Blundell and Bond (1998). However, the application of these estimators in the small panel with $N=29$ is somewhat problematic, especially since these estimators usually come at a certain costs, such as the problem of weak instruments in the case of Arellano and Bond (1991) or potentially suspect instrument proliferation in the case of Arellano and Bover (1995); Blundell and Bond (1998); see Roodman (2009b) for an introductory discussion. MC studies by Judson and Owen (1997) find a substantial bias for FE in typical macro panels with relatively large $T=30$ and recommend a corrected FE estimator proposed by Kiviet (1995) when $T$ is small and the IV estimator developed by Anderson and Hsiao (1981) when $T>10$. On the other hand, Hauk and Wacziarg (2009, p.125) find that the FE bias on the LDV is relatively small despite a rather short time dimension of $T=8$ five-year averages and of the same magnitude as for the GMM estimators mentioned above. Since my attempt is to make a qualitative point by comparing different series all of the same order of $T$ and I do not necessarily aim for an unbiased quantitative point estimate, FE estimation could principally be used because the resulting bias is expected to be of order $T^{-1}$ (Hsiao 1986, ch. 4.2) and hence the same for all series that are compared. However, I tackle the bias problem by using the bias correction of Bun and Kiviet (2003) in the extension to unbalanced panels derived by Bruno (2005a). The method is based on Kiviet (1995) and should hence work well considering the small $T$ dimension of the panel and was implemented in STATA by Bruno (2005b). ${ }^{76}$ This approach will prevent the results

\footnotetext{
${ }^{74}$ The data are described in more detail in section 2.1. There are other data sources that provide longer series but the advantage of BEA data is that it provides a consistent data set covering BOP and operational data.

${ }^{75}$ Note that there are nevertheless slight discrepancies in sample size, e.g. because flows could be negative and hence drop out in the log-log model.

${ }^{76}$ The consistent estimator of Anderson and Hsiao (1981) is used to initialize the bias
} 
to depend on the (somewhat arbitrary) choice of lag structures when instrumenting the LDV in GMM approaches and will prevent differences resulting from large variances due to weak instruments. I then calculate the long-run effect of market size (in line a of table 6) and compare this to the estimated parameters for a static FE (line b), a static RE (line c) and a BE model (line d). All (but the BE) models are estimated using time dummies. Note that no standard errors are reported because no analytical standard errors are computed by Bruno (2005b). While this could be resolved in principle (e.g. by bootstrapping), statistical inference is rather meaningless for the present exercise.

\section{Table 6: Different Parameter Estimates for Different Estimators and Functional Forms}

\begin{tabular}{lcccccc}
\hline model & $(1)$ & $(2)$ & $(3)$ & $(4)$ & $(5)$ & $(6)$ \\
\hline $\begin{array}{l}\text { dep. var. } \\
\text { specification }\end{array}$ & $\begin{array}{c}\text { stock } \\
\text { lin-lin }\end{array}$ & $\begin{array}{c}\text { flow } \\
\text { lin-lin }\end{array}$ & $\begin{array}{c}\text { sales } \\
\text { lin-lin }\end{array}$ & $\begin{array}{c}\log (\text { stock }) \\
\text { log-log }\end{array}$ & $\begin{array}{c}\log (\text { flow }) \\
\log -\log \end{array}$ & $\begin{array}{c}\log (\text { sales }) \\
\text { log-log }\end{array}$ \\
\hline LDV & 1.0358 & 0.3119 & 0.9657 & 0.7367 & 0.1550 & 0.8927 \\
real GDP & 0.0014 & -0.0006 & 0.0226 & & & \\
log(real GDP) & & & & 0.1093 & 0.5019 & 0.0765 \\
\hline a) long-run coef. & n.a. & -0.0009 & n.a. & 0.4150 & 0.5940 & 0.7132 \\
b) static FE coef. & 0.0437 & -0.0015 & 0.0800 & 0.3573 & 0.6996 & 0.4537 \\
c) static RE coef. & 0.0405 & 0.0017 & 0.0824 & 0.4158 & 0.5231 & 0.4782 \\
d) BE coef. & 0.0320 & 0.0025 & 0.0960 & 0.5171 & 0.4929 & 0.5367 \\
\hline
\end{tabular}

Note: Parameters do not display any information about statistical significance.

The results are displayed in table 6 , for linear models in columns (1) to (3) and for log-log models in columns (4) to (6). I will focus on the latter because the fact that the results can be interpreted as elasticities is easier for comparison across different response variables. However, in both the linear and the log-log models it is obvious that stocks and sales are very persistent series with a high parameter estimate for the LDV indicating a slow response speed while $\hat{\phi}$ for the flow series is rather low (and statistically not different from 0 when analytical SEs under FE are used). ${ }^{77}$ This is an outcome from relation (10) leading to (11) and generally indicates that the researcher is rather on the safe side when estimating a static model to FDI flow data. This can reduce econometric problems arising from dynamic models, though it causes a trade-off against other potential problems discussed below. Note that the linear results for the market size are negative (and far from significant when considering analytical FE SEs) for flow data, indicating a potential misspecification that is ironed out in the log-log model.

There is strong evidence that a static model is not appropriate for the sales and FDI

correction. The accuracy of approximation is up to order $O\left(1 / N T^{2}\right)$.

${ }^{77}$ The estimates in columns (1) and (3) are even close to a unit root. Accordingly, no long-run effects are calculated. 

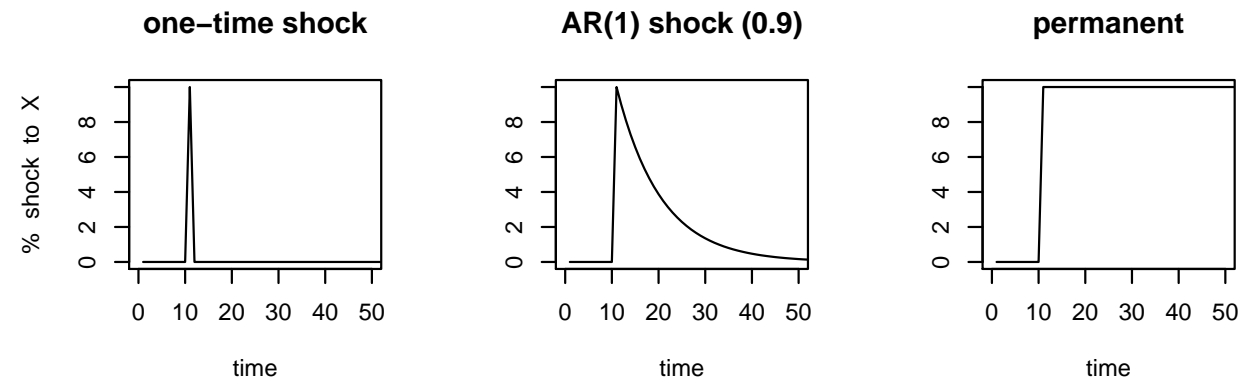

Figure 3: Shock Types

stock series. As a consequence, the FE estimate of the log-log models in line b) is always below the BE estimate that serves as a long-run estimate and also below the long-run estimate one obtains from the dynamic model by $\hat{\beta} /(1-\hat{\phi})$ and depicted in line a). To see what is going on, I simulated three different scenarios to the market size variable and depict the resulting responses of the three dependent variables under the assumption that the estimated dynamic model is the operating model. The scenarios are depicted in figure 3 . In all three of them, the market size $x$ is stable in the first 10 time periods and calibrated to $100 \times(1-\hat{\phi}) / \hat{\beta}$ so that $y$ equals 100 for comparison. ${ }^{78}$ In period $t=11$ a shock of magnitude $10 \%$ occurs to $x$ in all three scenarios. The scenarios differ in the periods thereafter. While it is a one-time shock in the first scenario depicted in the left panel, the shock to $x$ in the middle panel is an $\mathrm{AR}(1)$ shock with an autocorrelation coefficient of 0.9 . In the last and rightmost scenario it is a permanent shock (i.e. an $\mathrm{AR}(1)$ shock with autocorrelation coefficient 1 ).

Figure 4 shows how the series respond to these shocks. A striking result is the quick and large response by logged FDI flows (in the second line). They increase by more than $12 \%$ in the shock period and under the first scenario they are almost down to the level of 100 thereafter. ${ }^{79}$ This is the optimal response and it can be observed because the quasi-difference in (10) is the multinational's quantity of immediate response to the shock in market size. The statement related to equation (11) that $y^{*}$ cannot be observed from the IIP is correct but the careful reader might have noticed: It can be observed from the BOP since it is-FDI flows. The response of logged FDI stocks and logged sales is much more sluggish, although the overall effect in the long-run is similar if the shock is permanent (roughly $10 \%$ or above). The rightmost panel for FDI stocks and sales also makes clear why a FE estimator under this DGP will tend to underestimate the impact of $X$ on $y$ : Although the long-run impact

\footnotetext{
${ }^{78}$ Note that the $10 \%$ shock occurs to $x$, that is to $\log ($ real GDP) in this example, not to GDP.

${ }^{79}$ The precise value is 101.9 .
} 
is a change of $10 \%$ or more in $\operatorname{logs},{ }^{80}$ the response is below $3 \%$ in the first year. However, this is the year where (13) models the impact. To the extent that the $x \mathrm{~s}$ are (positively) serially correlated to each other, parts of the long-run effect will be captured by the misspecified FE estimation.

Table 6 shows at least three other important features. First, RE always lies between $\mathrm{FE}$ and $\mathrm{BE}$ (note that an estimator is a random variable and this hence does not have to be the case but we would expect it to be the case according to Maddala 1971). From this perspective, RE (and POLS) is a 'better' estimator (than FE) for estimating long-run effects in partial or general equilibrium approaches, however, it is hard to argue why preference should be given to the RE vs. the BE estimator. Certainly, it is good to know that RE converges to an average of short and long run but, to quote a recent statement of 'Apple' CEO Tim Cook, "anything can be forced to converge. You can converge a toaster and a refrigerator, but you know those things are probably not going to be pleasing to the user. ... The problem is ... about tradeoffs. You begin to make tradeoffs to the point that what you have left at the end of the day doesn't please anyone." ${ }^{81}$ In that sense, FE and BE have the advantage that they can be helpful for different purposes: If one is interested in the short-run impact of $x$ on $y$, e.g. in case one has to design a policy to prevent the exchange rate from appreciating, static FE using flows as the response might serve as a reasonable estimator, maybe with some lagged covariables added. In this special case one is more concerned about flows and can hence do well with the static model. In case one is more interested in the equilibrium effect of $x$ on a MNC's activities, BE estimation of a (static) model using FDI stocks or sales data is appropriate. One could also estimate a dynamic model, however, the potential econometric problems should be taken serious, while the $\mathrm{BE}$ is straightforward to implement since it only requires least squares estimation on the cross-sectional means. An optimal investigation will compare BE and a dynamic estimator and probably also distinguish between long run and short run effects and discuss the adjustment speed. For example, in the case of a LDV of 0.97 as for sales in table 6 , this translates into a half-life ${ }^{82}$ of almost 20 periods, meaning that the MNC needs on average 20 years to adjust half of its sales in the transition from one equilibrium to another.

The next point worth mentioning in table 6 is the fact that the BE (i.e. long-run) elasticities for stocks', flows' and sales' responses to market size are almost identical. $^{83}$ And from the above discussion one would expect exactly this outcome. The similarity between FDI stocks and sales is probably more intuitive. The similarity with FDI flows follows directly from (3): Since flows are a homogeneous function of

\footnotetext{
${ }^{80}$ Remember that the $10 \%$ shock occurs to $\log ($ GDP), not to GDP. Hence, one should not confuse it with the elasiticity of over $40 \%$ in line a) of table 6 which refers to a shock to GDP.

${ }^{81}$ Tim Cook about Windows 8 on a press conference, April 2012.

${ }^{82}$ estimated as half life $:=\ln (0.5) / \ln (\hat{\phi})$

${ }^{83}$ The same does not hold for the long-run effect of the dynamic model, highlighting the potential problems with estimation of dynamic models.
} 

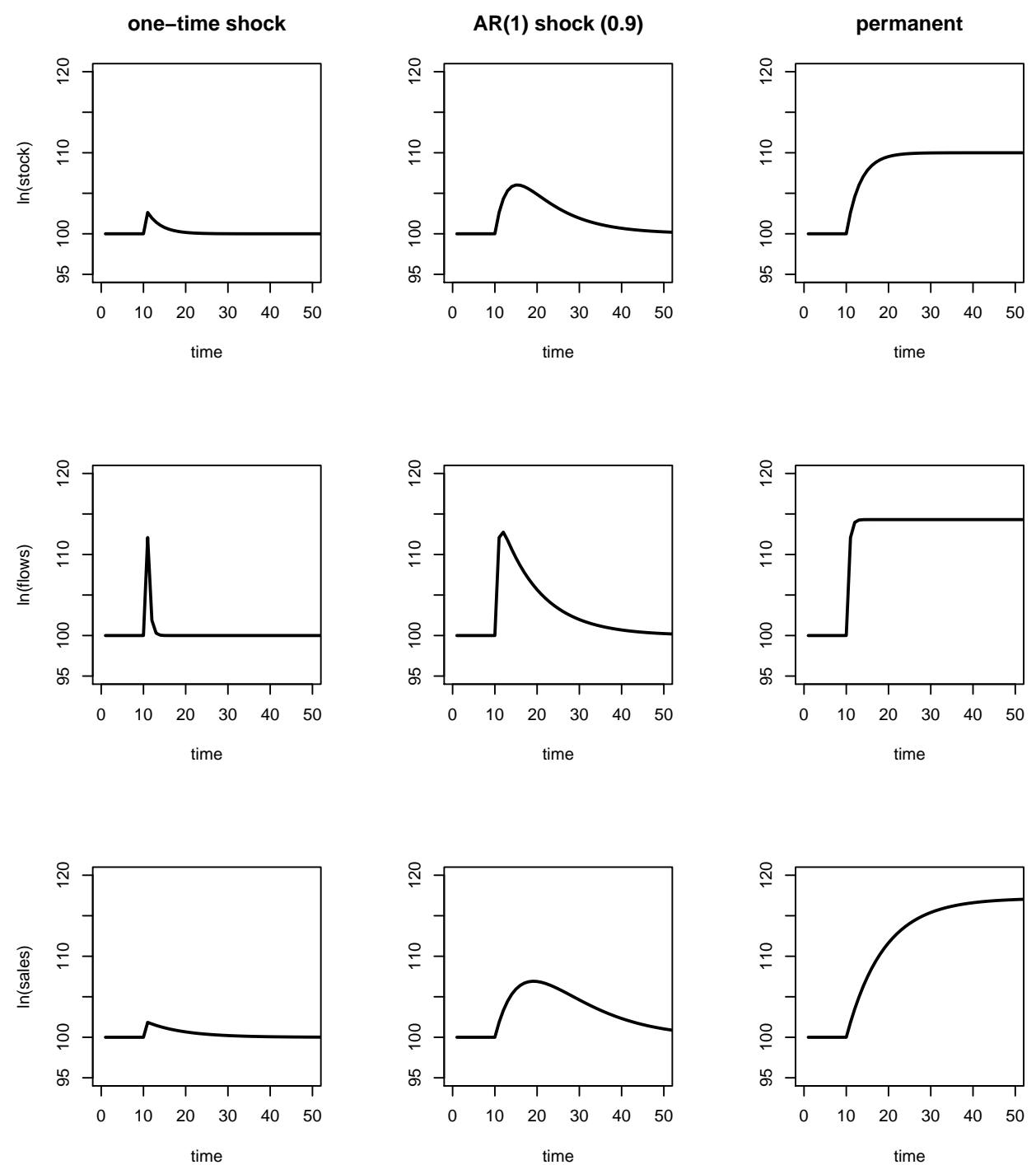

Figure 4: Response of the Dynamic Model to a Shock 
stocks, their elasticity in response to $x$ should be the same.

Finally, table 6 also raises some caution about the depiction of FDI flows' response in figure 4: This follows from the observation that the short-run effect in line b) is larger than the long run effect in line $\mathrm{d}$ ). This may be surprising on a first view but should be clear from equation (7): $y_{t}^{*}$ will first respond to the larger market size by expanding the stock via $\Delta y_{t}$. This will raise $y_{t-1}$ and hence $\delta y_{t-1}$ in the next period. However, after the new equilibrium is reached, $\Delta y_{t}=0$ and the increased $y_{t-1}$ and hence $\delta y_{t-1}$ will not make up for this. These dynamics would require an even more complex model such as an $\mathrm{AR}(2)$ model of the form $y_{t}=\phi_{1} y_{t-1}+\phi_{2} y_{t-2}+X \beta+\varepsilon$ with $\phi_{1}>0, \phi_{2}<0$ and $\phi_{1}>\left|\phi_{2}\right|$. Nevertheless, I would argue that a static FE model for flows can be an adequate model, especially for short-run open macro dynamics and for evaluating a policy change when the observation period is truncated. To see why this should be preferable, look at the rightmost column of figure 4 and suppose the researcher has a panel which only lasts until $T=13$. At that point, the increase was only about $5-6 \%$ for $\ln$ (stocks) and $\ln$ (sales) but more than $14 \%$ for $\ln$ (flows). It will hence be easier to find a statistically significant impact when using flows although this has to be balanced against the fact that FDI flows are usually measured with more noise than stocks and sales data. In any case, it can be helpful to also address the dynamics in this case. An example is given in subsection 3.4.3 of this dissertation.

Of course, there are also other potential estimators that can be used. ${ }^{84}$ However, there might be serious drawbacks of such estimators, although they have not yet been studied as extensively as the estimators mentioned before. ${ }^{85}$ Hence, vogue and computational convenience should not substitute economic reasoning and striving for consistency between arguments, data and model specification (as pointed out by Blonigen et al. 2003 for educational variables in the knowledge-capital model, for example). ${ }^{86}$

\footnotetext{
${ }^{84}$ Examples in the FDI literature are model averaging applications such as Blonigen and Piger (2011); Eicher et al. (2011); Antonakakis and Tondl (2012), or the application of the Plümper and Troeger (2007) estimator by Davies et al. (2008). In my personal opinion, nonparametric approaches to model-selection (cf. Henderson et al. 2012, for growth theories) seem the most promising due to their flexibility and the conclusions that can be drawn about the functional form of the operating model for economic theory.

${ }^{85}$ For the case of BMA see the (largely ignored) result by Pötscher (2006) that it is impossible to construct an estimator whose finite-sample cumulative density function converges uniformly (with respect to the parameters to be estimated) towards their asymptotic counterpart over compact subsets of the parameter space and the (probably related and generally more known) finding of Ciccone and Jarocinski (2010) that 'robust' growth determinants obtained by BMA are not so robust after all. Furthermore, BMA does not resolve functional misspecification. For the statistically worrisome properties of the mentioned Plümper and Troeger (2007) estimator see the discussion between Greene (2011a,b); Plümper and Troeger $(2011 \mathrm{a}, \mathrm{b})$.

${ }^{86}$ Another problem in the FDI literature is the fact that conventional statistical inference is derived under the assumption that the researcher explores the data set for the first and only time (cf. Pötscher 1991). This is certainly not the case in most empirical applications
} 


\subsubsection{The Real Valuation Problem}

Before concluding the chapter, I briefly want to point out another potential problem that is likely to plague empirical attempts to estimate FDI or MNCs' determinants, an exercise that should always be conducted in real (as opposed to nominal) terms. Let $M N C$ be a basket of a multinational firm's assets in the host economy with the corresponding asset price index $A P I$ that assigns a current price to each of these assets. Accordingly, $M N C \cdot A P I$ is the nominal 'value' of the multinational assets, e.g. the FDI stock. Similarly, let $G D P$ be the basket of goods produced within an economy with the respective prices $P P I$, such as the GDP deflator. Accordingly, $G D P \cdot P P I$ will be the nominal GDP. Since one (correctly) attempts to use real values in estimating the determinants of MNCs, one would use a model like

$$
\text { real } \mathrm{FDI} \text { stock }=\beta \cdot \text { real } \mathrm{GDP}+\varepsilon
$$

to estimate the effect of market size on FDI. In most applications this means estimating

$$
\frac{M N C \cdot A P I}{P P I}=\beta \cdot \frac{G D P \cdot P P I}{P P I}+\varepsilon .
$$

Now let us assume that $A P I$ is a (linear) function of $P P I$, such as $A P I=\alpha P P I$. It can then easily be seen that

$$
\begin{gathered}
\frac{M N C \cdot \alpha P P I}{P P I}=\beta \cdot \frac{G D P \cdot P P I}{P P I}+\varepsilon, \text { and hence } \\
M N C \cdot \alpha=\beta \cdot G D P+\varepsilon .
\end{gathered}
$$

This means, the estimator $\hat{\beta}$ will be upward biased if $\alpha>1$ and downward biased if $\alpha<1$. The former means that the asset prices increase faster than the overall price level. This may be the case because of 'animal spirit,' a shock in preferences in favor of financial as compared to other assets, a more regressive income distribution, monetary policy and rising discrepancies between $M 1$ and $M 3$ etc. All this may drive relative prices of financial assets up, which means $\alpha>1$. Hence, even if the FDI stock is technically correct valued at market prices, $\hat{\beta}$ will be biased.

One may argue that sales data is therefore more appropriate-however, a similar problem occurs in this case: If the pricing power of MNCs changes differently than the pricing power of domestic firms, the nominal measure of sales will not be divided by the same price index as the GDP (or consumer price) deflator. While the sales measure is still generally appropriate because its relatively higher increase due to increased market power reflects the increased relevance of multinational firms, the problem is that this increased MNCs' relevance is not due to an increase in market

and in the case of FDI, for example, the data set by Carr et al. (2001) has been explored several times. 
size or similar right hand side variables. ${ }^{87}$

From this perspective, using a truly real measure such as employment data would be preferable, however, its coverage and quality are too poor to do so. The best way to go would be using a chain-type price index for gross domestic investment as in Davies et al. (2008), though such measures are not available for all countries.

\subsection{Discussion and Conclusion}

The aim of this chapter was to introduce various measures of MNCs' activities, their advantages and disadvantages, to discuss the economic relations between them and to give an overview about the different parametric panel data models to estimate the determinants of MNCs' activities. Real data was used to to investigate and examplify the considerations. They lead to some implications for the applied researcher.

Not surprisingly, there is no a priori "best" way to measure MNCs' activities or to estimate its determinants, this rather depends on the circumstances. Nevertheless, my investigation shows that one usually does not too wrong using FDI stock data which has the main attractiveness (compared to operational data) of large availability over both countries and time. There are certain caveats discussed in this chapter and highlighted by Lipsey (2007) that have to do with accounting creativity of MNCs. However, in order to benefit from the intended shift of profits, sales data will also be shifted arbitrarily between host countries so that their use should not considerably help solving the problem. Since the issue is concentrated in a small number of countries (some small Islands, to a milder degree Ireland and potentially also Switzerland), they can easily be excluded from investigations or assumed to be a constant number (and hence decreasing fraction) in case $N \rightarrow \infty$.

Whether the researcher should use operational data or FDI data hence depends on the context. Besides availability, a main difference between the two is the degree of ownership it reflects: While operational data is based on an 'all or nothing' principle (extensive measurement), FDI data more appropriately reflects the degree of ownership (intensive measurement). For example, if a foreign direct investor in the source country decides to increase its share in the direct investment enterprise in the host country from $50 \%$ to $100 \%$, operational data will ceteris paribus stay unaffected while FDI data will show an increase. In certain circumstances, the researcher could make use of this fact, e.g. when the role of political risk on MNCs' activities is examined: As the results of Kesternich and Schnitzer (2010) suggest, ownership shares in multinational firms decrease as risk increases, meaning that FDI may decline (more strongly) with increased risk, while operational data should be less affected. For this reason, one should not overvalue robustness checks of using different measures of MNCs' activities because in certain settings the extensive and the intensive measure will necessarily lead to different quantitative implications. I rather suggest that

\footnotetext{
${ }^{87}$ Note that formulating the model in $\log$-log form does not resolve the problem if $\alpha$ is correlated with RHS variables.
} 
researchers try to make clear what they aim to measure. For example, if the aim is to measure the multinational influence on industrial and labor relations (as in chapter 5 of this dissertation), FDI data may be more appropriate than operational data since it more explicitly quantifies the MNCs' degree of influence in the host country affiliate and hence the degree to which it shapes the industrial and labor relations. Similarly, if measuring potential technology effects at the macro level, it is reasonable to assume that a higher share of ownership creates more incentives to transfer technology, especially in an environment where intellectual property rights are poorly defined, and hence FDI data is probably more appropriate.

Another issue I have looked at are the dynamics of the MNC's decision and potential problems in sales data arising from the MNC's market strategy. I have argued that, in case of a more competitive position of a MNC, its deflated sales data can underestimate its long-run position in the market when the firm uses a predatory or entry-threat strategy. My argument was, that FDI stock data should in contrast reflect the long-run position of the $\mathrm{MNC}$ if financial markets work properly and national compilers follow the market value approach - the latter being more and more the case, the first becoming more questionable these days. In the example of the last paragraph, where the share of MNC ownership doubles from 50 to $100 \%$, the FDI position might not only double but to the extent that markets anticipate a higher degree of technology transfer between parent and affiliate, the share price might rise and the FDI position hence more than doubles. As mentioned, this approach requires listed MNCs and hence a systematic bias might arise between countries with different levels of financial development.

The question of dynamics finally led to the issue of using appropriate econometric techniques to identify the quantitative impact of certain variables on MNCs' activities, especially since the long-run impact might be different from the short-run impact. I have outlined that FDI stock and sales data are relatively persistent and will hence need more time to completely adjust to a changing market environment. I have argued and exemplified that static FE (and, to a lesser extent POLS and $\mathrm{RE}$ ) estimation can result in misleading conclusions in case one is interested in the long-run equilibrium impact, and that BE estimation or using a dynamic model is a more appropriate way to address the issue.

However, I have also shown that using FDI flows can be an option. Therefore, I have emphasized that - contrary to widespread belief-FDI flows are (usually) not the first difference of FDI stocks (e.g. Harding and Javorcik 2011, use the first difference of stocks and label them "flows") but what I call the 'quasi-difference' and, in fact, the MNCs' quantity of response to a changing economic environment (cf. equation (7)). Since they are far less persistent than other data, using a static model is more appropriate for FDI flows and the fast response makes it a powerful measure to evaluate quick changes in covariables such as a policy change, especially when the time dimension of the panel is truncated and the stock and sales data have not completely responded to the shock yet. One can then use a FE estimator (if one is concerned about unobserved cross-country heterogeneity which is correlated with 
the covariables) because the within-variation will be strong. However, this strong signal has to be balanced against the higher noise in flow data compared to stocks and most operational data.

Using flow data instead of stock or operational data has another advantage. The high persistence in the latter raises the concern that these series contain a unit root. Since they are often regressed on other series that are suspicious of being $\mathrm{I}(1)$, conventional techniques such as LSDV may produce spurious inference (Kao 1999). The problem is growing with the increasing $T$ dimension of these panels (Entorf 1997).

Using flow data is also highly appropriate if one is concerned about short-run macro issues (such as the impact on the exchange rate), however, quantitative conclusions about the level of MNCs' activities should be treated with care: As explained and exemplified above, flows will 'overreact' as a first impulse to a changing environment because of being a combination of both the past FDI stock (via depreciation) and the first difference of FDI stocks (i.e. the move to a new equilibrium level). It is hence advisable to have a closer look at the dynamics to reach more appropriate quantitative conclusions. An example is given in subsection 3.4.3. However, since the first differences of stocks will tend to zero $(\Delta y \rightarrow 0)$ in the steady state, flows will then be a homogeneous function of FDI stocks (cf. equation (3)) and can therefore in principle serve as a measure for MNCs' long-run activities. For this purpose, however, a static FE model with annual data will be quantitatively misleading. A BE model will be more appropriate but could then also use FDI stock data (and should probably do so). Finally, FDI flows should be a rather poor ad hoc right hand side variable capturing MNC's activity because the noise in the data is relatively large and the low persistence and high fluctuation in flow data (that can be an advantage for some purposes) will make flows in $t$ a poor predictor of flows in $t+1$. If one hence does not specify the dynamics/lag structure appropriately, one will end up finding no or the wrong impact for reasons discussed above. In this case, a more explicit (theoretical) economic model is needed (see Borensztein et al. 1998, for example).

The discrepancies between the short and the long run and the arguments in this paper can also be seen as a suggestion to make more intensive use of the BE estimator when the purpose is to estimate long-run elasticities from a firms' equilibrium perspective.

Finally, I want to emphasize to pay more attention to the relationship between the short and the long run for both a policy reason and a reason related to the economic theory of the MNC. As highlighted by the IMF (Ostry et al. 2011, p.8), it is important to have an "appropriate quantitative metrics to guide policies" managing capital inflows. For a policy maker, it might be helpful to expect that increasing corporate taxation by 10 percentage points will, in equilibrium, lead to a decrease in FDI of magnitude $\beta$. However, probably even more important is some knowledge about the speed at which this change occurs. It certainly makes a difference for the design of a policy if the half-life or the mean lag $(\phi /(1-\phi)$ in the dynamic model) of the impact is one year or ten years. In the latter case, the tax might be an option for temporary 
fiscal consolidation. More knowledge about these dynamics would help provide more solid economic grounds for the public discussions about national business locations in the globalization context.

As far as our understanding of multinational corporations is concerned, the adjustment speed $\phi^{-1}$ also tells us something about the efficiency of a firm (or of an aggregate of firms) in adjusting to changes in the economic environment. Multinationals are usually perceived as the most productive and the most efficient firms in an economy. Without prejudice to this viewpoint, this distinguishes them from being just one in an infinite continuum of firms and this status might give them the possibility to externalize parts of the opportunity costs (due to forgone productivity) or of the internal transaction costs. As I have argued on page 48, the response (7) to changes in variables $X$ is bounded from below. Taking this fact and downward risks in $X$ into consideration, rational firms will be reluctant to increase their assets too quickly. The firm's situation is similar to an organism, where the amount of energy necessary for reproduction, the metabolic rate, is a (sub-linearly) increasing function of its mass: The need for finance and hence the claims of creditors and shareholders are increasing in the firm's assets. The described obstacles to selling off these assets quickly/profitable enough in the face of a negative shock demands a cautious business strategy. However, the largest firms might be able to roll over this 'mass' (i.e. fixed asset costs) to the public - an externality potentially lowering social welfare. This problem of soft-budget constraints of large corporations in 'market economies' has become apparent in recent years and is known in the public debate as being "too big to fail." 88 The phenomenon is especially striking in the financial sector where we are becoming eye-witnesses to the slow adjustment speed $\phi^{-1}$ in the form of long-lasting deleveraging processes, reductions in 'mass' that took Japanese banks more than the last decade and where the missing 'metabolic rate' is financed by the public through liquidity injections and other means. ${ }^{89}$

I do not argue that MNCs allocation will not be efficient in the long run, although they may be in the short run-un jour tout sera bien, voila notre esperance; tout est bien aujoud'hui, voila l'illusion. ${ }^{90}$ My point concerns the question how long this long run takes and if MNCs face incentives that extend their long run. If so, we should ask for the precise transmission channel in the Keynesian dictum that in the long run we are all dead.' For a bluebell and a rose it is the fact that the metabolic rate becomes unsustainable against the organism's mass at some point. The master of equations might have had something in mind when specifying that not all of her equations lead to infinities.

\footnotetext{
${ }^{88}$ Note, that this argument does not strictly apply to MNCs but 'large' corporations. However, most companies that are considered 'too large to fail' are operating multinationally and it may be argued that this multinational activity is an important factor in making them distinct from the continuum of homogeneous firms.

${ }^{89}$ The phenomenon is also present in non-financial sectors, as the state-owned enterprise 'General Motors' exemplifies.

90 'One day everything will be well, that is our hope. Everything's fine today, that is an illusion.' F.M.A. de Voltaire, Poème sur le désastre de Lisbonne, 1756
} 



\section{The Role of Information for International Capital Flows: New Evidence From the SDDS (joint with Yuko Hashimoto)}

A popular government without popular information or the means of acquiring it, is but a prologue to a farce, or a tragedy, or perhaps both.

J. Madison

\subsection{Introduction}

Economic theory attributes positive welfare effects to capital flowing from capitalabundant countries to those which have potentially productive assets, but where the capital necessary to employ them is scarce. This implicitly assumes that (foreign) investors are aware of these assets, i.e. they have the information necessary to make an optimal decision. The literature on the nexus of capital account openness and growth has somewhat lost sight of this obvious necessity. And indeed, it may not be immediately apparent that information comes at a certain cost in a world where more than five billion mobile phones are in use, where two thirds of households in industrialized countries have internet access and where pretended product information in the form of commercials keeps us updated about the newest and most important products during intermissions of real-time news and documentaries. Yet, most income earners deposit a considerable fraction of their salary on low-interest bank accounts instead of directing them to more profitable investment opportunities, indicating that their individual information costs outweigh their potential gains from interest earnings.

Markets for information in the context of investment necessarily face certain shortcomings. ${ }^{91}$ Some investors, especially foreign direct investors, are not specialized in acquiring information and those who are, especially larger portfolio funds and credit rating agencies, have to deal with non-excludable information they acquired, due to herd behavior in financial markets (cf. inter alia Banerjee 1992; Bikhchandani et al. 1992, and Avery and Zemsky 1998). On the demand side, countries with productive assets but lack of capital may find it difficult to signal their productivity while less productive countries may whitewash their signaled information, and the international asset market may turn out to be a market for lemons (cf. Akerlof 1970). ${ }^{92}$ The price mechanism may also fail in this context because countries with the highest interest rate and hence the most productive investment opportunities may be perceived as especially unstable so that risk averse investors may rather prefer to invest into safe havens (cf. Stiglitz and Weiss 1981).

Under such imperfections, high social opportunity costs may arise because capital is generally not allocated to its most productive employment opportunities, leading the global economy to perform below its potential output and to build up potentially

\footnotetext{
${ }^{91}$ Stulz (1981) was among the first to provide a modern model for barriers of international investment, though it does not explicitly focus on information.

${ }^{92}$ Bond and Samuelson (1986) and Gordon and Bovenberg (1996) provide models where productive countries can use tax-holidays to identify themselves to foreign investors.
} 
unsustainable imbalances. If worse comes to worse, this might even result in a vicious cycle where countries with high-potential investment opportunities but lack of capital (due to domestic saving rates being too low and foreign investors being too risk-averse) have to bail out less productive countries that have received too much investment. Furthermore, the large challanges of our time that may produce the highest long-run gain, first and foremost combating climat change and promoting human development, require large amounts of capital and hence a system where investors are willing to undertake an estimable risk instead of a system where finance is made boring again.

Previous research has already investigated the role of information for capital flows, both empirically and theoretically. However, most of the early empirical studies that I discuss in section 3.2 .5 could not convincingly identify a parameter for the quantitative impact of information on capital flows. Similar to the 'Solow residual' (cf. Vaizey 1964, p. 5), they attributed patterns in capital flows that models could not explain to informational frictions and it is hence justified to ask: Are these unexplained patterns really a measure of the impact of information asymmetries or are they simply a measure of our ignorance about the determinants of international capital flows? Probably the most convincing identification strategies have been provided by studies such as Gelos and Wei (2005), Daude and Fratzscher (2008), and Harding and Javorcik (2011). All these studies have a somewhat different focus and methodology from each other and from this investigation, which is probably the most related to the study of Daude and Fratzscher (2008).

More precisely, I look at the impact that compliance with the IMF's Special Data Dissemination Standard (SDDS) had on international capital flows, specifically foreign portfolio and direct investment. The SDDS, established in 1996 with the aim of enhancing member countries' access to the international capital market, is about macroeconomic data provision to the public. Institutional investors' decision on investments are based on macroeconomic and financial data, but not all the investors have time and money to collect information they need. A first look at the data supports this view, at least for FDI flows: As depicted in the left panel of figure 5, average levels of FDI inflows (relative to GDP) were higher for almost all subscriber countries after SDDS subscription than before. ${ }^{93}$ The picture is similar, though less definite for portfolio flows (right panel). I substantiate these descriptive findings in a sophisticated econometric framework where I find statistically significant and robust evidence of an economically relevant positive impact of providing more (accurate) information about the macroeconomic and financial environment under the umbrella of the SDDS on FDI inflows, but fail to find the same evidence for portfolio flows. Furthermore, I find evidence for macroeconomic risk-aversion for portfolio and for FDI flows and more robust evidence of political-risk aversion for portfolio flows.

This contribution further adds to the literature by looking at systematic differences

\footnotetext{
${ }^{93}$ Unweighted average over the 5 years prior to and after subscription. Outliers were deleted to provide the graph on a meaningful scale.
} 


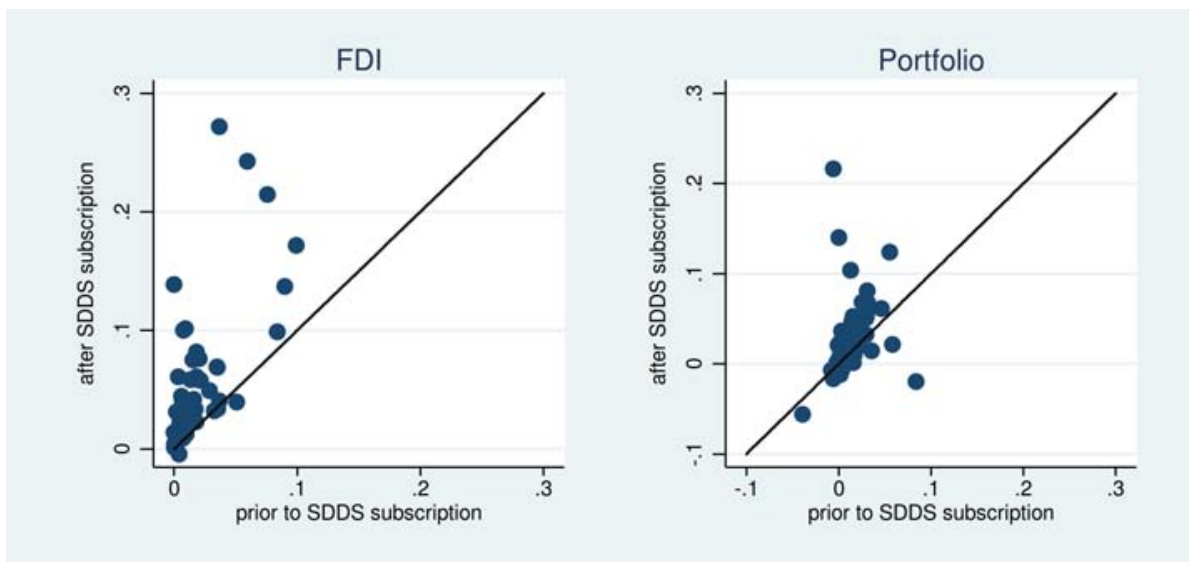

\section{Figure 5: Capital Flows (\% of GDP) Prior to and After SDDS Subscription}

between FDI and portfolio flows and by proposing new measures for a host country's productivity that may be especially relevant for the FDI literature. Finally, I also consider spatial interdependencies in this investigation. Contrary to previous studies on spatial relations in FDI flows, such as Coughlin and Segev (2000), Blonigen et al. (2007), or Baltagi et al. (2007), the approach relies on less stringent assumptions about the potentially underlying spatial process. In line with the results implied by Baltagi et al. (2008), I do not find evidence for significant spatial patterns in the empirical models.

The empirical model and variables used in this paper are introduced together with the data in section 3.2. A variable list with summary statistics of the data can be found in Appendix B.2. I present the results in section 3.3, showing that better data dissemination through SDDS initially increases FDI inflows by about $60 \%$, but has no significant aggregate effect on portfolio flows. In section 3.4, I show robustness checks that provide strong supplementary support for the impact of information on FDI. In section 3.5, I discuss the implications of the findings for macroeconomic stability and growth as well as potential lines of future research.

\subsection{Investment: Model, Previous Evidence and Data}

This contribution ties in with the literature on partial equilibrium analysis of macroeconomic factors affecting investment decisions. ${ }^{94}$ I focus on the investors' motives (i.e. the supply side) toward host country effects. This is not to say that home

\footnotetext{
${ }^{94}$ IMF (1991); Portes and Rey (2005), Daude and Fratzscher (2008); Blonigen (2005) and Blonigen and Piger (2011) may serve as meaningful first reference points for this literature.
} 
country effects do not matter, ${ }^{95}$ but the aim is to focus on a given country's policy options to attract investment. ${ }^{96}$ This means that source country fundamentals have to be taken as externally given ${ }^{97}$ and one can focus on overall inflows instead of bilateral flows. In line with the arguments from chapter 2, I use flow data instead of stock data. The use of flow data is less prone to reversed causality as discussed in section 3.4.1 below and since this study is basically an impact evaluation, one would expect to see more responsive changes in the flow data than in the stock data. Furthermore, threatening vulnerabilities to open economies that are important for multilateral surveillance mostly become acute by changes in capital flows.

\subsubsection{Portfolio and Foreign Direct Investment}

As outlined in chapter 2, portfolio and foreign direct investment refer to different economic concepts of investment, although their technical distinction in the balance of payments is somewhat arbitrary. It is hence surprising that previsous empirical studies have rarely investigated to what extent a difference between these types of flows exists with respect to their determinants (notable exceptions being Daude and Fratzscher 2008; De Vita and Kyaw 2008a,b).

In this specific context it might be part of the job of portfolio investors to acquire information about potential markets which leads to considerable economies of scale because of large externalities. MNCs, on the other hand, can barely benefit from such externalities of information and they would hence respond stronger to public provisioning of macroeconomic data.

The data on capital flows used in this investigation come from the International Financial Statistics (IFS) BOP data. Since IFS data for most countries do not start before 1993, I use data from the IMF's World Economic Outlook (WEO) where the IFS data are not available but WEO data are. ${ }^{98}$ In order to correct for potential errors from this procedure, I use a dummy variable that equals 1 if WEO data are

\footnotetext{
${ }^{95}$ In fact, studies such as Calvo et al. (1993), Fernandez-Arias (1996), di Giovanni (2005) or Dabla-Norris et al. (2010) show that external push factors are highly relevant, although the literature also suggests that the importance of push vs. pull factors depends on the time period and countries analyzed. See, e.g., Chuhan et al. (1998); Hernández et al. (2001); Albuquerque et al. (2005); Dabla-Norris et al. (2010).

${ }^{96}$ Hence, it is implicitly assumed that attraction of foreign capital is a policy motive. Potential gains from higher capital inflows generally include positive growth effects, higher resources for temporary fiscal stimulus in case of a domestic recession under constrained tax revenues and low savings of private households, or for inter-temporary utility maximization when future consumption is less valued than actual one.

${ }^{97}$ I econometrically control for these 'global' effects by using year dummies.

${ }^{98}$ WEO data are compiled by IMF staff based on the information gathered by the IMF country desk officers in the context of their missions to IMF member countries and through their ongoing analysis of the evolving situation in each country. Historical data are updated on a continual basis, as more information becomes available, and structural breaks in data are often adjusted to produce smooth series with the use of splicing and other techniques. See Pellechio and Cady (2006) on the general differences between IFS and other data sets.
} 
used and equals 0 if IFS data are used. I use data in constant US-\$ and take the natural logarithm thereof.

\subsubsection{Econometric Model}

I estimate a log-linear ${ }^{99}$ static model with th log of real capital flows on the left hand side and account for potential autocorrelation in inference using a heteroscedasticity and autocorrelation consistent (HAC) variance estimator based on Huber (1967) and White (1980), commonly referred to as 'cluster-robust' standard errors. I thus model the investment of type $j$ in country $i$ at year $t$ as given by

$$
y_{i t}^{j}=\Psi_{i t} \theta^{j}+S D D S_{i t} \lambda_{S D D S}^{j}+\eta_{t}^{j}+\alpha_{i}^{j}+\varepsilon_{i t}^{j},
$$

where $y_{i t}^{j}$ is the logarithm of capital flow of type $j=1,2$ (either FDI or portfolio) to country $i=1, \ldots, N$ in year $t=1, \ldots, T$ and $\Psi$ is a matrix of (up to) $K-N-T-1$ control variables which are discussed in the next subsections. The main variable of interest is a dummy variable of SDDS compliance which is equal to 1 in country $i$ in year $t$ if the country met the SDDS specifications by then. $\eta_{t}$ and $\alpha_{i}$ are time and country fixed effects, respectively. The country-fixed effect $\alpha_{i}$ can be interpreted as the average inflow of capital to country $i$ over time. The time-fixed effect $\eta_{t}$ controls for the overall volume of global cross-boarder capital flows in year $t$ and hence for source-country effects as well as for global factors such as the oil price or the general trend that international capital flows increased over time. This two-way fixed effect specification with controlling for main variables that change over time and country, allows interpreting the corresponding parameter estimate of SDDS subscription (after the transformation discussed in footnote 130 on page 83) as a difference-in-difference effect of compliance with the SDDS (under the assumption that the model is wellspecified). The sample generally covers $N=55$ countries between 1989 and 2008 but is unbalanced so that the actual number of observations is lower than $55 \times 20$. In summary, the identification strategy uses the data variation within countries over time, accounting for global shocks at every point in time and requires that there are no omitted variables that influence both, capital inflows and the decision to comply with SDDS, and that causality does not run from capital inflows to SDDS compliance. I will address these potential issues in section 3.4 below.

\subsubsection{Determinants of International Investment Flows}

A basic textbook (domestic) investment equation (e.g. Blanchard 2010) describes investment through demand $Y$ and interest rate $i$ :

$$
I=I(\underset{+}{Y}, \underline{i})
$$

The rationale of equation (19) is to capture the (expected) returns of investment and its (expected) cost as the determinants positively or negatively influencing the investment decision. In what follows, I discuss those aspects of international investment

\footnotetext{
${ }^{99}$ Note that logs are taken for GDP so it can be interpreted as an elasticity.
} 
costs and returns that have shown to be robust in the literature and I also present the data used to control for them.

Like for domestic investment, current and future market potential are a main driving force for international investment. It is well documented in the literature that capital flows thus positively react to the size of the market, usually measured by GDP, market capitalization and/or its growth rate (cf., inter alia, Blonigen et al. 2003; Portes and Rey 2005), to the investment rate and savings rate in the economy (cf. Hernández et al. 2001), and to the overall competitiveness of the economy (Stehrer and Woerz 2009).

In the regressions, I use GDP data from WEO and take the natural logarithm of its real value in US- $\$$ to account for current market size. I proxy future market potential by short and long run factors influencing GDP growth. Short-run growth is measured as the percentage change of real GDP p.c. in national currency, taken from WEO. The investment rate, measured as gross capital formation at current national prices to GDP at current national prices (both taken from WEO) proxies for long-run growth.

It is standard in FDI models to account for education as a measure for the overall competitiveness of the economy by using data on educational achievements as provided by Barro and Lee (2010). Obviously, human capital is a robust and important factor for long-run growth, but the rationale in the FDI literature is mainly to understand the relationship between vertical and horizontal motivations for firm's FDI decision (see especially Carr et al. 2001, and Blonigen et al. 2003). In my view, overall education measures can be a weak proxy for the exercise of examining the determinants of FDI. In many aggregated models, the Barro-Lee dataset does not enter the equation statistically significant. Investors may be more concerned about the competitiveness in sectors where host countries have overall comparative advantages - their export sector. I hence suggest to look at high-tech exports as provided by World Bank's World Development Indicators (WDI) as a measure for competitiveness in the export-related sector. From this data, I calculate a country's share of global high-tech exports in a certain year. Furthermore, I look at export unit values, provided by WEO. ${ }^{100} \mathrm{I}$ shall comment on the intuitions and underlying factors in the empirical part of this paper. Finally, I also include the OECD-provided total number of patents in a country to account for $\mathrm{R} \& \mathrm{D}$ seeking investment motivations. ${ }^{101} \mathrm{I}$ will compare the performance of these proposed measures to the average years of schooling from the Barro and Lee (2010) data set.

Some studies on international capital flows have accounted for the sustainability of

\footnotetext{
${ }^{100}$ An extensive discussion of unit values in international trade is provided by Silver (2010), see also the explanations and equation 32 on page 103 of this dissertation.

${ }^{101}$ An advantage of patent data over the Barro and Lee (2010) dataset is also that the former is available on annual basis while there are only data on a five-year basis for the latter.
} 
an economy using current account, public debt flow or public sector balance data (e.g. Hernández et al. 2001; Fratzscher 2011). To some extent, however, this confuses estimation of behavioral relations with accounting identities and furthermore short-term current account imbalances bear few information about its sustainability. However, I account for the trade share in the empirical model, which is measured as the sum of imports (including c.i.f.) and export from and to the rest of the world in current US-\$ (from IFS) relative to GDP in current US-\$ (from WEO). One reason is that as economies become more open, they might have larger markets. Furthermore, there might be important interdependencies between FDI and trade. In fact, one main argument in the FDI literature is that foreign affiliates of multinational firms can overcome trade costs and trade restrictions such as tariffs and non-tariff barriers to trade (cf. Blonigen 2002, although the empirical evidence is somewhat mixed). For this purpose as a control variable, the trade share should largely account for trade openness. ${ }^{102}$

The role of international trade and the fact that investment itself is trade in assets also gives rise to look at impacts of the exchange rate, as done by Froot and Stein (1991) who develop a model of informational imperfections where a depreciation leads to FDI inflows and provide evidence for this phenomenon. Blonigen (1997) shows that a depreciation of the host country's real exchange rate may increase profits of multinational firms that would (also) sell affiliate's products in the home market (or process them there). The depreciation allows foreign firms to make higher bids for host country's assets than domestic firms because the multinational can realize profits of the acquisition in its home currency. Since most FDI comes in the form of M \& A, real exchange rate depreciations will thus have a positive effect on FDI inflows. The relationship has also been addressed by other studies such as Chakrabarti (2001) and Pain and van Welsum (2003). I also control for these effects by taking the implied PPP exchange rate, measured in national currency per US-\$ from WEO. ${ }^{103}$

Although the above standard textbook investment equation (19) highlights the role of the interest rate, it is remarkable that the interest rate has not made it into the standard set of control variables for FDI models. ${ }^{104}$ As Lehmann et al. (2004) argue, local leveraging in the host economy is of high relevance for MNCs' affiliates and hence a low interest rate will be preferable because it provides easier access to credit or capital. The situation is completely different when the only focus is the capital flow component: in the Mundell-Fleming model, capital responds positively to the spread of the domestic to the foreign interest rate. This again highlights an impor-

\footnotetext{
${ }^{102}$ Also note that I am using fixed effect estimation, so the fact that larger countries will generally have a lower trade share than smaller economies will not pose a problem.

${ }^{103}$ As for many other variables, I lag the PPP exchange rate by one year to avoid the problem of reversed causality since a capital inflow will automatically lead to an increase in the exchange rate if the latter is allowed to float freely, although it is ultimately the net inflow of all forms of capital that is relevant.

${ }^{104}$ For example, it is not among the determinants discussed by Blonigen (2005) or Blonigen and Piger (2011).
} 
tant potential difference between portfolio and foreign direct investment. ${ }^{105}$ I hence include the spread of the money market rate (MMR) ${ }^{106}$ over LIBOR in percent p.a. (both taken from IFS) to proxy for the interest rate.

Finally, it is important to account for financial openness of the host country. Governments that attribute more positive growth effects to open financial markets may be more likely to open their capital account on one hand. But they may also be more likely to join SDDS on the other hand. Since both, capital account openness and SDDS will potentially increase capital flows, omission of controling for capital openness could cause an omitted variable bias. I hence include the index of Chinn and Ito $(2006,2008,2011)$ which measures a country's degree of capital account openness and is available up to 2009. It is based on binary dummy variables that codify the tabulation of restrictions on cross-border financial transactions reported in the IMF's Annual Report on Exchange Arrangements and Exchange Restrictions. It is hence a de jure measure, which corresponds to the present exercise since it would not make much sense to explain de facto capital flows using a measure based on de facto capital flows. A higher index value indicates a higher openness to cross-border capital transactions. ${ }^{107,108}$

\subsubsection{Risk}

In this analysis, I look at two broad categories of risk: macroeconomic and political risk. $^{109}$

\footnotetext{
${ }^{105}$ Furthermore, previous studies on the impact of political instability that failed to control for the interest rate are likely to suffer from an omitted variable bias: instable countries are more likely to have higher interest rates. The relationship between stability and FDI hence also captures the cost of financing, not only an "instability tax."

${ }^{106}$ The MMR is the rate at which banks lend to each other for short term.

${ }^{107}$ Since the index also takes into account restrictions on the current account, one may argue that it is too broad for this purpose. However, according to Jeanne (2011), import restrictions can have exactly the same effect as controls on capital inflows and reserve accumulation.

${ }^{108}$ I do not include measures for other investment costs such as wages or taxes because both theoretical models and empirical evidence are ample for these variables which are, above all, not available for some countries in the sample. Despite cost-minimization playing an important role (cf. Badinger and Egger 2010), MNCs do not necessarily shy away from paying high wages (Lipsey 2002) and Haufler and Mittermaier (2011) even argue that governments in countries with high unionization rates (and thus probably higher wages) will have more incentives to attract FDI, e.g. by tax incentives. Scholes and Wolfson (1990) provide a framework where FDI flows grow as a result of a tax increase. The results of Davies et al. (2009) highlight that MNCs' response to taxation is very complex. Since tax systems are usually highly persistent, the fixed effect should absorb most of their impact. An omitted variable bias for SDDS stemming from omitting wage data is economically less likely. Furthermore, wages should be highly correlated with GDP which is included in the control variables so that I control for this potential problem at least partially.

${ }^{109}$ I distinguish risk from uncertainty by the fact that one can principally estimate risk, for example the probability of an exchange rate devaluation, while the accuracy/variance
} 
Political risk (or instability) is an obvious cost to investors already outlined by the seminal work of Lucas Jr. (1990) and has both, indirect and direct effects. For the latter, political risk may increase the direct cost of doing business, e.g. by corruption that acts similar to a tax. Furthermore, investors may fear the threat of exploitation. Accordingly, Kesternich and Schnitzer (2010) provide a model showing that ownership shares in multinational firms decrease, as political risk increases and find empirical support for this statement. ${ }^{110}$ Indirect negative effects of political instability may arise on investment since a political economy perspective would suggest that governments that face the actual threat of being driven out of office will set spending priorities to short-term projects that politically pay off immediately, instead of undertaking necessary long-run infrastructure and education spendings.

Empirical studies addressing the role of political instability include Wei (2000a,b); Papaioannou (2009) and Daude and Fratzscher (2008). ${ }^{111}$ All of these studies find negative impacts of political risk on inward FDI. Daude and Fratzscher (2008) furthermore show that portfolio investment is much more sensitive to institutional indicators and market openness than FDI and that investor protection has a large effect on portfolio investment but does not appear to have any significant effect on FDI. This is in line with the predictions of the model of Albuquerque (2003) that FDI is harder to expropriate because of inalienability of its proprietary asset. ${ }^{112,113}$

The data set includes the political risk ratings provided by the International Country Risk Guide (ICRG). It takes into account factors of government stability, socioeconomic conditions, investment profile, internal conflict, external conflict, corruption, military in politics, religious tensions, law and order, ethnic tensions, democratic accountability, and bureaucracy quality. Data are provided on monthly basis and averages over one year were taken. Risk ratings range from a high of 100 (least risk) to a low of 0 (highest risk), though the lowest de facto rating in the sample is 56 .

As a measure for macroeconomic risk, I look at exchange rate volatility. This is motivated first by the indirect negative effect that exchange rate volatility can have on productivity, at least when financial markets are poorly developed, as recently pointed out by Aghion et al. (2009). Furthermore, exchange rate volatility usually does not come on its own and might thus be a good indicator that something else

of this estimate, that is uncertainty, is influenced by information.

${ }^{110}$ Similarly, Javorcik and Wei (2009) find that corruption reduces FDI and shifts the ownership structure towards joint ventures (because the local partner has an advantage in cutting through the red tape).

${ }^{111}$ Blonigen (2005, p. 390) points out that there are problems with the estimation of institutional quality.

${ }^{112}$ I discuss the study of Daude and Fratzscher (2008) in more detail in the subsequent subsection 3.2.5 and in the concluding section 3.5.

${ }^{113}$ Contrary to most of these studies, I explicitly control for the interest rate in the empirical model because otherwise parameter estimates are likely to be biased (cf. footnote 105 on page 72$)$. 
is going on in the economy. Finally, risk-averse MNCs will directly be affected by changes in the exchange rate when affiliates are not operating independently from each other but are part of complex vertical production networks and export platforms. This illustrates that effects will also depend on different types of FDI, an issue generally highlighted by Moran (2011) recently and emphasized by Cushman (1985) and Schmidt and Broll (2009) in the context of exchange rate volatility. While Campa (1993) and Kiyota and Urata (2004) find that volatile exchange rates have negative impacts on FDI, it is thus likely that the results are sensitive to the sample and methods used.

The calculation of exchange rate volatility is based on monthly data from the IFS and uses data on the national currency per Special Drawing Right (SDR) instead of per US- $\$$, in order to avoid variation that arises from volatility in one single reference currency. The aim is to investigate the effects of unforeseen (but estimated) movements in the exchange rate, so I take the squared deviations from the expected exchange rate for each month, divide it by last month's exchange rate and sum these deviations over the first 6 months of year $t$ and of the last 6 months of year $t-1$. As Engel and West (2005) show, even if exchange rates respond to economic fundamentals, their fluctuations should be nearly unpredictable, especially in the short run, so that today's exchange rate is a reasonable predictor for tomorrow's exchange rate. Hence, the measure for volatility of the exchange rate $e$ is

$$
\operatorname{Exrtvol}_{i t}=\sum_{m=t-1_{(7 / 12)}}^{t_{(6 / 12)}} \frac{\left(e_{m}-e_{m-1}\right)^{2}}{e_{m-1}},
$$

where $t_{(1 / 12)}$ denotes the first month of year $t .^{114}$ The intuition of the measure is that investors will make their investment decision based on previous volatility in exchange rates that serve as an estimate of future exchange rate volatility.

\subsubsection{Information}

I have outlined the economic motivation to investigate the role of information for capital flows in the introductory section 3.1. The basic idea is that financial markets on their own do not necessarily provide efficient mechanisms to cope with the social opportunity costs of imperfect information.

If investors will have imperfect information, cross-boarder capital flows will tend to be too low due to risk aversion, might not go into the most productive locations and hence keep global output below its potential. Furthermore, informational frictions could cause instabilities because investors may find it less expensive to conduct investment on a trial-and-error basis than to acquire all information necessary because social costs of the resulting volatilities (cf. e.g. Bianchi 2011) will not be internalized. Without public intervention, a free-market economy with risk averse investors and

\footnotetext{
${ }^{114}$ Note that results remain similar if I sum the deviation over the first three months of year $t$ and the last nine months of year $t-1$.
} 
asymmetric information about investment opportunities may hence not result in a socially efficient Nash-equilibrium.

The highly public nature of information thus sets the stage for its public provision. The International Monetary Fund has hence endorsed international efforts to adhere to certain data standards and its board has approved the Special Data Dissemination Standard (SDDS) in March, 1996. Compliance with this data standard is voluntary for IMF member states that are interested in getting or expanding access to international capital markets by signaling data of a certain quality in 18 macroeconomic and financial categories outlined in Appendix B.1. On February 19, 1999 Canada and the United States were the first SDDS subscribers that met the requested data standard specifications. To date (2012), SDDS has 71 member countries listed in Appendix B.1 with their exact timing of subscription, metadata posting and SDDS compliance.

Although improvements in data provisioning may have taken place prior to official compliance with SDDS, I assign a dummy variable equal 1 to an observation if the country $i$ has met the SDDS specification ${ }^{115}$ in year $t$ and 0 otherwise:

$$
S D D S_{i t}= \begin{cases}1, & \text { if country } i \text { meets SDDS specification in year } t \\ 0, & \text { else. }\end{cases}
$$

Accordingly, 1999 is the first year where 1-values are observed for at least some of the countries in the sample.

Previous (macro-)economic studies have already highlighted the role of information in international capital markets, but have mostly failed to provide a convincing empirical identification strategy for the impact of information. French and Poterba (1991), for example, note that even when being risk-averse, few investors diversify their portfolio internationally - despite potential nontrivial risk-reduction by crossborder holdings. Their results suggest that investors expect domestic returns to be systematically higher than those of a diversified portfolio by imputing an "extra risk to foreign investments because they know less about foreign markets, institutions, and firms" (p. 225). Tesar and Werner (1995) find that foreign equity portfolios were turned over much faster than domestic equity portfolios and argue that transactions costs associated with trading foreign securities hence cannot be the reason for the observed reluctance of investors to diversify their portfolios internationally. ${ }^{116}$ They conclude that informational constraints may play a role, but also argue that the observed lack of international diversification may have less to do with international' investment choices but simply reflect the tendency of individuals to hold ill-diversified portfolios. ${ }^{117}$ Using an unconventional but refreshing disequilibrium

\footnotetext{
${ }^{115}$ I perform a robustness check by looking at the impact of (lagged) SDDS subscription and investigating the dynamics of the process, see subsection 3.4.2.

${ }^{116}$ Because variable transaction costs would not explain the high turnover and because it seems generally improbable that the cumulated return on a well-diversified portfolio does not exceed the fixed entry barriers in most markets.

${ }^{117}$ Warnock (2002) argues that an underestimation of foreign-equity holdings drove some
} 
approach, Mody and Taylor (2003) find high probabilities of capital crunches for certain episodes in emerging economies and argue that this is not only influenced by default risk but also by asymmetric information but fail to convincingly identify this channel. Brennan and Cao (1997) argue that positive correlations of international equity flows with the returns on the markets of the destination countries can be due to information asymmetry between foreign and domestic investors and provide micro-level evidence for this hypothesis in follow-up work (Brennan et al. 2005). In another micro-study, Ahearne et al. (2004) find that countries with higher stock market listing in the US play a larger role in US portfolios whereas Pagano et al. (2002) find that foreign-listed European companies perform better in the US, but without significant leveraging effects. The role of information is also emphasized by the empirical evidence of Hau (2001a,b), using German stock markets data and showing that foreign traders perform worse on German stock markets because of the information disadvantage compared to the trading environment in headquarters in Germany. Finally, Byard et al. (2011) provide some evidence that the adoption of the European Union's International Financial Reporting Standards (IFRS) reduced financial analysts' absolute forecast errors in an environment of strong enforcement and where domestic accounting standards differ significantly from the IFRS.

On the macro level, Portes et al. (2001) follow up on previous work of the authors and find that distance matters in gravity models using two different data sets of gross bilateral equity transactions. Contrary to what one would expect from portfolio diversification, the impact is negative. ${ }^{118}$ They attribute this finding to the hypothesis that "distance is seen as a proxy for informational frictions" (p. 784). While distance has often been used for this purpose thereafter, it is questionable to what extent this proxy is appropriate. Savastano (2000, p. 157), for example, already notes "that distance (and hence gravity-type equations) is probably not among the factors that will help us understand the geography of capital flows," because distance may measure transaction costs in physical trade but capital transaction costs should not be related to geographical distance.

The work of Daude and Fratzscher (2008), which probably bears the most relation to the present investigation, provide both, a more sophisticated framework and more elaborate measures for information. They use a pseudo-fixed effects model of the Anderson and van Wincoop (2003) class for bilateral capital stocks to address the "pecking order" of different types of capital with emphasis on information and the quality of host country institutions by using seemingly unrelated regressions for the different capital forms. To measure informational frictions, they do not only use distance but also the volume of bilateral telephone calls, bilateral newspapers' and periodicals' trade, and the stock of immigrants from the source country in the host country. ${ }^{119}$ They find that all investigated forms of capital respond significantly to results of Tesar and Werner (1995), but also concludes that variable investment costs cannot explain the home-bias puzzle.

${ }^{118}$ Economies being geographically close tend to have higher correlations, portfolio diversification would thus suggest investing in distant economies.

${ }^{119}$ It should be noted that Portes et al. (2001) also look at the impact of of bilateral 
information but that the elasticity is higher for FDI than for other forms of capital which is evidence against the models of Razin et al. (1998) and Goldstein and Razin (2006) that suggests that portfolio should respond more elastic to informational frictions. ${ }^{120}$ While they provide serious efforts to demonstrate the robustness of their results, a number of caveats still applies. First and foremost, their information proxies cover a whole range of potential transaction costs that may include but are not limited to information. This may cause an omitted variable bias. For example, for vertical investment, legal enforcement may be easier in host countries that have a large stock of source country immigrants which lowers transaction costs not necessarily related to information. Also, immigrants may have different tastes and preferences for goods, e.g. a home-bias in consumption. This will create serious advantages in competition for horizontal investors from their home country that are not primarily related to informational frictions for the investor. Since newspaper circulation and telephone traffic will be correlated with immigrant stocks, using these measures is likely to provide biased and inconsistent estimates. The same applies to the study of Milesi-Ferretti and Lane (2004) who use a similar model and try to capture information by a number of cultural and physical proximity variables.

In my view, Gelos and Wei (2005) provide the most sophisticated measure for informational frictions in their study on the effect of the latter on portfolio holdings of emerging market funds (relative to the host country's share in the world market portfolio, proxied by Morgan Stanley's Emerging Markets Free Index) using monthly data for the late 1990s. They construct a measure for corporate opacity, another two for macropolicy opacity and one more for macroeconomic data opacity. The latter, based on Agça and Allum (2001), comes closest to my SDDS variable. Their overall results indicate that portfolio funds prefer to hold more assets in more transparent emerging markets. Furthermore, the authors (p. 3003ff) conduct a quasi-event study, where a dummy variable takes on the value 1 once a country either voluntarily publishes its IMF Article IV reports, publishes the IMF's "Reports on Standards and Codes," or adopts SDDS, and find a statistically significant, albeit moderate increase of the respective country's portfolio weighting.

Considering FDI, Wheeler and Mody (1992) find support for agglomeration economies as a driving factor for US manufacturing MNCs' location decision. Head et al. (1995, p. 226) attribute the agglomeration behavior of 751 Japanese multinationals in the USA to lowering the cost of acquiring information about the local market. Blonigen et al. (2005) also argue that information exchange in "Presidential Council" meetings of Japanese MNCs may lower information costs and thus implies positive impacts on FDI and find empirical support for agglomeration. In a similar vein, Kinoshita and Mody (2001) find Japanese investment in Asian emerging markets to be positively

telephone call traffic to account 'explicitly' for information so that their contribution takes more effort to identify the impact of information than other studies of that time. However, I find the empirical strategy of Daude and Fratzscher (2008) more convincing so that I focus on their results.

${ }^{120}$ Mody et al. (2003) also develop a model where FDI has an advantage over other forms of foreign investment in case of information asymmetries. 
correlated with Japan's own previous investment and the current investment by competitors and argue that this cannot be explained by industrial agglomeration but by the value of private information. ${ }^{121}$ Bobonis and Shatz (2007) find FDI agglomeration within the US and conclude that it would be desirable in future research to disentangle different economic motives for this behavior such as technological spillovers, information sharing or other externalities. The FDI-agglomeration literature hence shows that the potential role of information is not limited to portfolio considerations but also important for the assessment of foreign market potential in the FDI decision of multinationals, ${ }^{122}$ although clear identification of this channel is still wanting and Davies and Kristjánsdóttir (2010), for example, do not find similar agglomerative type effects for FDI flows to power-intensive industries in Iceland for the period 1989 - 2001. ${ }^{123,124}$ Other potential evidence for the importance of information for FDI can be derived from the results of Davies et al. (2009). Their finding that tax treaties only increase the extensive margin of FDI may in part be driven by the fact that information asymmetries decrease with tax treaties and the corresponding information exchange so that entry into the potential host market becomes more likely. Following up on an argument in Jones (1996), they in fact conclude that their "results suggest that the impact of treaties might be greatest due to their impact on issues of uncertainty, not by adjusting the effective tax rates firms face" (p. 108).

Finally, in a recent contribution Harding and Javorcik (2011) find that investment promotion agencies (IPAs) have a positive impact on FDI flows ${ }^{125}$ from the US to developing (but not to industrialized) countries. While they do not generally take a stand on whether IPAs play an informative or persuasive role (cf. footnote 29 on p. 1469), they also provide some evidence that the positive impact works by IPAs

\footnotetext{
${ }^{121}$ The authors run an ordered panel logit model but do not provide a convincing identification strategy to deal with the endogenous lagged dependent variable and the incremental parameter problem.

${ }^{122}$ Furthermore, more accurate information may even increase GDP and thus market potential in an economy because it allows efficient flexible inflation targeting by the central bank, whereas the readily observed interest rate may only bear loose connection to the true interest rate in an economy with information gaps (cf. Berg et al. 2010 on the issue).

${ }^{123}$ However, they find that fixed market entry costs play an important role and can lead to a bias in simple OLS estimation (instead of a Heckit procedure) when bilateral flows are used, especially for the parameter estimate of distance, which makes a strong statement for investigating the effect that information may play in this context.

${ }^{124}$ Note that there is also a potential channel how information could negatively affect FDI: Models of vertical FDI motivate such investments, inter alia, by the problem of contract enforcement in vertical market relationships. IMF (1991, p. 24) thus argues that asymmetrical information provides a clue why FDI has been such an important component of capital flows. Hence, more accurate information might also lower incentives for FDI. This is also the rationale of the models of Goldstein and Razin (2006) and Mody et al. (2003) and might be especially relevant in the case of power-intensive industries (cf. Williamson 1971, esp. p. 112). However, I find this argument-while potentially adequate in some special circumstances - not very important on the macro level, especially considering the fact that most FDI is driven horizontally.

${ }^{125}$ More precisely, they use the first difference of BEA stock data.
} 
alleviating information asymmetries although assistance to deal with red tape seems to be the more important channel. Furthermore, they use the common measures for information such as language, cultural and power distance and newspaper circulation which are likely to also capture other impacts, as discussed above. ${ }^{126}$

In summary, previous macro-studies on capital flow determinants have highlighted the potential role of information. But this contribution goes beyond these preliminary efforts since they have mainly drawn this conclusion indirectly by the residuals of capital flows that cannot be explained through other conventional determinants of capital flows or by identification strategies that seem worrisome at least.

This contribution is also related to the literature investigating other aspects of SDDS subscription. For example, Cady (2005) finds statistically significant evidence that SDDS subscription decreased borrowing costs for emerging market economies on primary markets by a considerable amount, ${ }^{127}$ thereby confirming previous studies mentioned in his paper that found similar effects on secondary markets. ${ }^{128}$ Cady and Gonzalez-Garcia (2007) find that the adoption of the reserves data dissemination standard under the umbrella of SDDS was associated with a decrease in exchange rate volatility of about 20 percent, but finds that SDDS itself has had no particular effect on nominal exchange rate volatility.

\subsubsection{Spatial Interdependencies}

The discussion so far has referred to distance as an exclusive measure for informational frictions for capital flows. However, distance may measure many other factors and cause spatial correlations of economic relevance and with adverse impacts on statistical inference.

For example, capital inflows to a certain country might allow this country to run larger current account deficits. Since trade depends negatively on distance, especially nearby economies may benefit from these flows. This, in turn, might foster investment in neighboring economies, suggesting a positive spatial correlation. Vice versa, a negative shock in one economy might cause contagion to neighboring economies, also suggesting positive spatial correlation in investment patterns (see footnote 118 on page 76). However, to the extent that investors will anticipate this contagion effect, they may spread their risk among several regions, leading to negative spatial correlation. Accordingly, it may not be determined a priori which effect is larger,

\footnotetext{
${ }^{126}$ In an older study using data from the early 1980s, Coughlin et al. (1991) find that US state government spending to attract FDI had a positive, statistically significant effect on FDI attraction.

${ }^{127}$ The parameter estimate is around 0.2 , translating into a decrease in borrowing costs of about 22 percent. See also Cady and Pellechio (2006) for an extension including the General Data Dissemination Standard. Glennerster and Shin (2008) find a somewhat smaller decline in borrowing cost spreads using a different sample and methodology.

${ }^{128}$ See Diamond and Verrecchia (1991) for a model how providing information can reduce the cost of capital from the firm-perspective.
} 
although the results of Portes et al. (2001) and Daude and Fratzscher (2008) for portfolio investment and the discussed agglomeration literature for FDI suggest that the diversification effect is not very strong. ${ }^{129}$

There may also be a close relation between spatial interdependence and information: In case investors lack other information about potential host countries, they may assume that countries that are geographically close may also be similar economically and base their investment decision on these grounds. For example, if no macroeconomic data were available, investors may assume that Poland is economically similar to Germany due to the fact that they are neighbor countries. However, if one takes GDP p.c. as a measure for the state of the economy, Poland is closer to the geographically much more distant countries Uruguay or Antigua and Barbuda. Accordingly, the more information becomes available to investors, the more one would expect the spatial correlation in a geographic sense to decline (in absolute terms) and the spatial correlation in an economic sense to rise.

Spatial correlation in investment has been investigated in studies such as Coughlin and Segev (2000), Hernández et al. (2001) and, later on, by Blonigen et al. (2007), and Baltagi et al. (2007). All but the last of these studies, as well as a number of other contributions, use spatial autoregressions (SARs) but only cover a sample of countries and thereby implicitly impose the restriction of zero-interaction of capitalmarket shocks between countries in the sample and out of the sample. Furthermore, their use of a t-statistic for the significance of the spatial lag (instead of a Moran statistic) implicitly assumes that the data generating process does not change as the number / composition of sampled countries grows. I find these assumptions to be somewhat strict but since even misspecified SARs may increase the forecasting performance of a model of determinants of investment and improve the inference of other regression coefficients (cf. Wall 2004, p. 311), these investigations have at least shown that the potential omitted variable bias of not including spatial autocorrelation terms or other spatial interdependence measures, if any, is negligible when country fixed effects are used.

In summary, the use of distance in such different contexts as measuring information and using SARs further adds to the argument that distance can measure many other aspects than informational frictions, hence making the interpretation of a related parameter estimate economically doubtful. Second, it points out that one should take into account potential spatial interdependencies in the econometric framework since untreated spatial correlation may bias the estimated covariance matrix (cf. Conley

\footnotetext{
${ }^{129}$ When considering the production aspect of MNCs for the case of FDI, the picture gets even more complex (see Yeaple 2003, for a model where complex integration strategies create complementarities between potential host countries): Export platform FDI may give rise to negative spatial correlation with positive third-country effects (see Blonigen et al. 2007) but potential FDI spillovers to neighboring economies might encourage other foreign investors to run businesses in these economies generating positive spatial correlations. In the case of complex vertical FDI, positive spatial correlations may also be present since multinationals will then ceteris paribus look for close production facilities in order to save trade costs.
} 
1999) similar to the time-series case of autocorrelation that most applied economists are familiar with.

To deal with this issue, I apply an approach based on Conley (1999) and Conley and Ligon (2002), which makes less stringent assumptions about the DGP, hence avoiding potential misspecification (cf. Kelejian and Prucha 1999, p. 511). To the best of my knowledge, the only contribution in the literature on international capital flows that comes close to this approach is Baltagi et al. (2008) who use the spatial heteroscedasticity and autocorrelation consistent estimator proposed by Kelejian and Prucha (2007). Correcting for such spatial heteroscedasticity, however, is only necessary if spatial correlation is present in the first place. My approach therefore is to non-parametrically estimate the correlation of error terms depending on their distance in space and bootstrap a 90 percent confidence region for the null hypothesis of no spatial correlation. The results indicate that there is no need to correct inference for spatial interdependencies.

More precisely, I first take the residuals $\varepsilon_{i t}$ from equation (18) and perform a Pearson transformation, i.e. I form

$$
\eta_{i t}=\frac{\varepsilon_{i t}-\bar{\varepsilon}}{\sigma_{\varepsilon}}
$$

While the transformation in the numerator is trivial (the mean of the residuals should be 0 ), the division by the standard error should make the results more comparable between different residual series and especially to potential future work in the field. In what follows, I denote the $N \cdot \bar{T}$ observations about the $\eta_{i t}$ simply as the (column) vector $\eta \in \mathbb{R}^{n}$. I then compose the correlation matrix $C=\eta \eta^{\prime}, C \in \mathbb{R}^{n \times n}$. Similarly, I compose a distance matrix $D$ of the same dimension, where element $d_{j l}$ measures the distance of the country in line $j$ to the country in column $l$. By (geographic) distance I mean the Euclidean distance between the longitude and latitude of the countries' main city as reported on www.cepii.fr:

$$
d_{j l}=110.57 \times \sqrt{\left(\text { lat }_{j}-\text { lat }_{l}\right)^{2}+\left(\operatorname{long}_{j}-\operatorname{long}_{l}\right)^{2}},
$$

where 110.57 is the conversion factor to translate distance into kilometers. Accordingly, all diagonal elements $d_{i i}$ of $D$ will be equal to 0 and it is trivial that both, $D$ and $C$ are symmetric: $D=D^{\prime}, C=C^{\prime}$. To eliminate this redundant information, I create vectors $s=\left\{d_{j l}: j<l\right\}$ and $\rho=\left\{c_{j l}: j<l\right\}$. Note that this simply creates vectors that contain information about the correlation between two residuals (in $\rho$ ) and the corresponding distance between the two countries from which these residuals come (in $s$ ) and that I eliminate correlations between residuals that both come from the same country because their correlation will be driven by persistence patterns that I do not want to disturb the spatial structure of interest. One can then plot $\rho$ against $s$, as done in figure 11 on page 96 and investigate the relation between the correlation of the standardized residuals and the (geographical) distance between them. 
In order to address the relationship between residual correlation and distance, few assumptions can be made so that a nonparametric method suggests itself. Conley (1999), for example, studies the case of nonparametric VCV estimation using a local average estimator. This has the advantage of being a flexible approach. However, it can also be too flexible: In some local environment on the distance dimension, correlations between the $j$ and $l$ countries will be characterized by the fact that countries in $j$ will be fairly similar in some respect while the same holds for the countries in $l$. For example: Suppose one has European, Sub-Sahara African and Latin American countries in the sample and wants to assess the standardized residual correlation in the three local environments $a, b, c$ with $a<b<c$, representing the distances within these regions itself $(a)$, the distance between countries from Sub-Saharan Africa and countries from Europe and Latin America (b) and between Latin American and European countries $(c)$. The correlation structure in environment $b$ will then probably differ in the data generating process from the one in $c$ or $a$ because of institutional issues not being accounted for by the model that produces the residuals. If one is really interested in the impact of geographical distance and assumes that it is measured correctly, one would not want the relationship to depend on such local characteristics but would like it to be more smooth, meaning that relatively more emphasis should be given to a low variance of the estimator.

I hence use a smoothing spline that is the solution to the minimization problem

$$
\hat{f}_{p}(s)=\underset{f(s) \in S_{m}\left(\Delta_{K}\right)}{\operatorname{argmin}}\left[\sum_{i=1}^{n}\left\{\rho_{i}-f\left(s_{i}\right)\right\}^{2} \lambda J(f)\right], \lambda>0,
$$

where $J(f):=\int_{a}^{b}\left\{f^{(m+1)}(s)\right\}^{2} d s$ is a penalty function and $S_{m}\left(\Delta_{K}\right)$ is the spline space of degree $m$ based on the partition $\Delta_{K}$. It can be shown that among all functions with $m+1$ continuous derivatives, there is a unique function that minimizes (24), which is called a 'smoothing spline'. The optimal $\lambda$ is estimated using leaveone-out cross-validation.

This approach raises the question: What is a (statistically) significant spatial correlation? The problem is that the undogmatic approach toward the spatial relationship makes it difficult to asymptotically derive a null hypothesis against a reasonable alternative. To overcome this problem I use a bootstrap approach. I.e., I assign the estimated (standardized) residuals randomly (with replacement) to the locations (which are kept fixed) and calculate the spatial correlation pattern of these (standardized) residuals. With this procedure, spatial correlation patterns will be purely random. I hence repeat the procedure $B$ times and order the estimated correlations at each location in ascending order. Then, the $0.05 \times B$ th and the $0.95 \times B$ th observation approximate a 90 percent pointwise confidence interval where one would not reject the null hypothesis of no spatial correlation. 


\subsection{Main Empirical Results}

The estimation results of equation (18) for FDI and portfolio investment are depicted in tables 7 and 8, respectively. The first columns show baseline results not including the SDDS variable which enters the model in the second column. The difference between the third column and the first two columns is that the latter use the standard Barro and Lee (2010) years of schooling while my proposed measures for skill intensity in the sector(s) of comparative advantage can be found in the third column which is my preferred specification. The last column provides the results using random effects instead of fixed effects regression specification. Note that the Hausman test does by no means suggest that random effects would provide consistent estimates, however, it is interesting to see what happens to the model if cross-section variation is taken into account.

For the FDI models (2a) - (4a) the SDDS dummy enters the model highly significant. The increase in the explanatory power when moving from model (1a) without SDDS to $(2 \mathrm{a})$ with SDDS is relatively small but it is important to stress that the impact of information is nevertheless economically highly relevant: Conditional on other factors, providing high-quality information about the macroeconomic and financial environment under the umbrella of SDDS increases FDI inflows by 56.2 to 61 percent. ${ }^{130}$ Furthermore, one should note that the change in the estimated parameters for the control variables is of minor importance when SDDS enters the model. This suggests that omitted variable biases in previous investigations that failed to account for informational asymmetries were negligible.

Considering the control variables, I first look at the performance of the proposed measures for human capital and technology in the export-relevant sector in model (3a) relative to the standard education variable of Barro and Lee (2010) in model (2a). As one can see, years of schooling do not turn out to be significant and the estimated sign is contrary to the expected effect, supporting the claim that overall education averages on the macro level may not be as relevant for a MNC's investment decision. On the other hand, the number of patents is at the borderline of weak statistical significance (t-statistic 1.46) and shows both the expected sign and an economically relevant impact. ${ }^{131}$ The impact of the world market share of high-tech exports is far from being statistically significant, maybe reflecting offsetting positive effects from high knowledge in the sector with comparative advantage and negative impacts from

\footnotetext{
${ }^{130}$ This is the straightforward calculation of the marginal effect in the log-linear models $(2 \mathrm{a})$ and $(3 \mathrm{a}), \ln (y)=X \beta$ :

$$
\frac{\mathbb{E}(y \mid x=1)-\mathbb{E}(y \mid x=0)}{\mathbb{E}(y \mid x=0)}=\frac{\exp (\beta)-\exp (0)}{\exp (0)}=\exp (\beta)-1 .
$$

An unbiased estimator for the marginal impact is discussed in Giles (1982).

${ }^{131}$ The parameter may look small on a first sight: Another patent increases FDI inflows by 0.004 percent. Considering that the annual average number of registered patents was above 10,000 for the United States and more than 9,000 in Japan (standard error about 3,000 in both cases), however, the relevance should not be neglected.
} 
Table 7: FDI Determinants

Dependent Variable: $\ln ($ FDI flow)

\begin{tabular}{|c|c|c|c|c|}
\hline model & (1a) & $(2 a)$ & $(3 a)$ & $(4 \mathrm{a})$ \\
\hline SDDS & & $\begin{array}{c}0.4462^{* * *} \\
(0.1522)\end{array}$ & $\begin{array}{c}0.4760^{* * *} \\
(0.1355)\end{array}$ & $\begin{array}{c}0.4590^{* * *} \\
(0.1310)\end{array}$ \\
\hline $\ln (\mathrm{GDP})$ & $0.7724^{* * *}$ & $0.7732^{* * *}$ & $0.7116^{* * *}$ & $0.8287 * * *$ \\
\hline$(-1)$ & $(0.0995)$ & $(0.0952)$ & $(0.0795)$ & $(0.0550)$ \\
\hline GDP growth & $\begin{array}{c}4.1104^{* * *} \\
(0.9197)\end{array}$ & $\begin{array}{c}4.4241^{* * *} \\
(0.8887)\end{array}$ & $\begin{array}{c}2.9280^{* * *} \\
(0.9967)\end{array}$ & $\begin{array}{c}3.8167^{* * *} \\
(1.2328)\end{array}$ \\
\hline investment rate & $3.1872^{* * *}$ & $3.4468^{* * *}$ & $2.1197^{*}$ & $2.0197^{* *}$ \\
\hline$(-1)$ & $(0.9126)$ & $(0.8909)$ & $(1.1974)$ & $(1.0252)$ \\
\hline capital account open & $\begin{array}{l}0.1445^{* *} \\
(0.0646)\end{array}$ & $\begin{array}{l}0.1299^{* *} \\
(0.0625)\end{array}$ & $\begin{array}{l}0.1399^{* *} \\
(0.0677)\end{array}$ & $\begin{array}{l}0.1377^{* *} \\
(0.0554)\end{array}$ \\
\hline political risk & $\begin{array}{c}0.1143^{* *} \\
(0.0458)\end{array}$ & $\begin{array}{c}0.1140^{* *} \\
(0.0473)\end{array}$ & $\begin{array}{c}0.0207 \\
(0.0380)\end{array}$ & $\begin{array}{c}0.0021 \\
(0.0240)\end{array}$ \\
\hline exchange rate volatility & $\begin{array}{c}-2.9418^{* * *} \\
(0.7488)\end{array}$ & $\begin{array}{c}-2.8234^{* * *} \\
(0.7428)\end{array}$ & $\begin{array}{c}-3.3692^{* * *} \\
(0.8635)\end{array}$ & $\begin{array}{c}-3.4416^{* * *} \\
(1.0731)\end{array}$ \\
\hline $\begin{array}{l}\text { exchange rate volatility } \\
(-1)\end{array}$ & $\begin{array}{l}-0.7471 \\
(0.7864)\end{array}$ & $\begin{array}{l}-0.7105 \\
(0.7611)\end{array}$ & $\begin{array}{c}-1.4820^{* *} \\
(0.5685)\end{array}$ & $\begin{array}{l}-1.1573 \\
(0.7046)\end{array}$ \\
\hline interest rate & 0.0000 & 0.0000 & $-0.0002^{* * *}$ & $-0.0003^{* * *}$ \\
\hline$(-1)$ & $(0.0000)$ & $(0.0000)$ & $(0.0001)$ & $(0.0001)$ \\
\hline real exchange rate & -0.0001 & -0.0001 & $-0.0003^{*}$ & $-0.0003^{* * *}$ \\
\hline$(-1)$ & $(0.0001)$ & $(0.0001)$ & $(0.0001)$ & $(0.0001)$ \\
\hline trade share & $\begin{array}{c}0.1873 \\
(0.2047)\end{array}$ & $\begin{array}{c}0.0990 \\
(0.1899)\end{array}$ & $\begin{array}{l}-0.1835 \\
(0.2890)\end{array}$ & $\begin{array}{c}0.4382^{* * *} \\
(0.1227)\end{array}$ \\
\hline yrs. of schooling & $\begin{array}{l}-0.1155 \\
(0.1383)\end{array}$ & $\begin{array}{l}-0.0926 \\
(0.1322)\end{array}$ & & \\
\hline $\begin{array}{l}\text { high-tech exports } \\
(-1)\end{array}$ & & & $\begin{array}{l}-0.0000 \\
(0.0000)\end{array}$ & $\begin{array}{l}-0.0000 \\
(0.0000)\end{array}$ \\
\hline export unit value & & & $-0.0098 * *$ & -0.0043 \\
\hline$(-1)$ & & & $(0.0042)$ & $(0.0036)$ \\
\hline $\begin{array}{l}\text { \# of patents } \\
(-1)\end{array}$ & & & $\begin{array}{c}0.0000 \\
(0.0000)\end{array}$ & $\begin{array}{l}-0.0000 \\
(0.0000)\end{array}$ \\
\hline WEO data dummy & $\begin{array}{l}0.8398^{*} \\
(0.4916)\end{array}$ & $\begin{array}{l}0.8663^{*} \\
(0.5097)\end{array}$ & $\begin{array}{l}-0.2562 \\
(0.4287)\end{array}$ & $\begin{array}{l}-0.6221 \\
(0.4193)\end{array}$ \\
\hline constant & $\begin{array}{l}-6.1518 \\
(3.8131)\end{array}$ & $\begin{array}{l}-6.3316 \\
(3.8362)\end{array}$ & $\begin{array}{c}2.4603 \\
(3.2122)\end{array}$ & $\begin{array}{c}0.0000 \\
(.)\end{array}$ \\
\hline estimation & $\mathrm{FE}$ & $\mathrm{FE}$ & $\mathrm{FE}$ & $\mathrm{RE}$ \\
\hline time dummies & yes & yes & yes & yes \\
\hline observations & 1,084 & 1,084 & 634 & 634 \\
\hline$(\mathrm{N} \times$ avg. $\mathrm{T})$ & $(70 \times 15.5)$ & $(70 \times 15.5)$ & $(55 \times 11.5)$ & $(55 \times 11.5)$ \\
\hline $\begin{array}{l}\text { within R-squared } \\
\text { Hausman (p-value) }\end{array}$ & 0.38 & 0.40 & \multicolumn{2}{|c|}{0.000} \\
\hline
\end{tabular}

Cluster-robust standard errors in parentheses; see text for further details. ${ }^{* * *},{ }^{* *}$, and $*$ denotes statistical significance at the $1 \%, 5 \%$ and $10 \%$ level, respectively. 
too competitive markets.

The considerable negative (and statistically significant) effect of (lagged) export unit values may be surprising on a first view if one thinks of commodity prices that are reflected in the export unit values. However, the sample mainly consists of advanced economies for which the large country assumption is reliable at least in their sectors of comparative advantage. Lower export unit values could then simply reflect high total factor productivity and hence high international competitiveness in this sector which would attract FDI. ${ }^{132}$

As expected, FDI responds positive to current and potential future market size measured by GDP, the growth of GDP p.c. and the investment rate, where the latter is only weakly significant in model (3a). Also, the positive impact of de jure capital account openness is statistically significant and very robust, capturing the incentives to transfer capital. ${ }^{133}$ On the other hand, the effect of local leveraging as measured by the spread of the interest rate is only statistically significant in models (3a) and (4a). There, however, it is highly significant but of minor economic relevance: An increase in the spread of one percentage point decreases FDI inflows by about 0.02 percent. Nevertheless, I find it important to control for the host country interest rate in FDI models, especially since data availability should not pose a problem in most applications. Furthermore, the small effect might simply reflect the fact the number of MNCs is growing because of cheap leveraging in the host economy, but for the same reason the amount of FDI per MNC is decreasing, resulting in an overall small effect. The insignificant effect of the interest spread in model (2a) may be driven by sample effects: The larger sample includes more less developed economies where multinationals have advantages over local competitors by having larger access to capital markets in their source countries. In the sample of more advanced (and more homogeneous) countries, access to local leverage might influence the multinationals' location decision more clearly.

A similar effect may influence the results for political risk: It is unlikely that it has a relevant impact in the subsample of more advanced economies but when a larger and more heterogeneous sample is investigated, FDI shies away from political risk. ${ }^{134}$

Considering exchange rate volatility, FDI clearly resiles from macroeconomic risk: The appropriate test statistic is an F-test for joint insignificance of both lags of exchange rate volatility and one can reject this null hypothesis both in model (2a) and

\footnotetext{
${ }^{132}$ Alternatively, the results could indicate that FDI shies away from monopolistic markets: High export unit values may indicate pricing power of domestic exporters.

${ }^{133}$ Note that the bias of omitting capital account openness on the SDDS variable is relatively small: Without controlling for capital account openness, the impact is about 65 percent.

${ }^{134}$ Remember that a higher value indicates higher stability. Also note that the withinvariation (which is the relevant signal for fixed effects estimation) of political risk will be larger for developing countries than for industrialized countries.
} 
(3a) at the 1 percent level of statistical significance. ${ }^{135}$

Contrary to Blonigen (1997), I find a negative impact of a real exchange rate devaluation on FDI inflows. This might be driven by the fact that he disaggregates the effect down to the industry level while I look at the aggregate effect in the whole economy. Furthermore, his rationale is only one of many potential channels between the real exchange rate and FDI. For example, under Dixit-Stiglitz preferences, a real exchange rate appreciation will ceteris paribus increase the relative demand for imported varieties (because they become relatively cheaper). This increased demand can then either be served by imports or by horizontal FDI, so both of them will increase. ${ }^{136}$

The results for portfolio investment are generally not as appealing as the ones obtained for FDI flows. I do not find a significant impact of SDDS compliance on inflows, neither is the size of the estimated parameter very relevant in economic terms. This contrasts with previous macro studies that held asymmetric information responsible for "too low" international portfolio capital flows (but could not empirically justify this assumption). I will discuss this issue in the concluding section 3.5. However, portfolio flows too respond positive to current and potential future market size, although the growth rate of GDP p.c. or the investment rate are not statistically different from 0 in models $(1+2 \mathrm{~b})$ or $(3 \mathrm{~b})$, respectively.

One can reject the null hypothesis that both lags of exchange rate volatility have no impact on portfolio flows at the 10 percent level in model (3b) but not in model (2a). As expected, portfolio investment responds positive to spreads in the interest rate in model (3b). Somewhat surprising, I do not find a statistically significant impact of de jure financial liberalization on portfolio inflows. I find very robust evidence of portfolio investment shying away from political risk in the fixed effects models. The positive significant correlation with political risk in the random effects model (4b) may be due to an omitted variable bias.

Finally, I find it interesting to notice that portfolio investment reacts more elastic to changes in the (current) market size than FDI. This corresponds to the theoretical assumption that more firm-internal considerations play a role for FDI. The evidence is more mixed when looking at potential future market size development but this is not too surprising: Since portfolio investment should be more flexible than FDI, its location decision is not as binding as for the latter.

\footnotetext{
${ }^{135}$ The same result holds if I exclude observations where countries of the Euro area share the same currency.

${ }^{136}$ The relative increase in trade will generally be stronger since the acquisition price for domestic assets will also increase. Note, however, that one of the main production factors of multinationals, its proprietary asset, is not located in the host economy, and hence its acquisition price will not be affected by the increase in the real exchange rate.
} 
Table 8: Portfolio Determinants

Dependent Variable: $\ln$ (portfolio flow)

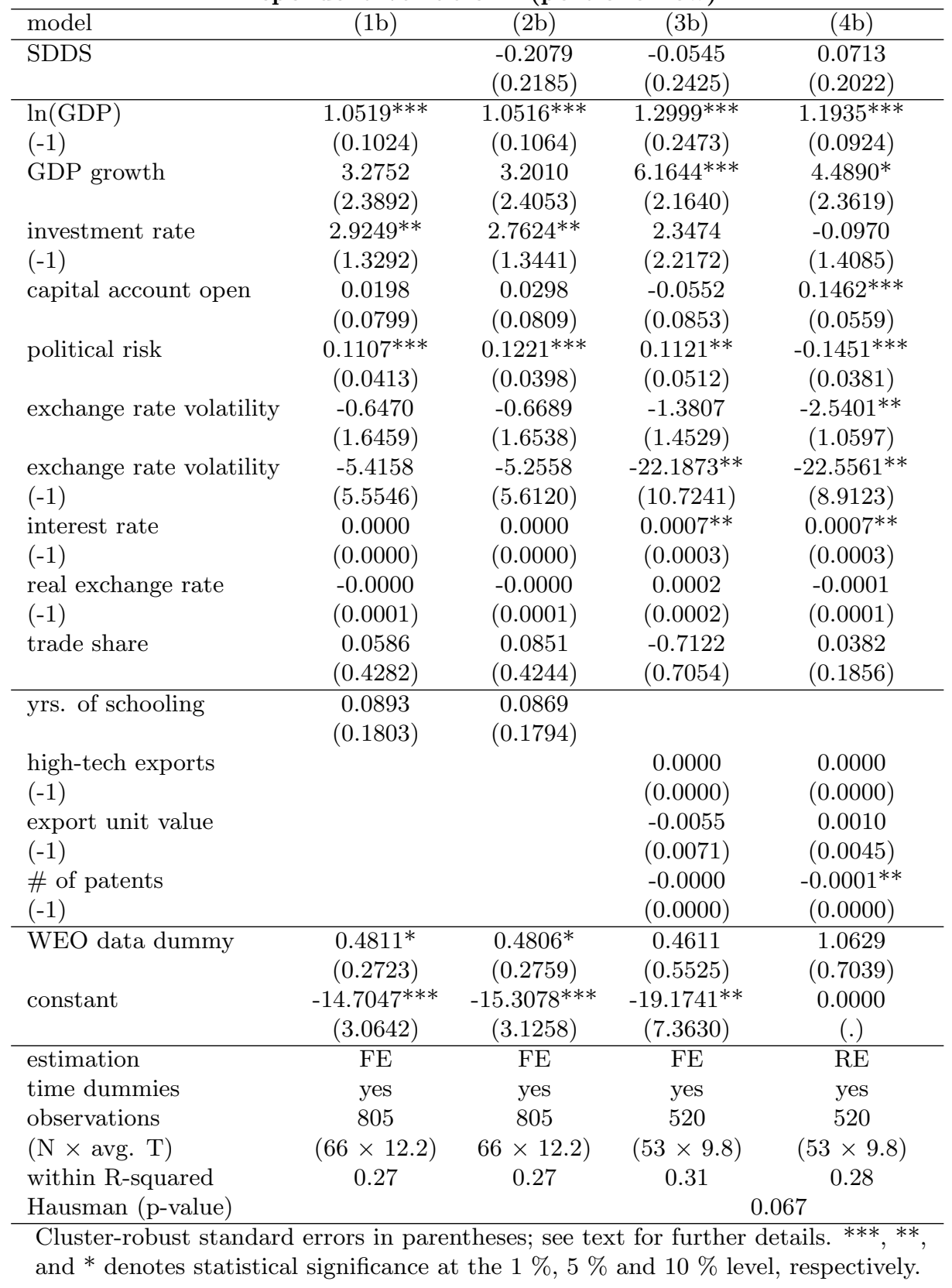




\subsection{Robustness and Further Results}

In section 3.3, I have estimated a highly significant effect of SDDS subscription on FDI inflows, obtaining a parameter estimate around 0.45 . The aim of this section is to investigate how appropriate the overall model specification and its identifying assumptions are and to check the robustness of the parameter estimate and its statistical inference. More precisely, I will investigate if there is an underlying timedependent process in an omitted variable that drives (or influences) the results, I will look how robust the parameter is to different specifications and subsamples, if the impact is persistent and how its dynamics work and whether there is spatial correlation in the residuals that might plague inference. Overall, neither the QQ and PP plot in figure 6 nor the kernel density estimate in figure 7 show any specific pattern in the residuals from the preferred model (3a), lending support to the overall model specification.
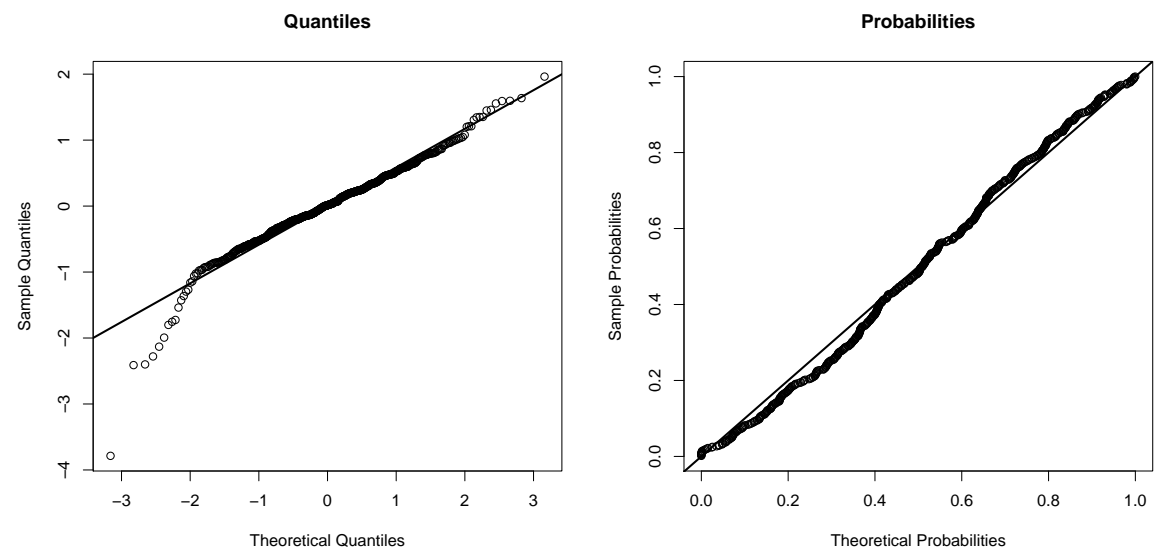

Figure 6: Plots for Normality of Residuals from Model (3a)

\subsubsection{Identifying assumptions and Potential Time-Dependent Omitted Variable Bias}

For further discussion of the statistical properties of the estimators used, I define a $N \cdot T \times K$ matrix $X$ that consists of $\Psi$, the (time and country) fixed effect dummy variables and the $S D D S$ dummy variable. Furthermore, let the parameter vector $\beta$ consist of the $K-1$ parameters for $\theta, \eta, \alpha$, and the parameter $\lambda_{S D D S}^{j}$ and let $\left.X\right\urcorner \alpha$ denote the columns of the $X$ matrix that do not include the country dummies $\alpha_{i}$. Then, assuming that

$$
\mathbb{E}\left(X_{i t}^{\neg \alpha} \alpha_{i}\right) \neq 0 \forall i, t,
$$

i.e. there is unobserved heterogeneity across countries correlated with the other variables in $X$, meaning that fixed effects is the operating model in equation (18), 


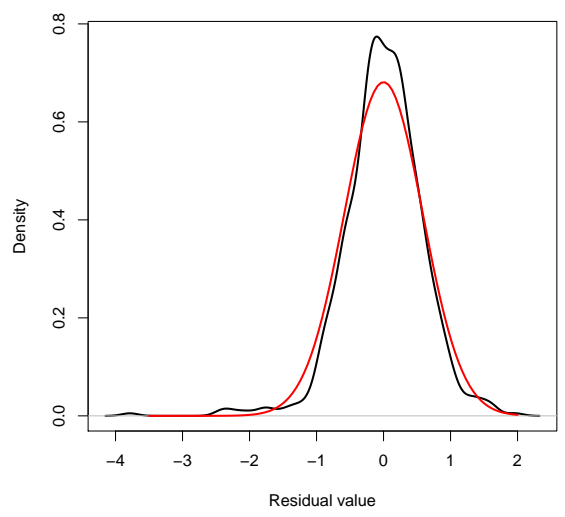

\section{Figure 7: Kernel Density Estimate for Residuals From Model (3a) With Corresponding Normal Distribution}

the main condition for obtaining an unbiased OLS estimator for $\beta, \hat{\beta}=\left(X^{\prime} X\right)^{-1} X^{\prime} y$, is

$$
\mathbb{E}\left(X_{i t} \varepsilon_{i t}\right)=0 \forall i, t
$$

because only then the same expression in $\mathbb{E}\left(\left(X^{\prime} X\right)^{-1} X^{\prime} y\right)=\beta+\mathbb{E}\left(\left(X^{\prime} X\right)^{-1} X^{\prime} \varepsilon\right)$ cancels out and leads to $\mathbb{E}(\hat{\beta})=\beta+\left(X^{\prime} X\right)^{-1} \cdot 0=\beta$. In the present case this means that there are no omitted variables that influence both, capital inflows and the decision to comply with SDDS and that causality does not run from capital inflows to SDDS compliance. One may think the latter is present: More investors in a country might push the government to provide more accurate data. However, the exclusion of this channel is pretty trivial: On one hand, SDDS is a multilateral initiative and most countries joined at a single point in time (1996), so exogeneity can be assumed. The concern that international investors grew very strong over time and pushed both FDI flows and the implication of SDDS in 1996 is controlled for by the time fixed effect. ${ }^{137}$ Furthermore, I look at the date when SDDS specifications are met by subscribers, which usually takes place three to four years after countries' subscription to SDDS so that the main explanatory variable is predetermined. ${ }^{138}$

The problem of omitted variables influencing both, capital inflows and SDDS subscription, is less trivial. This would lead to a self-selection bias because a country's decision to comply with SDDS is non-random. However, I should highlight that such omitted variables have to be country-specific and to vary over time. Moreover, they

\footnotetext{
${ }^{137}$ Also, this controls for cyclical push factors as discussed in footnote 95 on page 68 .

${ }^{138}$ In view of the results from chapter 2 , one may still argue that there is a certain level of serial correlation in capital flow data, but the country-fixed effect should take care of most of this negligible problem.
} 
will increase the probability of joining SDDS in later points of time (since once a country complies, the time dummy is set equal to 1 for all remaining observations) so they have to be variables that generally follow a time pattern. For example, assume one omitted to control for GDP and GDP would positively influence both FDI inflows and SDDS compliance. Then, one would have no problem with the fact that there are rich and poor countries in the sample because the fixed effects transformation takes care of this unobserved heterogeneity. Also, cyclical fluctuations in the world economy should not play a role (at least as long as they affect poor and rich countries similarly) since they are controlled for by the time dummy variables. However, if rich and poor countries have structurally different developments of GDP over time and GDP was omitted, its impact would go into the error term, $\varepsilon$ which will then be trended differently for subscriber and non-subscriber countries and since the SDDS dummy also follows a 'quasi-trend' (by changing to 1 in later periods in time), $\mathbb{E}\left(S D D S_{i t}^{\prime} \varepsilon_{i t}\right)>0$ and $\hat{\lambda}_{S D D S}$ will hence be upward biased. Following this line of reasoning, a trend in the unexplained part of the model that differs between subscriber and non-subscriber countries would be evidence of an omitted variable bias. To investigate this possibility, I estimate the model

$$
y_{i t}=\alpha_{i}+\Psi_{i t} \theta+\delta_{S D D S} t+\gamma_{n o n-S D D S} t+\varepsilon_{i t},
$$

for FDI flows up until certain points in time ${ }^{139}$ and perform a Wald test to check equality of parameters, $H_{0}: \delta_{S D D S}=\gamma_{n o n-S D D S}$. The estimates for the different parameters and the p-values of the F-statistic are displayed in table 9 . The results do not provide any evidence whatsoever that there would be an underlying time-dependent process that was omitted from equation (18) and influenced the probability of joining SDDS, i.e. there is no evidence for an omitted variable bias. ${ }^{140}$

\section{Table 9: Different Time Trends Between SDDS Subscribers and Non-Subscribers?}

\begin{tabular}{lcccc}
\hline before year... & 1996 & 1997 & 1998 & 1999 \\
\hline SDDS trend $(\hat{\delta})$ & -0.0764 & -0.0898 & -0.1173 & 0.0534 \\
non-SDDS trend $(\hat{\gamma})$ & -0.0468 & -0.0890 & -0.1295 & -0.0046 \\
\hline difference significant $(\mathrm{p}$-val)? & 0.563 & 0.989 & 0.822 & 0.377 \\
\hline observations & 150 & 190 & 234 & 278 \\
\hline
\end{tabular}

\footnotetext{
${ }^{139}$ If SDDS has a positive impact on FDI flows, there will obviously arise a differing trend once the effect takes place.

${ }^{140}$ Note that the power of this test will not necessarily be high and generally increase in $T$. However, after excluding all control variables in $\Psi$ from equation (27) one obtains p-values of 0.0135 (1996), 0.0076 (1997), 0.0057 (1998), and 0.0052 (1999), indicating that the test has at least some power in finding an omitted variable bias.
} 


\subsubsection{Parameter Robustness}

Another way to look at the problem of selection bias is to check what would happen to model (3a) after excluding the early subscribers from the sample. Countries that experience developments in potentially omitted variables influencing both SDDS subscription and FDI inflows should be those that are more likely to join early. The parameter estimate obtained when excluding the bulk of countries that subscribed to SDDS in 1996 is presented in the first column of table 10 and equals 0.50. Still being statistically significant, this is very strong evidence for the finding that SDDS has a strong positive impact on FDI inflows since the number of observations decreases considerably. ${ }^{141}$

Since subscribers will generally improve their data quality already after (or even slightly before) subscription to SDDS and it may take a while before official specifications are met, I also look at the impact when the dummy variable starts equaling 1 after countries subscribe to SDDS. As one can see from column 2 of table 10, most of the action seems to take place after subscription already. I will have a closer look at these dynamics in the following subsection 3.4.3.

Finally, I allow the parameter estimate to vary between different country income categories based on the World Bank classification 1987. I find that the impact of SDDS was stronger for high income countries (0.69) than for upper medium $(0.20)$ and lower medium (0.22) countries and that the fit of this extended model is "better" in terms of standard model selection criteria (AIC/BIC) and a likelihood ratio (LR) test statistic (13.24 with 2 degrees of freedom). Since the parameter estimate for upper medium and lower medium countries is fairly similar, I perform the same exercise comparing this extended model to one that has one parameter estimate for high income countries and another one for all other countries. I find the latter to outperform the extended model along all three lines (LR statistic 0.01 with 1 degree of freedom), so I report the corresponding coefficients of the latter in the last column of table 10. One can see that the impact of SDDS on FDI inflows is in fact driven by high-income countries. This, however, should not be too surprising: Economically, the better the overall performance of the economy, the better capital markets will respond to the provision of data. Statistically, most SDDS subscribers are high-income countries so that parameter identification is easier for these countries. This result does not imply that countries with a lower income level could not benefit from SDDS or from the signaling of macroeconomic data. In fact, the estimated parameter for other countries is still positive and economically relevant $(+23$ percent $)$ and the estimated standard error is of reasonable size (t-statistic 1.33). The result, however, highlights that data-provision on its own will not be sufficient to acquire FDI inflows but should be based on sound macroeconomic fundamentals. ${ }^{142}$

\footnotetext{
${ }^{141}$ Only 19 countries remain in this sample. When 1998 subscribers are excluded (in 1997, Portugal was the only subscribing country), the parameter estimate becomes 0.45 , being highly statistically significant.

${ }^{142}$ Since SDDS compliance for most countries took place within a relatively narrow time frame, one could also argue that capital was not abundant enough to raise the capital stock
} 


\section{Table 10: Parameter Robustness}

\begin{tabular}{lccc}
\hline SDDS (general) & $0.5016^{* *}$ & $0.4935^{* *}$ & 0.2056 \\
& $(0.1907)$ & $(0.2362)$ & $(0.1550)$ \\
SDDS (high inc) & & & $0.6905^{* * *}$ \\
& & & $(0.2340)$ \\
\hline Note & w/o 1996 & subscr. instead & parameter \\
& subscribers & of compl. & heterogeneity \\
\hline observations & 160 & 634 & 587 \\
\hline
\end{tabular}

\subsubsection{Dynamics}

As found in the preceding subsection 3.4.2, the impact of SDDS seems to start happening once countries subscribe to SDSS. I investigate the dynamics of the effect by first introducing dummy variables that that are specific to SDDS subscribers and measure the impact on FDI flows at each year before and after subscription. More precisely the model

$$
y_{i t}^{j}=\Psi_{i t} \theta^{j}+\eta_{t}^{j}+\zeta_{t}^{j}+\alpha_{i}^{j}+\varepsilon_{i t}^{j},
$$

is estimated with the same controls as in model (3a), where $\zeta_{t}$ is a SDDS subscriberspecific time dummy. The interpretation of this variable is the effect of subscription, conditional on other factors, at time period $t$. The results are depicted in the left panel of figure 8, where the subscription year is taken as reference year 0 . As can be seen, in the first four years after subscription, capital inflows considerably increase but the impact does not remain as robust thereafter with negative estimates for the years 5 and 7 and an overall picture that suggests somehow increased inflows.

Since year-specific effects are probably too volatile because they might be influenced by various other noise steaming from 'global' effects in the specific years or different countries having somewhat differing dynamics, I also construct period-specific dummies, that is a dummy that is equal to 1 at the year of subscription and two years thereafter (period 1), 3 to 5 years (period 2), 6 to 8 years (period 3), and 8 to 10 years (period 4) after subscription, respectively. Furthermore, I control for effects in the three years prior to subscription (period 0). The overall picture in the right panel of figure 8 is less volatile but shows the same general pattern as before: Most of the increased inflows occur in the first years after subscription, the effect decays afterwards but suggests slightly higher FDI inflows also at later periods in time.

In fact, this is also the dynamic one would expect from a theoretical perspective: Increased information should result in a permanently higher capital stock and to reach

in all countries to the new, higher, equilibrium level simultaneously. Under this restriction it seems reasonable that risk averse investors focus on the supposedly save havens in high income countries. 

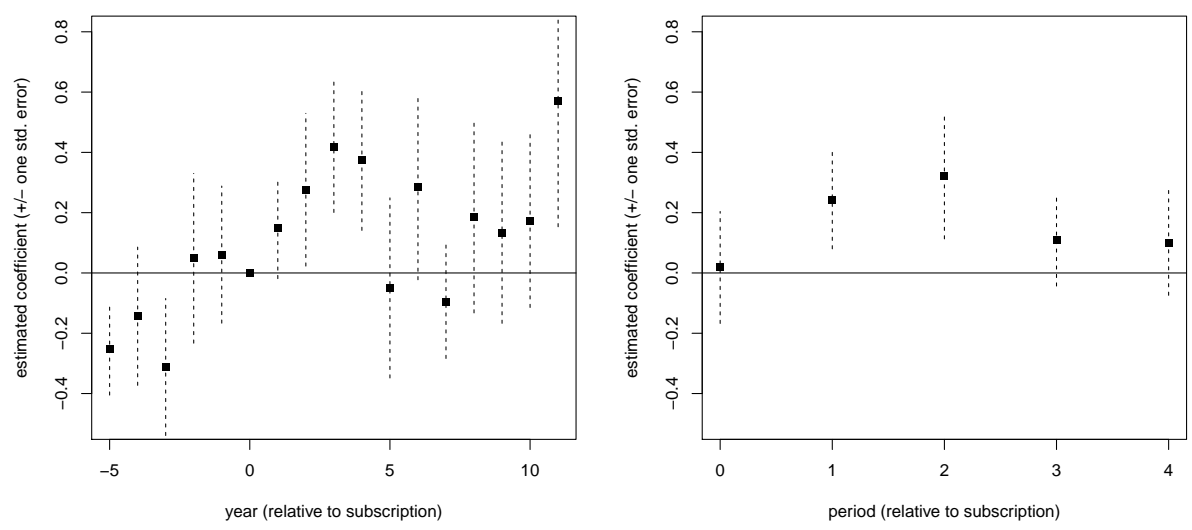

Figure 8: Dynamic effects of SDDS subscription

this higher stock level, an adjustment process has to take place once, which operates through increased inflows. After the new equilibrium level is reached, inflows should only be slightly higher in subscriber countries since replacement of the (now increased) capital stock will be higher than otherwise (cf. chapter 2). ${ }^{143}$

Finally, I also perform a recursive regression to investigate the stability of the estimated parameter (about 0.45 ) but also with the objective to gain more insights into the dynamic process taking place. The idea originates from the time-series context and progressively enlarges a subsample of the sample to look if the estimated parameter changes dramatically. The results are depicted in figure 9. For example, the solid line depicts the estimated coefficient of 0.45 to the very right, when the sample includes all years up to 2008, because this is the last year in the overall sample. As one can see, the effect is particularly strong when the sample is limited until 1999 which was the first year some subscribers met the SDDS specifications. After this, the impact decreased to about 0.25 and recovered when years after 2004 were included. Note that the line does not depict the impact of SDDS at specific years but when the sample is truncated at those years.

Since recursive regressions are derived under time-series assumptions while I have asymptotics where $N \rightarrow \infty$ first, the results of this exercise should not be overrated with respect to inference. However, I think the figure tells an important story: Countries that were eager to quickly signal their data to markets will most likely

\footnotetext{
${ }^{143}$ Harding and Javorcik (2011, footnote 25 on p. 1460) find that the positive effect of investment promotion agencies in developing countries increases over time. However, in their case support with bureaucracy and not with informational frictions is likely to be the driving factor.
} 


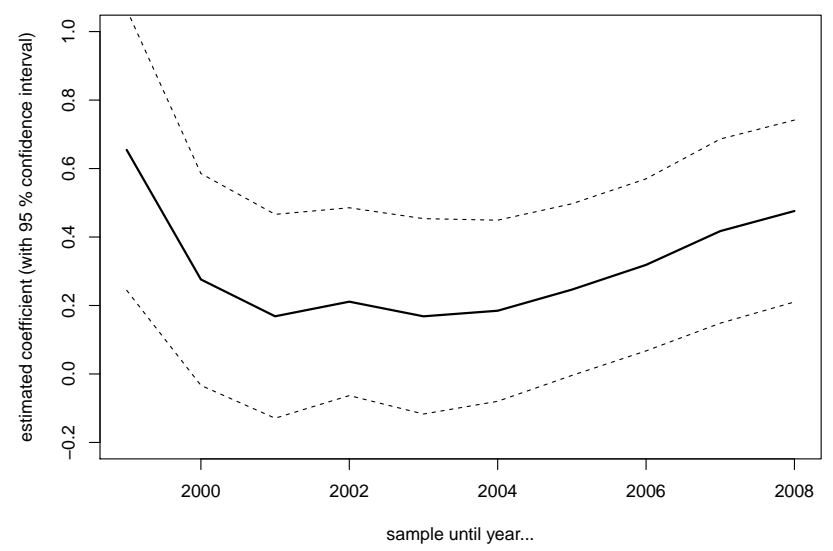

Figure 9: Recursive Regression

have had strong fundamentals; the impact of meeting the SDDS specifications will since be stronger. After them (i.e. after 1999), countries that met the specification might have also signaled less promising data so that the impact was not so strong (or even inexistent) for them, the overall parameter being a mixture of these types of countries. However, compliance with SDDS and increased screening by financial markets might have increased the pressure on these countries to bring their economic fundamentals in order, so that the impact would also turn (more) positive for these countries after several years. This can be seen from the increase in the parameter estimate when the sample reaches beyond 2004: It shows that the impact converges to the economically relevant parameter of 0.45 over the years also for countries that might have had weaker macroeconomic fundamentals in the first place.

\subsubsection{Spatial Correlation Patterns}

Finally, I estimate the spatial correlation pattern as outlined at the end of section 3.2.6. Figure 10 depicts the relationship between the correlation of (standardized) residuals from equation (18) and distance using a local average estimator with a window of $7,500 \mathrm{~km}$ (left panel) and a smoothing spline (right panel), respectively. As one can see, the spline function is much more smooth and hence gives a picture that is easier to interpret overall: There seems to be negative spatial correlation in the residuals that tends to increase if distance gets large.

However, as one can see from the scale of both figures, the correlation is fairly small and I hence test if it is in fact statistically significant using $B=1,000$ bootstrap replications. Figure 11 puts the estimated correlation into perspective: On this scale, the smoothing spline does not show any significant pattern or deviation from 0 and it 

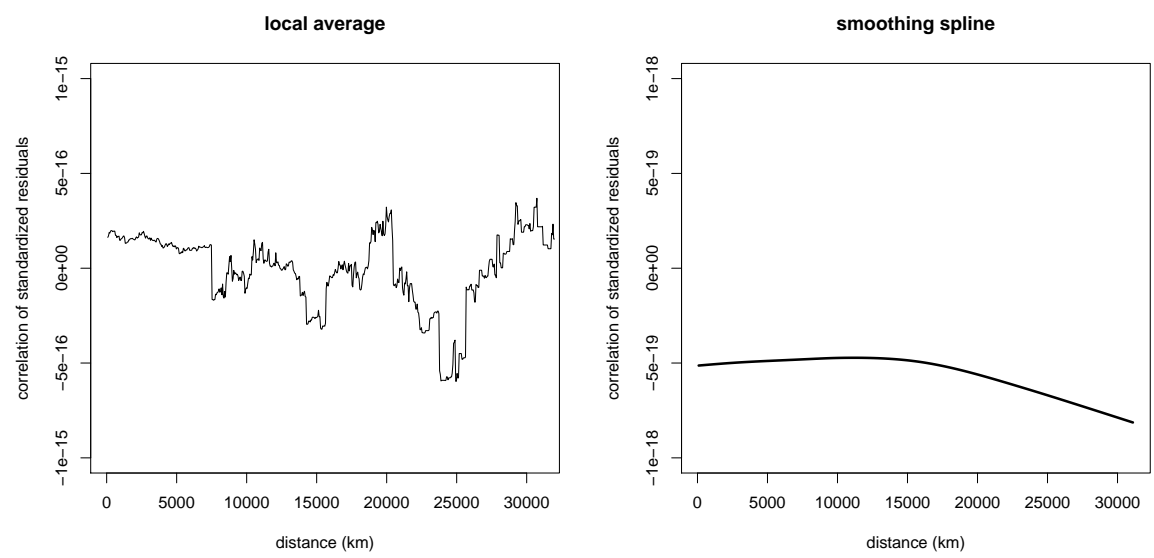

Figure 10: Spatial Correlation of FDI Residuals

does by no means reach a level that is beyond randomness so that one could not reject the null hypothesis of no spatial correlation in the residuals. This means, the inference in the empirical models is not plagued by spatial correlation in the residuals.

\subsection{Discussion and Conclusion}

\subsubsection{Main findings}

This analysis has shown that countries which committed themselves to provide macroeconomic data with a certain accuracy and timeliness, as requested by the IMF's Special Data Dissemination Standard, received more foreign direct investment inflows than other countries. The impact that accounts for a set of standard control variables, time- and country-specific effects, is both statistically significant and economically relevant: Compliance with the SDDS increases FDI inflows by about 60 percent. $^{144}$

The most important impact occurs in the first years after subscription to (or compliance with) the SDDS, especially for those countries that are able to submit data which is solid not only with respect to technical accuracy, but also considering the underlying economic fundamentals. Most industrialized countries hence experience

\footnotetext{
${ }^{144}$ This may seem large on a first view. But the impact of information is found to be large also by other studies: Gelos and Wei (2005, p. 2997) exemplify that a country like Venezuela could more than triple their weight in portfolio holdings by increasing its transparency to Singapore's level. Harding and Javorcik (2011) find that sectors targeted by IPAs in developing countries receive 155 percent more FDI inflows. Also note that the result does not imply an increase in stocks by 60 percent as discussed in subsection 3.4.3.
} 


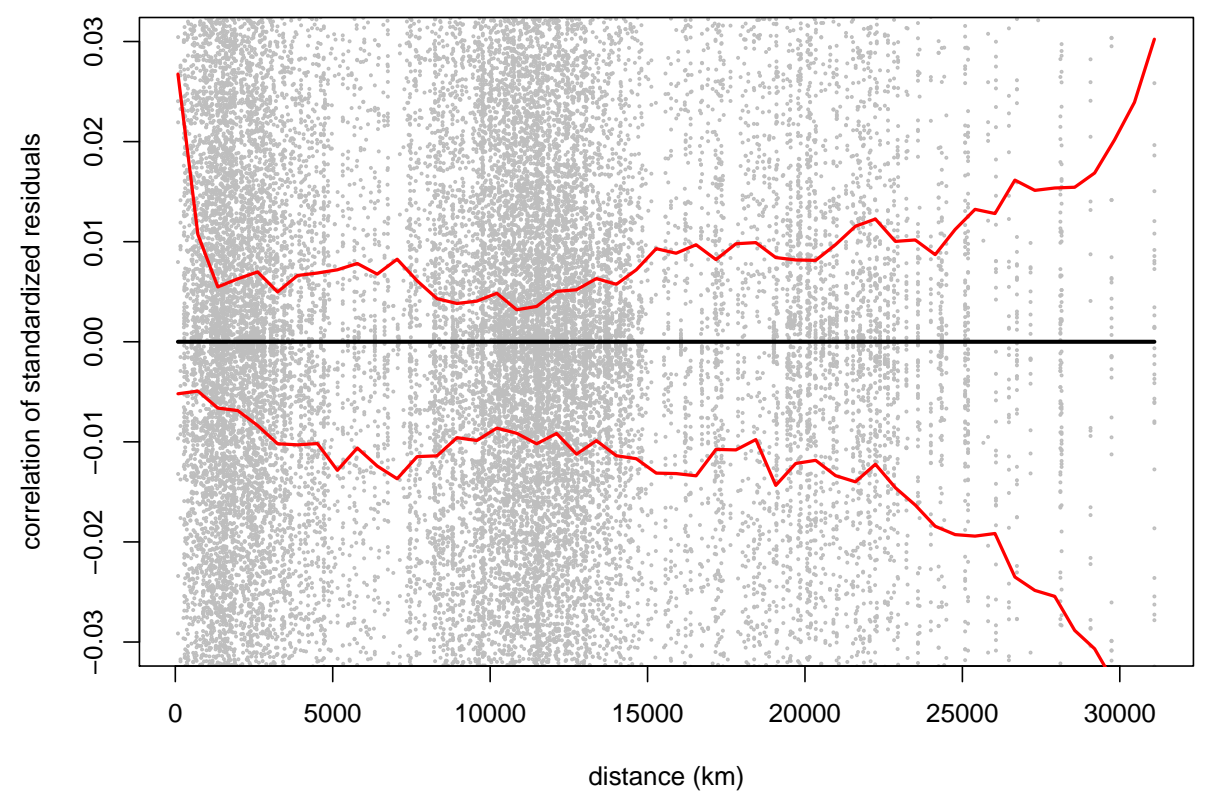

Figure 11: Smoothing Spline Estimate of Spatial Correlation in FDI Flow Residuals with 90 Percent Pointwise Confidence bands based on 1,000 bootstrap replications

an even larger impact of 100 percent as reported in table 10, while the comparable impact for other countries that do not possess such strong fundamentals may be somewhat above 20 percent. However, the results also indicate that in the longer run these countries can also catch up to the overall parameter of $60 \%$, probably driven by the fact that once financial markets are monitoring macroeconomic and financial data, there is a stronger incentive for countries to get these fundamentals straight.

Foreign portfolio and direct investment flows both shy away from political and macroeconomic risk, though political risk does not seem to matter much for FDI in the most advanced countries and the aversion against macroeconomic risk in the form of exchange rate volatility is less robust for portfolio investment.

\subsubsection{Relation to Other Findings in the Literature}

These main findings are generally in line with the result of Daude and Fratzscher (2008) that FDI is more responsive to information than other forms of capital flows. Supplementary to their mentioned arguments I should highlight that information 
about the macro environment is probably more important for FDI than for portfolio investment because the latter will usually focus more on firm-level information whereas a MNC will usually apply its own firm-specific assets and be more concerned about the overall market perspectives for its products. ${ }^{145}$ However, acquiring information privately is costly for these multinational firms ${ }^{146}$ because they are specialized in producing something else and cannot benefit from the positive externalities of informational investment. But portfolio investors are supposed to acquire information and this is essentially what portfolio funds are paid for. As the model of van Nieuwerburgh and Veldkamp (2009) points out, investors profit more from information others do not know. Especially large institutional investors might have an incentive to acquire information about potential host countries on their own. They may therefore lose short-run arbitrage gains from informational asymmetries once information is provided as a public good. On the other hand, smaller investors with more long-run perspective, that cannot acquire information on their own, may enter the market based on this public information. ${ }^{147}$ In our analysis, these two opposing public information effects on portfolio investment might simply offset each other resulting in an overall impact that is small and statistically not significantly different from zero. Hence, my findings do not necessarily contradict the results of Gelos and Wei (2005) that emerging market portfolio funds respond positively to information because their sample may only capture one third of the total portfolio flows to the relevant countries (p. 2989) and their specific measure for macrodata opacity, which is most comparable to my SDDS measure, loses statistical significance when including fixed region effects (p. 3002). It is also questionable if the results of Milesi-Ferretti and Lane (2004) are necessarily in contrast to the findings of this chapter. The authors find that a number of cultural and physical proximity variables positively affect bilateral portfolio equity holdings and argue that this should proxy for information effects. As discussed in section 3.2, however, there can be serious doubts whether variables such as distance, common language or colonial ties are convincing measures to explicitly identify informational content.

The results somewhat question the related finding of Daude and Fratzscher (2008) and other studies mentioned in their paper that capital account liberalization has no impact on $\mathrm{FDI}^{148}$ and my results can neither substantiate nor contradict their

\footnotetext{
${ }^{145}$ This assumption that can neither be supported nor dismissed by the findings of Gelos and Wei (2005, p. 3000f).

${ }^{146}$ Harding and Javorcik (2011, p. 1450f.) describe the FDI decision process in more detail: A list of potential host countries is usually restricted to 8-20 countries which is still narrowed down to up to five potential host countries, which is usually done without visiting the potential host. This highlights the importance of public information to come up with potential host countries in the first place.

${ }^{147}$ Ausubel 1990, suggests that if outsiders can assume that - due to increased macroeconomic information - insiders cannot take as much advantage of them, they may increase their investment.

${ }^{148}$ One potential explanation is that they use a cross-section 'pseudo'-fixed effect model where they try to explain the host country fixed effect by some country characteristics in the second step, in this case by the IMF's Annual Report of Exchange Arrangements
} 
finding that portfolio responds stronger to political risk, although their framework is generally more sophisticated to address the specific differences between different forms of capital flows.

\subsubsection{Further Results}

This study empirically supports the distinction of foreign portfolio from direct investment flows in the BOP - while it should be clear from a theoretical perspective that portfolio and FDI are very different concepts, I find empirical evidence that the elasticity of portfolio investment toward current market size is significantly higher than for FDI. I also find evidence of other differences between portfolio and FDI flows, most notably their contrary response toward the interest rate, highlighting that FDI is not simply a capital flow but also that finance aspects should play a more important role in the (micro-)economic attempt to understand the behavior of the multinational firm. The study also suggests that the empirical modeling of (firm demand for) education should probably focus more specific on know-how in sectors with comparative advantages and shows that spatial correlations do not play a significant role when FDI flows are estimated at an aggregate level using fixed effects. ${ }^{149}$

\subsubsection{Perspectives on Further Research and Policy Issues}

These results highlight the need for further, more disaggregated research about the role of information for portfolio (and potentially other forms of) investment. As mentioned above, the finding that there is no significant overall effect does not imply that the structure of portfolio investment stays unaffected. Informational asymmetries may attract market makers and hence more short-term oriented portfolio flows which would generally result in more volatility in capital markets (cf. e.g. Diamond and Verrecchia 1991; Du and Wei 2004) which, in turn, can cause adverse externalities (cf. Bianchi 2011). Public provisioning of more accurate and timely economic and financial data is hence a potentially important macroeconomic tool to manage capital inflows since it may attract more long-term oriented portfolio flows and the results strongly suggests that it will attract substantially more FDI which is generally seen as one of the most advantageous forms of capital inflows. This should result in a more sustainable and healthy IIP and hence help to lessen the degree of disequilibrium in the international BOP and to develop the productive resources of capital-scarce countries.

and Exchange Restrictions (which is also one source of the Chinn-Ito index I use). Such a cross-section approach assumes that there are no omitted variables and that the system is in equilibrium at the year of investigation. However, especially for FDI, where capital transaction costs are higher, the actual stock will be a cumulation of (depreciated) past flows and hence influenced by past (and unobserved) policies towards capital account openness.

${ }^{149} \mathrm{I}$ also did not find a significant spatial pattern in the residuals of the random effects specification. 


\section{The Impact of FDI on Developing Countries' Terms of Trade}

II n'est pas plus immoral de voler directement les citoyens que de glisser des taxes indirectes dans le prix de denrées dont ils ne peuvent se passer. ${ }^{150}$

\section{A. Camus - Caligula}

\subsection{Introduction}

Surges in capital flows to developing economies throughout the last years posed serious macroeconomic challenges to their policymakers (cf. IMF 2011b; Ostry et al. 2011; Unsal 2011) and are likely to persist (Miao and Pant 2012). A considerable of these flows come in the form of FDI of MNCs. While there is widespread consensus in economics that these flows can entail positive micro-level effects, ${ }^{151}$ the evidence is less clear from a macro perspective. ${ }^{152}$ Against this background, Li et al. (2007) raise concerns that large FDI inflows were responsible for China's terms of trade to deteriorate.

Such a negative relationship between FDI inflows and net barter terms of trade in developing countries would be harmful since the latter reflect a country's export prices relative to its import prices and hence their decline acts similar to an indirect tax on imported goods and implies a decreasing purchasing power of a country's exports. This would ceteris paribus directly cause the real income of an economy to decline and will increase the import price of other investment goods (see De Long and Summers 1991; Levine and Renelt 1992) and therefore hamper economic growth in the longer run (cf. Harrison and Rodríguez-Clare 2009, p. 53; Barro 1996, provides empirical evidence). Accordingly, a large time-series literature has emerged based on the seminal work of Prebisch (1950) and Singer (1950), trying to address the question whether there is a deterministic long-run decrease in developing countries' export prices. ${ }^{153}$

Probably even more important than countering a long-run decline in terms of trade is to battle their volatility. Mendoza (1995), for example, estimates that terms-oftrade shocks account for nearly $50 \%$ of GDP variability. Kose (2002) shows that world price shocks of primary products relative to capital goods account for more than $88 \%$ of business cycle variability in small open developing countries. Broda (2004) finds that the impact of terms-of-trade disturbances on real GDP fluctuations depends on the exchange rate regime and estimates smaller influences of 30 and 10 $\%$ for fixed and floating regimes, respectively. Blattman et al. (2007) find further

\footnotetext{
150 'Note, besides, that it is no more immoral to directly rob citizens than to slip indirect taxes into the price of goods that they cannot do without.'

${ }^{151}$ Lipsey (2002) provides a survey on wages and employment.

${ }^{152}$ Cf. Herzer et al. (2008), for the case of growth.

${ }^{153}$ The most influential contributions include Spraos (1980); Sapsford (1985); Thirlwall and Bergevin (1985); Grilli and Yang (1988); Cuddington and Urzúa (1998); Powell (1991), and Reinhart and Wickham (1994). Kim et al. (2003); Harvey et al. (2010), and Ghoshray (2011) were among those to address the issue more recently.
} 
evidence that terms-of-trade volatility has a more important impact on developing countries' growth prospects than has their long-run trend. As Brückner and Ciccone (2010) point out, terms-of-trade shocks can also seriously abate other aspects of human development: They investigate 39 Sub-Saharan countries between 1960/80 and 2006 and find that a $25 \%$ drop in their international commodity price index over a 3-year period raises the probability of civil war onset by $50 \%$ of the background probability. Finally, Bird (2007) concludes that terms-of-trade shocks significantly increase a developing country's probability to suffer balance-of-payment problems to an extent that it has to turn to the IMF as the lender of last resort. Other recent contributions such as UNCTAD (2005); Baxter and Kouparitsas (2006), and SantosPaulino (2010) have also addressed the issue of developing countries' terms-of-trade volatility. The aim to stabilize terms of trade and the interpretation of Cuddington and Urzúa (1998, p. 438ff) that terms of trade follow a stochastic trend model and thus respond to exogenous shocks raise the question about external factors influencing a country's terms of trade.

Previous economic work that is discussed in section 4.2 established a link between the operations of multinationals and terms of trade but has not come to precise statements about the theoretical impact of MNCs on terms of trade. After introducing data and methodology in section 4.3, the issue is thus addressed empirically by investigating data of more than 50 developing countries between 1980 and 2008. The results in section 4.4 show that concerns about MNCs, measured by FDI, deteriorating developing countries' export prices are generally not justified from an empirical perspective. On the contrary, FDI had a statistically significant positive impact on developing countries' net barter terms of trade (NBTT) and actually countered their long-run decline by about $50 \%$ throughout the period of investigation. Section 4.5 concludes.

\subsection{Multinationals and Terms of Trade - A Theoretically Unclear Link}

\subsubsection{Prebisch and Singer on Multinationals and Terms of Trade}

In 1949, Hans Singer published a series for the United Nations showing the price of primary commodities to deteriorate relative to manufactured goods over the period 1876 to 1938 which initiated the Singer-Prebisch hypothesis. ${ }^{154}$ Although his seminal interpretation of this finding (Singer 1950) has been widely cited in economics, only few have paid more attention to the title - "The Distribution of Gains between Investing and Borrowing Countries". Thereby, Singer clearly means foreign direct investment and raised concerns that it would bring about a certain "type of foreign trade" (Singer 1950, p. 483) that keeps the FDI-importing developing country in an export-specialization poverty-trap through falling terms of trade (1950: 477).

Prebisch' $(1950 ; 1959)$ interpretation of labor market asymmetries between a highly organized North and a Lewis-type South has found more attention in the literature

\footnotetext{
${ }^{154}$ For the origins of the hypothesis see Toye and Toye (2003).
} 
but it has barely been noticed that Prebisch (1950, p. 13-14) himself thought of these asymmetries as merely bringing into force an underlying mechanism of profit transfer (in the form of FDI and other capital flows) that operates through the business cycle. From a modern perspective on the multinational firm, one could also re-interpret a part of Prebisch' (1950) ideas as a firm's "hold-up problem:" vertical FDI in the South is motivated by imperfect competition in the upstream market that leads to an output level under the perfect-market equilibrium. The multinational firm enters the market to increase production which would ceteris paribus lead to a price decline and thus a fall in the Southern terms of trade.

Both main initiators of the terms-of-trade debate, Singer and Prebisch, have thus at least implicitly linked the issue to the activities of multinational corporations. ${ }^{155}$

\subsubsection{Expanding the Macro Transfer Problem}

Macroeconomic theory establishes a completely different relation between FDI and terms of trade that dates back to the discussion between Ohlin (1929) and Keynes (1929) about the German transfer problem: As an income transfer, FDI will lead to a higher purchasing power of the host country. ${ }^{156}$ If the marginal propensity to spend in the host country is in favor of the imported and against the domestic good, the relative demand for the domestic good will decrease, resulting in a decrease in terms of trade.

Although other studies reflected the transfer problem of monetary flows (cf., inter alia, Bhagwati et al. 1983; Martínez-Zarzoso et al. 2009; Darity et al. 2010), it should be stressed that the problem assumes the recipient's demand to be large enough to influence world-market prices and it is thus more than questionable whether the developing countries' excess-income generated by FDI is relevant enough to significantly influence global goods' prices. Probably more important than the demand effect of FDI is its supply response: Assuming that FDI does not simply replace domestic production, the relative supply of the developing country's export good will increase if the FDI is vertical in nature (cf. footnote 12 on page 20) and will decrease in the case of horizontal FDI. Given that global supply of MNCs is relevant in size, the relative price of the developing country's export good, i.e. the country's terms of trade, will decrease in the first case but increase in the latter.

\subsubsection{Impacts on the Micro-Level}

Most microeconomic considerations suggest a positive relationship between FDI and terms of trade: It is well-known that MNCs pay higher wages than domestic firms

\footnotetext{
${ }^{155}$ For a more comprehensive discussion of these ideas and channels, see Wacker (2011, pp. 8 ff.).

${ }^{156}$ From a BOP approach, FDI is obviously not a transfer. However, insofar as FDI generates supplementary income via spillover effects and higher wages in the host economy, it will have similar impacts as a transfer. Also, it may shift consumption from the future to the present and hence cause intertemporal terms-of-trade effects.
} 
(cf. e.g. Lipsey 2002, for an overview) and to the extent they are reflected in the final good's (export) price, this leads to more favorable terms of trade for the FDI host country. Since MNCs usually also produce more sophisticated goods than domestic producers and also demand more sophisticated inputs, their presence may lead to upgrading effects in the host economy. If this upgrading effect is not taking place between product groups but within a product group, this violates the assumption of homogeneous goods that is necessary to construct consistent price indices and the upgrade will thus show up as a terms-of-trade increase (cf. equation (32) on page 103 for the calculation of NBTT). Finally, structuralist reasoning about terms of trade (cf. Emmanuel 1972; Raffer 1987) highlighted the multinational's market power for terms-of-trade formation: According to this viewpoint, Northern producer's pricing power enables them to beat down developing countries' prices leading to a termsof-trade decrease for the latter. Following this rationale, one would expect FDI to have a positive impact on developing countries' terms of trade since by establishing an affiliate in a host country, the firm also "exports" its proprietary asset (and thus the pricing power) to the developing country.

\subsubsection{Terms of Trade in the Long Period}

Since most of these arguments only concerned the short run, Findlay (1980) set up a long-run equilibrium model (where growth is the same in the North and the South) to explain terms-of-trade movements and interestingly finds that they are independent of the North's mark-up. However, in his framework saving equals investment for both regions separately so that there is no international capital transfer, which he considers as one of the major limitations of the model.

In an attempt to overcome this problem, Darity (1990) derives a "long-period" model where capital moves (from North to South) and profit-equalization among all industries is the equilibrium condition. The equilibrium terms of trade are then equal to the ratio of the respective marginal products of capital:

$$
\theta^{*}=\frac{f^{\prime}\left(k_{N}^{0}\right)}{\pi^{\prime}\left(k_{S}^{*}\right)},
$$

where $\pi$ is the intensive form of the South's aggregate production function, $k$ is the capital-to-labor ratio and hence $\pi^{\prime}\left(k_{S}^{*}\right)$ is the marginal product of capital in the South. Equation (29) is remarkable for two reasons: First of all, Darity Jr. shows that it has a representation that includes the Northern mark-up but that the direction of the effect is theoretically unclear because it depends on other parameters of the model that are not predetermined. Secondly, the impact of FDI on $\pi^{\prime}\left(k_{S}^{*}\right)$ is also unclear: As long as FDI does not simply crowd out domestic investment, the capital-intensity of the South will rise and under $\pi^{\prime}\left(k_{S}\right)>0, \pi^{\prime \prime}\left(k_{S}\right)<0$ this leads to a decrease in the denominator, whereas one would expect FDI to also bring along more sophisticated techniques of production that lead to an increase in the marginal product of capital and a priori one does not know which of the two effects will be more important. ${ }^{157}$

\footnotetext{
${ }^{157}$ More formally, FDI will increase both $K$ and $A$ in a CRTS Cobb-Douglas produc-
} 
In summary, economic theory suggests that there exists a relationship between FDI in developing countries and their terms of trade. But the direction and magnitude of this relationship remains unclear. The subsequent part of this chapter therefore explores this relationship empirically and also tries to shed light on possible economic channels that can be explored in more detail in future research, both empirically and theoretically.

\subsection{Data and Methodology}

In line with the literature reviewed above, the focus of this paper is on developing countries which in this context means countries classified as "low income" or "lower middle income" by the World Bank classification 1987, the first year available. The list of countries included can be found in Appendix C. Data generally ranges from 1980 to 2008 , though missing values for many control variables restrict the sample size.

The main exercise is to investigate whether net barter terms of trade, NBTT, given a set of control variables, $\Psi$, depend in some functional form $f$ on the activity-level of multinational corporations, denoted as FDI, in the host economy:

$$
\mathbb{E}(N B T T \mid \Psi)=f(F D I)
$$

\subsubsection{Terms of Trade Data}

I take a country's net barter terms of trade (NBTT) index, as reported by World Bank (2010b) WDI, as a measure for export prices to import prices. More precisely, NBTT are defined as the ratio of the export unit value indices to the import unit value indices:

$$
N B T T=U V I_{x} / U V I_{m},
$$

where a unit value index $U V I$ for product group $i$ in period $t$, relative to a reference period 0 is given for comparison over $m=1, \ldots, M$ prices, $p_{m}^{t}$, and quantities, $q_{m}^{t}$, in period $t$ and over $n=1, \ldots, N$ prices, $p_{n}^{0}$, and quantities, $q_{n}^{0}$, in period 0 , where $m$ and $n$ are drawn from the same set (of $i$ ) and is defined by (cf. Silver, 2010: S209):

$$
U V I^{i}\left(p^{0}, p^{t}, q^{0}, q^{t}\right)=\frac{\sum_{m=1}^{M} p_{m}^{t} q_{m}^{t}}{\sum_{m=1}^{M} q_{m}^{t}} / \frac{\sum_{n=1}^{N} p_{n}^{0} q_{n}^{0}}{\sum_{n=1}^{N} q_{n}^{0}} .
$$

Export and import values are current values of exports (free on board) and imports (cost, insurance, freight), converted to US-\$, and quantities represent the most recent trade structure available. Unit values are then indexed with $2000=100$.

tion function, leading to opposing effects in its marginal productivity of capital, $\pi^{\prime}\left(k_{S}^{*}\right)=$ $\alpha A(L / K)^{1-\alpha}$. 
Two important things should be highlighted. First of all, this measure is different from the commodity terms of trade that Prebisch and Singer originally had in mind and that tried to capture the price relation of different types of products. Starting with Singer (1975), however, the debate shifted towards structural differences in export prices between different types of countries which found empirical support by studies such as Grilli and Yang (1988); Powell (1991); Sarkar and Singer (1991, 1993); Lutz (1999) and Ziesemer (2010). The measure has the advantage of capturing the whole export structure of the respective countries and not relying on single primary commodities. Secondly, unit values will only be a correct price measure as long as goods within all categories of $n$ (and $m$ ) are homogeneous. Country statistical offices take unit values from customs data, available to them up to the 10-digit Harmonized Commodity Description and Coding System - especially in developing countries at a more aggregated level. There is an extensive literature on the bias in unit values as price indicators resulting from the fact that due to this aggregation they capture price and compositional quantity changes (IMF 2009b, p. 71ff.; cf., inter alia, Lipsey 1994; $\mathrm{Yu}$ and Abler 2009; Silver 2010; McKelvey 2011). The bottom line of this literature, however, does emphasize that national authorities can collect unit values at relatively low costs and that they are hence widely available, especially for developing countries (e.g. Silver 2010, p. S211) so that their use in this study is justified, especially since the previous literature on terms of trade has also relied on these indices.

\subsubsection{Data on MNC's Activity (FDI)}

For measuring the importance of MNCs' activity in a host economy I also follow conventional rules (cf. Barba Navaretti and Venables 2006, p. 2 and chapter 2 of this dissertation) by taking foreign direct investment data from UNCTAD FDIstat, based on its World Investment Report 2009. More precisely, I take stock data as percentage of GDP since this captures the actual value of capital and reserves (including retained profits) attributable to the multinational's parent enterprise (plus the net indebtedness of affiliates to the parent enterprises) relative to the size of the host economy and thus provides a good measure of the MNCs' relative importance in the host economy.

Figure 12 depicts the development of FDI stock / GDP (average weighted by GDP in constant prices) and of NBTT (unweighted average) ${ }^{158}$ in developing countries over the time period under investigation. Indeed, this simple picture might suggest a negative relationship between NBTT and FDI: While the latter rose until the early 2000s, NBTT suffered a steady decline. When developing countries' NBTT stabilized and started to increase after 2000, this happened at a time when the FDI stock remained fairly static at a level of approximately $20 \%$ of GDP.

\footnotetext{
${ }^{158}$ Since FDI stocks are more volatile and small countries with very high levels of FDI inflows may dramatically change the picture, a weighted average is taken. The problem does not exist for NBTT, where a weighted average might cause discontinuity in the series when large countries exit or enter the sample.
} 


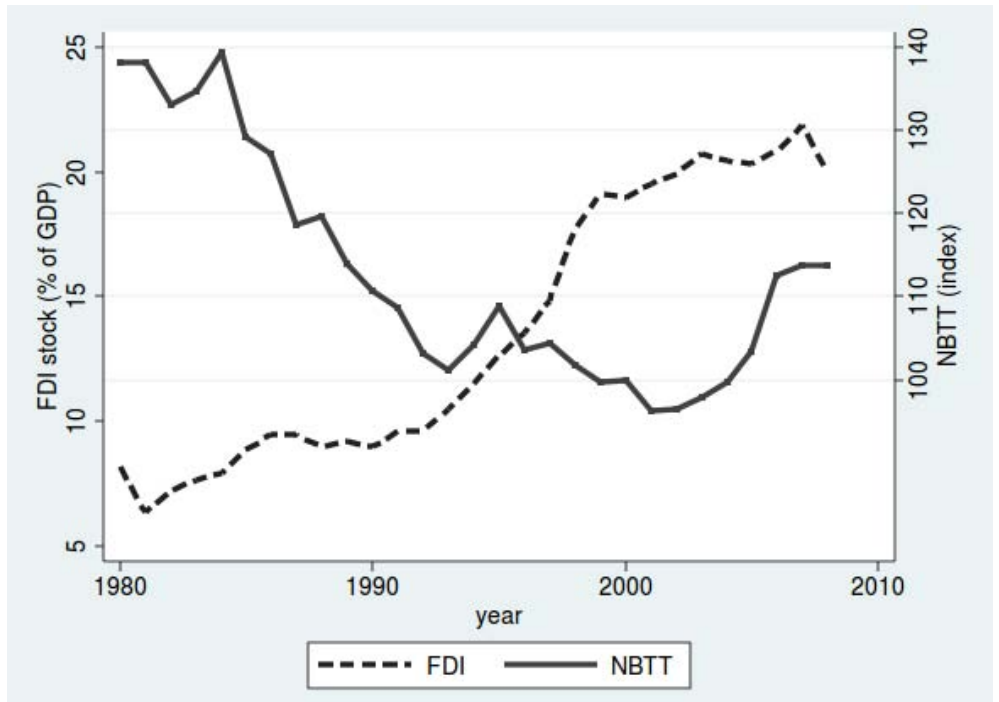

Figure 12: Development of FDI and NBTT Over Time

\subsubsection{Other Controls}

Other control variables, their sources and descriptive statistics are reported in table 11. The economic rationale for their inclusion is discussed together with their estimated impact in section 4.4. 


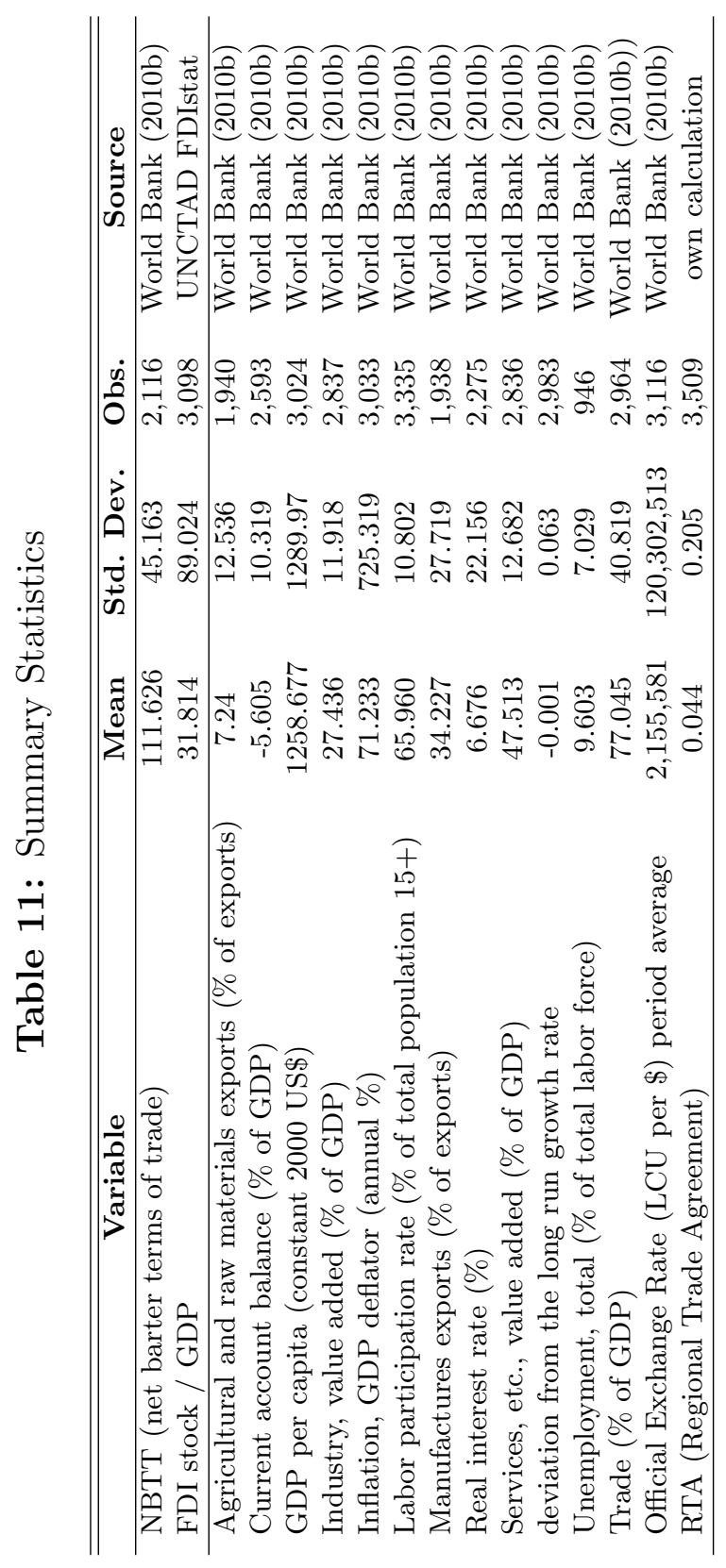




\subsubsection{Model Specification}

Since NBTT is a price index, thus a persistent series, and the impact of FDI is not expected to occur all at once but to rather entail an adaption process, a dynamic model is the appropriate model for the relationship suggested in equation (30):

$$
\ln (N B T T)_{i t}=\phi \ln (N B T T)_{i, t-1}+F D I_{i, t-1} \beta+\Psi \theta+\alpha_{i}+\gamma_{t}+\varepsilon_{i t} .
$$

Note that this is a log-linear ${ }^{159}$ fixed-effects (FE) model with time dummies and that the main covariate is lagged by one period to weaken endogeneity problems and to allow NBTT to respond by a delay of one period. It is well-known that OLS estimation of a lagged dependent variable (LDV) model such as (33) is biased (Nickell, 1981), so I use the System GMM estimator developed by Arellano and Bover (1995) and Blundell and Bond (1998) as implemented by Roodman (2009a) and compare it to FE and pooled OLS estimation to assess the reliability of the former estimate. This framework allows to address potential endogeneity of FDI and to assess autocorrelation in the residuals using the test statistic derived by Arellano and Bond (1991).

Because the bias of FE OLS estimation in the presence of simultaneity is equivalent to $T^{-1}$ under mild assumptions (Wooldridge 2002, p. 302), I also estimate a superreduced model where the control variables $\Psi$ are represented simply by time dummy variables. Since NBTT and FDI data are available for a large set of countries and years while most controls are not, this leads to an extensive sample.

\subsection{Empirical Results}

Model (1a) of table 12 shows a super-reduced version of equation (33) where separate time dummies for industrialized and developing countries are assumed to represent their respective control variables $\Psi$ (cf. Spraos 1983, p. 112). This allows the inclusion of 2,977 observations, thereof almost 2,000 from developing countries, with the time dimension being also relatively large $(T \approx 20)$. The estimated effect of FDI on terms of trade is negative (but not statistically significant) in industrialized countries but positive and statistically significant in developing countries: There, an increase in the FDI stock / GDP ratio of one percentage point leads to a $0.76 \%$ increase in the net barter terms of trade. ${ }^{160}$ Simple regression of the estimated time dummies on the corresponding years reveals that industrialized countries experienced a statistically significant increase in NBTT (conditional on FDI). The trend is not statistically significant for developing countries which does not necessarily mean good news: On the one hand, the estimated parameter is negative ${ }^{161}$ and the insignificance could simply reflect higher volatility in time-dependent shocks. Statistically, this would

\footnotetext{
${ }^{159}$ The log-linear model allows relatively easy interpretation and prevents the response from (potentially) taking on negative values, which would not make sense in the case of a price index.

${ }^{160}$ This is the long-run coefficient, calculated by dividing the respective coefficient by (1 minus the coefficient of the lagged dependent variable).

${ }^{161}$ The long-run trend of $-0.54 \%$ is in line with other results in the literature.
} 
entail a high noise-to-signal ratio (thus insignificant results), economically it would mean unpredictable shocks with potentially severe impacts on producers and growth perspectives. Since later model specifications will focus on developing countries exclusively, model (1b) provides results of the same approach using only the sample of developing countries to allow more adequate comparison.

\section{Table 12: Reduced Form Model}

Dependent Variable: $\ln (\mathrm{NBTT})$

\begin{tabular}{lccc}
\hline model & \multicolumn{2}{c}{$(1 \mathrm{a})$} & $(1 \mathrm{~b})$ \\
\hline countries & industrialized & developing & developing only \\
\hline $\ln (\mathrm{NBTT})$ & \multicolumn{2}{c}{$0.89024^{* * *}$} & $0.87947^{* * *}$ \\
$(-1)$ & \multicolumn{2}{c}{$(0.01739)$} & $(0.02222)$ \\
FDI stock & -0.00024 & $0.00083^{* *}$ & $0.00082^{*}$ \\
$(-1)$ & $(0.00038)$ & $(0.00041)$ & $(0.00042)$ \\
\hline time dummies & \multicolumn{2}{c}{ yes } & yes \\
time dummies' trend & $0.00097^{* * *}$ & -0.00059 & $0.00276^{* * *}$ \\
& $(0.00014)$ & $(0.00048)$ & $(0.00055)$ \\
\hline observations & 1,015 & 1,962 & 1,962 \\
$(N \times \bar{T})$ & $51 \times 20$ & $90 \times 22$ & $90 \times 22$ \\
\hline
\end{tabular}

FE OLS estimation with Huber (1967)-White (1980) cluster robust standard errors in parentheses.

$* * *, * *$, and $*$ denotes statistical significance at the $1 \%, 5 \%$ and $10 \%$ level, respectively.

The results for models (2) - (4) in table 13 and 14 include the full set of control variables. Due to the absence of convincing time-varying instruments for FDI that will be uncorrelated with $\varepsilon$ in equation (33), I use lagged first differences as instruments for FDI and the LDV in GMM models (2) and (5)-(7) (cf. Arellano and Bover 1995). ${ }^{162}$ Since the time dimension of the panel is relatively large, I collapse the FDI instrument set in order to prevent overfitting problems for the (potentially) endogenous variable as proposed by Roodman (2009b, p. 148f). For the lagged dependent variable, I combine collapsing the instruments with limiting the lag depth to lags 1-4 (ibid.). Since the instrument set is still large relative to the number of cross sections, a one-step approach had to be used which is generally not efficient, i.e. will result in more conservative inference. Estimated standard errors are consistent in the presence of any pattern of heteroskedasticity and autocorrelation within panels and a small-sample correction was applied.

In model (2), the estimated coefficient for the long-run impact of FDI on NBTT is $0.82 \%$ and weakly statistically significant despite the non-efficient one-step procedure. The result supports the view that the activity of multinational corporations has a positive impact on developing countries' terms of trade. It is remarkable that

\footnotetext{
${ }^{162}$ Since both, FDI and NBTT are persistent series, System GMM provides stronger instruments than the difference-GMM estimator developed by Holtz-Eakin et al. (1988) and Arellano and Bond (1991). To see this, take the most extreme case where $\phi=1$ in (33). Then, excluding other explanatory variables, $\Delta \ln (N B T T)=\varepsilon$, i.e. the differences of the series do not depend on actual (or lagged) levels.
} 
the inclusion of a wide set of control variables and the considerably reduced sample size lead to an estimated coefficient close to the one of the reduced model (1a) in table 12. The estimated parameter of the LDV of model (2) lies in between those of the OLS FE estimator (3) and the pooled OLS estimate which in this case is identical to the random effects model (4), though standard errors differ. ${ }^{163}$ Since the first one is generally expected to be downward biased while the second one is generally upward biased, this fact supports the reliability of the model (cf. Bond 2002, p. 4/5). The Arellano and Bond (1991) test for serial correlation of the residuals and the Sargan test provide further support for the model specification, however, the Hansen statistic is worrisome (but only in this specification). It should also be noted that the FDI-coefficient of the random effect model (4) is positive - since random effects is a matrix-weighted average of fixed and between effects estimation (cf. Maddala 1971) and thus also takes into account cross-country variation, this is in contrast to the above-cited view of Singer (1950) that countries with higher FDI levels suffer a worse terms-of-trade development.

Considering the other control variables, data on the industry structure, such as the share of agricultural and other raw material exports, ${ }^{164}$ industry value added, manufacturing exports and services value added, have been included because these characteristics may influence a country's potential to influence terms of trade. None of them turn out to be statistically significant and though standard errors are of reasonable size in some cases, the economic relevance is negligible.

\footnotetext{
${ }^{163}$ In both cases (3) and (4), Huber (1967)-White (1980) cluster robust standard errors are reported.

${ }^{164}$ The measure comprises SITC section 2 (crude materials except fuels) excluding divisions 22,27 , and 28 .
} 


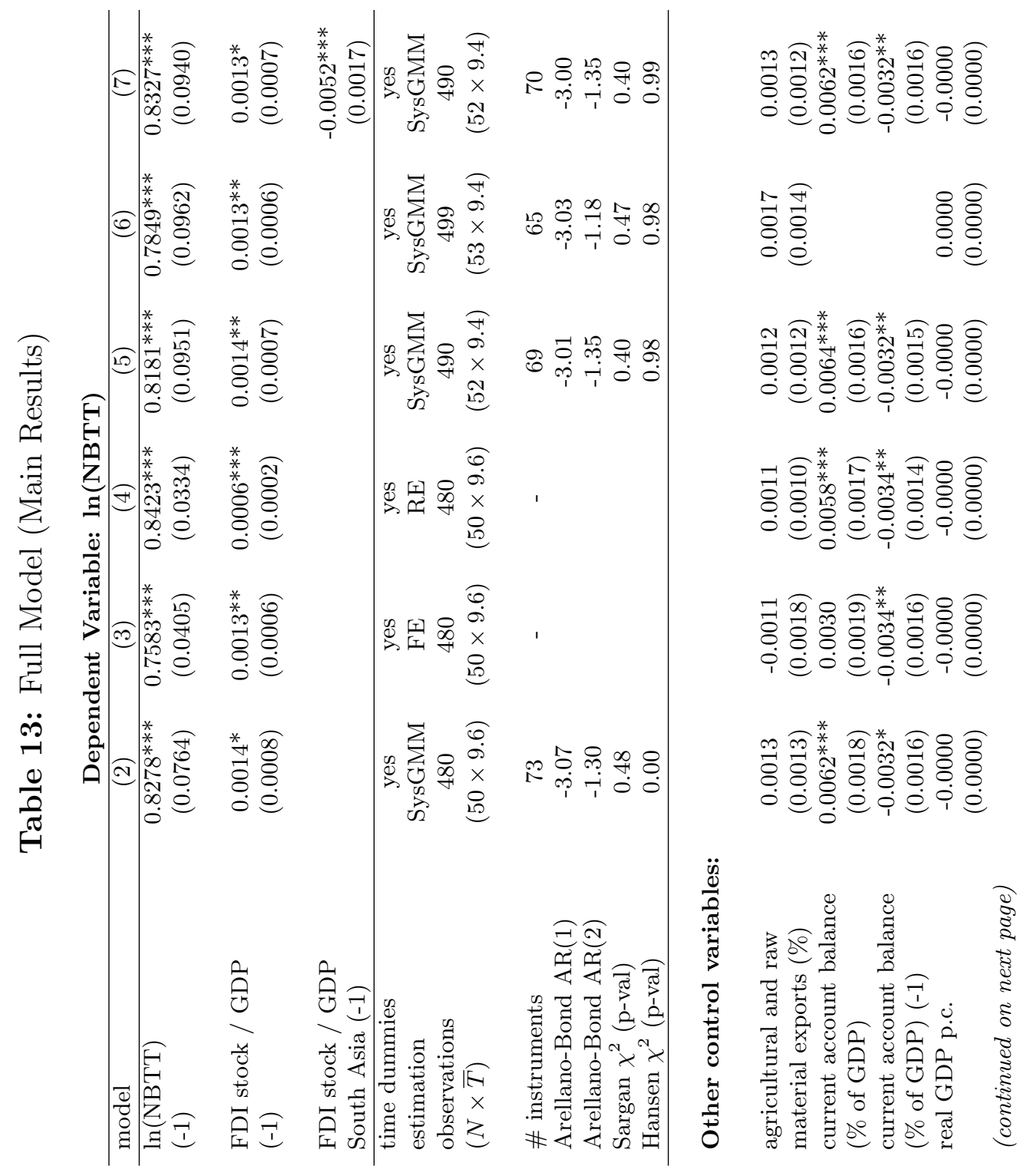




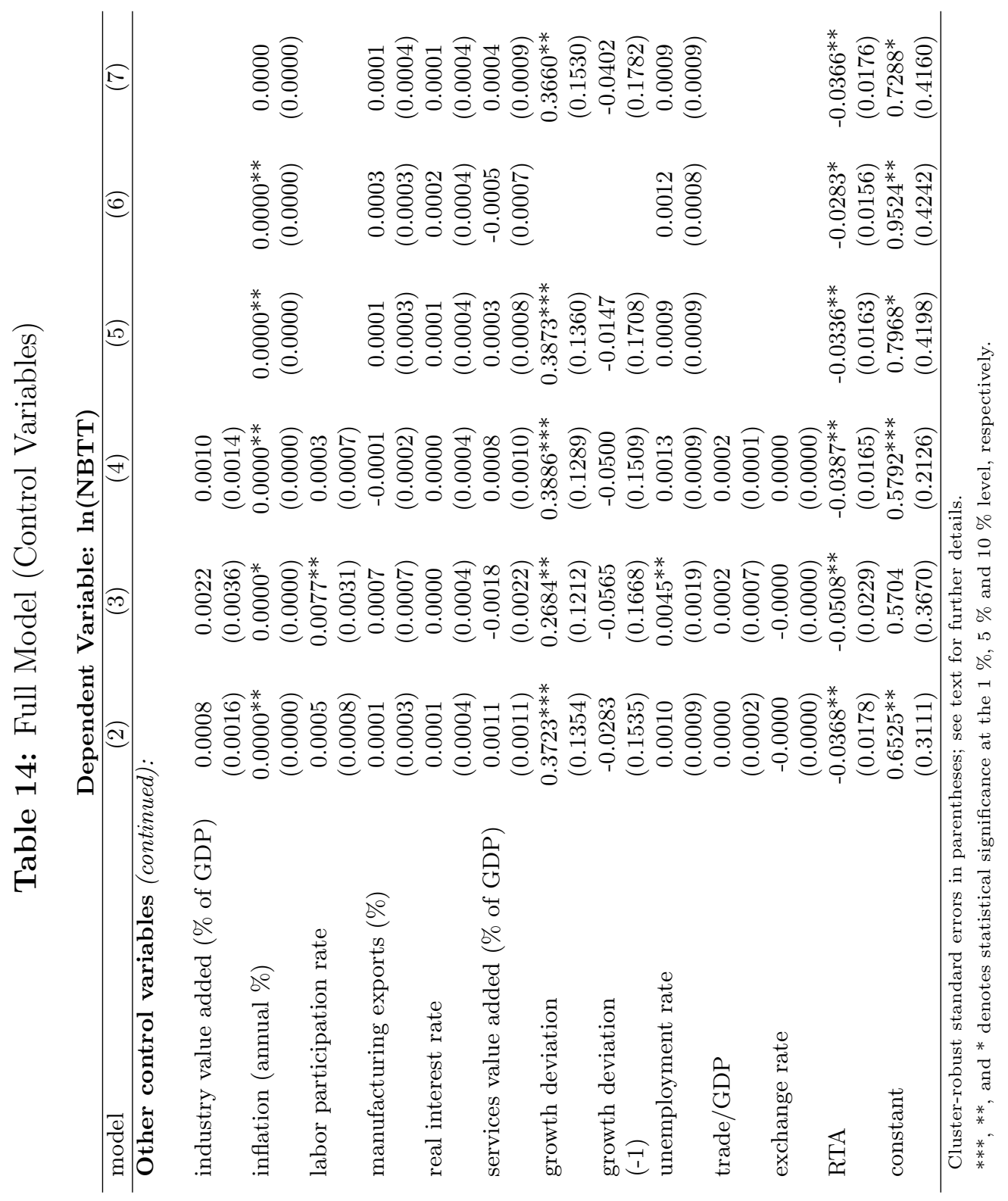


Labor market control variables (labor participation rate and unemployment rate) are included since especially Prebisch argued that the decline of developing countries' terms of trade operates through differences in labor markets between industrialized and developing countries; but an increase in the abundant factor (labor for developing countries) might also worsen terms of trade in neoclassical trade models (cf. Grilli and Yang 1988, p. 29). The finding that increased labor market participation in developing countries has no clear impact on terms of trade supports Prebisch' viewpoint to some extent: It is a conclusion from a Lewis-type labor market model, that increases in the labor force participation would not result in higher wages and thus have no impact on terms of trade. ${ }^{165}$ However, there is clearly no support for the neoclassical view that the increase in the abundant factor worsens terms of trade. More surprising is the fact that there is some evidence that an increase in unemployment is positively related to terms of trade. ${ }^{166}$ This contrasts with Prebisch' viewpoint that during a downswing, i.e. when unemployment rises, wage-pressure drives down the South's terms of trade. However, the finding that the actual deviation from the long-run growth rate is strongly statistically significant highlights that there is clearly a relationship between business-cycle fluctuations and terms of trade that is beyond the scope of this paper but worth future investigation (cf. also Thirlwall and Bergevin 1985, on the issue).

I also control for the exchange rate, the real interest rate and inflation since they all might influence terms of trade and, more importantly, may be correlated with FDI also. Controlling for GDP should capture different other country characteristics and is also important since many other variables are measured as a percentage of GDP.

The ratio of trade (imports + exports) to GDP is included because, inter alia, Lutz and Singer (1994) argue that for developing countries an increased export intensity might worsen their terms of trade and find empirical support for this statement. For similar purposes, a dummy variable was added which equals one if a country belongs to one of the regional trade agreements (RTA) of the Central American Free Trade Agreement (CAFTA), the Mercosur, or the ASEAN Free Trade Area (AFTA) at a specific year. While there is absolutely no support for the concern that high trade intensity negatively correlates with terms of trade in general, regional trade agreements seem to increase pressures on developing countries export prices.

Finally, since Santos-Paulino (2010, Table 2) finds a statistically highly significant impact of the (lagged) current account on terms of trade in 14 small island developing countries in a similar time period as the present study, the actual and the lagged current account balance are added among the control variables. This distributed lag specification was chosen because Santos-Paulino (2010, p. 864) finds a "J-curve response" caused by a shock in terms of trade onto the current account balance. The

\footnotetext{
${ }^{165}$ Note that the impact is positive and weakly statistically significant when models (2) and (3) are estimated for industrialized countries. Results are available upon request.

${ }^{166}$ Though not statistically significant for the GMM-models, the estimated coefficient is always positive and standard errors are of reasonable size.
} 
results, while hardly being comparable to the intentionally and methodically different study of Santos-Paulino (2010), still support a dynamic response of terms of trade to the current account and thus highlight the potential for further research on this relationship.

Since an F-test does not allow to reject the hypothesis that the parameters for industry value added, labor participation rate, the trade to GDP ratio and the exchange rate are jointly different from 0 (F-statistic 0.19 with 4 and 49 degrees of freedom), model (5) is estimated without these covariates. The estimate of the impact of FDI on terms of trade becomes statistically significant also at the $5 \%$ level and slightly reduced in size $(0.74 \%$ in the long run). In specification (6), the covariates covering the current account and the cyclical effects are omitted too, though this is statistically not justified (F-statistic of 7.00 with 4 and 51 degrees of freedom) but may give an intuition about the variability of the FDI coefficient. In fact, this has some impact on the relationship between FDI and terms of trade: At the same level of statistical significance, the long-run coefficient decreases to $0.59 \%$.

\subsubsection{Robustness Checks}

As a first robustness check, I investigate whether the relationship between FDI and terms of trade has changed over time. This might be the case, inter alia, when the nature of FDI varied. For example, throughout the 1990s and 2000s, the share of South-South FDI increased dramatically. Therefore, the model in equation (33) is re-estimated in the form:

$$
\begin{aligned}
\ln (N B T T)_{i t} & =\phi \ln (N B T T)_{i, t-1}+\mathbb{1}_{(t<1995)} F D I_{i, t-1} \beta_{1}+ \\
& +\mathbb{1}_{(t \geq 1995)} F D I_{i, t-1} \beta_{2}+\Psi \theta+\alpha_{i}+\gamma_{t}+\varepsilon_{i t}
\end{aligned}
$$

where $\mathbb{1}$ is the indicator function, i.e. the impact of FDI on terms of trade, $\beta$, is allowed to differ between the period prior to 1995 and the period thereafter. The model is estimated using OLS FE because the resulting bias is not expected to differ between the two parameters of interest and OLS will generally provide estimators with smaller variance than System GMM and hence tests for equality of parameters will have more power. Still, an F-test for $H_{0}: \beta_{1}=\beta_{2}$ in equation (34) cannot rejected the null, as is depicted in table 15: The estimated parameters are almost equal in size (F-statistic 0.03 with 1 and 49 degrees of freedom), suggesting that there is no reason to believe the relationship between FDI and terms of trade to have changed during the period of observation.

In another check that may also shed light on the potential channel of FDI influencing terms of trade, I investigate whether the impact of FDI depends on the trade policy regime of the developing host country, motivated by findings based on Bhagwati (1973, p. 50ff). ${ }^{167}$ I follow the rationale of Greenaway et al. (2007, p. 206) by dividing the sample according to whether the country-specific trade/GDP ratio exceeds

${ }^{167}$ See also Brecher and Diaz-Alejandro (1977) and Brecher and Findlay (1983). 
or falls short of the whole sample median value and apply a procedure comparable to the one outlined for equation (34), that is, $\beta$ is allowed to vary between the two subsamples. Results are again presented in table 15. Interestingly, the impact of FDI seems to be higher for closed economies (0.0017) than for open ones (0.0007) but the difference is not statistically significant. Accordingly, there is no evidence that the impact of FDI on terms of trade is more favorable for open (export promoting) economies than for more closed (import substituting) ones. On the contrary, there is even some evidence that countries with a low trade/GDP ratio may gain more from FDI in terms of their export price development.

Another concern, related to the original contributions of Prebisch and Singer, is the different impact of FDI in commodity exporting countries and manufacturing exporters. Splitting the sample according to the share of agricultural and raw material exports shows that countries with a higher share of primary exports indeed experience a weaker (but still positive) impact of FDI on terms of trade (cf. table 15). However, the difference to those developing countries with a lower share of primary exports is not statistically significant. Adding an interaction term of (lagged) FDI with the share of primary exports to the regression equation does not provide support for the hypothesis that FDI has a negative impact through commodity exports. ${ }^{168}$

To test whether the absorptive capacity of the local labor force matters for the impact of FDI on terms of trade, I apply a similar procedure as above using the Barro and Lee (2010) dataset on education. This is motivated by the fact that Borensztein et al. (1998) find for FDI flows to 69 developing countries after 1970 that they have a positive impact on productivity only when the host county has reached a minimum level of human capital. This finding is supported by the present investigation: As highlighted in table 15, the estimated parameter for the impact of FDI on terms of trade is higher for developing countries with a higher completion rate of primary education and with more years of schooling. While one could not reject equality of parameters in the first case, one can reject the hypothesis that FDI has the same impact in countries with low years of schooling as in countries with high years of schooling (on the 5 $\%$ level of statistical significance). This supports the view that the positive impact of FDI on terms of trade is fostered by or requires a certain threshold level of education.

I also split the sample for characteristics such as the initial GDP p.c. (1979-1981 average), employment in agriculture, employment in industry, GDP p.c., the growth rate of GDP p.c., and the ratio of the FDI stock of GDP (all over the whole sample range) but in neither case the relationship between FDI and terms of trade was significantly different for the subsamples, even when considering a level of statistical significance such as $20 \%$.

\footnotetext{
${ }^{168}$ Note that in the further case of different parameters, the impact is allowed to differ across countries. In the case of an interaction term in the regression, only the variation within countries is explored.
} 


\section{Table 15: Different Coefficients for FDI Impact for Different Sub-Samples}

\begin{tabular}{|c|c|c|c|}
\hline & $\hat{\beta}$ & $\mathrm{SE}(\hat{\beta})$ & $\begin{array}{c}\text { F-stat (d.f.) } \\
\text { (p-val) }\end{array}$ \\
\hline \multicolumn{4}{|l|}{ time } \\
\hline year $<1995$ & 0.00124 & 0.00089 & $0.03(1,49)$ \\
\hline year $\geq 1995$ & 0.00136 & 0.00089 & $(0.8650)$ \\
\hline \multicolumn{4}{|c|}{ trade intensity: trade/GDP } \\
\hline$<$ sample median & 0.00172 & 0.00061 & $1.06(1,49)$ \\
\hline$>$ sample median & 0.00074 & 0.00101 & $(0.3082)$ \\
\hline \multicolumn{4}{|c|}{ Primary Exports: agric. raw. mat. exports (\%) } \\
\hline$<$ sample median & 0.00207 & 0.00067 & $1.55(1,49)$ \\
\hline$>$ sample median & 0.00071 & 0.00090 & $(0.2185)$ \\
\hline \multicolumn{4}{|c|}{ Education I: percentage of primary complete } \\
\hline$<$ sample median & 0.00064 & 0.00070 & $1.74(1,43)$ \\
\hline$>$ sample median & 0.00176 & 0.00067 & $(0.1944)$ \\
\hline \multicolumn{4}{|c|}{ Education II: years of schooling } \\
\hline$<$ sample median & -0.00072 & 0.00097 & $6.78(1,43)$ \\
\hline$>$ sample median & 0.00165 & 0.00059 & $(0.0126)$ \\
\hline
\end{tabular}

Note: All estimates using model (3), $\hat{\beta}$ is the sort-run coefficient;

F-test is a test for equality of estimated parameters

Finally, I allow the impact of FDI on terms of trade to vary by six different regions. ${ }^{169}$ An F-test for equality of all parameters allows rejection of $H_{0}: \beta_{1}=\beta_{2}=\beta_{3}=\beta_{4}=$ $\beta_{5}=\beta_{6}$ at the $1 \%$ level of statistical significance (F-statistic 3.97 with 5 and 49 degrees of freedom) but one cannot reject equality of other parameters than the one for South Asia (F-statistic 1.52 with 4 and 49 degrees of freedom). This suggests the relationship between FDI and terms of trade to be different between South Asia, covering observations of Bangladesh, India, Pakistan and Sri Lanka, and the rest of the developing world which is confirmed by a likelihood ratio test, where the reduced model is the same as in specification (3) and the saturated model has an extra parameter for FDI in South Asia: The resulting $\chi_{(1)}^{2}$ statistic of 8.12 allows to reject the null hypothesis that the reduced model provides the same fit as the saturated model at the $1 \%$ level of statistical significance. ${ }^{170}$ Furthermore, the model selection criteria

\footnotetext{
${ }^{169}$ These are East Asia \& Pacific, Europe \& Central Asia, Latin America \& Caribbean, Middle East \& North Africa, South Asia, and Sub-Saharan Africa, according to the World Bank classification.

${ }^{170}$ For an LR-test comparing a saturated model with six different FDI parameters (one for each region) against a reduced model with one FDI parameter for South Asia and another one for the remaining regions does not allow rejection of the hypothesis that the reduced model provides the same fit as the saturated one $\left(\chi_{(4)}^{2}\right.$ statistic of 4.12$)$.
} 
AIC and BIC prefer the saturated over the reduced model. Accordingly, specification (5) was re-estimated in the same setting but allowing for a different FDI-impact on terms of trade in South Asia. Results are presented as specification (7) in tables 13 and 14 and show a negative (and highly significant) impact of FDI on terms of trade for South Asia of $-3.1 \%$ and a positive (and weakly significant, t-statistic 1.97) impact of $0.78 \%$ for the rest of the developing world (both long-run parameters). ${ }^{171}$ The South Asian exception poses some questions for further research since it may not be explained by largely different export structures. ${ }^{172}$ A possible explanation is discussed below.

In another robustness check I construct a new FDI stock series based on UNCTAD FDIstats flow data using the perpetual inventory method (PIM) since FDI stock values might suffer from problematic asset valuation (cf. IMF 1993, §377). ${ }^{173}$ Table 16 shows the estimated coefficients using the same covariates as in specification (2) with depreciation rates $\delta=0.05,0.1,0.15$. The results support the previous findings: Despite using the same System GMM specification as above (including the lag structure), the new measure meets significance at the $10 \%$ level in 2 out of 3 cases (with a t-statistic of 1.67 in the third case). More importantly, for the case of $\delta=0.1$, which is most appropriate for comparison with previous results since then the overall FDI growth comes closest to the value observed in the actual stock data, the estimated long-run parameter of $0.81 \%$ is almost identical to the one of model (2).

\section{Table 16: Results Using PIM Stock Data}

\begin{tabular}{cccc}
\hline$\delta$ & LDV coef. & FDI coef & long-run FDI coef. \\
\hline 0.05 & $0.7582^{* * *}$ & $0.0019^{*}$ & $0.78 \%$ \\
& $(0.0825)$ & $(0.0011)$ & \\
0.1 & $\begin{array}{c}0.7589^{* * *} \\
(0.0824)\end{array}$ & $\begin{array}{c}0.0019^{*} \\
(0.0012)\end{array}$ & $0.81 \%$ \\
& & & \\
0.15 & $0.7595^{* * *}$ & 0.0020 & $0.83 \%$ \\
& $(0.0822)$ & $(0.0012)$ & \\
\hline
\end{tabular}

\footnotetext{
${ }^{171}$ It is also investigated whether the different impact in South-Asia is driven by individual countries. For this purpose, one South Asian country at a time and any set of two South Asian countries at a time have been excluded from the regression. In each case a similar picture emerged, rejecting the suspicion that the effect is driven by individual countries.

${ }^{172}$ In the mid-1990s, when FDI was on the surge, all Asian economies were large exporters of textiles and apparel and/or food manufactures. It is true that countries such as Philippines, Singapore and Thailand had considerable higher export shares of machinery than South Asian exporters, but Indonesia, Mongolia and Vietnam, on the other hand had not.

${ }^{173}$ The method of Hall and Jones $(1999$, p. 89$)$ is used to estimate initial values of FDI stock and missing flow data is interpolated.
} 


\subsubsection{Economic Relevance}

Throughout this investigation, one can see a statistically significant positive longrun impact of the FDI stock (relative to GDP) on net barter terms of trade that ranged from $0.59 \%$ to $0.82 \%$, depending on the model specification. Assuming a long-run parameter of $0.74 \%$, as estimated in model (5) and lying between the above estimates, would mean that a one percentage point increase in the FDI stock to GDP ratio causes the NBTT to increase by $0.74 \%$. Considering those 32 out of 53 countries included in specification (6), where observations are available for 1980 and 2008, a simple time trend of $-0.63 \%$ is estimated for (the logarithm of) net barter terms of trade. $^{174}$ This would mean that a one percentage point increase in the FDI stock / GDP ratio could more than offset the developing countries' structural tendency of deteriorating terms of trade. In fact, between 1980 and 2008, the FDI/GDP ratio in these countries increased from $15.6 \%$ to $31.9 \%$, that is an average increase of 0.58 percentage points p.a. Put differently: The actually observed increase of FDI in developing countries between 1980 and 2008 countered their terms-of-trade decrease by $\frac{16.24 \times 0.74}{-0.239}=50.3 \%$, where 0.239 is the decrease in the logarithm of NBTT. There can thus be no doubt that the positive impact of FDI on the developing countries' terms of trade is of a magnitude that is highly relevant and thus provides space for future research.

\subsection{Discussion and Conclusion}

As shown above, economic theory has been inconclusive about the impact of multinational corporations (MNCs) and their foreign direct investment (FDI) on developing countries' net barter terms of trade. Accordingly, the issue was addressed empirically for more than 50 developing countries between 1980 and 2008. The main finding is that there is no empirical support for concerns that multinationals would beat down developing countries' export prices. On the contrary, I find that the observed increase of FDI countered the structural tendency of developing countries' terms of trade to deteriorate by an economically relevant magnitude of about $50 \%$, depending on the model specification, at conventional levels of statistical significance. Results are robust to the inclusion of differing sets of control variables and an alternative measure of the FDI stock. It should also be mentioned that FE OLS regression leads to similar results as the System GMM estimator, supporting the claim to compare GMM results to OLS results as a standard-procedure in applied research in order to assess the reliability of the former.

The positive impact of FDI is stronger for countries with higher school enrollment rates, supporting the findings of Borensztein et al. (1998) that the absorptive capacity of the host economy matters. The results in table 15 also suggest that the net barter terms of trade of primary exporters do not benefit as much from FDI as those of developing countries with a higher share of manufacturing exports. ${ }^{175}$ There is

\footnotetext{
${ }^{174} \ln (N B T T)_{i t}=\beta t+\varepsilon$; Ziesemer $(2010$, p. 7$)$ finds a $-0.42 \%$ p.a. long-run decrease of NBTT for low income countries.

${ }^{175}$ The difference in the estimated parameters, while considerable in economic magnitude,
} 
no support, however, for the widespread view that the impact of FDI positively depends on a country's international trade intensity. If anything, the data suggest that developing countries with a larger trade-to-GDP ratios experience a lower positive impact of FDI than "less open" economies.

As discussed in the introduction to this dissertation, a possible explanation for these findings is the relationship between the extent of the market and the social division of labor. Increased access to international markets will rise the the possibility of people to transform their potential capacities of performing meaningful tasks into outcomes - here: to work in occupations that produce goods with high export prices. Since the manufacturing sector provides more space for diversification and hence to perform tasks that match with individual capacities, one would expect more benefits from extending its market than from a larger market of primary goods that generally copies existing activities. A well-educated people will find much more opportunities and benefits from an increased extent of the market (and from other possibilities provided by MNCs) than a less educated one because the former possess a larger portfolio of performing tasks. ${ }^{176}$ Finally, since trade and (horizontal) FDI act as substitutes, the supplementary benefits of FDI in extending the market will be smaller in a more trade-open economy than in a relatively closed one. The findings concerning South Asia are in line with these considerations: South Asian countries had a poorly educated labor force that may have been unable to absorb the potential benefits from FDI: In the early 1990s, the (unweighted) average of South Asian population without any schooling was $45.7 \%$; it was barely $15 \%$ for East Asian countries. (Unweighted) Average years of schooling were 4.2 in South Asia and 6.1 in East Asia. Thereby, South Asian data is even biased by the good educational performance of Sri Lanka (Barro and Lee 2010). In this respect South Asia is underdeveloped, especially when compared to East Asia. The inner-Asian division of labor might thus have detained South Asian economies in product segments that correspond to their factor endowment but have less favorable price perspectives. Multinational corporations may have reinforced production in these segments with comparative "advantages" at lower stages at the value chain. Given that South Asian markets were moderately interesting for horizontal investment (with the exception of India), most FDI might have had vertical motives, thus leading to negative price impacts as explained towards the ends of sections 4.2.1 and 4.2.2.

Other channels to explore in future research involve the role of upgrading effects induced by MNCs (cf., inter alia, Javorcik 2004, and the extensive literature on global value chains) that show up as a "price" increase due to inappropriate measurement by unit values (cf. sections 4.2 .3 and 4.3 .1 ) and the plausibility that multinationals possess higher market power and more appropriate information about global market conditions which allow them to realize higher (export) prices.

is not statistically significant. However, note that the split of the sample at the median is somewhat artificial.

${ }^{176}$ Conversely, a larger extent of the market of course increases the incentives to invest in education. 
The results of this investigation do not imply that policy makers should blindly attract FDI in order to boost trade revenues, as the cautionary exception of South Asia shows. Firstly, improving and-possibly more important-stabilizing NBTT should only be one dimension of a coherent macro-development strategy. Secondly, the knowledge of the economic channels through which the FDI-NBTT nexus operates is still opaque and deserves further exploration. For example, the recent World Bank (2010a) study on farmland ownership-transfer to foreign investors has highlighted that their outcomes highly vary with factors such as information asymmetries, enforcement and awareness of existing ownership rights, stakeholder involvement and the potential to form linkages with the domestic producers. This emphasizes that policymakers should understand a developing country's investment policy as being only one part in the puzzle of development. 



\title{
5 Do Multinationals Influence Labor Standards? A Close Look at US Outward FDI (joint with Krishna Chaitanya Vadlamannati)
}

\author{
All labor that uplifts humanity has dignity and importance \\ and should be undertaken with painstaking excellence.
}

M. L. King, Jr.

Throughout the course of globalization, academic researchers, as well the general public, have discussed the controversial relationship between multinational corporations (MNCs) and labor standards. One line of arguments highlights that multinationals maximize profits. Since labor rights cause costs, multinationals will level down labor standards. Others have mainly emphasized that multinationals generally pay higher wages than domestic firms and have to provide other incentives to attract skilled labor that is needed for their production process, which makes them more likely to provide better labor standards. Like the theoretical arguments, the empirical evidence on the issue is rather scant.

My contribution to the literature builds on the stylized fact that labor markets in industrialized countries tend to be segmented by the educational level instead of being homogeneous. I then argue that the different motives of multinational firms to conduct foreign direct investment (FDI) will lead to the employment of different segments of the labor force and hence different results concerning labor standards.

My argument successfully integrates wages, labor standards and the employment / unemployment decision into the bargaining process and goes beyond the pure profitmaximization argument (which also holds for domestic firms), instead emphasizing the specific multinational component of multinational firms.

\subsection{Literature Review}

To date, the applied literature has failed to find clear evidence regarding the impact of MNCs on labor standards. In a series of papers, Neumeyer and de Soysa (2005, 2006, 2007), for example, focus on the impact of FDI on different aspects of labor right issues. In their first study on FDI and various measures of child labor, they find that countries which are more open to trade and FDI have a lower incidence of child labor. In their next study, they test the effect of globalization on a specific labor right, which forms part of what are commonly regarded as core or fundamental labor standards. Employing a new measure of free association and collective bargaining rights, they find that countries more open to trade have fewer rights violations than more closed ones in both a global and developing country sample. Interestingly, they fail to find any evidence of positive effects of FDI on labor rights and conclude that the process of globalization might not be beneficial for outcome-related labor standards, but is likely to promote the process-related standard of the right to free association and collective bargaining. Similar findings are echoed in their most recent study on globalization, women's rights and forced labor. Testing the competing claims on pro- and anti-globalization, they find that countries that are more open to 
trade provide better economic rights to women and have a lower incidence of forced labor. However, they also find that the extent of an economy's penetration through FDI has no statistically significant impact on women's rights or forced labor. Focusing on the effect on child labor, the results of Davies and Voy (2009) suggest that FDI and trade do not have any other impact on lowering child labor than through the increase in income they generate.

Similar concerns apply to the investigation of Mosley and Uno (2007), who address the issue with a new measure of labor rights capturing 37 aspects of de facto and de jure aspects of labor rights that I will also use in the present study. For a panel of 90 developing countries, they find support for "climb to the top" arguments, suggesting that FDI inflows are positively related (and statistically significant) to the rights of workers. However, as they use pooled OLS estimation (with panel-corrected standard errors), the results are likely to seriously suffer from omitted variable bias (cf. Wilson and Butler, 2007).

In another study covering 132 countries, Busse and Braun (2003) reverse the identification channel and look at where MNCs are investing. They find that MNCs are highly sensitive with respect to location and prefer countries with lower levels of child labor. However, they also show that a higher level of child labor leads to a comparative advantage in labor-intensive goods, which probably attracts labor-intensive FDI in these sectors. Busse et al. (2011) study the impact of fundamental labor rights using bilateral FDI flows from OECD countries to 82 developing countries. Their results indicate that investments by OECD firms are significantly higher in countries that adhere to labor rights, thereby refuting the hypothesis that repression of these rights fosters FDI.

In some studies on FDI and labor rights, attempts were made to go beyond aggregated analysis. Moran (2002) stressed that distinctions should be made between low-wage, unskilled industries (such as apparel or footwear) and high-skilled industries (e.g., electronics, automobile sector). Blanton and Blanton (2009) find that the correlation between labor rights and FDI varies considerably across different sectors.

I argue that previous studies have failed to find a robust and statistically significant impact of the activities of multinational corporations on labor standards because they have not accounted for these differences in various forms of multinational activities. The recent literature on multinational firms has highlighted the complex nature of multinational profit maximization (cf. e.g., Yeaple 2003; Bergstrand and Egger 2007; Davies 2005; Ekholm et al. 2007; Baltagi et al. 2007, 2008; Badinger and Egger 2010; Moran 2011). Most important in the present context is that horizontal and vertical FDI by multinational firms is driven by different rationales: Vertical multinationals try to globally organize commodity chains according to absolute cost advantages (cf. Helpman 1984; Feenstra and Hanson 1996; Jones 2000), while horizontal MNCs try to substitute trade costs by producing the same good in the host country as in the home country (cf. Markusen 1984; Smith 1987; Horstman and Markusen 1992; Brainard 1997; Markusen and Venables 1998, 2000). They will thus require different production 
factors and have divergent influences on labor markets and working conditions in the host economy. In the next section 5.2, I therefore derive a stylized model of the labor market of an industrialized country in an open economy that corresponds to economic reality. Here, I show that horizontally integrating MNCs will have a negative impact on labor standards. This is because they are in a different bargaining position than vertically integrating firms due to their different organization of the production process and different production factors. After introducing the data and methodology in section 5.3, the results in section 5.4 provide evidence of this channel. Section 5.5 concludes.

\subsection{A Simple Model of FDI and Labor Conditions}

Considerable rates of unemployment were a stylized fact in industrialized countries even before the 2008 financial crisis: $7.7 \%$ of the total labor force in the sample of 35 countries were unemployed throughout the study period of $1997-2002,{ }^{177}$ with South Africa reaching a maximum of $29.5 \%$ in 2001. A model able to explain the effects of FDI on labor markets should thus allow for unemployment in equilibrium (at least in the medium run). Furthermore, I build on the consideration that, in practice, the whole situation surrounding working conditions - including the employment / unemployment decision, wages and working standards - is determined together (cf. Brown et al. 2004, p. 297). Finally, the model should take into account that multinationals are different from comparable domestic firms and should shed light on the question as to how far a MNC's profit maximization behavior and corresponding factor demand influences labor market outcomes.

I start in a situation where the labor market is highly segmented into a high-skilled sector with virtually no unemployment, and a sector with lower educated workers and some unemployment. OECD data presented in figure 13 provide empirical justification for this assumption: based on the OECD average, the spread in the labor force participation rate between adults with tertiary education and those below an upper secondary educational level amounts to 25 percentage points.

I consider wages to be generally (downward) sticky (cf. Dickens et al. 2007, for empirical evidence), especially in the lower educated sector - the focus of my attentionwhere a fixed wage, such as a minimum wage, is set above the theoretical free market equilibrium. ${ }^{178}$ This situation is depicted in figure 14 , where $D 1$ is the domestic de-

\footnotetext{
${ }^{177}$ Unweighted average over all years and countries, 121 observations, standard deviation $5.0 \%$

${ }^{178}$ It is reasonable to assume that the difference between the minimum wage and the freemarket equilibrium wage is higher in the less-educated sector, since this is usually the sector with higher unionization rates in industrialized countries. An alternative interpretation is a situation where real frictions in the labor-market matching-process exist (Diamond 1982; Mortensen 1982; Pissarides 1985, 1990). In these models, one can consider a situation where either the minimum wage $m$ is above the domestic employers' reservation wage (though the workers' reservation wage may be lower), or where the bargaining set between the workers' and domestic employers' reservation wage is non-empty but search-costs do not pay off the
} 


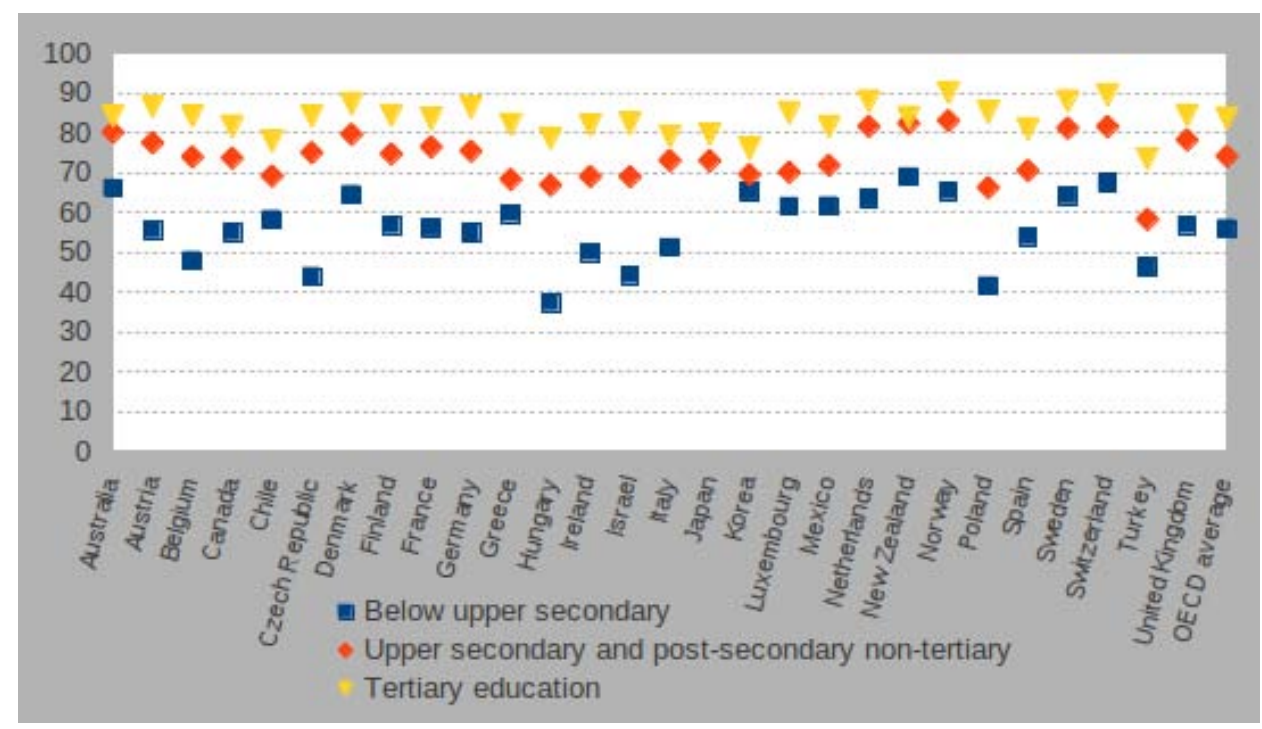

Figure 13: Labor Market Participation Rates by Skill Level

mand curve for labor, and $S$ is the labor supply curve. Since the minimum wage $m$ is above the intersection of $D 1$ and $S$, only $L 1$ workers are employed (instead of $L 3$ ). A multinational corporation starting business in the country acts like an exogenous shock since the investment decision of the firm is not driven by changes in the host economy but by events in the other locations of the firm. ${ }^{179}$ This shifts the demand curve for labor to the right (from $D 1$ to $D 2):{ }^{180}$ due to the higher productivity of multinational firms, they have a higher reservation wage than domestic firms and thus at any wage level, more labor will be employed. ${ }^{181}$ The new equilibrium employment rate is set at $L 2$.

difference between the two. An example is a decentralized labor market where a firm faces set-up related fixed costs to set up an establishment and workers face fixed costs to move (or variable commuting costs). However, I think the representation with a downward sticky wage is more intuitive and thus easier to follow.

${ }^{179}$ In practice, this is a strong statement because firms' behavior will obviously be influenced by events in the host country. It is sufficient to note, however, that the MNCs employment decision in the (potential) host economy may change even though conditions in the host country itself do not change. See the discussion in the FDI literature on push vs. pull factors, especially Calvo et al. (1993); Fernandez-Arias (1996); di Giovanni (2005); Albuquerque et al. (2005).

${ }^{180}$ The demand curve might also become flatter due to the fact that foreign firms - at least when driven horizontally - have a more elastic labor demand due to the fact that they have easier access to substitutes (cf. Rodrik 1997; Richardson and Khripounova 1998; Slaughter 2001). This point is only sketched here because it is not essential to the argument.

${ }^{181}$ Note that this would also happen if FDI simply crowds out domestic firms. 


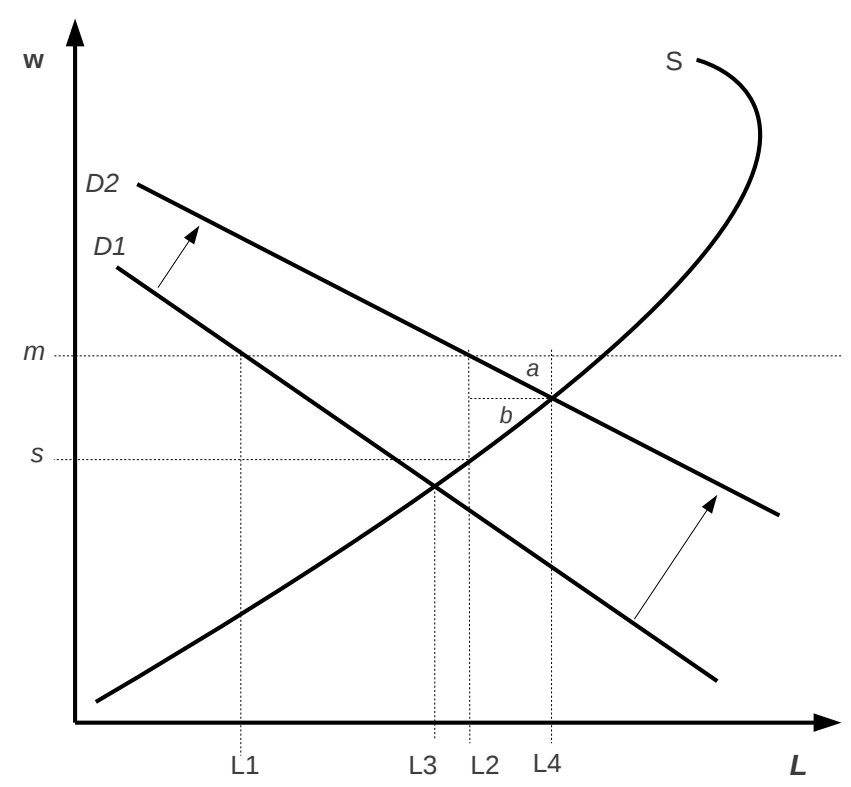

Figure 14: A Sketch of the Labor Market for the Less-Educated

Now suppose that firms have to pay the minimum wage $m$ but can bargain with workers over their working conditions and labor standards. This can be the case due to wages being easy to screen for the government, while - especially in times of public budget restrictions - violations of labor standards are not, at least if they are minimal. Thus, the domestic employment equilibrium may be somewhere between $L 1$ and $L 3 .^{182}$ Focusing now on the MNC-induced shift from $L 2$ to $L 4$, workers would have to accept a loss in working conditions which is equal to $a$ as this would imply that MNCs pay the difference between their demand curve D2, and the (above lying) minimum wage. Workers are willing to do so because the resulting outcome would still leave them above their supply curve $S$. The area equal to $b$ is then left to be bargained over. The area $a+b$ is the deadweight loss in a situation where minimum wages are too high and both parties cannot trade labor standards for jobs.

Now one must ask, what is a realistic outcome of such a bargain? Besides from their preferences concerning labor standards, the bargaining power of workers obviously depends on their opportunity costs of not getting the job. In the case of lower educated workers, unemployment and thus opportunity costs are high, so they are in a weak bargaining position. For MNCs, the bargaining power will positively

\footnotetext{
${ }^{182}$ It is reasonable to assume that intense violation of existing labor rights will not pay off because they become too obvious and may result in legal action or consumer protests. The return on "saving" labor rights is thus highly concave and the equilibrium point $L 3$ will not be reached. I disregard this negligibility here without a loss of generality.
} 
depend on the substitutability of labor, which is generally high in open economies for homogeneous, relatively low educated labor (see, for example, Arseneau and Leduc 2011, for a more sophisticated bargaining model with outside options in equilibrium).

My main argument concerns the fact that MNCs following a horizontal integration strategy in industrialized countries differ in this respect from vertical multinationals. The latter go to the host country in order to produce an input that is then shipped back to the home economy (or other countries where it is processed). This may be the case because input costs are low in the host country, such as a MNC producing a homogeneous, labor-intensive input in a low-wage country. Another reason may be the fact that the input is more or less exclusively available in the host economy, for example oil or other natural resources. The main resource of industrialized countries is human capital, and it is unlikely that US MNCs will go to countries like France or Australia based on the motive that they have wages low enough for the MNC to be able to realize cost advantages that are sufficiently large to overcome trade and disintegration costs. Moreover, most European countries - the majority of countries in the sample - do not have any significant primary commodities that could be exploited by vertical FDI. It is rather the case that most industrialized countries specialize in the production of specific high-tech products, e.g., certain chemical products in France or technical equipment in Germany, and MNCs use these as "inputs" in their home country in the sense of complex vertical FDI (cf. Davies 2005; Baltagi et al. 2007). The production of these goods requires a highly educated labor force that practically does not suffer significantly from unemployment, so their bargaining position vis-a-vis employers will be high. Also, domestic firms in this sector will be among the most competitive firms in the world economy so that the US multinational may not be much more productive, if at all (in other words, the labor demand curve in figure 14 will not shift much to the right, thus the impact of FDI will be negligible).

The case is completely different for horizontal FDI. The main modus operandi for this type of multinational is using a "blue print" from the home economy that is then copied in each of the host countries to avoid trade costs. Such a "copying process" usually does not need highly educated workers. Of course, skill intensity is relative. Here, one can imagine craftsmen working in a TV factory in Australia to serve the Australian market with TV screens from a US MNC. Unemployment is usually higher for these workers than for the highly educated employees working, inter alia, for vertical MNCs (in industrialized countries). Furthermore, the horizontal multinational is in a favorable bargaining position: in the case that the claims of the Australian workers are too high, the MNC could still serve the Australian markets through exports from the home country (or by export-platform FDI via New Zealand or Chile, for example).

One would therefore expect that horizontal MNCs are in a much more favorable bargaining position vis-a-vis the local labor force and would thus be able to level down labor standards, while vertical FDI is bound to the host country because of the availability of human capital which is hard to substitute and highly specialized. 
Figure 15 gives an overview of the proportion of vertical US FDI as a total of US FDI in Europe, Canada (for comparison) and the rest of the world for certain industries. ${ }^{183}$ Overall, the share of vertical FDI is much larger for Canada than for European countries, indicating (inter alia) the higher trade costs for European inputs that have to be weighed against potentially lower input costs. The rest of the world lies in between, potentially representing a moderate level of trade costs and very low input costs. For the purpose of this analysis, the most important feature in figure 15 concerns the share of vertical FDI per sector for European countries, which, as mentioned, make up the majority of the sample. This share is significantly above the average of all sectors in the chemical, machinery and electronic and computer industries. I argue that this is due to the skill content in these sectors, where Europe has developed a competitive advantage and it is hence profitable for US multinationals to produce in Europe and ship products (and potentially skills) back to the US. Unfortunately, data on the activities of MNCs are very scarce as far as the industrial breakdown is concerned, thus I cannot empirically substantiate my argument further. However, under the assumption of homogeneous labor and production technologies, it seems very odd to argue that US firms would go to Europe to produce and ship back electronics, for example. This is because labor is probably more expensive in Europe and even if it were not, the difference would hardly be sufficient to outweigh transportation and other costs such as forgone returns to scale and increased agency costs. An aggregate view of the data therefore suggests that vertical US FDI is demanding high skilled labor in a considerable part of the sample, and due to the lower threat of unemployment in this segment of the labor market, vertical multinationals will be in a worse bargaining position than horizontal ones. They may even provide better working conditions to attract the scarce amount of high-skilled workers.

These considerations lead to a set of testable hypotheses:

- Hypothesis 1: The impact of multinationals on labor standards depends on the motivation behind the multinationals' foreign direct investment (FDI) and the related segments of the labor market it employs.

- Hypothesis 1a: Horizontal FDI has a negative impact on labor standards in industrialized countries.

- Hypothesis 1b: Vertical FDI has an ambiguous impact on labor standards in industrialized countries.

- Hypothesis 2: The negative impact of horizontal FDI operates via unemployment.

- Hypothesis 3: The negative impact occurs in the actual labor market outcome (de facto), and not due to a leveling down of labor laws (de jure)

\footnotetext{
${ }^{183}$ The compilation of these shares is described in more detail in the "data" section. Unfortunately, industry level data for FDI is very scarce and often subject to disclosure, so I limit the descriptives to the year 2000 and to Canada, total Europe and the rest of the world (ROW). Note that 19 of the 34 countries in the sample are European countries.
} 


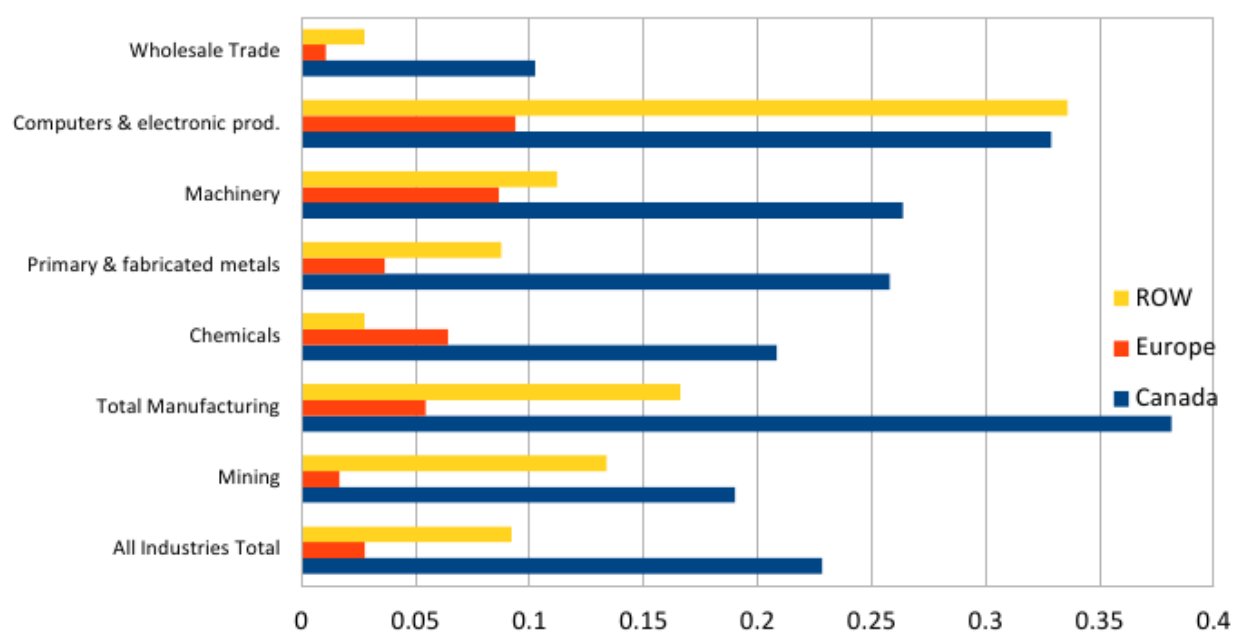

Figure 15: Share of Vertical Motives in Total US Outward FDI by Industries (in year 2000)

In the next section, I introduce the data and methodology used to test my hypothesesespecially the approach to separating FDI according to horizontal and vertical motives and how I measure labor rights. From there, the following section presents the results and the last section concludes.

\subsection{Data and Methodology}

\subsubsection{FDI Data}

To approximate the relevance of multinational corporations in the host economies, I use FDI stock data, in this case US direct investment abroad, provided by the $\mathrm{Bu}-$ reau of Economic Analysis (BEA). The focus on only one investing economy is due to the fact that US data allows disentangling horizontal from vertical FDI and has the advantage that the impact of FDI on labor rights may depend on the institutions in the home economy (cf. Locke et al. 2007; Harrison and Scorse 2010; Busse et al. 2011). Taking aggregated data from more investing economies may hence result in heterogeneity and insignificant results. Note, also, that the US is by far the world's largest foreign direct investor. ${ }^{184}$

The direct investment position consists of the investors' equity in, and net outstanding loans to, all their affiliates. The US FDI position is calculated on a historical cost basis derived from the books of affiliates, which generally reflects the acquisition

\footnotetext{
${ }^{184}$ In 2000, the US accounted for more than one third of the outward FDI stock globally, making it the world's most important foreign direct investor, followed by France $(11.6 \%$ of global outward FDI), the UK (11.3\%), and Germany (6.8 \%). Source: UNCTADstat.
} 
costs of the investment, reinvested earnings, and asset depreciation. ${ }^{185}, 186$

As mentioned, the US FDI data allows disentangling horizontal from vertical FDI, which is the main motivation of this paper. I have argued that vertical US FDI flows into industrialized countries to produce certain inputs, parts or components, which are then shipped back to the US and used as part of final goods or for the US capital formation (which effectively serves the same purpose). Similar to other studies (e.g., Liu and Nunnenkamp 2011), I therefore look at the share of total sales ${ }^{187}$ of the foreign affiliates of US firms that is re-imported into the US, ${ }^{188}$ using this as a proxy for the share of vertical FDI in a country. On the other hand, the number of goods that are sold in the host country can be assumed to serve the host market (or neighboring countries in the case of export-platform FDI), and is seen as horizontal investment accordingly. ${ }^{189}$ Formally, for host country $i$ :

$$
\text { Vertical FDI }=\frac{\text { US Imports from Affiliate }}{\text { Total Sales of Affiliate }} \cdot \text { Total FDI }
$$

$$
\text { Horizontal FDI = Total FDI - Vertical FDI. }
$$

For the sales data, I consider all foreign US affiliates rather than majority-owned foreign affiliates, since this corresponds to the definition used for the calculation of the FDI data (cf. chapter 2). Note, that after disentangling I take the logarithm of

\footnotetext{
${ }^{185}$ For comparison: IMF (2004: 25) mentions, that the 2001 US outward FDI book value was about $60 \%$ of its corresponding market value. Historical cost values may weaken endogeneity concerns since past investment values will barely be driven by actually observed labor rights standards.

${ }^{186}$ One may argue that employment data is more appropriate than FDI data but this is not the case: using employment data implicitly assumes that the multinational part of the enterprise (i.e., of its capital structure) is $100 \%$, which is generally not the case. More realistically, labor and industrial relations in a company will be shaped by the share of foreign to total voting rights in the corresponding enterprise, which is reflected in FDI data (see chapter 2 for details).

${ }^{187}$ Total sales are "the value of goods and services sold and, for financial firms, also includes investment income. It is net of returns, allowances, and discounts and excludes sale or consumption taxes levied directly on the consumer and excise taxes levied on manufacturers, wholesalers, and retailers" (BEA website).

188 "U.S. imports of goods by foreign affiliates consists of U.S. imports shipped by foreign affiliates to U.S. parent companies and to unaffiliated U.S. persons. Imports are valued on an f.a.s. (free alongside ship) basis - they exclude transit costs, such as the costs of shipping and insurance" (BEA website).

${ }^{189}$ One could argue that financial FDI should not be considered in this disentangling exercise. However, first of all it is not clear if this is justified since financial FDI shares many characteristics of other (tertiary sector) FDI (cf. Goldberg 2007) and "speculative" and other short-term intercompany flows are generally not considered FDI, although it may be hard to identify them in certain cases (cf. IMF 2004, pp. 3, 20-21). Furthermore, one would run into technical problems because BEA changed the FDI industry classification in 1999 from SIC to NAICS.
} 
all FDI stocks, so that estimated parameters can be interpreted as elasticities.

Table 32 in Appendix D shows the average total US outward FDI stocks for all countries in the sample, as well as the share of vertical FDI in these stocks. The UK, Netherlands and Switzerland were the main host countries of US outward FDI, but as is the case for most European countries (except Ireland and Sweden), the share of vertical investment is rather low (about $2 \%$ ). Since horizontal FDI is mainly driven by transportation costs, which increase with distance, this is not surprising and corresponds to the stylized fact presented by Markusen (1995) that most FDI is horizontal. The data may, however, overestimate the degree of horizontal FDI since, for example, a sale from a French US affiliate to an Irish US affiliate that is then imported by the US parent enters the statistics once as a horizontal sale (FranceIreland) and once as a vertical one (Ireland-USA), although the whole production chain is mainly vertical in nature. However, this mainly leads to a potential inadequacy across country statistics, while I am only exploring within-country variations by using country-fixed effects. Thus, the issue is of minor importance. ${ }^{190,191}$

\subsubsection{Labor Rights}

In order to examine labor rights violations, I use the labor rights dataset of Mosley and Uno (2007) with the extension of Greenhill et al. (2009), and refer the interested reader to their contributions for more details on the data. The index is constructed annually from 1985 to 2002 for 135 countries. Because of the non-availability of detailed FDI measures, I have to restrict the sample to the 1997-2002 period. Generally, this composite index, capturing "basic collective labor rights," follows the template of Kucera (2002), which covers 37 types of violations of labor rights under six different categories. It is noteworthy, however, that the index does not capture aspects of labor standards such as minimum wages, employment benefits or direct working conditions. The exclusion of minimum wages is especially helpful in this case since my model treats labor rights as a bargain against (minimum) wages. In each of the abovementioned six categories, violation of labor rights by the government or employers (local or foreign firms) are identified as an absence of legal rights, limitations on legal rights and a violation of those legal rights, thus dealing separately with both the de jure (laws) and de facto (practices) aspects of labor rights

\footnotetext{
${ }^{190}$ Badinger and Egger (2010) find that "motives of multinational activity and interdependence across host markets are at least as and even more strongly related to vertical than horizontal linkages" (753). This does not conflict with my data, however, since their findings only imply that vertical considerations of intermediate goods inputs do matter considerably for the exact location decisions of US MNCs in Europe, yet though the main motive of the activity is still horizontal. Furthermore, they also assume that the main determinants of horizontal and vertical interdependence between countries are time-invariant $(747 / 748)$ and, as mentioned above, fixed effects results will still be consistent in my case under this assumption as it only explores the within-country dimension.

${ }^{191}$ Another problem of valuating horizontal versus vertical FDI is the issue of transfer pricing in sales data. However, the problem is again expected to be more relevant across countries than within countries over time.
} 
prevailing in a country. If a violation of labor rights is reported by the US State Department's annual country reports on human rights practices, the Committee of Experts on the Application of Conventions and Recommendations (CEACR) and the Committee on Freedom of Association (CFA), Mosley and Uno (2007) assign a score of 1 to the corresponding (of the 37) indicators for a country. If this is not the case, a score of 0 is assigned. ${ }^{192}$ These individual scores are then combined with weights given for each category. The sum of these category scores is then the annual measure of labor rights violations, ranging from 0 (high violations) to 76.5 (no or very few violations). ${ }^{193}$ Although the theoretical maximum value is 76.5 , no country has a score of above 37 in the sample. Overall, the comprehensive measure of Mosley and Uno (2007) is a huge improvement on previous measurements, like Cingranelli and Richards (2006) and Bohning (2005), because of the multiple sources of information, sophisticated weighting methodology and reliability of the information (the annual reports mentioned earlier are evaluated by trained experts from the ILO).

As mentioned before, the labor rights index is further disaggregated into two components based on Greenhill et al. (2009), namely a de jure labor rights laws index and a de facto labor rights practices index. While the aforementioned previous studies in the literature quantify both legal and practices using single dimension measures, I disaggregate labor rights into law and practice sub-indices. Labor law and labor practice sub-indices are derived from the aggregate labor rights index, where the former refers to the extent to which the laws put in place safeguard labor rights, and the latter gauges the actual violations of these laws in a country. The 37 aspects of the labor rights index are divided among these two sub-indices, in which 21 items are reserved for laws and the rest of the 16 categories are associated with practices. As explained by Greenhill et al. (2009: 676), typical 'law' components of the scale include measures such as whether certain industrial sectors are allowed to impose limits on the right of workers to join unions or strike (items 16 and 34 in table 34 in Appendix D), or whether workers need government approval in order to engage in collective bargaining in the first place (item 25 in table 34 in Appendix D). In contrast, representative 'practice' components of the scale include whether acts of violence are reported to have been carried out against union leaders (items 1 and 2 in table 34 in Appendix D), or whether some firms make employment conditional on non-membership in a union (item 9 in table 34 in Appendix D). Table 34 in Appendix D provides a detailed classification of these categories between the two sub-components. Similar to the overall index, the de jure labor laws rights are coded on a scale of $0-28.5$, while de facto labor practice rights range from $0-27.5$, wherein higher values represent upholding respect for labor laws and practices.

Unlike other indices, these two dimensions of the labor rights index are independent

\footnotetext{
${ }^{192}$ If a violation of labor rights in respective indicators is recorded more than once, in either one source or in multiple sources, the maximum value according to Mosley and Uno remains 1.

${ }^{193}$ For ease of interpretation, the original score (in which 76.5 is high violation of labor rights and 0 being low violations) is reversed by Mosley and Uno.
} 
Table 17: Bivariate Correlations Among the Two Components of Labor Rights

\begin{tabular}{lccc}
\hline & LR Index & LR Laws & LR Practices \\
\hline Labor Rights Index & 1.0000 & & \\
Labor Rights Laws & 0.8277 & 1.0000 & \\
Labor Rights Practices & 0.7197 & 0.2060 & 1.0000 \\
\hline
\end{tabular}

of each other. As seen in table 17, the two different components that make up the labor rights index are only moderately correlated with each other $(\hat{\rho}=0.21)$, albeit both being highly correlated with the aggregated labor rights index $(\hat{\rho}=$ 0.83 and 0.72 , respectively). Note that I especially focus on de facto labor rights in industrialized countries because the model in the previous section refers to the matching of employees and employers in market economies, rather than being a political economy model about institutions and corresponding de jure labor rights.

\subsubsection{Other Control Variables}

First and foremost, the set of control variables $\left(\Psi_{i t}\right)$ includes the unemployment rate because the model in the previous section suggests that unemployment might lead to a higher willingness to accept de facto repression of labor rights. I include other potential determinants of labor rights according to the extant literature on the subject. I follow the studies of Greenhill et al. (2009); Mosley and Uno (2007); Neumeyer and de Soysa (2005, 2006, 2007); Busse (2004) and other comprehensive evaluations focusing on determinants of labor rights violations (Caraway 2009; Arestoff and Granger 2004; Brown 2001). Accordingly, the models control for the effects of development by including (logged) per capita GDP in US-\$, using year 2000 constant prices. Following Neumeyer and de Soysa (2006), I include manufacturing value added share in $G D P$, which is included as it is more difficult to identify the violation of labor rights in the primary sector, and the total labor force participation rate taken from World Bank (2010b) WDI.

I also include political variables, namely democracy measured by the Polity IV index ranging from -10 (hereditary monarchy) to +10 (consolidated democracy), and ideology of the incumbent government (cf. Boockmann 2006). The latter is taken from the database of political institutions (Beck et al. 2001) and converted into a dummy variable leftist, which equals 1 when a leftist government is in power and 0 otherwise. Additionally, I account for basic human rights using the physical integrity rights (PIR) index constructed by Cingranelli and Richards (1999), ranging from 0 (no government respect for human rights) to 8 (full government respect for basic rights). For the data sources and their means and standard deviations, see table 33 in Appendix D. 


\subsubsection{Econometric Model}

The main statement I want to investigate is the hypothesis that the state of labor rights, $y$, in a country $i$ at time $t$, depends to some functional form $g(\cdot)$ on the degree of vertical and horizontal activities of multinational corporations $\left(x^{v}\right.$ and $x^{h}$, respectively) and a set of control variables $\Psi$ :

$$
\mathbb{E}\left(y_{i t} \mid \Psi_{i t}\right)=g_{i}\left(\beta_{1} x^{v}, \beta_{2} x^{h}\right) .
$$

I start my analysis by using a simple static two-way fixed effects (FE) model ${ }^{194}$ in a $\log -\log$ form:

$$
\log (\text { laborrights })_{i t}=\hat{\alpha}_{i}+\hat{\beta} \log (F D I)_{i, t-1}+\Psi_{i, t-1} \hat{\theta}+\hat{\gamma}_{t}+\varepsilon_{i t}
$$

where $i=1, \ldots, N$ indicates a host country, $t=1, \ldots, T$ is a time period, $\log (F D I)$ may either be one or more measures of the logarithm of FDI, $\Psi$ includes the set of control variables, and $\varepsilon \dot{\sim} N\left(0, \sigma^{2}\right)$ is an i.i.d. error term. ${ }^{195}$ I compare the model using my disentangled FDI measure to a model with the overall FDI measure that is usually used in the literature.

In a second step, I then use a dynamic model that accounts for potential persistence in the dependent variable:

$$
\log (\text { laborrights })_{i t}=\hat{\alpha}_{i}+\hat{\phi} \log (\text { laborrights })_{i, t-1}+\hat{\beta} \log (F D I)_{i, t-1}+\Psi_{i, t-1} \hat{\theta}+\hat{\gamma}_{t}+\varepsilon_{i t} .
$$

It is well-known that OLS estimation of a lagged dependent variable (LDV) model like in equation (5) is biased (Nickell 1981). Therefore, I use the System GMM estimator developed by Arellano and Bover (1995) and Blundell and Bond (1998) as implemented by Roodman (2009a), and compare it to FE and pooled OLS estimation to assess the reliability of the former estimate. This framework uses suitably lagged first differences as instruments for the levels equation and also allows addressing potential endogeneity of FDI and assess autocorrelation in the residuals with the test statistic derived by Arellano and Bond (1991). In any specification, I instrument the lagged dependent variable and (lagged) FDI variables with lags 1 and 2, as well as collapsing the instrument set in order to prevent overfitting problems with the (potentially) endogenous variables, as proposed by Roodman (2009b, pp. 148f). Note that due to the low number of observations relative to the moment conditions, I have to rely on a one-step estimation of the VCV matrix, which will lead to an overestimation of standard errors, i.e., conservative inference.

In both the OLS and the System GMM framework I lag all covariables by one period since I would not expect an immediate response in most cases. This also helps in weakening endogeneity concerns. I also include time dummies $\gamma$, which are important

\footnotetext{
${ }^{194}$ A Hausman-test clearly allows to reject the null hypothesis that the difference between the $\mathrm{FE}$ and $\mathrm{RE}$ is not systematic in all specifications in table 18, thus I have to rely on the (potentially consistent) FE estimator instead of the (more efficient) RE estimator.

${ }^{195}$ I control for heteroscedasticity and autocorrelation in the residuals by using a Huber (1967) and White (1980) covariance estimator.
} 
when accounting for potentially positive cross-country correlations due to "global" shocks. Furthermore, I will look at the aggregate overall labor rights index, de facto labor rights practices and de jure labor rights laws separately.

\subsection{Empirical Results}

\subsubsection{Static Estimation}

Table 18 shows the results for the static FE estimation. In the first two columns, the (log of the) aggregated labor rights index is the dependent variable. Here, I find that overall FDI (in model (2)) has a negative impact on aggregate labor rights, which is weakly statistically significant. If one looks at model (1), where horizontal and vertical FDI are split up, horizontal FDI has a negative and statistically significant influence on labor rights, while vertical FDI does not seem to matter. The significance of horizontal FDI is remarkable because the specification suffers from collinearity between horizontal and vertical FDI $(\hat{\rho}=0.71)$, which will increase the standard errors (while still producing consistent estimates). ${ }^{196}$ With an $R^{2}$ of about $1 / 3$ within countries, and of about 0.5 overall, the model provides a reasonable fit and one can easily reject the null hypothesis of the F-test, i.e., that the whole set of covariates has no impact on labor rights, at the $1 \%$ level.

While standard model selection criteria such as BIC and AIC prefer model (2) over model (1), there is some evidence suggesting that one should rely on model (1) when one is interested in the impact of FDI on labor rights: the Wald test (p-value reported in the last line of table 18) for the null hypothesis of equality of the coefficients for vertical and horizontal FDI allows to reject the null, at the $10 \%$ level of statistical significance. Accordingly, the model which is preferable depends on the purpose of the investigation. Note that AIC and BIC both try to incorporate the trade-off between errors due to approximation and due to estimation (cf. Zucchini 2000), and the second depends on the sample size, which is rather low in this case. This means that the models with less parameters are less volatile to random structures in the data and thus lead to more robust prediction performance, for example. In applied economic research, however, one is often more interested in the correct identification of the economic channels than in the overall model performance, and the reported results suggest that the impact of horizontal FDI on labor rights might be different from the impact of vertical FDI.

To further investigate the economic channel at work, I look at de facto and de jure labor rights as the dependent variable in the other columns of table 18. I find that the impact of horizontal FDI on labor rights seems to work through undermining existing legal standards in practice. This is because the impact is statistically significant in models (3) and (4), but not in models (5) and (6), which take de jure labor rights as the dependent variable. Note that overall, the model characteristics are also much worse for the latter ones $\left(R^{2}\right.$ is only about half the size of the former models:

\footnotetext{
${ }^{196}$ If horizontal FDI is excluded, vertical FDI is still not significant (t-statistic 0.05). When excluding vertical FDI, horizontal FDI is weakly significant (t-statistic -1.78).
} 
in model (5) we would not reject the F-hypothesis that the whole set of covariates has no impact on labor rights, at the $5 \%$ level).

Again, in models (3) and (4), model selection criteria that look at the overall model fit prefer the reduced model (4) that only takes total FDI into account, but again, this might shadow the economic channels at work, i.e., the fact that the effect is mainly driven by horizontal investment, which is suggested by the parameter estimate. However, one could not statistically reject the null hypothesis of equality of parameters due to the imprecise estimation of the coefficient for vertical FDI in model (3). ${ }^{197}$

Table 18: Fixed Effects Results (static)

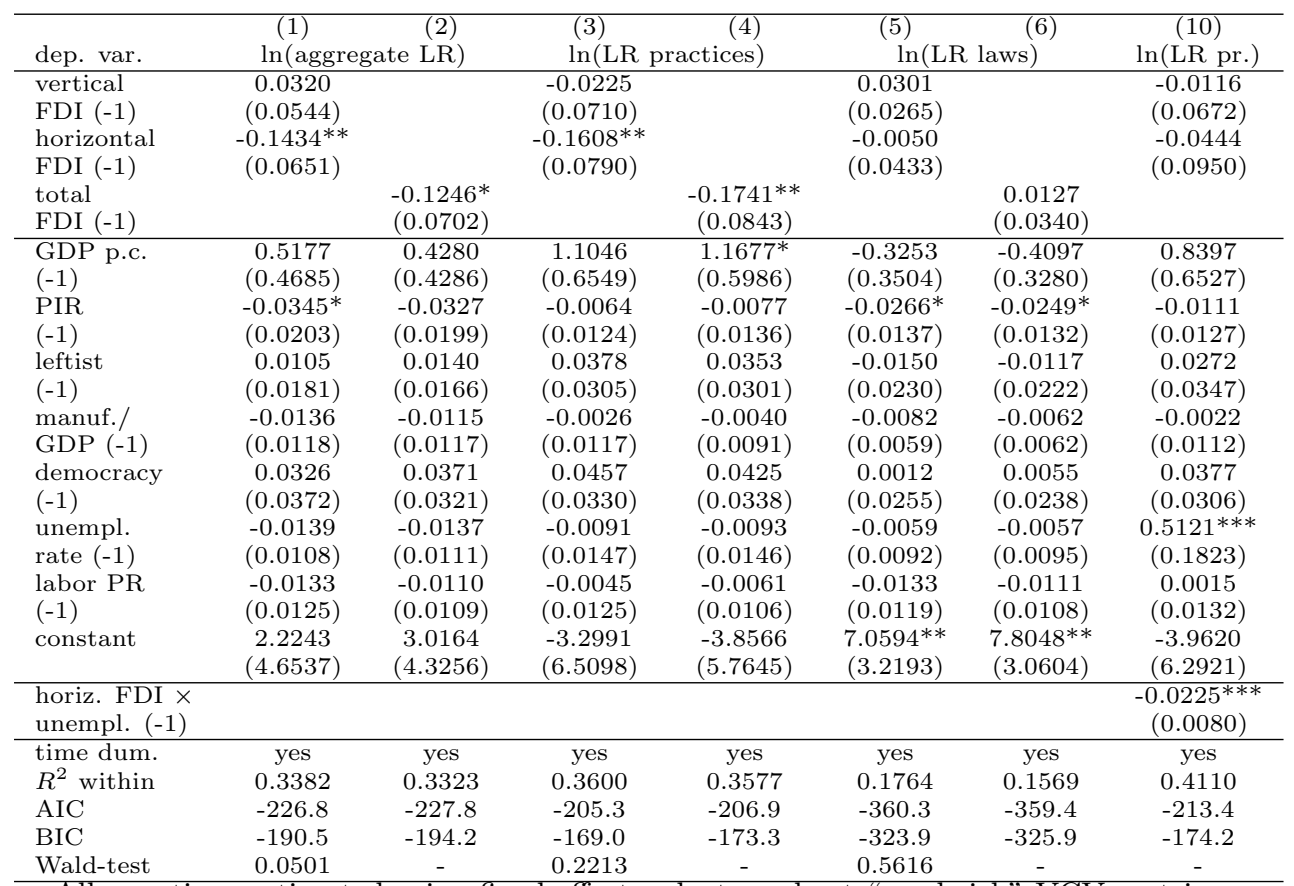

All equations estimated using fixed effects, cluster robust "sandwich" VCV matrices, 121 observations $(\mathrm{N}=34$, average $\mathrm{T}=3.6)$

\footnotetext{
${ }^{197}$ Remember that there is collinearity between vertical and horizontal FDI. Accordingly, standard errors will increase which in turn reduces the power of the Wald test.
} 


\subsubsection{Dynamic Estimation}

In table 19, I provide the results of the dynamic specification where a lagged dependent variable (LDV) is added as a supplementary covariable on the right hand side. In model (7), where aggregated labor rights is the dependent variable, I still find a negative impact of horizontal FDI. However, now it is only significant at the $10 \%$ level (t-statistic -1.71), but one must remember that the standard errors are overestimated due to the one-step procedure. The size of the parameter (-0.1006) appears to be smaller than the one from the static estimation in model (1). However, one must keep in mind that this is only the short-run effect. After taking long-run effects into account via the lagged dependent variable ${ }^{198}$ this would correspond to an impact of -0.19 and thus be somewhat higher than in the static estimation. Looking at key indicators of the overall model, I find support for the specification: the lagged dependent variable is highly significant and far from a random walk. One would expect it to lie between the generally downward-biased $\mathrm{FE}$ and the generally upward-biased pooled OLS estimate (cf. Bond 2002, p. 4/5), which are reported in the last lines of table 19, and this is in fact the case. As one would expect, one can reject no $\operatorname{AR}(1)$ serial correlation in the residuals but cannot reject no autocorrelation of order 2 . Furthermore, one cannot reject the null hypothesis of the Hansen test statistic that the whole set of instruments is jointly valid.

When looking at the dynamic impact on labor rights practices in model (8), I do not find a significant effect for either of the FDI measures. However, as outlined, the inference is conservative due to the one-step procedure and the estimate is at the borderline of weak significance for horizontal FDI (t-statistic -1.56) despite a rather small set of instruments. The long-run coefficient of -0.21 is again similar and slightly higher than the static estimate in model (3). Conventional test statistics indicate that the model is well-specified. I hence find it important to highlight that the quantitative economic implication is similar under both models and to not confuse this with a statistical concept of significance (cf. Ziliak and McCloskey 2004) that is over-conservative in this application.

Interestingly, when looking at labor laws, which one would expect to be highly persistent over time, I do not find the dynamic specification to be very appropriate. Here, the LDV is insignificant and falls outside the interval given by the FE and POLS estimations, and both the AR(1) and the Sargan test results seem worrisome.

\subsubsection{Other Controls}

Besides the GMM specification in model (7), the control variables are barely significant. However, this should not be of major concern because their identification is not the exercise of this paper, and many cases are just on the borderline of weak significance. As expected, I find a positive impact of GDP p.c. on labor rights in most specifications, and a leftist government seems to be favorable for labor rights,

\footnotetext{
${ }^{198}$ long-run coefficient $=\beta /(1-\phi)$
} 
Table 19: System GMM Results (dynamic)

\begin{tabular}{lccc}
\hline dep. var. (logs) & $\begin{array}{c}(7) \\
\text { agg. LR }\end{array}$ & $\begin{array}{c}(8) \\
\text { LR practices }\end{array}$ & $\begin{array}{c}(9) \\
\text { LR laws }\end{array}$ \\
\hline LDV & $0.4715^{* * *}$ & $0.6185^{* * *}$ & -0.2659 \\
& $(0.1642)$ & $(0.1480)$ & $(0.3351)$ \\
\hline vertical & 0.0412 & 0.0049 & $0.0843^{*}$ \\
FDI (-1) & $(0.0389)$ & $(0.0395)$ & $(0.0463)$ \\
horizontal & $-0.1006^{*}$ & -0.0807 & -0.0969 \\
FDI (-1) & $(0.0589)$ & $(0.0518)$ & $(0.0667)$ \\
\hline GDP p.c. & $0.2389^{* * *}$ & $0.1911^{* * *}$ & 0.1176 \\
(-1) & $(0.0583)$ & $(0.0448)$ & $(0.0722)$ \\
PIR & 0.0001 & -0.0098 & 0.0213 \\
(-1) & $(0.0182)$ & $(0.0162)$ & $(0.0191)$ \\
leftist & $0.1013^{* *}$ & 0.0516 & 0.0770 \\
(-1) & $(0.0440)$ & $(0.0346)$ & $(0.0563)$ \\
manuf./ & $-0.0104^{*}$ & -0.0054 & $-0.0135^{* *}$ \\
GDP (-1) & $(0.0053)$ & $(0.0034)$ & $(0.0062)$ \\
democracy & $0.0171^{* * *}$ & -0.0027 & $0.0424^{* * *}$ \\
(-1) & $(0.0050)$ & $(0.0054)$ & $(0.0141)$ \\
unempl. & $0.0134^{* *}$ & -0.0007 & $0.0238^{* * *}$ \\
rate (-1) & $(0.0060)$ & $(0.0046)$ & $(0.0071)$ \\
labor PR & -0.0024 & -0.0052 & 0.0045 \\
(-1) & $(0.0035)$ & $(0.0036)$ & $(0.0046)$ \\
constant & 1.1009 & $1.6538^{* * *}$ & $2.9259^{* * *}$ \\
& $(0.8771)$ & $(0.5946)$ & $(0.9983)$ \\
\hline time dummies & yes & yes & yes \\
\# of instruments & 21 & 21 & 21 \\
AB AR(1) z-stat & -2.52 & -2.63 & -0.05 \\
AB AR(2) z-stat & 0.51 & -0.12 & -0.60 \\
Sargan (p-val) & 0.16 & 0.91 & 0.00 \\
Hansen (p-val) & 0.55 & 0.91 & 0.48 \\
\hline FE LDV & 0.27 & 0.37 & 0.05 \\
POLS LDV & 0.82 & 0.67 & 0.74 \\
\hline All & $-16 u t i o n s$ & \\
\hline
\end{tabular}

All equations estimated using one-step system GMM with cluster robust "sandwich" VCV matrices and small-sample correction; 121 observations ( $\mathrm{N}=34$, average $\mathrm{T}=3.6)$; $\mathrm{AB} \mathrm{AR}(\mathrm{l})$ is the Arellano and Bond (1991) test for no autocorrelation of order 1.

especially their practices. Notwithstanding statistical insignificance, the impact of the manufacturing ratio relative to GDP on labor rights and the democracy control variable both show the expected sign. Interestingly, there is some evidence that the physical integrity rights index is negatively correlated to labor rights in most specifications.

When focusing on the dynamic model in table 19, I find all the aforementioned controls (besides the PIR index) to be (at least weakly) significant and showing the expected sign in specification (7). The positive impact of democracy seems to operate 
via legislation. Somewhat surprising is the positive impact of unemployment on labor rights. However, it seems this impact also operates via legislation and one cannot totally exclude reversed causality or simultaneity in this case because although the unemployment rate is lagged by one year, this series is very persistent. Hence, strong de jure labor rights might have an adverse impact on employment, or governments may see a reduction of de jure labor rights as a potential policy to generate more employment.

\subsubsection{Identifying the Economic Channel}

I have argued that the negative effect of horizontal FDI on labor rights operates via the strong bargaining position of horizontal MNCs and the higher unemployment rate for the factors that are used intensively by horizontally integrating multinationals. To address the reliability of the latter channel, I add an interaction term between horizontal FDI and the unemployment rate to the specification in model (3). The results are provided in model (10) of table 18 and show that the overall fit of the model, measured by $R^{2}$, considerably increases, although the model selection criteria still prefer model (1) or (2) over (10).

The estimated coefficients can be interpreted from the results in table 20, which explicitly addresses labor rights practices and uses standardized variables, i.e., each variable (excluding the interaction) is transformed so that their mean is 0 and the standard error is 1 . I find a strong negative and statistically weakly significant impact of horizontal FDI on labor rights practices that becomes even stronger when the unemployment rate is higher (indicated by the negative coefficient of the interaction). The impact of the unemployment rate, though not the focus of this investigation, is surprisingly positive but economically small and far from being statistically significant. An F-test allows rejection of the null hypothesis that horizontal FDI and its interaction with the unemployment rate jointly have no impact on labor rights practices, at the $10 \%$ level of statistical significance. On the contrary, we cannot reject the null of joint insignificance of unemployment and its interaction with vertical FDI at conventional levels of significance. Since the F-test of joint significance of the single variable of interest and its interaction with unemployment is the appropriate test statistic, this finding provides support for my main argument, i.e., the negative coefficient on horizontal FDI and its interaction with unemployment clearly suggests that the higher unemployment is, the more negative the impact of horizontal FDI will be on labor rights practices.

\subsubsection{Economic Relevance}

Before concluding the chapter, I want to highlight the economic relevance of the results in regards to the negative impact of horizontal FDI on labor rights. The standard deviation of horizontal FDI during the time period under investigation was 1.35, meaning that a one standard deviation increase in horizontal FDI would, ceteris paribus, lead to a decrease in aggregate labor rights of about $20 \%$ (using the estimate from model (1)). Throughout the same period, the log of horizontal FDI grew from 
Table 20: OLS Results With Interaction (and standardized variables)

\begin{tabular}{lcc}
\multicolumn{2}{c}{ dependent variable: $\ln$ (labor rights practices) } \\
\hline Variable (standardized) & Coefficient & Standard Errors \\
\hline (1) horizontal FDI & $-1.04^{*}$ & 0.564 \\
(2) unemployment rate & 0.029 & 0.429 \\
(3) interaction of (1) \& (2) & -0.683 & 0.428 \\
\hline other controls & \multicolumn{2}{c}{$7+$ vertical FDI } \\
time dummies & \multicolumn{2}{c}{ yes } \\
p-val of joint F-test (1) \& (3) & \multicolumn{2}{c}{0.074} \\
p-val of joint F-test (2) \& (3) & \multicolumn{2}{c}{0.246} \\
\hline
\end{tabular}

23.2 to 23.6, while the $\log$ of aggregate labor rights fell from 3.38 to 3.27 . This means that the increase in horizontal FDI was responsible for $\frac{-0.14 \cdot 0.4}{-0.11}=56.6 \%$ of the decrease in (aggregate) labor rights observed during the period under investigation. This is a very considerable magnitude, but the effect may also capture (parts of) the impact of horizontal FDI from other countries that I could not measure due to non-availability of data. Maybe even more important is that the increased presence of multinationals may not only lead to an erosion of labor standards, but also to an increase in labor disputes. As mentioned in the introduction, multinationals arise from the industrial relations of a certain home country context, and may therefore have certain expectations regarding labor practices and industrial relations that are not adequate for the host country. This could lead to an initial dispute that could be ironed out afterwards. Nevertheless, the dataset used would pick up the resulting struggles between multinationals and workers as an erosion of labor rights practices. Having this potential limitation - that certainly applies to other studies based on the same data set - in mind, the estimated effect of multinational corporations on labor standards may be too large.

\subsection{Conclusion}

In this chapter, I have argued that the previous economic literature has failed to find robust evidence of an impact of FDI on labor rights because it has not accounted for the different rationales behind horizontal and vertical investment, nor the different factor intensities they employ. With this in mind, I derived an economic explanation of why this should lead to different outcomes and showed that horizontal FDI is expected to have a negative impact on de facto labor standards.

Focusing on FDI stocks from the world's largest investor, i.e., the USA, in 34 industrialized countries between 1997 and 2002, I have shown that the horizontal part of FDI indeed has a negative impact on labor standards that mainly operates through de facto labor rights practices. It is thus possible that the statistical significance of the impact of FDI on labor rights in other studies is shadowed by opposing effects of horizontal and vertical FDI. By only capturing total FDI, researchers implicitly assume both parameters to be equal. In this study, however, I show that this hypothesis can be rejected, at the $10 \%$ level of statistical significance (in model (1)). 
Some of the results even suggest that the impact of vertical FDI on labor rights is positive; most related results are at the borderline of weak statistical significance. Furthermore, these results indicate that the impact operates via de jure labor laws. One could imagine a situation in which monopolistic competition exists in the vertical sector, where foreign and home multinationals compete for the best workers and influence policy to implement high labor standards in order to deter other firms from entering the market. Future research might explore this possibility in more detail but it is beyond the scope of this chapter.

This chapter clearly supports attempts in the field to go beyond "one-size-fits-all" arguments. Furthermore, I see the focus on one home country not as a limitation, but instead as a potential strength: investors come from different institutional backgrounds and assuming homogeneity in the impact of their investments in the host economy is often a strong assumption. Also, this research shows the distinction between the impact of de facto and de jure labor rights, as brought forward by Greenhill et al. (2009), to be fruitful.

The results do not necessarily imply that horizontal FDI would decrease welfare in the host economy. In the presented model, the reduction in labor standards is an outcome of the bargaining process between employers and employees. Since the latter voluntarily prefer the (lower quality) job over unemployment (or previous employment), there cannot be negative welfare implications. However, negative welfare implications might arise under bounded rationality, e.g., if individuals fail to adequately estimate the long-run consequences of low labor standards (such as deteriorating health conditions or ending up in a low-quality labor market trap).

In terms of policy, the results imply that short-run reform approaches from labor interest groups to create high standard, high income employment face the problem that income, labor standards and employment work as substitutes to some extent. This does not mean, however, that the creation of a full employment society with decent work, such as the situation aspired to by the ILO's "Decent Work Agenda" (cf. also European Commission 2008; Ocampo and Jomo 2007; Parent-Thirion et al. 2007; Clark 2009, G-20 2009, §99), is impossible in a globalized economy. In the model, the negative impact of horizontal FDI on labor standards emerges through the high bargaining power of these MNCs due to high unemployment in the segments of the labor market they use intensively. Here, I find empirical support for this channel. A macro policy that aims at lowering the equilibrium unemployment rate(s) is thus the most promising starting point towards achieving the goal of decent and full employment. 


\section{A Note on Globalization and Female Labor Force Participation in Developing Countries (joint with Arusha Cooray and Isis Gaddis)}

The end of labor is to gain leisure.

Aristotle

\subsection{Motivation}

An increase in female labor force participation (FLFP) is one of the most significant global developments of the last decades. There is a broad consensus that this is a generally welcome trend since it may contribute to women's economic empowerment and because underutilizing women's skills and labor causes economic costs (World Bank 2011; Klasen and Lamanna 2009). However, the determinants of this development are more controversial.

One strand in the literature has argued that FLFP would follow a U-shaped pattern with respect to economic development over the long term (cf. Gaddis and Klasen 2012, for a discussion and empirical assessment of this literature). Others (Çağaty and Berik 1990; Anderson 2005; Standing 1989; Wood 1991) have emphasized the role that openness and globalization play in this context. According to this literature, globalization exploits and changes the 'traditional' social and wage discrimination of women. Since the latter are prepared to work long for a low wage and without joining a union, exporting and multinational firms are more likely to employ women, especially since most tasks of the industries where developing countries have a comparative advantage are less skill-intensive or a priori expected to be femaleintensive. ${ }^{199}$ As Standing (1989) and Çă̆aty and Özler (1995) argue, the process might have been accelerated by structural adjustment programs often coming along with globalization, since the thereby increased labor market flexibility would make it easier for firms to substitute women for men.

Early case studies such as Cho and Koo (1983); Hein (1984); ILO (1985), or, later on, by Kabeer and Mahmud (2004), that are based on rather descriptive and anecdotal evidence, suggest that aspects related to globalization, such as export-led industrialization, export processing zones and increased employment in multinational firms have had a positive impact on FLFP. Using a fairly simple OLS regression for 3-digit SIC Turkish manufacturing industries in 1966 and 1982, Çăgaty and Berik (1990) show that the ratio of exports to output had a statistically significant positive impact on the female share of wage workers. A similar empirical strategy is applied to Indian

\footnotetext{
${ }^{199}$ Even if male-intensive sectors benefit most from increased openness, Sauré and Zoabi (2009) argue that FLFP may rise since men might leave female-intensive industries to take up the new jobs in the export sector, thereby opening up employment opportunities for women. Similarly, arguments in line with the agricultural linkages literature (Mellor and Lele 1973, 1975; Lele and Mellor 1981) can be built where the openness-induced surge in the male-intensive sector also spills over to the female-intensive sector through production and consumption linkages.
} 
industry data from the late 1990s and early 2000s by Pradhan (2006), who finds that exports have a significant and positive (though economically small) impact on the female/male working-days ratio, while FDI has no significant impact.

Özler (2000) improves upon this strand of the literature by using plant-level data for the period 1983-1985 from the Turkish manufacturing sector and shows that the female share of employment in a plant increases with the export-to-total-output ratio of the respective sector. While the plant-level perspective of the study has certain advantages, it fails to convincingly resolve the problem of an unobserved heterogeneity bias and cannot reveal any spillover effects on non-manufacturing sectors. In line with the arguments above, she notes that women are often employed in low-skill and low-paid jobs and especially among those establishments where investment in machinery and equipment leads to a decline in the female employment share, thus pointing to dynamic long-run effects disadvantageous to a feminization of the labor force (in this context, see also Wood 1998 and Seguino 2000). This suggests, globalization may first lead to an expansion of female-intensive sectors which then rationalize production by investment and technological progress.

Tying in with the above-mentioned literature on the feminization-U, Çağaty and Özler (1995) use another approach by using pooled data from 1985 and 1990 for 165 countries to investigate the impact of long-term development on the female share of the labor force. They argue that structural adjustment policies have led to an increase in feminization of the labor force via worsening income distribution and increased openness.

Gray et al. (2006) use data for 180 countries at five-year intervals between 1975 and 2000 to estimate the impact of trade (measured as the log of total imports plus total exports to GDP), FDI (as a percentage of the gross fixed capital formation) and other globalization-related variables on the female percentage share of the workforce and other female-specific outcome variables. Their finding (p. 319ff) that none of the two former variables has a significant impact on (relative) FLFP may be due to the fact that they exert a converse impact in developing versus industrialized countries; a heterogeneity that results in overall insignificant estimates.

Similarly, Bussmann (2009) addresses the wider research question whether economic globalization (in particular, total trade/GDP) improved certain aspects of women's welfare (especially health care and education). Using FE and GMM techniques for annual panel data for the period 1970 - 2000, she finds that trade/GDP increases overall FLFP in non-OECD countries.

While there are some opposite arguments highlighting that globalization, especially FDI, in developing economies benefits male engineers or computer programmers more than female ones because they are likely to be better educated (Oostendorp 2009), or pointing to occupational gender segregation (Greenhalgh 1985; Anker 1998; Anker 
et al. 2003), ${ }^{200}$ the large majority of empirical studies seems to suggest that globalization has raised FLFP in developing countries.

The aim of this chapter is to empirically (re-)address the above arguments from a broader perspective. This seems necessary since the supposed "stylized facts" from the above-mentioned studies suffer from certain methodological shortcomings. First, I find it risky to generalize from country-case studies to an overarching tale of globalization, feminization and development. On the other hand, most cross-country studies so far have suffered from the problem of potentially biased estimates due to unobserved heterogeneity. Finally, rather short time dimensions or the use of annual data have imposed certain restrictions on the equilibrium dynamics of the relationship between openness and FLFP. By using a comprehensive panel of 80 developing countries over almost three decades and applying a FE methodology that bases identification exclusively on over-time variation, I can deal with all of these potential problems and show that this leads to quite contrary results than the ones obtained in the mainstream literature. Furthermore, I improve on this literature by allowing for heterogeneous effects across age cohorts and emphasizing the role that the sectoral structure of the economy plays.

I describe the data in the subsequent section 6.2 because it is essential to understand their structure for the empirical model explained in section 6.3. I present the results in section 6.4. Section 6.5 discusses the results and concludes.

\subsection{Data}

I use data on FLFP from the 5th revision of the ILO's Estimates and Projections of the Economically Active Population (EAPEP) database (ILO 2009). The EAPEP contains data on the male and female economically active population based on country reports and ILO staff estimates for 191 countries, which includes both industrialized and developing countries. The 5th revision data covers the period 1980 - 2008; the data thus have a high overlap with the FDI and trade data used. In line with Gray et al. (2006) and Gaddis and Klasen (2012) and in order to weaken problems associated with serial correlation and to focus more on long-run effects (cf. chapter 2 of this dissertation), I consider the observations for every fifth year over the period 1980 - 2005 for estimation. ${ }^{201}$ The FLFP rate (FLFPR) of cohort $j$ in country $i$ at time $t$ is defined as the number of economically active women divided by the total female population (FPOP) of the relevant age group:

\footnotetext{
${ }^{200}$ Note that the effect of occupational gender segregation on female labor force participation in the context of globalization is not clear a priori and depends on the elasticity of substitution between female and male labor, the pattern of trade liberalization, and associated relative demand shifts.

${ }^{201}$ This should generally be similar to using 5 -year averages. However, much data is only available for every 5th year (e.g. the Barro and Lee 2010, dataset), or values between these observations are interpolated (e.g. for certain values in the EAPEP database) so that the argument for using 5-year averages is rather weak.
} 


$$
F L F P R_{i j t}=\frac{F L F P_{i j t}}{F P O P_{i j t}} .
$$

The ILO definition of economic activity captures all persons (employed or unemployed) that supply labor for activities included in the United Nations System of National Accounts (SNA, cf. ILO 1990). This includes self-employment for the production of marketed goods and services as well as the production of goods consumed within the household. It does, however, not include the production of non-marketed services (domestic tasks, nursing of own children), so they are also not included in the SNA. This distinction is important to remember, as many women outside of the labor force are employed in producing such non-marketed services. It should also be noted that the EAPEP data only provide information on economic activity rates, but not on total hours worked. Hence, the data allows investigating changes in labor supply at the extensive margin (participation decision) but not at the intensive margin (hours worked).

As one of the two main explanatory variables, I use the stock of inward FDI relative to GDP, taken from UNCTAD, as a proxy for the activity of MNCs in the economy under investigation. Financial stock data, as opposed to operational data reflects the effective share of foreign ownership in host country firms and is available for a large group of countries and years (cf. chapter 2). Furthermore, I use trade, imports and exports relative to GDP as measures of globalization. These data include trade in goods and services and come from the World Bank (2010b) World Development Indicators (WDI). WDI also provide most of the control variables such as GDP per capita in constant 2005 international PPP $\$$, the total fertility rate (births per woman), and the shares of agriculture and industry value added in GDP. From WDI, I also construct the percentage growth rate of real GDP p.c. (in constant local currency). Since I use FE models, the FE takes out the long-run average growth so that this variable should be interpreted as the cyclical component of the model. For years of schooling, I use the female measures of the corresponding cohorts provided by Barro and Lee (2010). In cases where I aggregate their data over various cohorts, I use the ILO female population data as weights. ${ }^{202}$ An overview over the variables and their summary statistics are provided in table 35 in Appendix E. Since the focus of this paper is on developing countries, I use countries classified as "low income" or "lower middle income" by the World Bank classification 1987, the first year available. This leaves a sample of 80 developing countries in total.

\subsubsection{Descriptive Analysis}

Figure 16 plots the distribution of the FLFPR for three decades (in 1985, in 1995 and in 2005). ${ }^{203}$ As one can see, the distribution gets smoother in the center in 2005 when

\footnotetext{
${ }^{202}$ Linear interpolation is used to obtain data points between the 5 -year survey intervals. This is necessary since most explanatory variables are lagged by one year.

${ }^{203}$ In order to make the data in and between figures 16 and 17 comparable, I only use observations which have no missing observations for FLFPR, FDI/GDP and trade/GDP in 1985, 1995 and 2005 for both graphs. I end up with 77 (developing) countries.
} 
compared to the decades before, which is also reflected in a decreasing standard error in table 21. The steadily increasing mean of the distribution in table 21 also shows that FLFP indeed increased over the period usually referred to as "globalization."

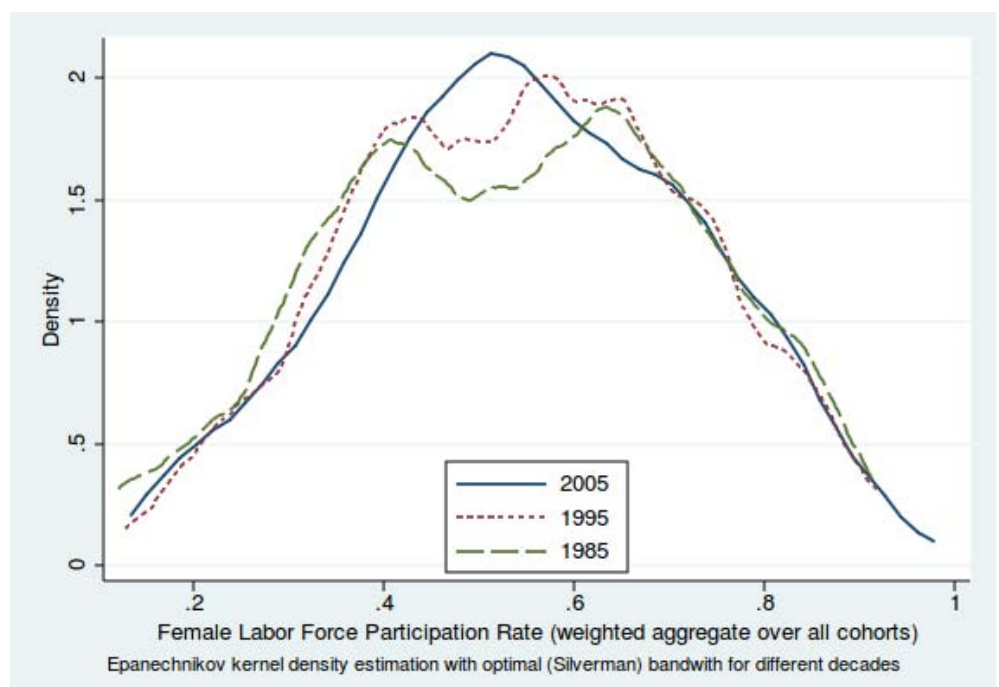

Figure 16: Distribution of Female Labor Force Participation Rate

Table 21: Descriptive Statistics of Main Variables

\begin{tabular}{lcccc}
\hline Variable & Statistic & 1985 & 1995 & 2005 \\
\hline \multirow{4}{*}{ FLFPR } & Mean & 0.507 & 0.524 & 0.549 \\
& Std. Dev. & 0.199 & 0.185 & 0.173 \\
& Min & 0.121 & 0.129 & 0.199 \\
& Max & 0.917 & 0.918 & 0.913 \\
\hline \multirow{4}{*}{ FDI stock / GDP } & Mean & 0.211 & 0.236 & 0.365 \\
& Std. Dev. & 0.339 & 0.275 & 0.355 \\
& Min & $8 \times 10^{-6}$ & 0.001 & 0.002 \\
& Max & 1.650 & 1.399 & 1.606 \\
\hline \multirow{5}{*}{ Trade / GDP } & Mean & 0.648 & 0.760 & 0.844 \\
& Std. Dev. & 0.376 & 0.408 & 0.401 \\
& Min & 0.130 & 0.025 & 0.003 \\
& Max & 1.517 & 2.133 & 2.121 \\
\hline
\end{tabular}

Figure 17 depicts the development of the two variables measuring globalization in the present context, FDI stock / GDP and trade / GDP, for the same years. As one can see, trade to GDP increased relatively steadily throughout the three decades while FDI / GDP experienced its main surge only in the last decade. 


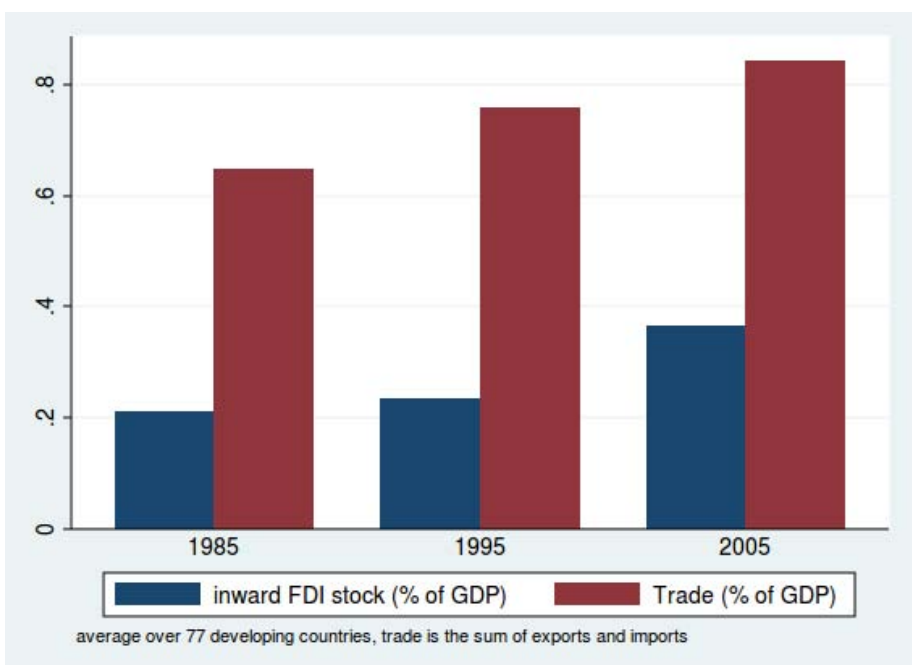

Figure 17: Development of Main Explanatory Variables

\subsection{Econometric Model}

Following the literature on determinants of FLFP (Çăgaty and Özler 1995; Bloom et al. 2009; Mammen and Paxson 2000; Gaddis and Klasen 2012), I estimate a linear model where the dependent variable is the FLFPR in levels and is explained by a number of covariates in $Z$ and $X$ that differ from each other by the fact that covariables in $Z$ are cohort and country specific, while covariables in $X$ are only country-specific. Accordingly,

$$
\frac{F L F P_{i j t}}{F P O P_{i j t}}=F L F P R_{i j t}=Z_{i j t} \theta+X_{i t} \beta+u_{i j t},
$$

where $u$ is an error term discussed below.

The dataset thus has two levels of cross-sections: countries $i=1, \ldots, N$ and age cohorts $j=1, \ldots, 10 .^{204}$ In the model, which hence can be considered as "hierarchical," I use country-specific cohort fixed effects, i.e. FE for every cohort which are allowed to vary by country. The reason is, first, that unobserved heterogeneity across countries is likely and the same holds for age cohorts. For example, the age cohort 15-19 years is less likely to join the labor force than the age cohort 35-39 if the former has a higher probability of being in education. Furthermore, I assume that these cohortfixed effects are country-specific due to different educational systems and differing conceptions of life across countries. Note that not controlling for this unobserved

${ }^{204}$ The age cohorts are 15-19, 20-24, 25-29, 30-34, 35-39, 40-44, 45-49, 50-54, 55-59, and 60-64. I excluded the cohort of $65+$ years from the analysis because labor force participation in this cohort is driven by factors that might be very different from other cohorts. 
heterogeneity will result in biased and inconsistent results if the heterogeneity is correlated with some right-hand side variables. This is a clear advantage over previous cross-section studies in the field. In the sample of 80 countries with 10 age cohorts, this leads to $80 \times 10=800$ cross-section fixed effects.

Furthermore, I control for time-fixed effects. This is motivated by the consideration that there may be global effects influencing the FLFPR which are correlated with the covariables. This may lead to both, biased results and cross-sectional dependence in the structure of the error term. Accordingly, $u$ has the structure

$$
u_{i j t}=\eta_{t}+\mu_{i j}+\varepsilon_{i j t},
$$

where $\mu_{i j}$ and $\eta_{t}$ are the country-cohort and time fixed effects, respectively, which are estimated and $\varepsilon$ is an i.i.d. error term. ${ }^{205}$ Note that I only take every fifth observation in time, i.e. $t=1980,1985, \ldots, 2005$ and that the only cohort-specific covariable in $Z$ is the educational data. In each of the columns of $X$, there will be 10 identical entries.

In summary, the identification strategy exclusively uses the data variation within the country-specific cohorts over 5-year intervals, accounting for global shocks at every point in time.

\subsubsection{Error Structure of the Model}

A concern of the model is the correlation structure of the idiosyncratic error $\varepsilon$. Despite using a 5-year interval, autocorrelation is one potential issue. Together with potential heteroscedasticity, this can easily be accommodated by using the HAC robust approach of Huber (1967) and White (1980) to estimate the VCV matrix. However, the hierarchical structure of the model (cf. Wooldridge 2003, and Wooldridge 2010, ch. 20, for an introductory treatment to such models) poses additional problems since, for example, the error $\varepsilon_{i j t}$ is likely to be correlated with the error $\varepsilon_{i, j+1, t+1}$ because the individuals in cohort $j$ in period $t$ will be in cohort $j+1$ in period $t+1$. Furthermore, there might be correlation between all errors $\varepsilon_{\cdot j t}$ within country $i$ if there is a systematic measurement error on the country level. All these potential problems with standard inference in linear models point to different forms of error correlation within countries. In line with the conventional panel data literature and given the dimension of the data set, one can assume that $N \rightarrow \infty$ and hence the number of countries, which are considered to be the "clusters," is large while the size

\footnotetext{
${ }^{205} \mathrm{~A}$ potential shortfall of the $\mathrm{FE}$ estimator is the fact that the process under investigation is likely to have a complex dynamic structure while FE can be seen as a 'short-run' estimator, as discussed in chapter 2 of this dissertation. An alternative dynamic estimator, however, is difficult to specify depending on the complexity of the dynamic process and will potentially suffer severely from parameter heterogeneity (cf. e.g. Pesaran and Smith 1995; Phillips and Sul 2003) which is in fact present as we show in Cooray et al. (ress). The FE estimator, in my view, has the advantage that its properties are studied extensively and well-known. Furthermore, since I use 5-year intervals and the main explanatory variables, FDI stocks and trade (or, exports) relative to GDP are very persistent variables, the static FE estimator may approximate the long-run impact, see chapter 2.
} 
of these clusters (i.e. the cohorts by country) is small. As discussed in Wooldridge (2003, p. 134, see also Wooldridge, 2010: pp. 864ff), a robust estimate for the VCV matrix is obtained by clustering the errors on the country level. Assuming that the matrix $W_{i}$ contains all fixed effects and explanatory variables, classified as $X$ and $Z$ above, for country $i$ and that the corresponding parameter vector $\delta$ contains $\beta, \theta, \mu$, and $\eta$, a robust VCV estimator for $\delta$ is given by

$$
V \hat{C} V(\delta)=\left(\sum_{i=1}^{N} W_{i}^{\prime} W_{i}\right)^{-1}\left(\sum_{i=1}^{N} W_{i}^{\prime} \hat{\varepsilon}_{i} \hat{\varepsilon}_{i}^{\prime} W_{i}\right)\left(\sum_{i=1}^{N} W_{i}^{\prime} W_{i}\right)^{-1}
$$

where $\hat{\varepsilon}_{i}$ is the $10 \cdot T \times 1$ vector of residuals for country (i.e. cluster) $i .{ }^{206}$ Using time-fixed effects is important in this context because it prevents the most likely form of cross-section, i.e. contemporaneous, correlation of the error term. I want to emphasize that clustering the errors at the country level has a tremendous impact on inference, as one would expect (cf. Wooldridge 2010, p. 865). If one would (wrongly) cluster on the country-specific cohort level instead, which is the standard option in most econometric packages, standard errors would be severely underestimated (cf. table 36 in Appendix E).

\subsection{Results}

The first four columns of table 22 show regressions of the FLFPR on the globalization variables without controlling for other effects (besides from the fixed effects). One can see that the impact is negative throughout and statistically significant only in two specifications for trade and exports. Note that trade and FDI are highly correlated, ${ }^{207}$ so multicollinearity inflates standard errors (while parameter estimates are still consistent) and I therefore report specifications with both variables together and separately. The negative impact of trade is driven by exports, so I rather focus on exports for the remainder of the analysis. The most striking fact besides from wanting statistical significance and the negative prefix, is the notably small economic relevance of both effects. The highest parameter is -0.064 for exports in column (4), implying that a 10 percentage points increase in exports / GDP ratio, roughly the increase observed over the 20 years 1985-2005, leads to a 0.64 percentage points decrease of FLFPR. Considering that the actual increase in FLFPR during the 20 years between 1985 and 2005 was 4.2 percentage points, this is a rather small magnitude.

The remaining models in table 22 include the seven control variables. While there is some change in the levels of statistical significance, the overall result remains rather

\footnotetext{
${ }^{206}$ An alternative approach would be using some FGLS model. Depending on the assumptions, this might provide statistically more efficient results, it is, however, computationally less efficient. I hence prefer the above approach because I find the assumptions less demanding and in the worst case the framework will provide conservative inference compared with potentially efficient FGLS results.

${ }^{207}$ Regressing FDI stock / GDP on the other covariables of model (7) using the same subsample and each 5th yearly observation leads to a highly significant estimator of 0.267 for trade / GDP (t-statistic 2.58).
} 
stable: There is no evidence so far, that globalization had an economically relevant impact on the FLFPR. With the control variables included, it is the FDI stock that seems to be more robust statistically, however, the magnitude is negligible since the estimated parameter, -0.0116 in the "best" case, implies that a 10 percentage points increase in FDI stock / GDP leads to a 0.12 percentage points decrease of FLFPR. Exports are only statistically significant when FDI stock is excluded (though standard errors are reasonable in model (5) as well), the economic relevance is barely higher than in the unconditional model (4), however.

These first results do not necessarily mean that the measures for globalization have no impact on women in their decision to join the labor force - they are aggregate effects and capture a wide range of different activities. In table 23 and figure $18 \mathrm{I}$ show the impact of the measure on different cohorts. (Note that the vertical axis is differently scaled for the two panels in figure 18.) This means that I allow the parameter for the impact of the globalization variables to vary between age cohorts. The overall picture that emerges shows that the impact is stronger for younger cohorts. This corresponds to the rationale that more labor market variability in going on at younger age levels and that the income effect might be particularly strong at these cohorts when compared to the substitution effect: A potential rise in wages due to a globalization boost might increase household income via the father's or spouse's wage bill whereas the substitution effect between staying out of the labor force or joining it may even become negative in the short run since the skill-premia might have risen and this creates supplementary incentives to stay currently out of the labor force and invest in education, especially for young women where the premium pays off over a longer lifetime.

While the impact is still very small for FDI, the effect of exports is now considerable for young females' labor decision: The parameter is 0.254 and 0.159 for the age groups 15-19 and 20-24, respectively. A parameter of 0.2 would imply that a 10 percentage point increase in exports would result in a 2 percentage point decrease in the FLFPR, a non-negligible effect. ${ }^{208}$ Note that the estimated impact is negative for all cohorts for both measures of globalization but not for all of them statistically significant in case of exports (the interval of \pm 2 standard errors roughly approximates a pointwise $95 \%$ confidence interval).

\footnotetext{
${ }^{208}$ Remember from table 21 that FLFPR increased by roughly 2 percentage points per decade.
} 


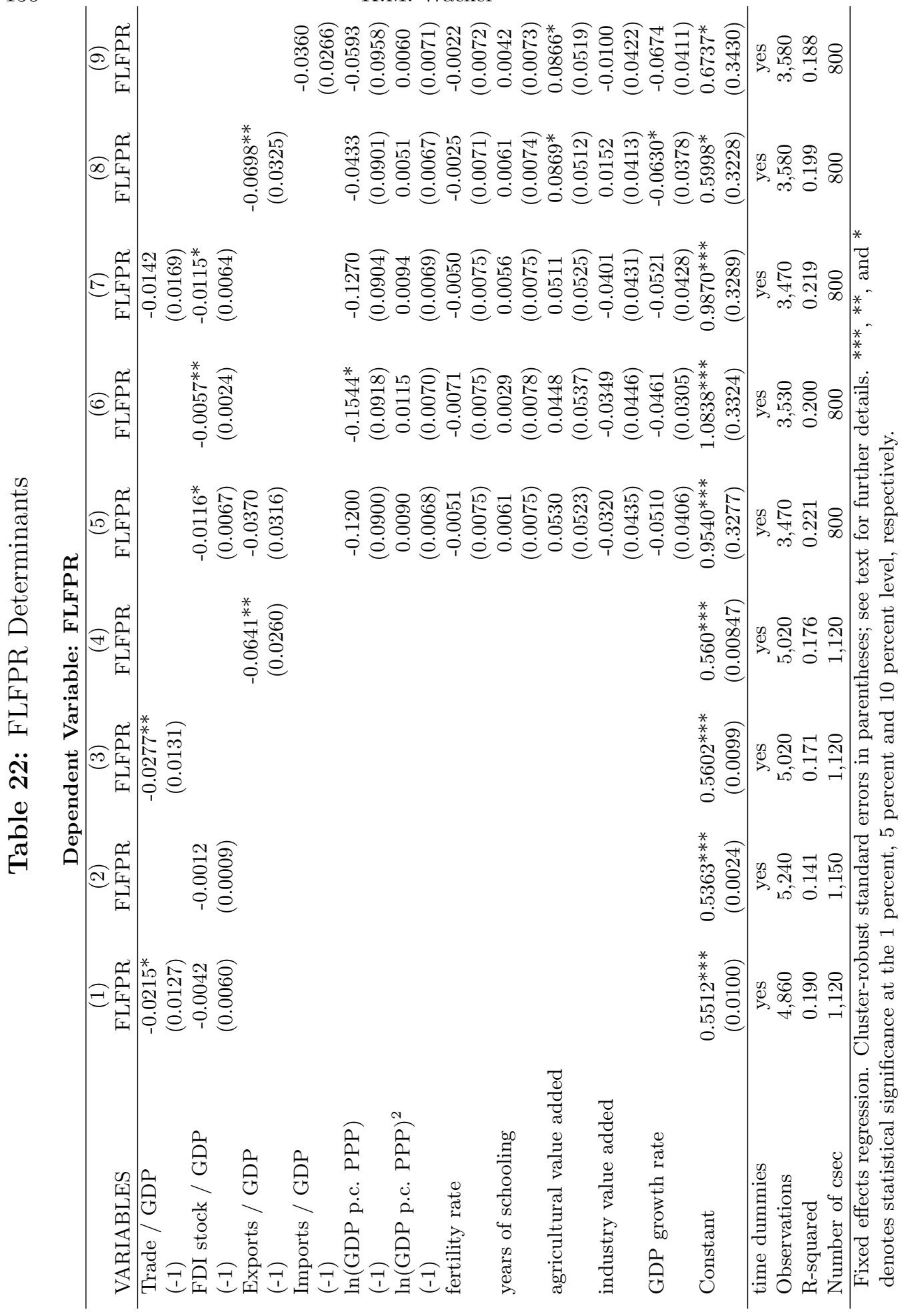


FDI

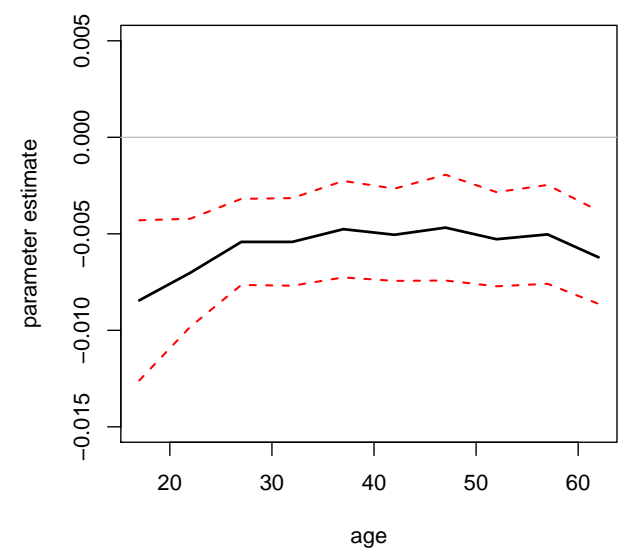

exports

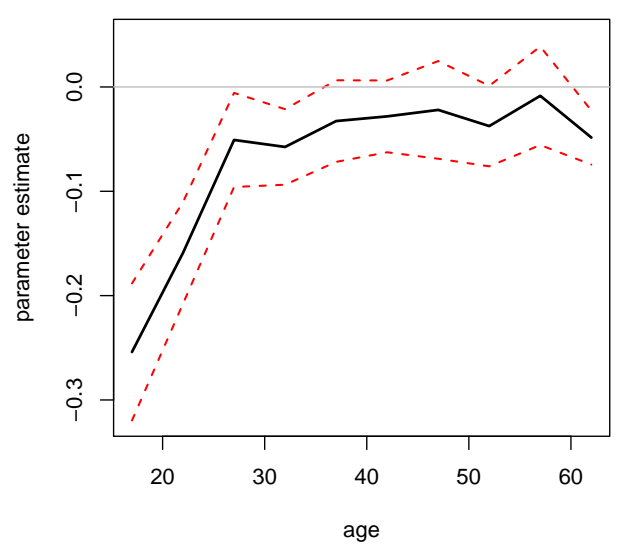

Figure 18: Impact of Globalization Variables ( \pm 2 standard errors) by Cohort

What could explain such a pattern? If one thinks within a standard trade framework, after trade-liberalization, countries will develop those sectors of their economy where they have a comparative advantage. For least developed countries these are lower skilled labor intensive industries. While women may have a "natural" advantage in some of these industries (especially certain task in the textile sector), most other tasks may benefit from physical strength and hence primarily demand male labor. Accordingly, one would expect that the impact depends on the country's comparative advantage and its level of industrial development. ${ }^{209}$

Another exercise supports this view, see table 24. In the first two columns I allow FDI to interact with the value added in the industry sector and the primary sector, respectively. In the first column, FDI stock is highly significant and negative with a similar magnitude as in model (5) of table 22, the interaction is about 3.5 the size of the mere FDI parameter and positive. ${ }^{210}$ This means that once the industrial sector is developed, more FDI will have no negative impact on FLFP. More precisely, once the industrial sector accounts for at least $28 \%$ of value added of the developing country's economy, additional FDI will have a positive impact. ${ }^{211}$ The magnitude

\footnotetext{
${ }^{209}$ This would suggest that the impact should generally be different between regions. In Cooray et al. (ress, table 4), we show that this is indeed the case.

${ }^{210}$ The estimate of the interaction parameter itself is not statistically significant (t-statistic 1.34). The relevant test statistic, however, is an F-test for joint significance of FDI and the interaction term. Here, one can reject that they jointly have no impact on FLFPR on the $1 \%$ level of statistical significance.

${ }^{211}$ A 10 percentage point increase in FDI will then have a $0.10 \times(-0.0179)+0.10 \times 0.28 \times$ $0.0642=0.0000076$ percentage points impact.
} 
Table 23: FLFPR Determinants per Cohort

Dependent Variable: FLFPR

\begin{tabular}{|c|c|c|}
\hline VARIABLES & $\begin{array}{c}(1) \\
\text { FLFPR }\end{array}$ & $\begin{array}{c}(2) \\
\text { FLFPR }\end{array}$ \\
\hline $\ln ($ GDP p.c. PPP $)$ & $-0.154^{*}$ & -0.0433 \\
\hline$(-1)$ & $(0.0920)$ & $(0.0902)$ \\
\hline $\ln (\text { GDP p.c. } P P P)^{2}$ & 0.0115 & 0.00506 \\
\hline$(-1)$ & $(0.00701)$ & $(0.00676)$ \\
\hline fertility rate & $\begin{array}{l}-0.00707 \\
(0.00753)\end{array}$ & $\begin{array}{l}-0.00247 \\
(0.00710)\end{array}$ \\
\hline years of schooling & $\begin{array}{c}0.00290 \\
(0.00781)\end{array}$ & $\begin{array}{c}0.00612 \\
(0.00738)\end{array}$ \\
\hline agricultural value added & $\begin{array}{c}0.0448 \\
(0.0537)\end{array}$ & $\begin{array}{l}0.0869^{*} \\
(0.0512)\end{array}$ \\
\hline industry value added & $\begin{array}{l}-0.0349 \\
(0.0447)\end{array}$ & $\begin{array}{c}0.0152 \\
(0.0413)\end{array}$ \\
\hline GDP growth rate & $\begin{array}{l}-0.0461 \\
(0.0305)\end{array}$ & $\begin{array}{c}-0.0630^{*} \\
(0.0378)\end{array}$ \\
\hline ...at age $15-19$ & $\begin{array}{c}\text { Effect of FDI... } \\
-0.00845^{* *}\end{array}$ & $\begin{array}{c}\text { Effect of Exports... } \\
-0.254^{* * *}\end{array}$ \\
\hline$(-1)$ & $(0.00415)$ & $(0.0657)$ \\
\hline $\begin{array}{l}\ldots \text { at age } 20-24 \\
(-1)\end{array}$ & $\begin{array}{c}-0.00702^{* *} \\
(0.00280)\end{array}$ & $\begin{array}{c}-0.159^{* * *} \\
(0.0487)\end{array}$ \\
\hline ...at age $25-29$ & $-0.00542^{* *}$ & $\begin{array}{l}-0.0508 \\
(0.0451)\end{array}$ \\
\hline ....at age $30-34$ & $-0.00542^{* *}$ & -0.0575 \\
\hline$(-1)$ & $(0.00227)$ & $(0.0362)$ \\
\hline $\begin{array}{l}\ldots \text { at age } 35-39 \\
(-1)\end{array}$ & $\begin{array}{l}-0.00476^{*} \\
(0.00250)\end{array}$ & $\begin{array}{l}-0.0327 \\
(0.0391)\end{array}$ \\
\hline ...at age $40-44$ & $-0.00505^{* *}$ & -0.0282 \\
\hline$(-1)$ & $(0.00239)$ & $(0.0344)$ \\
\hline $\begin{array}{l}\ldots \text { at age } 45-49 \\
(-1)\end{array}$ & $\begin{array}{l}-0.00468^{*} \\
(0.00274)\end{array}$ & $\begin{array}{l}-0.0220 \\
(0.0468)\end{array}$ \\
\hline ...at age $50-54$ & $-0.00528^{* *}$ & -0.0375 \\
\hline$(-1)$ & $(0.00244)$ & $(0.0386)$ \\
\hline ...at age $55-59$ & $-0.00503^{*}$ & -0.00847 \\
\hline$(-1)$ & $(0.00256)$ & $(0.0472)$ \\
\hline $\begin{array}{l}\ldots \text { at age } 60-64 \\
(-1)\end{array}$ & $\begin{array}{c}-0.00622^{* *} \\
(0.00241)\end{array}$ & $\begin{array}{l}-0.0485^{*} \\
(0.0259)\end{array}$ \\
\hline Constant & $\begin{array}{c}1.084^{* * *} \\
(0.333)\end{array}$ & $\begin{array}{l}0.600^{*} \\
(0.323)\end{array}$ \\
\hline Year dummies & Yes & Yes \\
\hline Observations & 3,530 & 3,580 \\
\hline R-squared & 0.201 & 0.225 \\
\hline Number of csec & 800 & 800 \\
\hline
\end{tabular}

Fixed effects regression taking every 5 year. Robust standard errors in parentheses. ${ }^{* * *},{ }^{* *}$, and ${ }^{*}$ denotes statistical significance at the 1 percent, 5 percent and 10 percent level, respectively. 
is still low: Assuming that the economy is producing half or all of its output in the industrial goods sector, a 10 percentage point increase in FDI stock / GDP will cause a 0.14 or 0.46 percentage point increase in FLFPR, respectively. This relationship is depicted in the left panel of figure 19. It shows that the higher the share of industry value added, the more favorable the marginal impact of FDI on FLFPR. The right panel does the same with agriculture, which basically is the mirrored image of the left panel. In order to get an impression for the economic magnitudes, I added some country examples to the graph. I included China in 1985, 1995 and 2005 because it serves as an example of a developing country that has gone through an enormous structural change over the last decades and is well-known to the profession. From the right panel one can see that the share of agriculture in China's value added has decreased from 1985 to 2005 . This led to expansion of the industrial sector in the first decade and of the service sector in the second decade (the data point in 1995 and 2005 is almost identical in the left panel). This change has brought China into a more favorable condition concerning the impact of FDI on FLFPR: The model predicts that the positive effect of FDI on FLFPR was stronger in later years than in 1985. Nepal in 1980 serves as an example of a very agrarian economy, the impact of FDI is accordingly negative. Finally, South Africa in 2005 was a fairly modern economy; the model would hence suggest a positive impact of FDI on FLFPR.
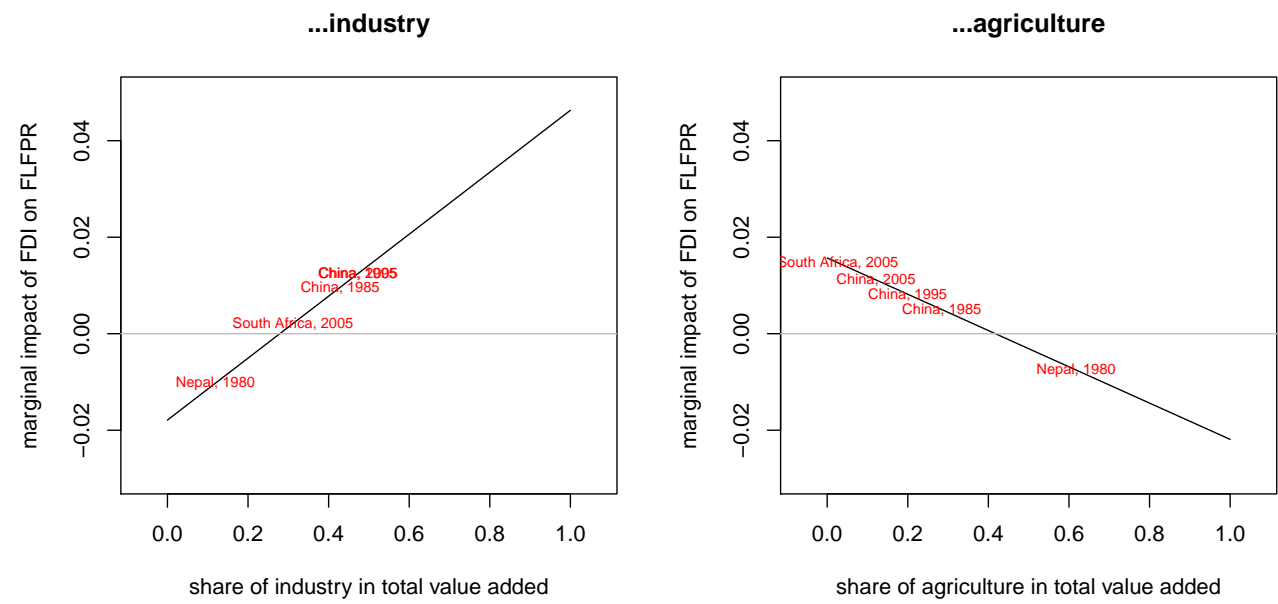

Figure 19: Impact of FDI Depending on the Sectoral Structure of the Economy

These results imply that the factor demand of MNCs does not necessarily have a (conditional) anti-female bias since the above mentioned negative impact of FDI appears to be mainly driven by changes in the industry structure. This is supported by column (2) of table 24 where I allow FDI to interact with the primary sector. The 
Table 24: Interaction with Sectoral Structure

Dependent Variable: FLFPR

\begin{tabular}{|c|c|c|c|}
\hline VARIABLES & $\begin{array}{c}(1) \\
\text { FLFPR }\end{array}$ & $\begin{array}{c}(2) \\
\text { FLFPR }\end{array}$ & $\begin{array}{c}(3) \\
\text { FLFPR }\end{array}$ \\
\hline $\ln$ (GDP p.c. PPP) & -0.132 & -0.133 & -0.144 \\
\hline$(-1)$ & $(0.0893)$ & $(0.0885)$ & $(0.0991)$ \\
\hline $\ln (\text { GDP p.c. } P P P)^{2}$ & 0.00987 & 0.00990 & 0.0100 \\
\hline$(-1)$ & $(0.00681)$ & $(0.00676)$ & $(0.00763)$ \\
\hline fertility rate & $\begin{array}{l}-0.00500 \\
(0.00746)\end{array}$ & $\begin{array}{l}-0.00498 \\
(0.00756)\end{array}$ & $\begin{array}{l}-0.00302 \\
(0.00749)\end{array}$ \\
\hline years of schooling & $\begin{array}{c}0.00529 \\
(0.00746)\end{array}$ & $\begin{array}{c}0.00494 \\
(0.00755)\end{array}$ & $\begin{array}{c}0.00604 \\
(0.00814)\end{array}$ \\
\hline agricultural value & 0.0484 & 0.0537 & 0.0523 \\
\hline added & $(0.0529)$ & $(0.0542)$ & $(0.0565)$ \\
\hline industry value added & $\begin{array}{l}-0.0674 \\
(0.0494)\end{array}$ & $\begin{array}{l}-0.0487 \\
(0.0444)\end{array}$ & $\begin{array}{r}-0.00549 \\
(0.0411)\end{array}$ \\
\hline GDP growth rate & $\begin{array}{l}-0.0423 \\
(0.0425)\end{array}$ & $\begin{array}{l}-0.0451 \\
(0.0421)\end{array}$ & $\begin{array}{l}-0.113^{* *} \\
(0.0488)\end{array}$ \\
\hline FDI stock / GDP & $-0.0179^{* * *}$ & 0.0157 & \\
\hline$(-1)$ & $(0.00507)$ & $(0.0246)$ & \\
\hline $\begin{array}{l}\text { Industry v.a. } \times \text { FDI } \\
(-1)\end{array}$ & $\begin{array}{c}0.0642 \\
(0.0480)\end{array}$ & & \\
\hline $\begin{array}{l}\text { Agricultural v.a. } \times \text { FDI } \\
(-1)\end{array}$ & & $\begin{array}{l}-0.0376 \\
(0.0294)\end{array}$ & \\
\hline $\begin{array}{l}\text { Trade / GDP } \\
(-1)\end{array}$ & $\begin{array}{l}-0.0217 \\
(0.0162)\end{array}$ & $\begin{array}{l}-0.0215 \\
(0.0163)\end{array}$ & \\
\hline $\begin{array}{l}\text { Exports / GDP } \\
(-1)\end{array}$ & & & $\begin{array}{l}-0.0251 \\
(0.0338)\end{array}$ \\
\hline $\begin{array}{l}\text { Trade in Services / GDP } \\
(-1)\end{array}$ & & & $\begin{array}{c}-0.0473^{* * *} \\
(0.0160)\end{array}$ \\
\hline Constant & $\begin{array}{c}1.012^{* * *} \\
(0.322)\end{array}$ & $\begin{array}{c}1.013^{* * *} \\
(0.319)\end{array}$ & $\begin{array}{c}1.007^{* * *} \\
(0.349)\end{array}$ \\
\hline Year Dummies & Yes & Yes & Yes \\
\hline Observations & 3,450 & 3,450 & 3,280 \\
\hline R-squared & 0.216 & 0.217 & 0.244 \\
\hline No of cross sections & 800 & 800 & 790 \\
\hline
\end{tabular}

Fixed effects regression taking every 5 year. Robust standard errors in parentheses. $* * *, * *$, and $*$ denotes statistical significance at the 1 percent, 5 percent and 10 percent level, respectively. 
negative impact of FDI now vanishes, it becomes insignificant and positive while the interaction with the primary sector is negative and insignificant. ${ }^{212}$

Similarly, with trade in column (3) of table 24, I find that its negative impact is, somewhat surprisingly, driven by trade in services: including trade in services into the model turns the overall export parameter estimate statistically insignificant, whereas trade in services is negative and highly significant but of small magnitude. This result is rather surprising on a first view because one would expect that women are very likely to work in the service sector. However, especially in the tradable service sector, the skill-premium might be high, hence inducing young women to invest more into education and stay off the labor market in younger cohorts. Furthermore, these results are in line with the findings of Oostendorp (2009) that globalization may benefit male engineers or computer programmers more than female ones because they are likely to be better educated, and with an aspect of the results of Bussmann (2009, p. 1035), that globalization is related to a lower percentage of women employed in the service sector in non-OECD countries.

As a robustness check, I investigate to what extent the obtained results change when specifying another functional form of the model, namely a logarithmic model of the form

$$
\ln (F L F P)=Z_{i j t} \theta+X_{i t} \beta+\alpha \ln (F P O P)_{i j t}+u_{i j t} .
$$

In my view, this functional form has the advantage that it is is economically more appealing than the standard models in the literature because it allows for interactions of the covariables and does not force the response to be linear in the latter. Second, the model in equation (44) is more flexible because it does not pose the implicit restriction $\alpha=1 .^{213}$ Third, the model in equation (44) avoids meaningless predictions of the response variable. ${ }^{214}$ Finally, the model in equation (44) is not necessarily more difficult to interpret because changes in any covariable can be interpreted as elasticity of FLFP (if the covariable is itself in logs) or as a percentage change in FLFP if the covariable changes by one unit (if it is not in logs).

The results from this exercise, reported in table 6 of Cooray et al. (ress), are qualitatively similar to the ones obtained above. Parameter estimates for the interaction of FDI with industry value added and for FDI are statistically significant and highly

\footnotetext{
${ }^{212}$ They are jointly significant on the $1 \%$ level using an F-test but the magnitude of the effect is again small.

${ }^{213}$ Note that if the restriction $\alpha=1$ is indeed true, a restricted estimator will be more efficient than the model in equation (44). However, in the context of a sample as large as the present one, I find this of minor relevance though it may be important for policy making and evaluation on the country level when facing a much smaller sample.

${ }^{214}$ Note that a linear model like in equation (41) may lead to predictions of the FLFPR that are smaller than 0 or larger than $100 \%$ which does not make sense economically. Since in the model $\mathbb{E}(\ln (F L F P))=X \theta$, the predictor for FLFP is $e^{X \theta}$, which is a positive number for any value of $X \theta$, a meaningful prediction of FLFP is ensured.
} 
significant, respectively, and are jointly highly significant (F-statistic of 5.53 with 2 and 79 degrees of freedom). While the prefix of the parameter estimates are the same as in table 24, the positive impact of the interaction is more dominant over the negative impact of the FDI stock: A positive impact of FDI on FLFP occurs at a level of industrial value added above $16.2 \%$ of GDP. More precisely, for an economy producing half or all of its output in the industrial goods sector, a $10 \%$ increase in FDI will cause a 0.8 or $2.1 \%$ increase in FLFP, respectively. For this functional form, I also find that trade in services absorbs the negative impact of exports.

\subsection{Discussion and Conclusion}

This chapter has investigated the influence of globalization, as measured by trade and FDI, on the FLFPR in a panel of 80 developing economies over the time period 1980 - 2005. The results suggest that openness generally has a negative but small impact on the FLFPR - which contrasts most previous studies that have generally found a positive effect. As an improvement over the previous literature, I have shown that the effect is stronger for young women. This might be driven by the higher responsiveness to external factors in younger years, since younger persons are more flexible, and by the fact that the potential rise in the skill premium due to globalization creates a particularly strong incentive for younger women to invest in education (and to hence not join the labor force) because the returns will be realized over a longer (expected) remaining lifetime. Both theoretical models and micro-econometric studies might help address this channel in the future.

A main takeaway from this chapter is that one should be very cautious in generalizing results from country-level studies to an overarching tale about the female labor market effects of globalization because the estimated parameters, though being statistically significant, are mostly negligible in economic terms. Even in the unconditional model (1) in table 22, the potential role of globalization for the FLFPR is small. As noted, the results furthermore show a large degree of regional heterogeneity. $^{215}$

Since the results show that the direction of the FDI impact on FLFPR depends on the size of the industrial/primary sector, they strongly suggest that any economic explanation about the impact of globalization on FLFP has to take into account the industrial structure of the economy under consideration. Potential arguments could be built along the lines of a Lewis (1954) type labor market: In agrarian economies, a large pool of laborers is available. Since comparative advantages of these economies

\footnotetext{
${ }^{215}$ See Cooray et al. (ress). The finding of a statistically significant positive effect of FDI on the FLFPR in Eastern Europe and Central Asia compared with a significant negative effect in Africa further supports the notion that the potentially increased skill-premium due to globalization/FDI creates incentives to build up human capital before joining the labor force: A high human capital stock (with relatively low gender inequality) was a heritage from the past in former centrally planned economies and would allow women to join the labor force and reap the benefits from an increased skill-premium right away, whereas female educational attainment is much lower in Africa (cf. Barro and Lee 2010, table 3).
} 
lies in the production intensively using physical labor and surplus labor keeps wages low, MNCs and exporting firms might be more likely to go for the "low hanging fruits" by drawing from the pool of male laborers. By still paying a somewhat higher wage (cf. Lipsey 2002), the income effect on the household level might then have a small negative impact on FLFP and the mainstream argument of a female-intensive comparative-advantage sector does not hold for these countries. The more industrialized a country becomes, the smaller the pool of (male) surplus labor becomes and MNCs and exporters might hence demand more female labor, especially since the process of industrial development and the division of labor will create linkages with the service sector where female labor is not "physically disadvantaged" and gender wage gaps might even provide an incentive to employ women, so that the mainstream arguments begin to come into force at this development stage.

These results can be seen in the context of the finding by Gaddis and Klasen (2012) that different industrial structures of the economy generate different dynamics for female employment. To some extent this nests the studies of Çă̆aty and Berik (1990); Özler (2000); Kabeer and Mahmud (2004), and Pradhan (2006) that find a positive impact of exports on FLFP: The sampling period of the first study coincides with the time when Turkey reached the threshold level of industrial development of 28 $\%$ that I find in this study, the second study uses data from the mid-1980s where the size of the industrial sector in Turkey was about $27 \%$ and hence close to the threshold of $28 \%$ and clearly above the threshold of $16 \%$ found in the multiplicative model. The data of Kabeer and Mahmud (2004) come from a 2001 survey when the industrial share made up for $26 \%$ of the Bangladeshi economy. For the study of Pradhan (2006) on India around 2000, industrial value added was always over $25 \%$ of GDP (all sector data: WDI). Accordingly, industrial development was rather high in these economies compared with other developing countries and this might have driven the results of previous country-case studies.

In terms of welfare and policy, the results of a generally negative effect of globalization on FLFPR is not necessarily bad news for women since their decrease in labor force participation might simply be the optimal response to benefit from an increased skill premium or because household income is sufficiently high and allows women to stay home if they want to. Indeed, Gray et al. (2006, pp. 317ff) find that trade (but not FDI) decreases female illiteracy rates for 180 countries (although the elasticity is rather small) and Bussmann (2009, p. 1032) also finds some evidence that women in non-OECD countries get more access to education when trade/GDP is growing, at least in primary and secondary schools. As I show in simple regressions of female years of schooling on the globalization measures reported in table 37 in Appendix E, increased exports (for which the impact on FLFPR is stronger than for FDI) are also positively correlated with female educational attainments in the present sample. The parameter of 0.78 in the first column of the table would mean that women respond to a 10 percentage points increase in exports/GDP by staying 7.8 years longer in school-years they are generally absent from the labor force.

Therefore, while the aggregate results challenge the viewpoint of a large fraction of 
the literature arguing that globalization generally has a positive impact on FLFP in developing countries, this does not mean that a negative relationship necessarily exercises an adverse impact on female well-being or empowerment. However, problems may arise under bounded rationality, e.g. if females do not enter the labor force because family income is sufficient, but do neither engage in educational programs even though this will decrease their probability of finding a job in the future. As argued in the introduction to this dissertation, the likelihood of a shock may increase in a globalized economy and if such a negative shock occurs in the future and household income declines, females will find it more difficult to make up for this wage decrease because of forgone job-market experience.

An important policy implication stemming from this chapter is that countries that open up for globalization should tightly monitor developments on their female labor market. Long-term employability of women who leave the labor force because of sufficiently increased household earnings should be ensured. This may include continued education programs or offering more flexible working schedules. Another potential policy tool is an income-tax scheme that is relatively progressive on the individual but less progressive on the household level, although the effectiveness of the latter is questionable, especially in countries where less than $28 \%$ of value added are produced in the manufacturing sector. 


\section{A Appendix - Chapter 2}

Table 25: Correlation Coefficients Between Different BEA Measures, 2008

\begin{tabular}{lrrrrrrr}
\hline & stock & flows & assets & empl. & wages & sales & income \\
\hline stock & 1.00 & & & & & & \\
flows & 0.83 & 1.00 & & & & & \\
assets & 0.97 & 0.78 & 1.00 & & & & \\
employees & 0.58 & 0.28 & 0.59 & 1.00 & & & \\
wages & 0.72 & 0.33 & 0.77 & 0.84 & 1.00 & & \\
sales & 0.80 & 0.51 & 0.82 & 0.80 & 0.92 & 1.00 & \\
income & 0.74 & 0.84 & 0.69 & 0.13 & 0.23 & 0.43 & 1.00 \\
\hline$\Sigma$ & 5.64 & 4.58 & 5.63 & 4.23 & 4.82 & 5.29 & 4.05 \\
\hline sample containing 47 different host countries in year 2008 \\
$\Sigma$ is the sum over all correlation coefficients of the measure, \\
not just the ones displayed.
\end{tabular}

Table 26: Correlation Coefficients Between Different BEA Measures, 1997

\begin{tabular}{lrrrrrrr}
\hline & stock & flows & assets & empl. & wages & sales & income \\
\hline stock & 1.00 & & & & & & \\
flows & 0.89 & 1.00 & & & & & \\
assets & 0.94 & 0.86 & 1.00 & & & & \\
employees & 0.84 & 0.72 & 0.79 & 1.00 & & & \\
wages & 0.86 & 0.68 & 0.86 & 0.92 & 1.00 & & \\
sales & 0.91 & 0.75 & 0.89 & 0.91 & 0.98 & 1.00 & \\
income & 0.92 & 0.84 & 0.82 & 0.77 & 0.77 & 0.86 & 1.00 \\
\hline$\Sigma$ & 6.37 & 5.74 & 6.16 & 5.95 & 6.07 & 6.29 & 5.98 \\
\hline
\end{tabular}

sample containing 90 different host countries in year 1997

$\Sigma$ is the sum over all correlation coefficients of the measure, not just the ones displayed. 
Table 27: Correlation Coefficients Between Different BEA Measures, Canada

\begin{tabular}{lrrrrrrr}
\hline & stock & flows & assets & empl. & wages & sales & income \\
\hline stock & 1.00 & & & & & & \\
flows & 0.10 & 1.00 & & & & & \\
assets & 0.92 & -0.09 & 1.00 & & & & \\
employment & 0.59 & 0.38 & 0.50 & 1.00 & & & \\
wages & 0.90 & -0.04 & 0.97 & 0.53 & 1.00 & & \\
sales & 0.92 & -0.06 & 0.96 & 0.54 & 0.98 & 1.00 & \\
income & 0.83 & -0.21 & 0.92 & 0.29 & 0.95 & 0.95 & 1.00 \\
\hline$\Sigma$ & 5.25 & 1.09 & 5.19 & 3.83 & 5.29 & 5.28 & 4.73 \\
\hline
\end{tabular}

sample containing 12 observations over time (1997-2008)

$\Sigma$ is the sum over all correlation coefficients of the measure, not just the ones displayed.

Table 28: Correlation Coefficients Between Different BEA Measures, 'All Countries Total'

\begin{tabular}{lrcccccc}
\hline & stock & flows & assets & empl. & wages & sales & income \\
\hline stock & 1.00 & & & & & & \\
flows & 0.54 & 1.00 & & & & & \\
assets & 0.97 & 0.50 & 1.00 & & & & \\
employment & 0.96 & 0.49 & 0.94 & 1.00 & & & \\
wages & 0.98 & 0.54 & 0.97 & 0.96 & 1.00 & & \\
sales & 0.98 & 0.52 & 0.94 & 0.94 & 0.99 & 1.00 & \\
income & 0.96 & 0.47 & 0.95 & 0.91 & 0.98 & 0.99 & 1.00 \\
\hline$\Sigma$ & 6.39 & 4.06 & 6.28 & 6.21 & 6.41 & 6.36 & 6.26 \\
\hline \multicolumn{7}{c}{ sample containing 12 observations over time $(1997-2008)$ for the aggregate of }
\end{tabular}

all host countries, $\Sigma$ is the sum over all correlation

coefficients of the measure, not just the ones displayed. 


\section{B Appendix - Chapter 3}

\section{B.1 Information on SDDS}

Table 29: List of SDDS Subscribers

\begin{tabular}{|c|c|c|c|c|c|c|c|}
\hline Country & subsc & meta & spec & Country & subsc & meta & spec \\
\hline Argentina & 1996 & 1996 & 1999 & Korea & 1996 & 1998 & 1999 \\
\hline Armenia & 2003 & 2003 & 2003 & Kyrgyz Republic & 2004 & 2004 & 2004 \\
\hline Australia & 1996 & 1998 & 2001 & Latvia & 1996 & 1997 & 1999 \\
\hline Austria & 1996 & 1997 & 2001 & Lithuania & 1996 & 1997 & 1999 \\
\hline Belarus & 2004 & 2004 & 2004 & Luxembourg & 2006 & 2006 & 2006 \\
\hline Belgium & 1996 & 1997 & 2001 & Macedonia & 2011 & 2011 & 2011 \\
\hline Brazil & 2001 & 2001 & 2001 & Malaysia & 1996 & 1996 & 2000 \\
\hline Bulgaria & 2003 & 2003 & 2003 & Malta & 2009 & 2009 & 2009 \\
\hline Canada & 1996 & 1996 & 1999 & Mauritius & 2012 & 2012 & 2012 \\
\hline Chile & 1996 & 1997 & 2000 & Mexico & 1996 & 1996 & 2000 \\
\hline Colombia & 1996 & 1997 & 2000 & Moldova & 2006 & 2006 & 2006 \\
\hline Costa Rica & 2001 & 2001 & 2001 & Morocco & 2005 & 2005 & 2005 \\
\hline Croatia & 1996 & 1996 & 2001 & Netherlands & 1996 & 1996 & 2000 \\
\hline Cyprus & 2009 & 2009 & 2009 & Norway & 1996 & 1996 & 2000 \\
\hline Czech Republic & 1998 & 1998 & 1999 & Peru & 1996 & 1996 & 1999 \\
\hline Denmark & 1996 & 1996 & 2000 & Philippines & 1996 & 1996 & 2001 \\
\hline Ecuador & 1998 & 1998 & 2000 & Poland & 1996 & 1996 & 2000 \\
\hline Egypt & 2005 & 2005 & 2005 & Portugal & 1997 & 1998 & 2000 \\
\hline El Salvador & 1998 & 1998 & 1999 & Romania & 2005 & 2005 & 2005 \\
\hline Estonia & 1998 & 1999 & 2000 & Russia & 2005 & 2005 & 2005 \\
\hline Finland & 1996 & 1996 & 2000 & Singapore & 1996 & 1996 & 2001 \\
\hline France & 1996 & 1996 & 2000 & Slovak Republic & 1996 & 1998 & 1999 \\
\hline Georgia & 2010 & 2010 & 2010 & Slovenia & 1996 & 1996 & 2000 \\
\hline Germany & 1996 & 1997 & 2000 & South Africa & 1996 & 1996 & 2000 \\
\hline Greece & 2002 & 2002 & 2002 & Spain & 1996 & 1998 & 2000 \\
\hline Hong Kong SAR & 1996 & 1997 & 2000 & Sweden & 1996 & 1996 & 2000 \\
\hline Hungary & 1996 & 1997 & 2000 & Switzerland & 1996 & 1996 & 2001 \\
\hline Iceland & 1996 & 1998 & 2004 & Thailand & 1996 & 1996 & 2000 \\
\hline India & 1996 & 1997 & 2001 & Tunisia & 2001 & 2001 & 2001 \\
\hline Indonesia & 1996 & 1997 & 2000 & Turkey & 1996 & 1996 & 2001 \\
\hline Ireland & 1996 & 1996 & 2001 & Ukraine & 2003 & 2003 & 2003 \\
\hline Israel & 1996 & 1996 & 2000 & United Kingdom & 1996 & 1996 & 1999 \\
\hline Italy & 1996 & 1996 & 2000 & United States & 1996 & 1996 & 1999 \\
\hline Japan & 1996 & 1996 & 2000 & Uruguay & 2004 & 2004 & 2004 \\
\hline Jordan & 2010 & 2010 & 2010 & West Bank and Gaza & 2012 & 2012 & 2012 \\
\hline Kazakhstan & 2003 & 2003 & 2003 & & & & \\
\hline
\end{tabular}

"subsc" is the date of subscription to SDDS, "meta" is the year where metadata were posted on the Dissemination Standards Bulletin Board, "spec" is the first year where subscribers met SDDS specification. 


\section{Table 30: SDDS Data Coverage}

\begin{tabular}{|l|l|}
\hline Category & Component (example) \\
\hline Real Sector & GDP by categories \\
National Accounts & idustrial / commodity production \\
Lroduction Indices & (un)employment, wages \\
Price Indices & CPI, producer price index \\
\hline Fiscal Sector & revenue, expenditure, financing \\
General Government Operations & revenue, expenditure, financing \\
Central Government Operations & domestic / foreign (by currency) \\
Central Government Debt & \\
\hline Financial Sector & money, credit \\
Analytical Banking Accounts & reserve money, domestic claims, external position \\
Analytical Central Bank Accounts & government security rates \\
Interest Rates & share price index \\
Stock Market & goods and services \\
\hline External Sector & reserves \\
Balance of Payments & exports and imports \\
Reserves & \\
Merchandise Trade & spot rates, 3- and 6-month forward markets \\
International Investment Position & debt of different sectors (government, banking etc.) \\
Exchange Rates & \\
External Debt & \\
\hline Population & SDDS \\
\hline
\end{tabular}

This is just an illustrative list of the SDDS data coverage. For comprehensive information on SDDS data coverage please consult the SDDS website. 
B.2 Sample, Variables and Descriptive Statistics

\section{Table 31: List of Variables}

\begin{tabular}{|c|c|c|c|}
\hline Variable & Explanation & $\begin{array}{c}\text { Mean } \\
\text { (Std. Dev.) }\end{array}$ & Source \\
\hline $\ln (\mathrm{FDI})$ & $\begin{array}{l}\text { Logarithm of real foreign direct investment } \\
\text { inflows in USD }\end{array}$ & $\begin{array}{l}22.04 \\
(1.70)\end{array}$ & $\begin{array}{c}\text { IFS } \\
(\mathrm{WEO})\end{array}$ \\
\hline $\ln$ (portfolio) & $\begin{array}{l}\text { Logarithm of real foreign portfolio investment } \\
\text { inflows in USD }\end{array}$ & $\begin{array}{l}22.10 \\
(2.40)\end{array}$ & $\begin{array}{c}\text { IFS } \\
(\text { WEO })\end{array}$ \\
\hline SDDS & $\begin{array}{l}\text { dummy variable equal } 1 \text { if country } i \text { met 'Special Data } \\
\text { Dissemination Standard' in yeart } t \text {, see table } 29\end{array}$ & $\begin{array}{l}0.40 \\
(0.49)\end{array}$ & IMF \\
\hline $\ln (\mathrm{GDP})$ & Logarithm of real GDP in USD & $\begin{array}{l}25.95 \\
(1.79)\end{array}$ & WEO \\
\hline GDP growth & $\begin{array}{l}\text { percentag change }\left(\left(y_{t}-y_{t-1}\right) / y_{t-1}\right) \text { of } \\
\text { real GDP per capita in national currency }\end{array}$ & $\begin{array}{c}0.031 \\
(0.036)\end{array}$ & $\begin{array}{c}\text { calc } \\
\text { from WEO }\end{array}$ \\
\hline investment rate & $\begin{array}{l}\text { gross capital formation (at current prices) / GDP } \\
\text { (also at current prices) }\end{array}$ & $\begin{array}{c}0.233 \\
(0.058)\end{array}$ & $\begin{array}{c}\text { calc } \\
\text { from WEO }\end{array}$ \\
\hline $\begin{array}{l}\text { capital account } \\
\text { open }\end{array}$ & $\begin{array}{l}\text { Chinn and Ito (2006) index for capital account openness } \\
\text { (higher values mean higher openness }\end{array}$ & $\begin{array}{c}1.12 \\
(1.40)\end{array}$ & $\begin{array}{l}\text { Chinn/ } \\
\text { Ito }(2011)\end{array}$ \\
\hline political risk & $\begin{array}{l}\text { political risk rating of International Country Risk } \\
\text { guide (ICRG, yearly average), } 0 \text { (high risk) }-100\end{array}$ & $\begin{array}{l}65.89 \\
(3.49)\end{array}$ & ICRG \\
\hline $\begin{array}{l}\text { exchange rate } \\
\text { volatility }\end{array}$ & see equation (20) on page 74 & $\begin{array}{l}0.0026 \\
(0.024)\end{array}$ & $\begin{array}{c}\text { calc } \\
\text { from IFS }\end{array}$ \\
\hline interest rate & $\begin{array}{l}\text { spread of money market rate over } \\
\text { LIBOR (both in percent p.a.) }\end{array}$ & $\begin{array}{c}19.08 \\
(231.37)\end{array}$ & $\begin{array}{c}\text { calc } \\
\text { from IFS }\end{array}$ \\
\hline $\begin{array}{l}\text { real exchange } \\
\text { rate }\end{array}$ & $\begin{array}{l}\text { implied purchasing power parity exchange rate } \\
\text { measured in national currency per USD }\end{array}$ & $\begin{array}{c}85.90 \\
(371.63)\end{array}$ & WEO \\
\hline trade share & $\begin{array}{l}\text { sum of imports (including c.i.f.) and export from and } \\
\text { to the world in current USD / GDP in current USD }\end{array}$ & $\begin{array}{c}0.696 \\
(0.601)\end{array}$ & $\begin{array}{l}\text { calc from } \\
\text { IFS, WEO }\end{array}$ \\
\hline $\begin{array}{l}\text { yrs. of } \\
\text { schooling }\end{array}$ & $\begin{array}{l}\text { Years of Schooling from Barro and Lee }(2010) \text { using } \\
\text { a smoother with weights } 25,16,9,4, \text { and } 1\end{array}$ & $\begin{array}{l}9.04 \\
1.99\end{array}$ & $\begin{array}{c}\text { Barro/ } \\
\text { Lee }(2010)\end{array}$ \\
\hline $\begin{array}{l}\text { high-tech } \\
\text { exports }\end{array}$ & $\begin{array}{l}\text { country } i \text { 's share of high-tech exports in } \\
\text { global high-tech exports at year } t\end{array}$ & $\begin{array}{c}1.84 \mathrm{e}+10 \\
(3.47 \mathrm{e}+10)\end{array}$ & $\begin{array}{c}\text { calc } \\
\text { from WDI }\end{array}$ \\
\hline $\begin{array}{l}\text { export unit } \\
\text { value }\end{array}$ & export unit value index & $\begin{array}{c}87.31 \\
(20.59)\end{array}$ & $\mathrm{WEO}$ \\
\hline \# of patents & total number of patents & $\begin{array}{c}841.73 \\
(2,592.6)\end{array}$ & OECD \\
\hline $\begin{array}{l}\text { WEO data } \\
\text { dummy }\end{array}$ & $\begin{array}{l}\text { dummy variable equal } 1 \text { if WEO data was used for } \\
\text { dependent variable (instead of IFS data) }\end{array}$ & $\begin{array}{c}0.121 \\
(0.327)\end{array}$ & $\begin{array}{l}\text { own } \\
\text { calc. }\end{array}$ \\
\hline
\end{tabular}

Mean and standard deviation are reported for those observations included in model (3a),

except for $\ln$ (portfolio), where observations included in model (3b) are taken.

List of countries in the sample (model 3a): Algeria, Argentina, Australia, Austria, Brazil, Bulgaria, Canada, Chile, Colombia, Croatia, Czech Republic, Estonia, Finland, France, Germany, Greece, Hong Kong (China), Iceland, Indonesia, Ireland, Italy, Jamaica, Japan, Jordan, Korea, Rep., Kuwait, Latvia, Lithuania, Malaysia, Mexico, Moldova, Morocco, Netherlands, New Zealand, Norway, Pakistan, Peru, Philippines, Poland, Romania, Russian Federation, Singapore, Slovak Republic, Slovenia, South Africa, Spain, Sri Lanka, Switzerland, Thailand, Turkey, Ukraine, United Kingdom, United States, Uruguay, Venezuela 


\section{Appendix - Chapter 4}

\section{Countries Included:}

Countries included in specifications (3) - (9): Bangladesh, Belize, Bolivia, Botswana, Chile, China, Cameroon, Colombia, Costa Rica, Dominican Republic, Ecuador ${ }^{216}$, Egypt (Arab Rep.), Ethiopia, Fiji, Guatemala, Guyana, Honduras, Indonesia, India, Jamaica ${ }^{217}$, Jordan, Kenya, Cambodia, Lebanon, St. Lucia, Sri Lanka, Morocco, Madagascar, Mexico, Mongolia, Mauritania ${ }^{218}$, Mauritius, Malawi, Malaysia, Namibia, Nicaragua, Pakistan, Peru, Philippines, Poland, Paraguay, Rwanda, El Salvador, Syrian Arab Republic, Thailand, Tunisia, Tanzania, Uganda, Vietnam, Samoa, South Africa, Zambia ${ }^{219}$, Zimbabwe

Developing countries supplementary included in specifications (1a) and (1b): Angola, Burundi, Benin, Burkina Faso, Cote d'Ivoire, Congo (Rep.), Colombia, Comoros, Cape Verde, Cuba, Djibouti, Eritrea, Ghana, Guinea, Gambia, Equatorial Guinea, Grenada, Haiti, Lao PDR, Lesotho, Maldives, Mali, Myanmar, Mozambique, Niger, Nigeria, Nepal, Papua New Guinea, Sudan, Senegal, Solomon Islands, Swaziland, Togo, Turkey, St. Vincent and the Grenadines, Yemen, Congo (Dem. Rep.)

\footnotetext{
${ }^{216}$ not in specifications (3)-(5)

${ }^{217}$ not in specifications (3)-(5)

${ }^{218}$ not in specifications (3)-(6)

${ }^{219}$ not in specification (6)
} 


\section{Appendix - Chapter 5}

Table 32: Average US Outward FDI Stocks by Countries

\begin{tabular}{|c|c|c|}
\hline country & FDI stock (Mio. US-\$) & thereof vertical \\
\hline Argentina & $13,028.7$ & $2.36 \%$ \\
\hline Australia & $47,304.2$ & $1.77 \%$ \\
\hline Austria & $7,055.1$ & $1.36 \%$ \\
\hline Belgium & $32,381.4$ & $2.48 \%$ \\
\hline Brazil & $34,430.0$ & $2.93 \%$ \\
\hline Chile & $10,552.4$ & $4.10 \%$ \\
\hline Czech Republic & $2,136.8$ & $0.95 \%$ \\
\hline Denmark & $5,430.4$ & $1.17 \%$ \\
\hline Finland & $1,746.5$ & $2.62 \%$ \\
\hline France & $50,952.7$ & $2.58 \%$ \\
\hline Germany & $69,837.3$ & $2.03 \%$ \\
\hline Greece & $1,259.1$ & $0.15 \%$ \\
\hline Hungary & $2,955.4$ & $5.71 \%$ \\
\hline Ireland & $52,557.0$ & $11.29 \%$ \\
\hline Israel & $5,878.2$ & $7.02 \%$ \\
\hline Italy & $22,325.2$ & $1.78 \%$ \\
\hline Japan & $62,657.6$ & $3.47 \%$ \\
\hline Korea (Rep. of) & $13,957.6$ & $2.28 \%$ \\
\hline Luxembourg & $62,633.9$ & $1.00 \%$ \\
\hline Malaysia & $8,297.2$ & $23.87 \%$ \\
\hline Mexico & $54,908.2$ & $29.79 \%$ \\
\hline Netherlands & $185,353.9$ & $1.78 \%$ \\
\hline New Zealand & $5,057.5$ & $0.87 \%$ \\
\hline Norway & $7,339.5$ & $1.52 \%$ \\
\hline Poland & $6,192.2$ & $1.04 \%$ \\
\hline Singapore & $48,729.1$ & $15.81 \%$ \\
\hline South Africa & $3,542.3$ & $0.41 \%$ \\
\hline Spain & $34,847.0$ & $1.16 \%$ \\
\hline Sweden & $23,564.5$ & $11.19 \%$ \\
\hline Switzerland & $74,063.1$ & $1.89 \%$ \\
\hline Turkey & $2,305.3$ & $1.19 \%$ \\
\hline United Arab Emirates & $1,563.9$ & $0.20 \%$ \\
\hline United Kingdom & $277,542.6$ & $2.36 \%$ \\
\hline Venezuela & $8,925.5$ & $2.25 \%$ \\
\hline
\end{tabular}

Countries covered (1997-2002): Argentina, Australia, Austria, Belgium, Brazil, Chile, Czech Republic, Denmark, Finland, France, Germany, Greece, Hungary, Ireland, Israel, Italy, Japan, Republic of Korea, Luxembourg, Malaysia, Mexico, Netherlands, New Zealand, Norway, Poland, Singapore, South Africa, Spain, Sweden, Switzerland, Turkey, United Arab Emirates, UK, Venezuela 


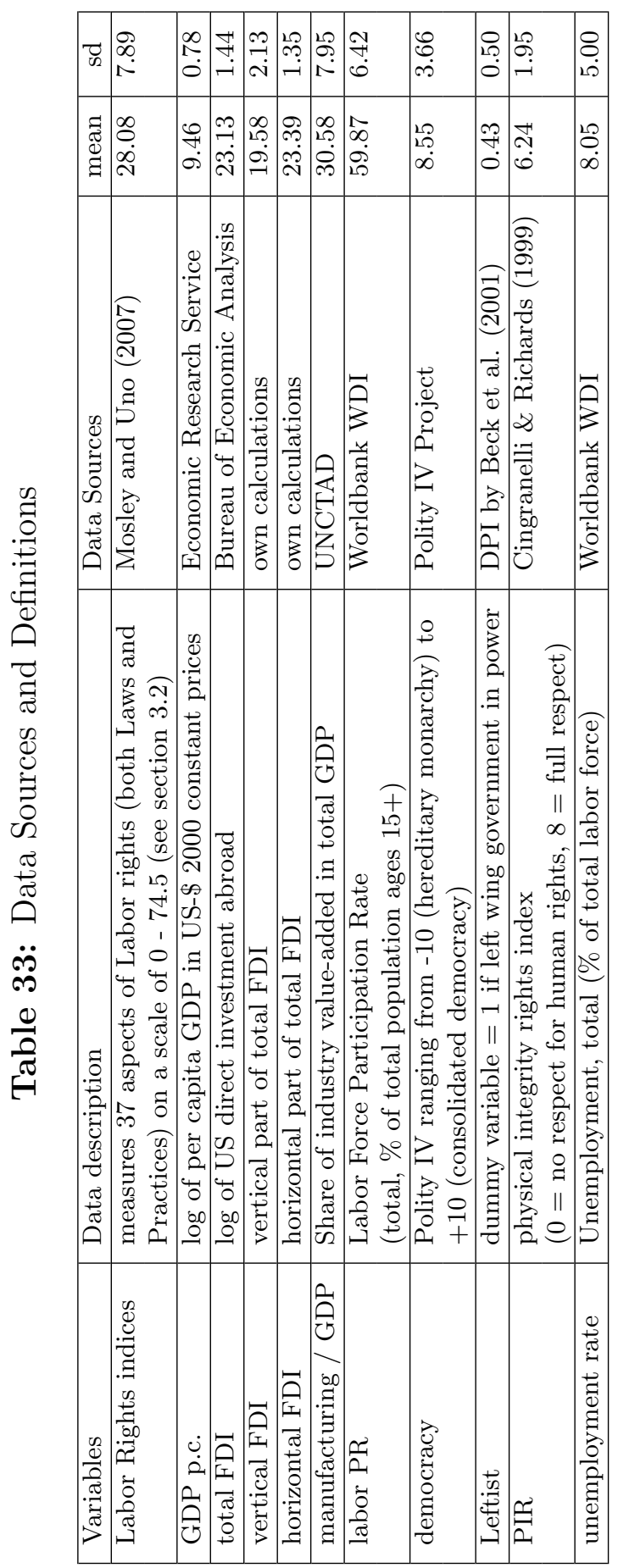




\section{Table 34: Mosley and Uno's (2007) Labor Rights Coding Based on Kucera's (2002) Template With the Extention of Greenhill et al.}

(2009)

\begin{tabular}{|c|c|c|c|}
\hline No. & $\begin{array}{l}\text { Category } \\
\text { Assigned }\end{array}$ & Description & Weights \\
\hline \multicolumn{4}{|c|}{ Freedom of association/collective bargaining related liberties } \\
\hline 1 & Practices & Murder or disappearance of union members or organizers & 2 \\
\hline 2 & Practices & Other violence against union members or organizers & 2 \\
\hline 3 & Practices & Arrest, detention, imprisonment, or forced exile for union membership or activities & 2 \\
\hline 4 & Practices & Interference with union rights of assembly, demonstration, free opinion, free expression & 2 \\
\hline 5 & Practices & Seizure or destruction of union premises or property & 2 \\
\hline \multicolumn{4}{|c|}{ Right to establish and join union and worker organizations } \\
\hline 6 & Laws & General prohibitions & 10 \\
\hline 7 & Practices & General absence resulting from socio-economic breakdown & 10 \\
\hline 8 & Laws & Previous authorization requirements & 1.5 \\
\hline 9 & Practices & Employment conditional on non-membership in union & 1.5 \\
\hline 10 & Practices & Dismissal or suspension for union membership or activities & 1.5 \\
\hline 11 & Practices & Interference of employers (attempts to dominate unions) & 1.5 \\
\hline 12 & Practices & Dissolution or suspension of union by administrative authority & 2 \\
\hline 13 & Laws & Only workers' committees and labor councils permitted & 2 \\
\hline 14 & Laws & Only state-sponsored or other single unions permitted & 1.5 \\
\hline 15 & Laws & Exclusion of tradable/industrial sectors from union membership & 2 \\
\hline 16 & Laws & Exclusion of other sectors or workers from union membership & 2 \\
\hline 17 & Practices & Other specific de facto problems or acts of prohibition & 1.5 \\
\hline 18 & Laws & (No) Right to establish and join federations or confederations of unions & 1.5 \\
\hline 19 & Laws & Previous authorization requirements regarding above row & 1 \\
\hline \multicolumn{4}{|c|}{ Other union activities } \\
\hline 20 & Laws & (No) right to elect representatives in full freedom & 1.5 \\
\hline 21 & Laws & (No) right to establish constitutions and rules & 1.5 \\
\hline 22 & Laws & General prohibition of union/federation participation in political activities & 1.5 \\
\hline 23 & Practices & (No) Union control of finances & 1.5 \\
\hline \multicolumn{4}{|c|}{ Right to collectively bargain } \\
\hline 24 & Laws & General prohibitions & 10 \\
\hline 25 & Laws & Prior approval by authorities of collective agreements & 1.5 \\
\hline 26 & Laws & Compulsory binding arbitration & 1.5 \\
\hline 27 & Practices & Intervention of authorities & 1.5 \\
\hline 28 & Practices & Scope of collective bargaining restricted by non-state employers & 1.5 \\
\hline 29 & Laws & Exclusion of tradable/industrial sectors from right to collectively bargain & 1.75 \\
\hline 30 & Laws & Exclusion of other sectors or workers from right to collectively bargain & 1.75 \\
\hline 31 & Practices & Other specific de facto problems or acts of prohibition & 1.5 \\
\hline \multicolumn{4}{|c|}{ Right to strike } \\
\hline 32 & Laws & General prohibitions & 2 \\
\hline 33 & Laws & Previous authorization required by authorities & 1.5 \\
\hline 34 & Laws & Exclusion of tradable/industrial sectors from right to strike & 1.5 \\
\hline 35 & Laws & Exclusion of other sectors or workers from right to strike & 1.5 \\
\hline 36 & Practices & Other specific de facto problems or acts of prohibition & 1.5 \\
\hline \multicolumn{4}{|c|}{ Export processing zones } \\
\hline 37 & Laws & Restricted Rights in EPZs & 2 \\
\hline \multicolumn{4}{|c|}{ TOTAL SCORE } \\
\hline
\end{tabular}




\section{E Appendix - Chapter 6}

Countries Included: Albania, Armenia, Bangladesh, Belize, Benin, Bolivia, Botswana, Burundi, Cambodia, Cameroon, Central African Republic, Chile, China, Colombia, Congo, Rep., Costa Rica, Cote d'Ivoire, Cuba, Dominican Republic, Ecuador, Egypt, Arab Rep., El Salvador, Fiji, Gambia, Ghana, Guatemala, Guyana, Honduras, India, Indonesia, Jamaica, Jordan, Kazakhstan, Kenya, Kyrgyz Republic, Lao PDR, Lesotho, Liberia, Malawi, Malaysia, Maldives, Mali, Mauritania, Mauritius, Mexico, Mongolia, Morocco, Mozambique, Namibia, Nepal, Nicaragua, Niger, Pakistan, Papua New Guinea, Paraguay, Peru, Philippines, Poland, Rwanda, Senegal, Sierra Leone, Slovak Republic, South Africa, Sri Lanka, Sudan, Swaziland, Syrian Arab Republic, Tajikistan, Tanzania, Thailand, Togo, Tonga, Tunisia, Turkey, Uganda, Ukraine, Vietnam, Yemen, Rep., Zambia, Zimbabwe

Table 35: Summary Statistics

\begin{tabular}{lccccc} 
Name & Obs & Mean & Std. Dev. & Min & Max \\
\hline FLFPR & 3470 & 0,54 & 0,23 & 0,01 & 0,98 \\
ln(GDP p.c. PPP) & 3470 & 6,67 & 1,02 & 4,69 & 8,82 \\
fertility rate & 3470 & 4.21 & 1,61 & 1,10 & 7,813 \\
years of schooling & 3470 & 4,79 & 2,85 & 0,26 & 11,53 \\
agricultural value added & 3470 & 0,24 & 0,14 & 0,02 & 0,72 \\
industry value added & 3470 & 0,29 & 0,10 & 0,10 & 0,72 \\
GDP growth rate & 3470 & 0,02 & 0,05 & $-0,14$ & 0,37 \\
FDI stock / GDP & 3470 & 0,26 & 0,52 & $8,09 \mathrm{e}-06$ & 6,91 \\
Trade / GDP & 3470 & 0,77 & 0,39 & 0,11 & 2,20 \\
Exports / GDP & 3470 & 0,34 & 0,20 &, 03 & 1,12 \\
Trade in Services / GDP & 3220 & 0,18 & 0,15 & 0,02 & 2,06 \\
\hline Summary Statistics based on those observations included in model $(5)$ \\
Trade and Exports are for goods and services.
\end{tabular}


Table 36: Impact of Clustering on Inference

\begin{tabular}{|c|c|c|}
\hline & $(\mathrm{A} 1)$ & $(\mathrm{A} 2)$ \\
\hline \multirow{2}{*}{$\begin{array}{l}\text { VARIABLES } \\
\text { clustering }\end{array}$} & FLFPR & FLFPR \\
\hline & Country level & Country-cohorts \\
\hline \multirow{2}{*}{$\begin{array}{l}\ln (\text { GDP p.c. } P P P) \\
(-1)\end{array}$} & -0.120 & $-0.120^{* * *}$ \\
\hline & $(-1.333)$ & $(-2.614)$ \\
\hline \multirow{2}{*}{$\begin{array}{l}\ln (\text { GDP p.c. } P P P)^{2} \\
(-1)\end{array}$} & 0.00901 & $0.00901^{* * *}$ \\
\hline & $(1.317)$ & $(2.606)$ \\
\hline \multirow{2}{*}{ fertility rate } & -0.00508 & -0.00508 \\
\hline & $(-0.676)$ & $(-1.394)$ \\
\hline \multirow[t]{2}{*}{ years of schooling } & 0.00612 & $0.00612^{*}$ \\
\hline & $(0.814)$ & $(1.717)$ \\
\hline \multirow[t]{2}{*}{ agricultural value added } & 0.0530 & $0.0530 * *$ \\
\hline & $(1.014)$ & $(2.409)$ \\
\hline \multirow[t]{2}{*}{ industry value added } & -0.0320 & -0.0320 \\
\hline & $(-0.737)$ & $(-1.532)$ \\
\hline \multirow[t]{2}{*}{ GDP growth rate } & -0.0510 & $-0.0510^{* * *}$ \\
\hline & $(-1.255)$ & $(-2.662)$ \\
\hline \multirow{2}{*}{$\begin{array}{l}\text { Exports / GDP } \\
(-1)\end{array}$} & -0.0370 & $-0.0370^{* *}$ \\
\hline & $(-1.173)$ & $(-2.543)$ \\
\hline \multirow{4}{*}{$\begin{array}{l}\text { FDI stock / GDP } \\
(-1) \\
\text { Constant }\end{array}$} & $-0.0116^{*}$ & $-0.0116^{* * *}$ \\
\hline & $(-1.733)$ & $(-3.755)$ \\
\hline & $0.954^{* * *}$ & $0.954^{* * *}$ \\
\hline & $(2.911)$ & $(5.760)$ \\
\hline $\begin{array}{l}\text { Year dummies } \\
\text { Observations }\end{array}$ & Yes & Yes \\
\hline \multirow{2}{*}{ Observations } & 3,470 & 3,470 \\
\hline & 0.221 & 0.221 \\
\hline $\begin{array}{l}\text { R-squared } \\
\text { Number of csec }\end{array}$ & 800 & 800 \\
\hline
\end{tabular}

Fixed effects regression equivalent to model (5) in table 22, taking every 5 th year. Cluster-robust t-statistics in parentheses. $* * *, * *, *$ denote statistical significance at the $1 \%, 5 \%$, and $10 \%$ level, respectively. 
Table 37: Correlation Between Globalization and Female Education

\begin{tabular}{lcc}
\hline VARIABLES & $\begin{array}{c}(1) \\
\text { yrs of schooling }\end{array}$ & $\begin{array}{c}(2) \\
\text { yrs of schooling }\end{array}$ \\
\hline Exports / GDP & $0.779^{* *}$ & $0.918^{* *}$ \\
$(-1)$ & $(0.375)$ & $(0.363)$ \\
FDI stock / GDP & $-0.111^{*}$ & $-0.119^{*}$ \\
$(-1)$ & $(0.0638)$ & $(0.0625)$ \\
Constant & $3.925^{* * *}$ & 0 \\
& $(0.121)$ & $(0)$ \\
Time Dummies & Yes & Yes \\
Estimation & Fixed Effects & Random Effects \\
Observations & 3,750 & 3,750 \\
Number of csec & 830 & 830 \\
\hline Cluster-robust standard errors in parentheses. $* * *, * *$, and & $* 1$ \\
denotes statistica significance at the 1 percent, 5 percent & \\
and 10 percent level, respectively.
\end{tabular}




\section{References}

Agça, M. and Allum, P. (2001). Economic data dissemination: What influences country performance on frequency and timeliness? IMF Working Paper 01/173, International Monetary Fund, Washington, DC.

Aghion, P., Bacchetta, P., Rancière, R., and Rogoff, K. (2009). Exchange rate volatility and productivity growth: The role of financial development. Journal of Monetary Economics, $56(4): 494-513$.

Ahearne, A. G., Griever, W. L., and Warnock, F. E. (2004). Information costs and home bias: An analysis of US holdings of foreign equities. Journal of International Economics, $62(2): 313-336$.

Akerlof, G. A. (1970). The market for 'lemons': Quality uncertainty and the market mechanism. Quarterly Journal of Economics, 84(3):488-500.

Albuquerque, R. (2003). The composition of international capital flows: Risk sharing through Foreign Direct Investment. Journal of International Economics, 61(2):353-383.

Albuquerque, R., Loayza, N., and Serven, L. (2005). World market integration through the lens of foreign direct investors. Journal of International Economics, 66(2):267-295.

Anderson, E. (2005). Openness and inequality in developing countries: A review of theory and recent evidence. World Development, 33(7):1045-1063.

Anderson, J. E. and van Wincoop, E. (2003). Gravity with gravitas: A solution to the border puzzle. American Economic Review, 93(1):170-192.

Anderson, T. and Hsiao, C. (1981). Estimation of dynamic models with error components. Journal of the American Statistical Association, 76:589-606.

Anker, R. (1998). Gender and Jobs Sex Segregation of Occupations in the World. International Labour Office, Geneva.

Anker, R., Melkas, H., and Korten, A. (2003). Gender based occupational segregation in the 1990s. Working paper, International Labour Office.

Antonakakis, N. and Tondl, G. (2012). Do determinants of FDI to developing countries differ among OECD investors? Insights from Bayesian model averaging. Discussion Papers 1/12, Europa-Kolleg Hamburg, Institute for European Integration.

Arellano, M. and Bond, S. (1991). Some tests of specification for panel data: Monte Carlo evidence and an application to employment equations. Review of Economic Studies, 58:277-297.

Arellano, M. and Bover, O. (1995). Another look at the instrumental variable estimation of error-components models. Journal of Econometrics, 68(1):29-51.

Arestoff, F. and Granger, C. (2004). Does trade openess affect core labour standards? European Study Group Conference, Nottingham (UK): September, 9-11.

Arseneau, D. M. and Leduc, S. (2011). Threatening to offshore in a search model of the labor market. Paper presented at the Conference 'Globalization: Strategies and Effects', Aarhus University, November 10, 2011.

Ausubel, L. M. (1990). Insider trading in a rational expectations economy. American Economic Review, 80(5):1022-41.

Avery, C. and Zemsky, P. (1998). Multidimensional uncertainty and herd behavior in financial markets. American Economic Review, 88(4):724-48.

Badinger, H. and Egger, P. (2010). Horizontal vs. vertical interdependence in multinational activity. Oxford Bulletin of Economics and Statistics, 72(6):744-768.

Bair, J. (2005). Global capitalism and commodity chains: Looking back, going forward. Competition \& Change, 9(2):153-180.

Baldwin, R. E. and Martin, P. (1999). Two waves of globalisation: Superficial similarities, fundamental differences. Working Paper No. 6904, NBER, Cambridge, MA. 
Baltagi, B. H., Egger, P., and Pfaffermayr, M. (2007). Estimating models of complex FDI: Are there third-country effects? Journal of Econometrics, 140(1):260-281.

Baltagi, B. H., Egger, P., and Pfaffermayr, M. (2008). Estimating regional trade agreement effects on FDI in an interdependent world. Journal of Econometrics, 145(1-2):194-208.

Baltagi, B. H. and Griffin, J. M. (1984). Short and long run effects in pooled models. International Economic Review, 25(3):631-45.

Banerjee, A. V. (1992). A simple model of herd behavior. The Quarterly Journal of Economics, 107(3):797-817.

Barba Navaretti, G. and Venables, A. J. (2006). Multinational Firms in the World Economy. Princeton University Press, Princeton, NY.

Barro, R. (1996). Determinants of economic growth: a cross-country empirical study. Working paper, NBER, Cambridge, MA. reprinted 1997 in MIT Press.

Barro, R. and Lee, J.-W. (2010). A new data set of educational attainment in the world, 1950-2010. Working Paper No. 15902, National Bureau of Economics Research, Cambridge, MA.

Baxter, M. and Kouparitsas, M. A. (2006). What can account for fluctuations in the terms of trade? International Finance, 9:63-86.

Beck, T., Clarke, G., Groff, A., Keefer, P., and Walsh, P. (2001). New tools in comparative political economy: The database of political institutions. World Bank Economic Review, 15(1):165-176.

Berg, A., Papageorgiou, C., Pattillo, C. A., Schindler, M., Spatafora, N., and Weisfeld, H. (2011). Global shocks and their impact on low-income countries: Lessons from the global financial crisis. IMF Working Paper 11/27, International Monetary Fund, Washington, DC.

Berg, A., Portillo, R., and Unsal, D. F. (2010). On the optimal adherence to money targets in a New-Keynesian framework: An application to low-income countries. IMF working paper, International Monetary Fund, Washington, DC.

Bergstrand, J. H. and Egger, P. (2007). A theoretical and empirical model of international trade and Foreign Direct Investment with outsourcing: Part i, developed countries. Working papers, University of Notre Dame.

Bhagwati, J. N. (1973). The theory of immiserizing growth: Further applications. in: M. Connolly and A. Swoboda (eds.): International Trade and Money, University of Toronto Press, Toronto: 45-54.

Bhagwati, J. N., Brecher, R. A., and Hatta, T. (1983). The generalized theory of transfers and welfare: Bilateral transfers in a multilateral world. American Economic Review, 73(4):606-618.

Bianchi, J. (2011). Overborrowing and systemic externalities in the business cycle. American Economic Review, 101(7):3400-3426.

Bikhchandani, S., Hirshleifer, D., and Welch, I. (1992). A theory of fads, fashion, custom, and cultural change as informational cascades. Journal of Political Economy, 100(5):9921026 .

Blalock, G. and Gertler, P. J. (2008). Welfare gains from foreign direct investment through technology transfer to local suppliers. Journal of International Economics, 74(2):402-421.

Blanchard, O. (2010). Macroeconomics. Prentice Hall, Upper Saddle River, New Jersey, 5. edition.

Blanchard, O., Dell'Ariccia, G., and Mauro, P. (2010). Rethinking macroeconomic policy. Journal of Money, Credit and Banking, 42(s1):199-215.

Blanton, R. G. and Blanton, S. L. (2009). Labor dumping' or building up? Assessing labor rights and FDI. Paper presented at the Annual Meeting of the International Studies Association, February 15-18, New York. 
Blattman, C., Hwang, J., and Williamson, J. G. (2007). Winners and losers in the commodity lottery: The impact of terms of trade growth and volatility in the periphery 1870-1939. Journal of Development Economics, 82:156-179.

Blonigen, B. A. (1997). Firm-specific assets and the link between exchange rates and Foreign Direct Investment. American Economic Review, 87(3):447-65.

Blonigen, B. A. (2002). Tariff-jumping antidumping duties. Journal of International Economics, $57(1): 31-49$.

Blonigen, B. A. (2005). A review of the empirical literature on FDI determinants. Atlantic Economic Journal, 33:383-403.

Blonigen, B. A., Davies, R. B., and Head, K. (2003). Estimating the knowledge-capital model of the multinational enterprise: Comment. American Economic Review.

Blonigen, B. A., Davies, R. B., Waddell, G. R., and Naughton, H. T. (2007). FDI in space: Spatial autoregressive relationships in Foreign Direct Investment. European Economic Review, 51(5):1303 - 1325 .

Blonigen, B. A., Ellis, C. J., and Fausten, D. (2005). Industrial groupings and Foreign Direct Investment. Journal of International Economics, 65(1):75-91.

Blonigen, B. A. and Piger, J. (2011). Determinants of Foreign Direct Investment. Working Papers 16704, NBER, Cambridge, MA.

Bloom, D., Canning, D., Fink, G., and Finlay, J. (2009). Fertility, female labor force participation, and the demographic dividend. Journal of Economic Growth, 14(2):79101.

Blundell, R. and Bond, S. (1998). Initial conditions and moment restrictions in dynamic panel data models. Journal of Econometrics, 87(1):115-143.

Bobonis, G. J. and Shatz, H. J. (2007). Agglomeration, adjustment, and state policies in the location of Foreign Direct Investment in the United States. The Review of Economics and Statistics, 89(1):30-43.

Bohning, W. (2005). Labour Rights in crisis: Measuring the achievements of human rights in the world of work. Palgrave, London.

Bond, E. W. and Samuelson, L. (1986). Tax holidays as signals. American Economic Review, $76(4): 820-26$.

Bond, S. (2002). Dynamic panel data models: A guide to micro data methods and practice. Working Paper CWP09/02, Institute for Fiscal Studies, UCL.

Boockmann, B. (2006). Partisan politics and treaty ratification: The acceptance of international labour organization conventions by industrialized democracies, 1960-1996. European Journal of Political Research, 45(1):153-180.

Borensztein, E., Gregorio, J. D., and Lee, J.-W. (1998). How does Foreign Direct Investment affect economic growth? Journal of International Economics, 45(1):115 - 135.

Brainard, S. L. (1997). An empirical assessment of the proximity-concentration trade-off between multinational sales and trade. American Economic Review, 87(4):520-44.

Brecher, R. A. and Diaz-Alejandro, C. F. (1977). Tariffs, foreign capital and immiserizing growth. Journal of International Economics, 7(3):317-322.

Brecher, R. A. and Findlay, R. (1983). Tariff, foreign capital and national welfare with sectorspecific factors. Journal of International Economics, 14(3-4):277-288.

Brennan, M. J. and Cao, H. H. (1997). International portfolio investment flows. Journal of Finance, 52(5):1851-1880.

Brennan, M. J., Cao, H. H., Strong, N., and Xu, X. (2005). The dynamics of international equity market expectations. Journal of Financial Economics, 77(2):257 - 288.

Broda, C. (2004). Terms of trade and exchange rate regimes in developing countries. Journal of International Economics, 63(1):31-58.

Brown, D. K. (2001). Labor standards: Where do they belong on the international trade 
agenda? Journal of Economic Perspectives, 15(3):89-112.

Brown, D. K., Deardorff, A. V., and Stern, R. M. (2004). The effects of multinational production on wages and working conditions in developing countries. in: Robert E. Baldwin and L. Alan Winters (eds.): Challenges to Globalization, University of Chicago Press: 279-330.

Brückner, M. and Ciccone, A. (2010). International commodity prices, growth and the outbreak of civil war in Sub-Saharan Africa. Economic Journal, 120(544):519-534.

Bruno, G. S. (2005a). Approximating the bias of the LSDV estimator for dynamic unbalanced panel data models. Economics Letters, 87(3):361-366.

Bruno, G. S. (2005b). XTLSDVC: Stata module to estimate bias corrected LSDV dynamic panel data models. Statistical Software Components, Boston College Department of Economics.

Bun, M. J. G. and Kiviet, J. F. (2003). On the diminishing returns of higher-order terms in asymptotic expansions of bias. Economics Letters, 79(2):145-152.

Busse, M. (2004). On the determinants of core labor standards: The case of developing countries. Economics Letters, 83(2):211-217.

Busse, M. and Braun, S. (2003). Export structure, FDI and child labour. Discussion Paper 26174, Hamburg Institute of International Economics.

Busse, M., Nunnenkamp, P., and Spatareanu, M. (2011). Foreign direct investment and labor rights: A panel analysis of bilateral FDI flows. Applied Economics Letters, 18(2):149-154.

Bussmann, M. (2009). The effect of trade openness on women's welfare and work life. World Development, 37(6):1027-1038.

Byard, D., Li, Y., and Yu, Y. (2011). The effect of mandatory IFRS adoption on financial analysts' information environment. Journal of Accounting Research, 49(1):69-96.

Cady, J. (2005). Does SDDS subscription reduce borrowing costs for emerging market economies? IMF Staff Papers, 52:503-517.

Cady, J. and Gonzalez-Garcia, J. (2007). Exchange rate volatility and reserves transparency. IMF Staff Papers, 54(4):741-754.

Cady, J. and Pellechio, A. J. (2006). Sovereign borrowing cost and the IMF's data standards initiatives. IMF Working Paper 06/78, International Monetary Fund, Washington, DC.

Calvo, G., Leiderman, L., and Reinhart, C. (1993). Capital inflows and the real exchange rate appreciation in Latin America: The role of external factors. IMF Staff Papers, 40(1):108-151.

Campa, J. M. (1993). Entry by foreign firms in the United States under exchange rate uncertainty. The Review of Economics and Statistics, 75(4):614-22.

Caraway, T. L. (2009). Labor rights in East Asia: Progress or regress? Journal of East Asian Studies, 9:153-186.

Carr, D. L., Markusen, J. R., and Maskus, K. E. (2001). Estimating the knowledge-capital model of the multinational enterprise. American Economic Review, 91(3):693-708.

Çağaty, N. and Berik, G. (1990). Transition to export led growth in turkey: Is there a feminization of employment? Review of Radical Political Economics, 22(1):115-134.

Çağaty, N. and Özler, c. (1995). Feminization of the labor force: The effects of long-term development and structural adjustment. World Development, 23(11):1883-1894.

Chakrabarti, A. (2001). The determinants of Foreign Direct Investment: Sensitivity analyses of cross-country regressions. Kyklos, 54(1):89-113.

Cheng, L. K. and Kwan, Y. K. (2000). What are the determinants of the location of Foreign Direct Investment? the Chinese experience. Journal of International Economics, 51(2):379-400.

Chinn, M. D. and Ito, H. (2006). What matters for financial development? Capital controls, institutions, and interactions. Journal of Development Economics, 81(1):163-192. 
Chinn, M. D. and Ito, H. (2008). A new measure of financial openness. Journal of Comparative Policy Analysis, 10(3):309-322.

Chinn, M. D. and Ito, H. (2011). Notes on the Chinn-Ito financial openness index 2009 update. mimeo.

Cho, U. and Koo, H. (1983). Economic development and women's work in a newly industrializing country: The case of Korea. Development and Change, 14(4):515-531.

Chuhan, P., Claessens, S., and Mamingi, N. (1998). Equity and bond flows to Latin America and Asia: The role of global and country factors. Journal of Development Economics, 55(2):439-463.

Ciccone, A. and Jarocinski, M. (2010). Determinants of economic growth: Will data tell? American Economic Journal: Macroeconomics, 2(4):222-46.

Cingranelli, D. L. and Richards, D. L. (1999). Measuring level, pattern and sequence of government respect for physical integrity rights. International Studies Quarterly, 43(2):407417.

Cingranelli, D. L. and Richards, D. L. (2006). The Cingranelli-Richards human rights dataset, version 2009.10.02. http://www.humanrightsdata.org.

Clark, A. E. (2009). Work, jobs and well-being across the millennium. Social, Employment and Migration Working Papers 83, OECD.

Coase, R. (1937). The nature of the firm. Economica, 4(16):386-405.

Conley, T. G. (1999). GMM estimation with cross sectional dependence. Journal of Econometrics, 92(1):1-45.

Conley, T. G. and Ligon, E. (2002). Economic distance and cross-country spillovers. Journal of Economic Growth, 7(2):157-87.

Cooray, A., Gaddis, I., and Wacker, K. M. (in press). Globalization and female labor force participation in developing countries: The role of sectoral change. Working paper series, Univeristy of Göttingen.

Coughlin, C. C. and Segev, E. (2000). Foreign direct investment in China: A spatial econometric study. The World Economy, 23(1):1-23.

Coughlin, C. C., Terza, J. V., and Arromdee, V. (1991). State characteristics and the location of Foreign Direct Investment within the United States. The Review of Economics and Statistics, 73(4):675-683.

Cuddington, J. T. and Urzúa, C. M. (1998). Trends and cycles in the net barter terms of trade: A new approach. Economic Journal, 99(396):426ff.

Cushman, D. O. (1985). Real exchange rate risk, expectations, and the level of direct investment. The Review of Economics and Statistics, 67(2):297-308.

Dabla-Norris, E., Honda, J., Lahreche, A., and Verdier, G. (2010). FDI flows to low-income countries: Global drivers and growth implications. Working Paper 10/132, International Monetary Fund, Washington, DC.

Darity, W. A. J. (1990). The fundamental determinants of the terms of trade reconsidered: Long-run and long-period equilibrium. American Economic Review, 80(4):816-827.

Darity, W. A. J., Lahiri, B., and Frank, D. (2010). Reparations for African Americans as a transfer problem: A cautionary tale. Review of Development Economics, 14(2):248-261.

Daude, C. and Fratzscher, M. (2008). The pecking order of cross-border investment. Journal of International Economics, 74(1):94 - 119.

David, P. A. (1985). Clio and the economics of qwerty. The American Economic Review: Papers and Proceedings, 75(2):332-337.

Davies, R. B. (2005). Fragmentation of headquarter services and FDI. North American Journal of Economics and Finance, 16(1):16-79.

Davies, R. B. (2008). Hunting high and low for vertical FDI. Review of International Economics, 16(2):250-267. 
Davies, R. B., Ionascu, D., and Kristjánsdóttir, H. (2008). Estimating the impact of time-invariant variables on FDI with fixed effects. Review of World Economics (Weltwirtschaftliches Archiv), 144(3):381-407.

Davies, R. B. and Kristjánsdóttir, H. (2010). Fixed costs, Foreign Direct Investment, and gravity with zeros. Review of International Economics, 18(1):47-62.

Davies, R. B., Norbäck, P.-J., and Tekin-Koru, A. (2009). The effect of tax treaties on multinational firms: New evidence from microdata. World Economy, 32(1):77-110.

Davies, R. B. and Voy, A. (2009). The effect of FDI on child labor. Journal of Development Economics, 88(1):59-66.

De Long, B. J. and Summers, L. H. (1991). Equipment investment and economic growth. Quarterly Journal of Economics, 106(2):445-502.

De Vita, G. and Kyaw, K. S. (2008a). Determinants of capital flows to developing countries: A structural VAR analysis. Journal of Economic Studies, 35:304-322.

De Vita, G. and Kyaw, K. S. (2008b). Determinants of FDI and portfolio flows to developing countries: A panel cointegration analysis. European Journal of Economics, Finance and Administrative Sciences, 13:161-168.

di Giovanni, J. (2005). What drives capital flows? The case of cross-border M and A activity and financial deepening. Journal of International Economics, 65(1):127 - 149.

Diamond, D. W. and Verrecchia, R. E. (1991). Disclosure, liquidity, and the cost of capital. Journal of Finance, 46(4):1325-1359.

Diamond, P. (1982). Aggregate demand management in search equilibrium. Journal of Political Economy, 90(5):881-894.

Dickens, W., Goette, L., Groshen, E. L., Holden, S., Messina, J., Schweitzer, M. E., Turunen, J., and Ward, M. (2007). How wages change: Micro evidence from the international wage flexibility project. Journal of Economic Perspectives, 21(2):195-214.

Du, J. and Wei, S.-J. (2004). Does insider trading raise market volatility? Economic Journal, 114(498):916-942.

Egger, P. and Pfaffermayr, M. (2005). Estimating long and short run effects in static panel models. Econometric Reviews, 23(3):199-214.

Eicher, T. S., Helfman, L., and Lenkoski, A. (2011). Robust FDI determinants: Bayesian model averaging in the presence of selection bias. Working Papers UWEC-2011-07-FC, University of Washington, Department of Economics.

Ekholm, K., Forslid, R., and Markusen, J. R. (2007). Export-platform Foreign Direct Investment. Journal of the European Economic Association, 5(4):776-795.

Elliott, D. J. (2010). A primer on bank capital. mimeo, Brookings Institution.

Emmanuel, A. (1972). Unequal Exchange, A Study in the Imperialism of Trade. Monthly Review Press, New York \& London. (French Original: Paris: Maspéro, 1969).

Engel, C. M. and West, K. D. (2005). Exchange rates and fundamentals. Journal of Political Economy, 113:485-517.

Entorf, H. (1997). Random walks with drifts: Nonsense regressions and spurious fixed-effect estimation. Journal of Econometrics, 80(2):287-296.

European Commission (2008). Employment in Europe 2008. European Communities, Brussels.

Feenstra, R. and Hanson, G. (1996). Globalization, outsourcing and wage inequality. American Economic Review, 86(2):240-245.

Fernandez-Arias, E. (1996). The new wave of private capital inflows: Push or pull? Journal of Development Economics, 48(2):389 - 418.

Findlay, R. (1980). The terms of trade and equilibrium growth in the world economy. American Economic Review, 70(3):291-299.

Fratzscher, M. (2011). Capital flows, push versus pull factors and the global financial crisis. 
Working Paper 1364, European Central Bank, Frankfurt, Germany.

French, K. R. and Poterba, J. M. (1991). Investor diversification and international equity markets. American Economic Review, 81(2):222-26.

Froot, K. A. and Stein, J. C. (1991). Exchange rates and Foreign Direct Investment: An imperfect capital markets approach. The Quarterly Journal of Economics, 106(4):11911217.

G-20 (2009). Pittsburgh summit commitments. September 25, 2009.

Gaddis, I. and Klasen, S. (2012). Economic development, structural change and women's labor force participation a reexamination of the feminization $U$ hypothesis. Discussion papers, Courant Research Centre: Poverty, Equity and Growth.

Gelos, R. G. and Wei, S.-J. (2005). Transparency and international portfolio holdings. Journal of Finance, 60(6):2987-3020.

Gereffi, G. (2005). The Global Economy: Organization, Governance, and Development, pages 160-182. Princeton University Press and Russell Sage Foundation, 2nd edition.

Ghoshray, A. (2011). A reexamination of trends in primary commodity prices. Journal of Development Economics, 95(2):242-251.

Giles, D. E. A. (1982). The interpretation of dummy variables in semilogarithmic equations : Unbiased estimation. Economics Letters, 10(1-2):77-79.

Glennerster, R. and Shin, Y. (2008). Does transparency pay? IMF Staff Papers, 55(1):183209.

Goldberg, L. (2007). Financial sector FDI and host countries: New and old lessons. Economic Policy Review, 13(1):1-17.

Goldin, C. (1995). Cliometrics and the nobel. Journal of Economic Perspectives, 9(2):191208.

Goldstein, I. and Razin, A. (2006). An information-based trade off between Foreign Direct Investment and foreign portfolio investment. Journal of International Economics, 70(1):271 - 295 .

Gordon, R. H. and Bovenberg, A. L. (1996). Why is capital so immobile internationally? Possible explanations and implications for capital income taxation. American Economic Review, 86(5):1057-75.

Görg, H. and Strobl, E. (2005). Spillovers from foreign firms through worker mobility: An empirical investigation. Scandinavian Journal of Economics, 107(4):693-709.

Graham, E. M. and Krugman, P. R. (1989). Foreign Direct Investment in the United States. Peterson Institute, Washington, DC.

Gray, M. M., Kittilson, M. C., and Sandholtz, W. (2006). Women and globalization: A study of 180 countries, 19752000. International Organization, 60(02):293-333.

Greenaway, D., Sapsford, D., and Pfaffenzeller, S. (2007). Foreign direct investment, economic performance and trade liberalization. The World Economy, 30(2):197-210.

Greene, W. (2011a). Fixed effects vector decomposition: A magical solution to the problem of time-invariant variables in fixed effects models? Political Analysis, 19(2):135-146.

Greene, W. (2011b). Reply to rejoinder by Plümper and Troeger. Political Analysis, 19(2):170-172.

Greenhalgh, S. (1985). Sexual stratification: The other side of "growth with equity" in east asia. Population and Development Review, 11:265-314.

Greenhill, B., Mosley, L., and Prakash, A. (2009). Trade-based diffusion of labor rights: A panel study, 1986-2002. American Political Science Review, 103(4):169-190.

Grilli, E. and Yang, M. C. (1988). Primary commodity prices, manufactured goods prices and the terms of trade of developing countries: What the long run shows. World Bank Economic Review, 2(1):1ff.

Hall, R. E. and Jones, C. I. (1999). Why do some countries produce so much more output 
per worker than others? Quarterly Journal of Economics, 114(1):83-116.

Harding, T. and Javorcik, B. S. (2011). Roll out the red carpet and they will come: Investment promotion and FDI inflows. Economic Journal, 121(557):1445-1476.

Harrison, A. E. and McMillan, M. S. (2003). Does direct foreign investment affect domestic credit constraints? Journal of International Economics, 61(1):73-100.

Harrison, A. E. and Rodríguez-Clare, A. (2009). Trade, foreign investment, and industrial policy for developing countries. Working paper, NBER, Cambridge, MA.

Harrison, A. E. and Scorse, J. (2010). Multinationals and anti-sweatshop activism. American Economic Review, 100(1):247-273.

Hart, O. and Holmstrom, B. (2010). A theory of firm scope. The Quarterly Journal of Economics, 125(2):483-513.

Harvey, D. I., Kellard, N. M., Madsen, J. B., and Wohar, M. E. (2010). The Prebisch-Singer hypothesis: Four centuries of evidence. Review of Economics and Statistics, 92(2):367377.

Hau, H. (2001a). Geographic patterns of trading profitability in Xetra. European Economic Review, 45(4-6):757-769.

Hau, H. (2001b). Location matters: An examination of trading profits. Journal of Finance, 56(5):1959-1983.

Haufler, A. and Mittermaier, F. (2011). Unionisation triggers tax incentives to attract Foreign Direct Investment. Economic Journal, 121(553):793-818.

Hauk, W. and Wacziarg, R. (2009). A Monte Carlo study of growth regressions. Journal of Economic Growth, 14(2):103-147.

Havranek, T. and Irsova, Z. (2011). Estimating vertical spillovers from fdi: Why results vary and what the true effect is. Journal of International Economics, 85(2):234-244.

Head, K., Ries, J., and Swenson, D. (1995). Agglomeration benefits and location choice: Evidence from Japanese manufacturing investments in the United States. Journal of International Economics, 38(3-4):223-247.

Hein, C. (1984). Jobs for the girls: Export manufacturing in Mauritius. International Labour Review, 123(2):251-265.

Helpman, E. (1984). A simple theory of international trade with multinational corporations. Journal of Political Economy, 92(3):451-471.

Helpman, E., Melitz, M. J., and Yeaple, S. R. (2004). Export versus FDI with heterogeneous firms. American Economic Review, 94(1):300-316.

Henderson, D. J., Papageorgiou, C., and Parmeter, C. F. (2012). Growth empirics without parameters. Economic Journal, 122(559):125-154.

Hernández, L., Mellado, P., and Valdés, R. (2001). Determinants of private capital flows in the 1970s and 1990s: Is there evidence of contagion? Working Paper 01/64, International Monetary Fund, Washington, DC.

Herzer, D., Klasen, S., and D., F. N.-L. (2008). In search of FDI-led growth in developing countries: The way forward. Economic Modelling, 25(5):793 - 810.

Holtz-Eakin, D., Newey, W., and Rosen, H. S. (1988). Estimating vector autoregressions with panel data. Econometrica, 56(6):1371-1395.

Horstman, I. and Markusen, J. R. (1992). Endogenous market structures in international trade (natura facit saltum). Journal of International Economics, 32:109-129.

Hsiao, C. (1986). Analysis of Panel Data. Cambridge University Press, New York.

Huber, P. J. (1967). The behavior of maximum likelihood estimates under nonstandard conditions. in: Proceedings of the Fifth Berkeley Symposium on Mathematical Statistics and Probability. Berkeley, CA: University of California Press, Vol. 1: 221-233.

ILO (1985). Women Workers in Multinational Enterprises in Developing Countries. International Labour Organization, Geneva. 
ILO (1990). Surveys of Econmically Active Population, Employment, Unemployment and Underemployment. An ILO Manual on Concepts and Methods. International Labour Organization, Geneva.

ILO (2009). ILO Estimates and Projections of the Economically Active Population: 19802020. International Labour Organization, Geneva, 5 edition.

IMF (1991). Determinants and systemic consequences of international capital flows: a study. Occasional Paper no. 77, International Monetary Fund, Research Department, Washington, DC.

IMF (1992). Report on the measurement of international capital flows. Report, International Monetary Fund.

IMF (1993). Balance of Payments and International Investment Position Manual. International Monetary Fund, Washington, DC.

IMF (2004). Foreign Direct Investment: Trends, Data Availability, Concepts, and Recording Practices. International Monetary Fund, Washington, DC. edited by Neil Patterson, Marie Montanjees, John Motala, and Colleen Cardillo.

IMF (2009a). Balance of Payments and International Investment Position Manual. International Monetary Fund, Washington, DC.

IMF (2009b). Export and Import Price Index Manual: Theory and Practice. ILO, IMF, OECD, Eurostat, UNECE, World Bank, Washington, DC.

IMF (2011a). Managing Volatility: A Vulnerability Exercise for Low-Income Countries. International Monetary Fund, Washington, DC.

IMF (2011b). Recent Experiences in Managing Capital Inflows: Cross-Cutting Themes and Possible Policy Framework. International Monetary Fund: Strategy, Policy and Review Department, Washington, DC.

Irish Central Statistics Office (2011). Estimates of the capital stock of fixed assets. puslished by the Central Statistics Office on December 8, 2011; www.cso.ie.

Javorcik, B. S. (2004). Does Foreign Direct Investment increase the productivity of domestic firms? In search of spillovers through backward linkages. American Economic Review, 94(3):605-627.

Javorcik, B. S. and Wei, S.-J. (2009). Corruption and cross-border investment in emerging markets: Firm-level evidence. Journal of International Money and Finance, 28(4):605624.

Jeanne, O. (2011). Capital account policies and the real exchange rate. John Hopkins University, mimeo.

Jeanne, O. (2012). Capital flow management. American Economic Review, 102(3):203-06. Jeanne, O., Subramanian, A., and Williamson, J. (2012). Who Needs to Open the Capital Account? Peterson Institute for International Econometrics, Washington, DC.

Jensen, M. C. and Meckling, W. H. (1976). Theory of the firm: Managerial behavior, agency costs and ownership structure. Journal of Financial Economics, 3(4):305-360.

Jones, B. (1996). International tax developments and double taxation agreements in Australia. in: Richard Vann (ed.): Tax Treaties: Linkages between OECD Member Countries and Dynamic Non-Member-Economies, Paris: OECD, 19-25.

Jones, R. W. (2000). Globalization and the theory of input trade. MIT Press, Cambridge, MA.

Judson, R. A. and Owen, A. L. (1997). Estimating dynamic panel data models: A practical guide for macroeconomists. Finance and Economics Discussion Series 1997-3, Board of Governors of the Federal Reserve System (U.S.).

Kabeer, N. and Mahmud, S. (2004). Globalization, gender and poverty: Bangladeshi women workers in export and local markets. Journal of International Development, 16(1):93-109.

Kao, C. (1999). Spurious regressions and residual-based tests for cointegration in panel 
data. Journal of Econometrics, 90:1-44.

Karkinsky, T. and Riedel, N. (2012). Corporate taxation and the choice of patent location within multinational firms. Journal of International Economics, 88(1):176 - 185.

Kelejian, H. H. and Prucha, I. R. (1999). A generalized moments estimator for the autoregressive parameter in a spatial model. International Economic Review, 40(2):509-33.

Kelejian, H. H. and Prucha, I. R. (2007). HAC estimation in a spatial framework. Journal of Econometrics, 140(1):131 - 154 .

Kesternich, I. and Schnitzer, M. (2010). Who is afraid of political risk? Multinational firms and their choice of capital structure. Journal of International Economics, 82(2):208 218.

Keynes, J. M. (1929). The German transfer problem. Economic Journal, 39:1-7.

Keynes, J. M. (1936). The General Theory of Employment, Interest and Money. Macmillan, London.

Kim, T.-H., Pfaffenzeller, S., Rayner, T., and Newbold, P. (2003). Testing for linear trend with application to relative primary commodity prices. Journal of Time Series Analysis, 24(5):539-551.

Kim, Y. J. and Zhang, J. (2012). Decentralized borrowing and centralized default. Journal of International Economics, 88(1):121 - 133.

Kinoshita, Y. (2012). Foreign direct investment and the crisis: Is this time different? IMF Research Bulletin, 13(1):1-3.

Kinoshita, Y. and Mody, A. (2001). Private information for foreign investment in emerging economies. Canadian Journal of Economics/Revue canadienne d'économique, 34(2):448464.

Kiviet, J. F. (1995). On bias, inconsistency, and efficiency of various estimators in dynamic panel data models. Journal of Econometrics, 68(1):53-78.

Kiyota, K. and Urata, S. (2004). Exchange rate, exchange rate volatility and Foreign Direct Investment. The World Economy, 27(10):1501-1536.

Klasen, S. and Lamanna, F. (2009). The impact of gender inequality in education and employment on economic growth: New evidence for a panel of countries. Feminist Economics, 15(3):91-132.

Knight, K. and Fu, W. (2000). Asymptotics of LASSO-type estimators. Annals of Statistics, 28(5):1356-1378.

Kose, M. A. (2002). Explaining business cycles in small open economies: 'How much do world prices matter?'. Journal of International Economics, 56(2):299-327.

Krugman, P. (2011). The profession and the crisis. Eastern Economic Review, 37:307-312.

Kucera, D. (2002). Core labour standards and FDI. International Labour Review, 141(1$2): 31-69$.

Lafontaine, F. and Slade, M. (2007). Vertical integration and firm boundaries: The evidence. Journal of Economic Literature, 45(3):629-685.

Leeb, H. and Pötscher, B. M. (2005). Model selection and inference: Facts and fiction. Econometric Theory, 21(01):21-59.

Lehmann, A., Sayek, S., and Kang, H. G. (2004). Multinational affiliates and local financial markets. Working Paper 04/107, International Monetary Fund, Washington, DC.

Lele, U. and Mellor, J. W. (1981). Technological change, distributive bias and labor transfer in a two-sector economy. Oxford Economic Papers, 33(3):426-41.

Levine, R. and Renelt, D. (1992). A sensitivity analysis of cross-country growth regressions. American Economic Review, 82(4):942-963.

Lewis, W. A. (1954). Economic development with unlimited supplies of labour. The Manchester School, 22(2):139-191.

Li, H., Huang, P., and Li, J. (2007). China's FDI net inflow and deterioration of terms of 
trade: Paradox and explanation. China \& World Economy, 15(1):87-95.

Lin, J. Y. (2011). New structural economics: A framework for rethinking development. World Bank Research Observer, 26(2):193-221.

Lipsey, R. E. (1994). Quality change and other influences on measures of export prices of manufactured goods and the terms of trade between primary products and manufactures. Working Paper 4671, NBER, Cambridge, MA.

Lipsey, R. E. (2002). Home and host country effects of FDI. Working Paper No. 9293, National Bureau of Economics Research, Cambridge, MA.

Lipsey, R. E. (2007). Defining and measuring the location of FDI output. Working Paper 12996, NBER, Cambridge, MA.

Liu, W.-H. and Nunnenkamp, P. (2011). Domestic repercussions of different types of FDI: Firm-level evidence for Taiwanese manufacturing. World Development, 39(5):808-823.

Locke, R. M., Qin, F., and Brause, A. (2007). Does monitoring improve labor standards? Lessons from Nike. Industrial and Labor Relations Review, 61(1):3-31.

Lucas Jr., R. E. (1990). Why doesn't capital flow from rich to poor countries? American Economic Review, 80(2):92-96.

Luhmann, N. (1975). Evolution und geschichte. in: Niklas Luhmann: Soziologische Aufklärung. Aufsätze zur Theorie der Gesellschaft. Band II. Opladen: Westdeutscher Verlag.

Lutz, M. and Singer, H. W. (1994). The link between increased trade openness and the terms of trade: An empirical investigation. World Development, 22(11):1697-1709.

Lutz, M. G. (1999). A general test of the Prebisch-Singer hypothesis. Review of Development Economics, 3(1):44-57.

Maddala, G. S. (1971). The use of variance components models in pooling cross section and time series data. Econometrica, 39(2):341-358.

Mammen, K. and Paxson, C. (2000). Women's work and economic development. Journal of Economic Perspectives, 14(4):141-164.

Markusen, J. R. (1984). Multinationals, multi-plant economies and the gains from trade. Journal of International Economics, 16:49-57.

Markusen, J. R. (1995). The boundaries of multinational enterprises and the theory of international trade. Journal of Economic Perspectives, 9(2):169-189.

Markusen, J. R. (2002). Multinational Firms and the Theory of International Trade. MIT Press, Cambridge, MA.

Markusen, J. R. and Venables, A. J. (1998). Multinational firms and the new trade theory. Journal of International Economics, 46:335-356.

Markusen, J. R. and Venables, A. J. (2000). The theory of endowment, intra-industry and multi-national trade. Journal of International Economics, 52(2):209 - 234.

Martínez-Zarzoso, I., Nowak-Lehmann Danzinger, F., Klasen, S., and Larch, M. (2009). Does German development aid promote German exports. German Economic Review, 10:317-338.

McKelvey, C. (2011). Price, unit value, and quantity demanded. Journal of Development Economics, 95(2):157-169.

Mellor, J. W. and Lele, U. (1973). Growth linkages of the new foodgrain technologies. Indian Journal of Agricultural Economics, 23(1):35-55.

Mellor, J. W. and Lele, U. (1975). Interaction of growth strategy, agriculture and foreign trade - The case of India. in: George S. Tolley and Peter Zadrozny (eds.): Trade, agriculture, and development.

Mendoza, E. G. (1995). The terms of trade, the real exchange rate, and economic fluctuations. International Economic Review, 36(1):101-137.

Miao, Y. and Pant, M. (2012). Coincident indicators of capital flows. Working Papers 
12/55, International Monetary Fund.

Milesi-Ferretti, G. M. and Lane, P. R. (2004). International investment patterns. IMF working paper, International Monetary Fund, Washington, DC.

Mody, A., Sadka, E., and Razin, A. (2003). The role of information in driving FDI flows: Host-country transparency and source-country specialization. IMF Working Paper 03/148, International Monetary Fund, Washington, DC.

Mody, A. and Taylor, M. P. (2003). International capital crunches: The time-varying role of informational asymmetries. Discussion Papers 3757, C.E.P.R.

Moran, T. H. (2002). Beyond Sweatshops. Foreign Direct Investment and Globalization in Developing Countries. Brookings Institution Press, Washington, DC.

Moran, T. H. (2011). Foreign Direct Investment and Development: Launching a Second Generation of Policy Research: Avoiding the Mistakes of the First, Reevaluating Policies for Developed and Developing Countries. Peterson Institute for International Economics, Washington, DC.

Mortensen, D. (1982). Property rights and efficiency in mating, racing, and related games. American Economic Review, 72(5):968-979.

Mosley, L. and Uno, S. (2007). Racing to the bottom or climbing to the top? economic globalization and collective labor rights. Comparative Political Studies, 40(8):923-948.

Neumeyer, E. and de Soysa, I. (2005). Trade openness, Foreign Direct Investment and child labor'. World Development, 33(1):43-63.

Neumeyer, E. and de Soysa, I. (2006). Globalization and the right to free association and collective bargaining: An empirical analysis. World Development, 34(1):31-49.

Neumeyer, E. and de Soysa, I. (2007). Globalization, women's economic rights and forced labor. World Economy, 33(1):43-63.

Newey, W. K. and West, K. D. (1987). A simple, positive semi-definite, heteroskedasticity and autocorrelation consistent covariance matrix. Econometrica, 55(3):703-08.

Nickell, S. (1981). Biases in dynamic models with fixed effects. Econometrica, 49:1417-1426.

Ocampo, J. A. and Jomo, K. S. (2007). Towards Full and Decent Employment. Zed and others in association with the United Nations, London.

OECD (2007). Measuring Globalisation: Activities of Multinationals - Volume 1: Manufacturing. Organization for Economic Cooperation and Development, Paris.

Ohlin, B. (1929). The reparations problem: A discussion. Economic Journal, 39:172-178.

Oostendorp, R. H. (2009). Globalization and the gender wage gap. World Bank Economic Review, 23(1):141-161.

Ostry, J. D., Ghosh, A. R., Habermeier, K., Laeven, L., Chamon, M., Qureshi, M. S., and Kokenyne, A. (2011). Managing capital inflows: What tools to use? IMF Staff Position Note, $11 / 06$.

Ostry, J. D., Ghosh, A. R., and Korinek, A. (2012). Multilateral aspects of managing the capital account. IMF Staff Position Note, 12/10.

Özler, c. (2000). Export orientation and female share of employment: Evidence from turkey. World Development, 28(7):1239-1248.

Pagano, M., Röell, A. A., and Zechner, J. (2002). The geography of equity listing: Why do companies list abroad? Journal of Finance, 57(6):2651-2694.

Pain, N. and van Welsum, D. (2003). Untying the Gordian Knot: The multiple links between exchange rates and Foreign Direct Investment. Journal of Common Market Studies, 41(5):823-846.

Papaioannou, E. (2009). What drives international financial flows? Politics, institutions and other determinants. Journal of Development Economics, 88(2):269 - 281.

Parent-Thirion, A., Fernández Macías, E., Hurley, J., and Vermeylen, G. (2007). Fourth european working conditions survey. Technical report, European Foundation for the 
Improvement of Living and Working Conditions.

Pellechio, A. and Cady, J. (2006). Differences in IMF data: Incidence and implications. IMF Staff Papers, 53(2):326-349.

Pesaran, M. H. and Smith, R. (1995). Estimating long-run relationships from dynamic heterogeneous panels. Journal of Econometrics, 68(1):79-113.

Phillips, P. C. and Sul, D. (2007). Bias in dynamic panel estimation with fixed effects, incidental trends and cross section dependence. Journal of Econometrics, 137:162-188.

Phillips, P. C. B. and Sul, D. (2003). Dynamic panel estimation and homogeneity testing under cross section dependence. Econometrics Journal, 6(1):217-259.

Pirotte, A. (1999). Convergence of the static estimation toward the long run effects of dynamic panel data models. Economics Letters, 63(2):151-158.

Pissarides, C. (1985). Short-run equilibrium dynamics of unemployment, vacancies, and real wages. American Economic Review, 75(4):676-690.

Pissarides, C. (1990). Equilibrium Unemployment Theory. Blackwell, Oxford.

Plümper, T. and Troeger, V. E. (2007). Efficient estimation of time-invariant and rarely changing variables in finite sample panel analyses with unit fixed effects. Political Analysis, 15(2):124-139.

Plümper, T. and Troeger, V. E. (2011a). Fixed-effects vector decomposition: Properties, reliability, and instruments. Political Analysis, 19(2):147-164.

Plümper, T. and Troeger, V. E. (2011b). Fixed effects vector decomposition: Reply. Working paper, SSRN.

Porta, R. L., Lopez-De-Silanes, F., and Shleifer, A. (1999). Corporate ownership around the world. Journal of Finance, 54(2):471-517.

Portes, R. and Rey, H. (2005). The determinants of cross-border equity flows. Journal of International Economics, 65(2):269 - 296.

Portes, R., Rey, H., and Oh, Y. (2001). Information and capital flows: The determinants of transactions in financial assets. European Economic Review, 45(4-6):783-796.

Pötscher, B. M. (1991). Effects of model selection on inference. Econometric Theory, 7(02):163-185.

Pötscher, B. M. (2006). The distribution of model averaging estimators and an impossibility result regarding its estimation. IMS Lecture Notes - Monograph Series: Time Series and Related Topics, 52:113-129.

Powell, A. (1991). Commodity and developing country terms of trade: What does the long run show? Economic Journal, 101(409):1485-1496.

Pradhan, J. P. (2006). How do trade, foreign investment and technology affect empoyment patterns in organized Indian manufacturing? Indian Journal of Labour Economics, 49(2):249-272.

Prebisch, R. (1950). The Economic Development of Latin America and Its Principal Problems. United Nations, New York.

Prebisch, R. (1959). Commercial policies in the underdeveloped countries. American Economic Review, Papers and Proceedings, 49:251ff.

Raffer, K. (1987). Unequal Exchange and the Evolution of the World System - Reconsidering the Impact of Trade on North-South Relations. Macmillan, Basingstoke.

Rajan, R. G. (2010). Fault Lines : How hidden fractures still threaten the world economy. Princeton University Press, Princeton, NJ.

Razin, A., Sadka, E., and Coury, T. (2003). Trade openness, investment instability and terms-of-trade volatility. Journal of International Economics, 61(2):285-306.

Razin, A., Sadka, E., and Yuen, C.-W. (1998). A pecking order of capital inflows and international tax principles. Journal of International Economics, 44(1):45-68.

Reardon, T. and Timmer, C. P. (2007). Transformation of markets for agricultural output 
in developing countries since 1950: How has thinking changed? in: Robert Evenson and Prabhu Pingali (eds.): Handbook of Agricultural Economics, Vol. 3, Ch. 55, pp. 2807-2855.

Reinhart, C. M. and Wickham, P. (1994). Commodity prices: Cyclical weakness or secular decline? IMF Staff Papers, 41(2):175-213.

Richardson, J. and Khripounova, E. (1998). U.S. labor market power and linkages to international trade: Indentifying suspects and measures. mimeo, Draft for the US Department of Labor.

Robertson, R. (2003). The Three Waves of Globalization: A History of a Developing Global Consciousness. Fernwood, Winnipeg/Black Point.

Rodríguez-Clare, A. (1996). The division of labor and economic development. Journal of Development Economics, 49(1):3-32.

Rodrik, D. (1997). Has Globalization Gone Too Far? Institute for International Economics, Washington, DC.

Roemer, J. E. (2011). The ideological and political roots of american inequality. GINI Discussion Paper 8, Growing Inequalities' Impacts.

Roodman, D. (2009a). How to do xtabond2: An introduction to difference and system gmm in stata. Stata Journal, 9(1):86-136.

Roodman, D. (2009b). A note on the theme of too many instruments. Oxford Bulletin of Economics and Statistics, 71(1):135-158.

Ross, S. A., Westerfield, R. W., and Jaffe, J. F. (2007). Corporate Finance. Mc Graw Hill/China Machine Press, Beijing, 7th edition.

Santos-Paulino, A. U. (2010). Terms of trade shocks and the current account in small island developing states. Journal of Development Studies, 46(5):855-876.

Sapsford, D. (1985). The statistical debate on the net barter terms of trade between primary commodities and manufactures: A comment and some additional evidence. Economic Journal, 95:781ff.

Sarkar, P. and Singer, H. W. (1991). Manufactured exports of developing countries and their terms of trade since 1965. World Development, 19(4):333ff.

Sarkar, P. and Singer, H. W. (1993). Manufacture-manufacture terms of trade deterioration, a reply. World Development, 21:1617ff.

Sauré, P. and Zoabi, H. (2009). Effects of trade on female labor force participation. Working Papers 2009-12, Swiss National Bank.

Savastano, M. (2000). Comment on Gosh and Wolf. in: Sebastian Edwards (ed.): Capital Flows and the Emerging Economies: Theory and Evidence, and Controversies, University of Chicago Press, 156-158.

Schmidt, C. and Broll, U. (2009). Real exchange-rate uncertainty and us Foreign Direct Investment: an empirical analysis. Review of World Economics, 145:513-530.

Scholes, M. and Wolfson, M. (1990). The effects of changes in tax law on corporate reorganization activity. Journal of Business, 63:S141-S164.

Seguino, S. (2000). The effects of structural change and economic liberalisation on gender wage differentials in South Korea and Taiwan. Cambridge Journal of Economics, 24(4):437-59.

Sen, A. K. (1999). Development As Freedom. Oxford University Press, Oxford, 1st edition.

Silver, M. (2010). The wrongs and rights of unit value indices. Review of Income and Wealth, 56(S1):S206-S223.

Singer, H. W. (1949). Post-war price relations in trade between under-developed and industrialized countries. UN document no E/CN.1/Sub.2/W.5. Lake Success, NY: UNDEA.

Singer, H. W. (1950). The distribution of gains between investing and borrowing countries. American Economic Review, Papers and Proceedings, XL:478ff.

Singer, H. W. (1975). The distribution of gains from trade and investment - revisited. 
Journal of Development Studies, 11(4):376-382.

Slaughter, M. (2001). International trade and labor demand elasticities. Journal of International Economics, 54(1):27-56.

Smith, A. (1987). Strategic investment, multinational corporations and trade policy. European Economic Review, 31:89-96.

Spanos, A. (1993). Statistical foundations of Econometric Modelling. Cambridge University Press, Cambridge, reprinted edition.

Spraos, J. (1980). The statistical debate on the net barter terms of trade between primary products and manufactures. Economic Journal, 90:107-128. (reprinted in Spraos, 1983: ch. III).

Spraos, J. (1983). Inequalising Trade, A Study of Traditional North/South Specialisation in the Context of Terms of Trade Concept. Claredon, Oxford.

Spulber, D. (2009). The Theory of the Firm: Microeconomics with Endogenous Entrepreneurs, Firms, Markets, and Organizations. Cambridge University Press, Cambridge, UK.

Staiger, D. and Stock, J. H. (1997). Instrumental variables regression with weak instruments. Econometrica, 65(3):557-586.

Standing, G. (1989). Global feminization through flexible labor. World Development, 17(7):1077-1095.

Stehrer, R. and Woerz, J. (2009). 'Attract FDI!' - A universal golden rule? Empirical evidence for OECD and selected non-OECD countries. European Journal of Development Research, 21(1):95-111.

Stern, D. I. (2010). Between estimates of the emissions-income elasticity. Ecological Economics, 69(11):2173-2182.

Stiglitz, J. E. (1989). Markets, market failures, and development. American Economic Review, 79(2):197-203.

Stiglitz, J. E. and Weiss, A. (1981). Credit rationing in markets with imperfect information. American Economic Review, 71(3):393-410.

Stulz, R. M. (1981). On the effects of barriers to international investment. Journal of Finance, 36(4):923-934.

Tesar, L. L. and Werner, I. M. (1995). Home bias and high turnover. Journal of International Money and Finance, 14(4):467 - 492.

Thirlwall, A. P. and Bergevin, J. (1985). Trends, cycles and asymmetries in the terms of trade of primary commodities from developed and less developed countries. World Development, 13(7):805ff.

Tibshirani, R. (1996). Regression shrinkage and selection via the LASSO. Journal of the Royal Statistical Society B, 58:267-288.

Toye, J. and Toye, R. (2003). The origins and interpretation of the Prebisch-Singer thesis. History of Political Economy, 35(3):437ff.

Trapp, K. (2012). The Influence of Foreign Direct Investment and Portfolio Investment on the Labor Share in Developing Countries: An Empirical Analysis. MA thesis in International Economics at the University of Göttingen, Germany.

UNCTAD (2005). New features of global interdependence. Trade and development report, United Nations Conference of Trade and Development.

UNCTAD (2010). Investing in a low-carbon economy. World investment report, United Nations Conference of Trade and Development.

Unsal, D. F. (2011). Capital flows and financial stability: Monetary policy and macroprudential responses. Working Paper 11/189, International Monetary Fund, Washington, DC.

Vaizey, J. (1964). The residual factor and economic growth. Study Group in the Economics 
of Education, Paris: OECD.

van Nieuwerburgh, S. and Veldkamp, L. (2009). Information immobility and the home bias puzzle. Journal of Finance, 64(3):1187-1215.

Vora, A. (2001). Impact of Foreign Direct Investment on developing country credit markets. Latin American and Caribbean Economic Association Conference Paper.

Wacker, K. M. (2011). The impact of Foreign Direct Investment on developing countries' terms of trade. Working Paper 2011/06, United Nations University - World Institute of Development Economics Research, Helsinki.

Wall, M. M. (2004). A close look at the spatial structure implied by the CAR and SAR models. Journal of Statistical Planning and Inference, 121(1):311-324.

Warnock, F. E. (2002). Home bias and high turnover reconsidered. Journal of International Money and Finance, 21(6):795-805.

Wei, S.-J. (2000a). How taxing is corruption on international investors? The Review of Economics and Statistics, 82(1):1-11.

Wei, S.-J. (2000b). Local corruption and global capital flows. Brookings Papers on Economic Activity, 31(2):303-354.

Wheeler, D. and Mody, A. (1992). International investment location decisions : The case of U.S. firms. Journal of International Economics, 33(1-2):57-76.

White, H. (1980). A heteroskedasticity-consistent covariance matrix estimator and a direct test for heteroskedasticity. Econometrica, 48:817-830.

Williamson, O. E. (1971). The vertical integration of production: Market failure considerations. American Economic Review, 61(2):112-23.

Wood, A. (1991). North-south trade and female labour in manufacturing: An asymmetry. Journal of Development Studies, 27(2):168-189.

Wood, A. (1998). Globalisation and the rise in labour market inequalities. Economic Journal, 108(450):1463-82.

Wooldridge, J. M. (2002). Econometric Analysis of Cross Section and Panel Data. MIT Press.

Wooldridge, J. M. (2003). Cluster-sample methods in applied econometrics. American Economic Review, 93(2nd):133-138.

Wooldridge, J. M. (2010). Econometric Analysis of Cross Section and Panel Data. The MIT Press, Cambridge, MA, 2 edition.

World Bank (2010a). Rising Global Interest in Farmland. The World Bank, Washington, DC.

World Bank (2010b). World Development Indicators. Washington, DC: The World Bank.

World Bank (2011). Gender equality and development. World Development Report 2012, The World Bank Group.

Yeaple, S. R. (2003). The complex integration strategies of multinationals and cross country dependencies in the structure of Foreign Direct Investment. Journal of International Economics, 60(2):293-314.

$\mathrm{Yu}, \mathrm{X}$. and Abler, D. (2009). The demand for food quality in rural china. American Journal of Agricultural Economics, 91(1):57-69.

Ziesemer, T. (2010). From trends in commodities and manufactures to country terms of trade. Working Paper 2010-022, UNU-MERIT.

Ziliak, S. T. and McCloskey, D. N. (2004). Size matters: the standard error of regressions in the American Economic Review. Journal of Socio-Economics, 33(5th):527-546.

Zucchini, W. (2000). An introduction to model selection. Journal of Mathematical Psychology, 44:41-61. 
ncreased capital flows in the form of foreign direct investment (FDI) and the growing relevance of multinational corporations are two characteristics of the most recent wave of globalization. This volume extensively discusses how these phenomena are interrelated, what determines FDI flows and which role macroeconomic information plays for the latter. It then empirically investigates what these foreign direct investments mean for economic development, especially for the export prices of developing countries and labor market outcomes. 